ANTONIO VIEIRA DA SILVA NETO

MODELO DE PREDIÇÃO DE FALHAS BASEADO EM PROCESSOS ESTOCÁSTICOS E FILTRAGEM KALMAN PARA SUPORTE À MANUTENÇÃO PREDITIVA DE SISTEMAS ELÉTRICOS, ELETRÔNICOS E PROGRAMÁVEIS 

ANTONIO VIEIRA DA SILVA NETO

MODELO DE PREDIÇÃO DE FALHAS BASEADO EM PROCESSOS ESTOCÁSTICOS E FILTRAGEM KALMAN PARA SUPORTE À MANUTENÇÃO PREDITIVA DE SISTEMAS ELÉTRICOS, ELETRÔNICOS E PROGRAMÁVEIS

Dissertação apresentada à Escola

Politécnica da Universidade de São Paulo para obtenção do título de Mestre em Ciências 



\section{MODELO DE PREDIÇÃO DE FALHAS BASEADO EM PROCESSOS ESTOCÁSTICOS E FILTRAGEM KALMAN PARA SUPORTE À MANUTENÇÃO PREDITIVA DE SISTEMAS ELÉTRICOS, ELETRÔNICOS E PROGRAMÁVEIS}

Dissertação apresentada à Escola Politécnica da Universidade de São Paulo para obtenção do título de Mestre em Ciências

Área de Concentração:

Engenharia de Computação e Sistemas Digitais

Orientador:

Prof. Dr. Paulo Sérgio Cugnasca 
Este exemplar foi revisado e corrigido em relação à versão original, sob responsabilidade única do autor e com a anuência de seu orientador.

São Paulo, de julho de 2014.

Assinatura do autor

Assinatura do orientador

\section{Catalogação-na-publicação}

Silva Neto, Antonio Vieira da Modelo de predição de falhas baseado em processos estocásticos e filtragem de Kalman para suporte à manutenção preditiva de sistemas elétricos, eletrônicos e programáveis / A.V. da Silva Neto. -- versão corr. -- São Paulo, 2014.

$298 \mathrm{p}$.

Dissertação (Mestrado) - Escola Politécnica da Universidade de São Paulo. Departamento de Engenharia de Computação e Sistemas Digitais.

1.Manutenção preditiva 2.Processos estocásticos 3.Filtro de Kalman 4.Sistemas elétricos I. Universidade de São Paulo. Escola Politécnica. Departamento de Engenharia de Computação e Sistemas Digitais II.t. 


\section{AGRADECIMENTOS}

A todos os meus familiares mais próximos (pais, avós, tios e primo), pelo enorme apoio, pelos conselhos e pelas palavras de conforto ao longo dos três anos desta prazerosa e árdua empreitada.

Ao Prof. Dr. Paulo Sérgio Cugnasca, pela excelente orientação e pelas importantes fagulhas de motivação fornecidas desde o início desta pesquisa.

Ao Prof. Dr. João Batista Camargo Junior, ao Prof. Dr. Jorge Rady de Almeida Junior e novamente ao Prof. Dr. Paulo Sérgio Cugnasca, coordenadores do Grupo de Análise de Segurança, pelo inestimável suporte acadêmico, profissional e pessoal.

Ao Prof. Dr. Valter Fernandes Avelino e novamente ao Prof. Dr. João Batista Camargo Junior, pelas valiosas contribuições feitas no Exame de Qualificação.

Ao Prof. Paulo Sérgio Cugnasca, ao Prof. Dr. Flávio Matsuyama e mais uma vez ao Prof. Dr. João Batista Camargo Junior, pelos elogios ao trabalho e pelas contribuições finais para a Edição Revisada desta Dissertação.

Aos colegas e ex-colegas de trabalho e de pesquisa do Grupo de Análise de Segurança, pela convivência e pelo aprendizado desde o início de minhas atividades como estagiário, em 2009. 

"A ciência não é uma ilusão, mas seria uma ilusão acreditar que poderemos encontrar noutro lugar o que ela não nos pode dar."

(Sigmund Freud) 



\section{RESUMO}

Com o aumento do uso de sistemas elétricos, eletrônicos e programáveis em aplicações de diversos domínios, tais como entretenimento, realização de transações financeiras, distribuição de energia elétrica, controle de processos industriais e sinalização e controle em transporte de passageiros e carga, é essencial que as políticas de manutenção utilizadas sejam capazes de minimizar os custos associados a eventuais falhas que afetem negativamente os serviços providos. Ao longo das últimas décadas, foi sedimentada a tendência de que a adoção de técnicas de manutenção preditiva representa uma das abordagens mais viáveis e promissoras para que falhas de sistemas utilizados em diversas aplicações possam ser detectadas antes de elas efetivamente ocorrerem. Considerando-se que uma parcela significativa dos estudos recentes na área de manutenção preditiva de sistemas apresenta como limitação o custo elevado para se instalar uma infraestrutura específica para realizar a coleta de dados que serão usados para dar suporte à predição das falhas futuras de um sistema, o modelo proposto no presente estudo visa permitir que os índices de dependabilidade e as falhas futuras de sistemas elétricos, eletrônicos e programáveis sejam estimados utilizando-se dados já disponíveis de falhas e manutenções passadas. Para tanto, foram empregadas técnicas como processos estocásticos, filtragem Kalman e modelos de incorporação de dados de histórico preconizados no padrão internacional RIAC-HDBK-217Plus. Como principal conclusão do presente trabalho, é possível ressaltar que foi possível atingir, com o modelo proposto, o objetivo de suporte à manutenção preditiva de sistemas elétricos, eletrônicos e programáveis a partir do uso de dados preexistentes de histórico operacional; no entanto, foram constatadas limitações no grau de utilização prática do modelo em situações nas quais a quantidade dos dados de histórico disponíveis para consulta é pequena.

Palavras-chave: Manutenção preditiva, processos estocásticos, filtros de Kalman, sistemas elétricos, dependabilidade, histórico operacional. 



\begin{abstract}
With the increased use of electrical, electronic and programmable systems in various application fields such as entertainment, financial transactions, power distribution, industrial process control and signaling and control of transportation modes, it is essential for the maintenance policies used in those systems to be able to minimize the costs of any faults that may adversely affect the services provided. Over the past decades, the use of predictive maintenance techniques has shown to be a viable and promising approach to detect faults before they actually occur in systems used in different application fields. Considering that a significant part of the recent scientific research in the area of predictive maintenance usually demands high-cost infrastructure to be installed to support the acquisition of all the data that will be used to calculate the prediction of future faults of a system, the model proposed within this study was designed to allow both dependability levels and future faults of electrical, electronic and programmable systems to be estimated using past faults and maintenance data that may already be available. For this purpose, techniques such as stochastic processes, Kalman filtering and models prescribed within the international standard RIAC-HDBK-217Plus to incorporate history data to dependability calculation were used. As the main conclusion of this study, it is possible to highlight that the main objective of the model proposed, related to its ability to support predictive maintenance of electrical, electronic and programmable systems through the use of pre-existing operating history data, has been reached; nevertheless, limitation of practical use of the model was verified in situations in which not enough operating data is available.
\end{abstract}

Keywords: Predictive maintenance, stochastic processes, Kalman filters, electrical systems, dependability, operating history. 



\section{LISTA DE ILUSTRAÇÕES}

Figura 1 - Distribuição das Principais Atividades Executadas na Internet em 2008 pela População Brasileira com 10 ou mais Anos de Idade

Figura 2 - Percentual de Homem-hora por Tipo de Manutenção...............................35

Figura 3 - Perfis das Curvas de Taxa de Falha ..................................................43

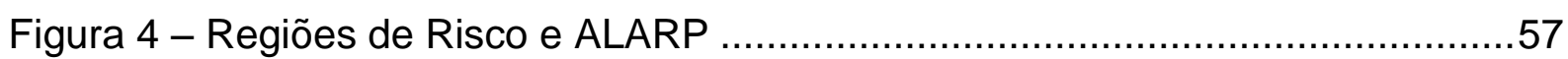

Figura 5 - Manifestação de Falhas, Erros e Disfunções em um Sistema ..................59

Figura 6 - Circuito Elétrico de Polarização do Transistor Bipolar Q1 .......................60

Figura 7 - Estudo de Sensibilidade da Saída OUT do Circuito Elétrico da Figura 6 devido à Variação da Resistência Elétrica de RB

Figura 8 - Técnicas de Combate a Falhas Contextualizadas na Sequência Lógica das Causas de uma Disfunção.

Figura 9 - Curva da Banheira para Sistemas Elétricos, Eletrônicos e Programáveis

Figura 10 - Curva da Banheira com Crescimento da Taxa de Falhas no Período de

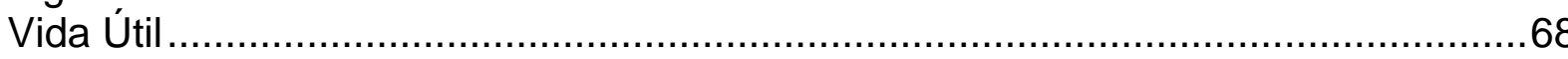

Figura 11 - Relacionamento entre MTTF, MTTR e MTBF ……............................71

Figura 12 - Modelo de Cálculo de Taxa de Falhas de Sistemas segundo RIAC-

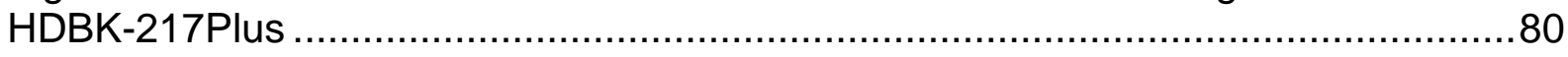

Figura 13 - Modelo de Markov da Confiabilidade de um Sistema Simples...............85

Figura 14 - Modelo de Markov da Disponibilidade de um Sistema Simples .............86

Figura 15 - Modelo de Markov da Segurança Crítica (Safety) de um Sistema Simples

Figura 16 - Modelo de Markov da Figura 14 com a Aproximação da Equação (16).88

Figura 17 - Algoritmo de Cálculo de Modelos de Markov .........................................94

Figura 18 - Aplicação de um Filtro de Kalman no Controle de um Velocímetro

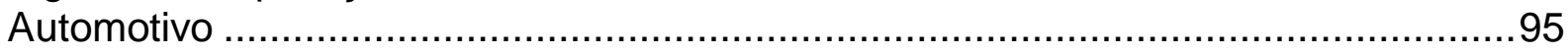

Figura 19 - Interfaces de Entrada e Saída de um Filtro de Kalman .........................97

Figura 20 - Exemplo de Utilização Recursiva de um Filtro de Kalman ....................102

Figura 21 - Arquitetura do Modelo da Pesquisa Contextualizado em um Ambiente de Operação de um Sistema Hipotético .................................................................105

Figura 22 - Fluxograma do Funcionamento do Modelo da Figura 21 ...................106

Figura 23 - Encadeamento Dinâmico dos Eventos de Histórico de Operação de um

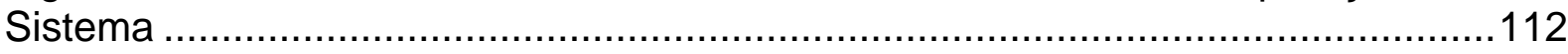

Figura 24 - Contextualização do Subsistema de Diagnóstico ...............................113

Figura 25 - Adaptação do Cálculo de Taxas de Falhas do Padrão RIAC-HDBK217Plus à Determinação de Taxas de Reparos a partir de Histórico de Operação de Sistemas Elétricos, Eletrônicos e Programáveis .................................................118 
Figura 26 - Filtro de Kalman Utilizado no Modelo Proposto na Pesquisa

Figura 27 - Utilização Recursiva do Filtro de Kalman da Figura 26 na Determinação de Múltiplas Falhas Futuras de um Componente

Figura 28 - Exemplo de Saída da Disponibilidade de um Sistema Gerada pelo Bloco

"Cálculos Matemáticos do Modelo de Markov Estendido"..... 132

Figura 29 - Diagrama Nassi-Schneiderman da Dinâmica Operacional do Ambiente de Desenvolvimento e Ensaio do Modelo. 137

Figura 30 - Diagrama Nassi-Schneiderman do Simulador de Dados de Entrada .. 142 Figura 31 - Diagrama Nassi-Schneiderman do Bloco "A" da Figura 30 ................ 143 Figura 32 - Diagrama Nassi-Schneiderman do Bloco "B" da Figura 30 ................ 143 Figura 33 - Diagrama Nassi-Schneiderman da Função

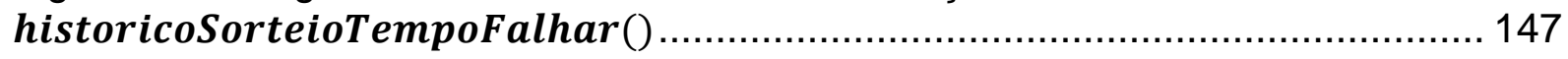

Figura 34 - Diagrama Nassi-Schneiderman do Bloco "A" da Figura 33 ................ 148

Figura 35 - Diagrama Nassi-Schneiderman do Bloco "B" da Figura 33 ................. 149

Figura 36 - Diagrama Nassi-Schneiderman da Função

historicoSorteioReparoOuSubstituicao() 155

Figura 37 - Diagrama Nassi-Schneiderman da Função

historicoSorteioTempoInicioManut() 157

Figura 38 - Diagrama Nassi-Schneiderman do Bloco "A" da Figura 37 158

Figura 39 - Diagrama Nassi-Schneiderman da Função

historicoSorteioTempoReparar () 162

Figura 40 - Diagrama Nassi-Schneiderman do Bloco "A" da Figura 39 163

Figura 41 - Diagrama Nassi-Schneiderman do Bloco "B" da Figura 39 164

Figura 42 - Diagrama Nassi-Schneiderman da Função

historicoSorteioTempoSubstituir() 170

Figura 43 - Diagrama Nassi-Schneiderman do Bloco "A" da Figura 42 171

Figura 44 - Diagrama Nassi-Schneiderman do Bloco "B" da Figura 42 172

Figura 45 - Diagrama Nassi-Schneiderman do Algoritmo Utilizado para Calcular os Instantes de Tempo das k Próximas Falhas de um Componente mediante Utilização Recursiva do Filtro de Kalman 182

Figura 46 - Modelo de Markov da Confiabilidade do Sistema Simples 187

Figura 47 - Gráficos da Função Confiabilidade do Sistema Simples nos Quatro Cenários Estudados 188

Figura 48 - Gráficos da Função Taxa de Falhas do Sistema Simples nos Quatro Cenários de Estudo da Função Confiabilidade..... 190

Figura 49 - Modelo de Markov da Segurança Crítica (Safety) do Sistema Simples192 Figura 50 - Gráficos da Função Segurança Crítica (Safety) do Sistema Simples nos Quatro Cenários Estudados. 
Figura 51 - Gráficos da Função Taxa de Falhas do Sistema Simples nos Quatro Cenários de Estudo da Função Confiabilidade

Figura 52 - Modelo de Markov da Disponibilidade do Sistema Simples

Figura 53 - Gráficos da Função Disponibilidade do Sistema Simples nos Quatro Cenários Estudados.

Figura 54 - Gráfico da Taxa de Falhas do Sistema Simples nos Quatro Cenários de Estudo da Função Disponibilidade

Figura 55 - Gráfico da Taxa de Reparos do Sistema Simples nos Quatro Cenários de Estudo da Função Disponibilidade.

Figura 56 - Diagrama de Blocos do Sistema Série com Dois Componentes.

Figura 57 - Modelo de Markov da Confiabilidade do Sistema Série com Dois Componentes

Figura 58 - Gráficos da Função Confiabilidade do Sistema Série com Dois Componentes nos Quatro Cenários Estudados

Figura 59 - Gráficos da Função Taxa de Falhas do Componente C1 do Sistema Série com Dois Componentes nos Quatro Cenários de Estudo da Função Confiabilidade.

Figura 60 - Gráficos da Função Taxa de Falhas do Componente C2 do Sistema Série com Dois Componentes nos Quatro Cenários de Estudo da Função Confiabilidade.

Figura 61 - Modelo de Markov da Segurança Crítica (Safety) do Sistema Série com Dois Componentes.

Figura 62 - Gráficos da Função Segurança Crítica (Safety) do Sistema Série com Dois Componentes nos Quatro Cenários Estudados

Figura 63 - Gráficos da Função Taxa de Falhas do Componente C1 do Sistema Série com Dois Componentes nos Quatro Cenários de Estudo da Função Segurança Crítica (Safety)

Figura 64 - Gráficos da Função Taxa de Falhas do Componente C2 do Sistema Série com Dois Componentes nos Quatro Cenários de Estudo da Função Segurança Crítica (Safety) 220

Figura 65 - Modelo de Markov da Disponibilidade do Sistema Série com Dois Componentes

Figura 66 - Gráficos da Função Disponibilidade do Sistema Série com Dois Componentes nos Quatro Cenários Estudados

Figura 67 - Gráficos da Função Taxa de Falhas do Componente C1 do Sistema Série com Dois Componentes nos Quatro Cenários de Estudo da Função Disponibilidade.

Figura 68 - Gráficos da Função Taxa de Falhas do Componente C2 do Sistema Série com Dois Componentes nos Quatro Cenários de Estudo da Função Disponibilidade.... 
Figura 69 - Gráficos da Função Taxa de Reparos do Componente C1 do Sistema Série com Dois Componentes nos Quatro Cenários de Estudo da Função Disponibilidade

Figura 70 - Gráficos da Função Taxa de Reparos do Componente C2 do Sistema Série com Dois Componentes nos Quatro Cenários de Estudo da Função Disponibilidade

Figura 71 - Diagrama de Blocos do Sistema Paralelo com Dois Componentes Redundantes

Figura 72 - Gráficos da Função Confiabilidade do Sistema Paralelo com Dois Componentes Redundantes nos Quatro Cenários Estudados

Figura 73 - Gráficos da Função Taxa de Falhas do Componente C1 do Sistema Paralelo com Dois Componentes Redundantes nos Quatro Cenários de Estudo da Função Confiabilidade

Figura 74 - Gráficos da Função Taxa de Falhas do Componente C2 do Sistema Paralelo com Dois Componentes Redundantes nos Quatro Cenários de Estudo da Função Confiabilidade

Figura 75 - Gráficos da Função Confiabilidade do Sistema Paralelo com Dois Componentes Redundantes nos Cenários Sem Histórico e com Histórico Pessimista entre $77.500 \mathrm{~h}$ e $83.000 \mathrm{~h}$

Figura 76 - Gráficos da Função Segurança Crítica (Safety) do Sistema Paralelo com Dois Componentes Redundantes nos Quatro Cenários Estudados

Figura 77 - Gráficos da Função Taxa de Falhas do Componente C1 do Sistema Paralelo com Dois Componentes Redundantes nos Quatro Cenários de Estudo da Função Segurança Crítica (Safety).

Figura 78 - Gráficos da Função Taxa de Falhas do Componente C2 do Sistema Paralelo com Dois Componentes Redundantes nos Quatro Cenários de Estudo da Função Segurança Crítica (Safety)

Figura 79 - Gráficos da Função Segurança Crítica (Safety) do Sistema Paralelo com Dois Componentes Redundantes nas Primeiras 25.000 Horas de Estudo. 252

Figura 80 - Gráficos da Função Disponibilidade do Sistema Paralelo com Dois Componentes Redundantes nos Quatro Cenários Estudados

Figura 81 - Gráficos da Função Taxa de Falhas do Componente C1 do Sistema Paralelo com Dois Componentes Redundantes nos Quatro Cenários de Estudo da Função Disponibilidade.

Figura 82 - Gráficos da Função Taxa de Falhas do Componente C2 do Sistema Paralelo com Dois Componentes Redundantes nos Quatro Cenários de Estudo da Função Disponibilidade.

Figura 83 - Gráficos da Função Taxa de Reparos do Componente C1 do Sistema Paralelo com Dois Componentes Redundantes nos Quatro Cenários de Estudo da Função Disponibilidade.

Figura 84 - Gráficos da Função Taxa de Reparos do Componente C2 do Sistema Paralelo com Dois Componentes Redundantes nos Quatro Cenários de Estudo da Função Disponibilidade. 
Figura 85 - Arquitetura da Proposta de Extensão do Simulador de Dados de Entrada .283 



\section{LISTA DE TABELAS}

Tabela 1 - Melhorias Tangíveis com a Adoção de um Programa Eficiente de Gerência de Manutenção Preditiva

Tabela 2 - Principais Setores Econômicos das Empresas Consultadas pela ABRAMAN em 2011.

Tabela 3 - Valores dos Percentuais da Figura 2

Tabela 4 - Resumo das Equações dos Índices de Confiabilidade, Disponibilidade e

Segurança Crítica (Safety) de Sistemas Elétricos, Eletrônicos e Programáveis

Tabela 5 - Exemplo de Matriz de Relacionamento entre Índice Numérico $\beta$ e

Instantes de Tempo t $\lambda$ das Falhas de um Componente

Tabela 6 - Exemplo de Saída Esperada do Bloco "Detector de Comportamento e

Filtro de Kalman" contendo Previsões das Próximas Falhas dos Componentes de um

Sistema

Tabela 7 - Relação de Valores de probPos e das Probabilidades do Sinal da Variação dos Intervalos de Tempo para a Ocorrência de Falhas de Componentes150

Tabela 8 - Relação de Valores de probPeq, probMed e das Probabilidades de Variação Positiva dos Intervalos de Tempo para a Ocorrência de Falhas de Componentes

Tabela 9 - Relação de Valores de probPeq, probMed e das Probabilidades de Variação Negativa dos Intervalos de Tempo para a Ocorrência de Falhas de Componentes

Tabela 10 - Relação das Probabilidades de Todas as Combinações de Sinal e Valor Absoluto da Variação do Intervalo de Tempo para a Ocorrência de Falhas de Componentes.

Tabela 11 - Relação de Valores de probPeq, probMed e probGde e das

Probabilidades das Categorias Qualitativas dos Intervalos de Tempo entre Falha e Início de Manutenção

Tabela 12 - Relação de Valores de probPos e das Probabilidades do Sinal da Variação dos Intervalos de Tempo para a Execução de Reparos de Componentes

Tabela 13 - Relação de Valores de probPeq, probMed e das Probabilidades de

Variação Positiva dos Intervalos de Tempo de Execução de Reparos de Componentes.....

Tabela 14 - Relação de Valores de probPeq, probMed e das Probabilidades de Variação Negativa dos Intervalos de Tempo de Execução de Reparos de Componentes

Tabela 15 - Relação das Probabilidades de Todas as Combinações de Sinal e Valor Absoluto da Variação do Intervalo de Tempo para a Execução de Reparos de Componentes 168

Tabela 16 - Relação de Valores de probPos e das Probabilidades do Sinal da Variação dos Intervalos de Tempo para a Execução de Substituições de Componentes 
Tabela 17 - Relação de Valores de probPeq, probMed e das Probabilidades de Variação Positiva dos Intervalos de Tempo de Execução de Substituições de Componentes

Tabela 18 - Relação de Valores de probPeq, probMed e das Probabilidades de Variação Negativa dos Intervalos de Tempo de Execução de Substituições de Componentes

Tabela 19 - Relação das Probabilidades de Todas as Combinações de Sinal e Valor Absoluto da Variação do Intervalo de Tempo para a Execução de Substituições de Componentes 176

Tabela 20 - Eventos de Falha Gerados nos Cenários de Estudo da Confiabilidade do Sistema Simples com Histórico de Operação..... 189

Tabela 21 - Confiabilidade do Sistema Simples após Tsim $=105$ horas 191

Tabela 22 - Eventos de Falha Gerados nos Cenários de Estudo da Segurança Crítica (Safety) do Sistema Simples com Histórico de Operação

Tabela 23 - Disponibilidade do Sistema Simples após $\mathbf{T} \boldsymbol{s i m}=\mathbf{1 0 5}$ horas. 202

Tabela 24 - Relação das Cinco Próximas Falhas do Sistema Simples após Tsim = 105 horas 203

Tabela 25 - Comparação dos Instantes de Ocorrência das Três Últimas Falhas do Sistema Simples com as Previsões Produzidas pelo Modelo Proposto - Ensaio Baseado em Histórico Normal 205

Tabela 26 - Comparação dos Instantes de Ocorrência das Três Últimas Falhas do Sistema Simples com as Previsões Produzidas pelo Modelo Proposto - Ensaio Baseado em Histórico Otimista. 206

Tabela 27 - Comparação dos Instantes de Ocorrência das Três Últimas Falhas do Sistema Simples com as Previsões Produzidas pelo Modelo Proposto - Ensaio Baseado em Histórico Pessimista

Tabela 28 - Eventos de Falha Gerados nos Cenários de Estudo da Confiabilidade do Sistema Série com Dois Componentes e com Histórico de Operação 212

Tabela 29 - Confiabilidade do Sistema Série com Dois Componentes após $\mathbf{T s i m}=$ 105 horas 215

Tabela 30 - Eventos de Falha Gerados nos Cenários de Estudo da Segurança Crítica (Safety) do Sistema Série com Dois Componentes e com Histórico de Operação

Tabela 31 - Disponibilidade do Sistema Série com Dois Componentes após $\mathbf{T} \boldsymbol{s i m}=$ 105 horas

Tabela 32 - Relação das Cinco Próximas Falhas do Componente C1 do Sistema Série após $T$ sim $=105$ horas

Tabela 33 - Relação das Cinco Próximas Falhas do Componente C2 do Sistema Série após $T$ sim $=105$ horas

Tabela 34 - Comparação dos Instantes de Ocorrência das Três Últimas Falhas do Componente C1 do Sistema Série com as Previsões Produzidas pelo Modelo Proposto - Ensaio Baseado em Histórico Normal 
Tabela 35 - Comparação dos Instantes de Ocorrência das Três Últimas Falhas do Componente C1 do Sistema Série com as Previsões Produzidas pelo Modelo Proposto - Ensaio Baseado em Histórico Otimista

Tabela 36 - Comparação dos Instantes de Ocorrência das Três Últimas Falhas do Componente C1 do Sistema Série com as Previsões Produzidas pelo Modelo Proposto - Ensaio Baseado em Histórico Pessimista

Tabela 37 - Comparação dos Instantes de Ocorrência das Duas Últimas Falhas do Componente C2 do Sistema Série com as Previsões Produzidas pelo Modelo Proposto - Ensaio Baseado em Histórico Normal.

Tabela 38 - Comparação dos Instantes de Ocorrência das Três Últimas Falhas do Componente C2 do Sistema Série com as Previsões Produzidas pelo Modelo Proposto - Ensaio Baseado em Histórico Pessimista

Tabela 39 - Eventos de Falha Gerados nos Cenários de Estudo da Confiabilidade do Sistema Paralelo com Dois Componentes Redundantes e com Histórico de Operação.

Tabela 40 - Confiabilidade do Sistema Paralelo com Dois Componentes após Tsim = 105 horas

Tabela 41 - Eventos de Falha Gerados nos Cenários de Estudo da Segurança Crítica (Safety) do Sistema Paralelo com Dois Componentes Redundantes e com Histórico de Operação.

Tabela 42 - Disponibilidade do Sistema Paralelo com Dois Componentes

Redundantes após $\mathrm{Tsim}=105$ horas

Tabela 43 - Relação das Cinco Próximas Falhas do Componente C1 do Sistema

Paralelo após $\mathbf{T}$ sim $=105$ horas.

Tabela 44 - Relação das Cinco Próximas Falhas do Componente C2 do Sistema Paralelo após $\mathbf{T s i m}=105$ horas.

Tabela 45 - Comparação dos Instantes de Ocorrência das Três Últimas Falhas do Componente C1 do Sistema Paralelo com as Previsões Produzidas pelo Modelo Proposto - Ensaio Baseado em Histórico Normal...

Tabela 46 - Comparação dos Instantes de Ocorrência das Duas Últimas Falhas do Componente $\mathrm{C} 1$ do Sistema Paralelo com as Previsões Produzidas pelo Modelo Proposto - Ensaio Baseado em Histórico Otimista .

Tabela 47 - Comparação dos Instantes de Ocorrência das Três Últimas Falhas do Componente C1 do Sistema Paralelo com as Previsões Produzidas pelo Modelo Proposto - Ensaio Baseado em Histórico Pessimista.

Tabela 48 - Comparação dos Instantes de Ocorrência da Última Falha do Componente C2 do Sistema Paralelo com as Previsões Produzidas pelo Modelo Proposto - Ensaio Baseado em Histórico Normal.

Tabela 49 - Comparação dos Instantes de Ocorrência das Três Últimas Falhas do Componente C2 do Sistema Paralelo com as Previsões Produzidas pelo Modelo Proposto - Ensaio Baseado em Histórico Pessimista

Tabela 50 - Sumário dos Principais Resultados Obtidos nos Três Estudos de Caso 
Tabela 51 - Relação dos Tempos de Execução das Simulações dos Estudos de Caso

Tabela 52 - Histórico Operacional do Sistema Simples no Ensaio Normal da Função

Disponibilidade

Tabela 53 - Histórico Operacional do Sistema Simples no Ensaio Otimista da Função Disponibilidade.

Tabela 54 - Histórico Operacional do Sistema Simples no Ensaio Pessimista da Função Disponibilidade.

Tabela 55 - Histórico Operacional do Sistema Série de Dois Componentes no Ensaio Normal da Função Disponibilidade

Tabela 56 - Histórico Operacional do Sistema Série de Dois Componentes no Ensaio Otimista da Função Disponibilidade.

Tabela 57 - Histórico Operacional do Sistema Série de Dois Componentes no Ensaio Pessimista da Função Disponibilidade

Tabela 58 - Histórico Operacional do Sistema Paralelo de Dois Componentes no Ensaio Normal da Função Disponibilidade 296

Tabela 59 - Histórico Operacional do Sistema Paralelo de Dois Componentes no Ensaio Otimista da Função Disponibilidade.

Tabela 60 - Histórico Operacional do Sistema Paralelo de Dois Componentes no Ensaio Pessimista da Função Disponibilidade 


\section{LISTA DE SIGLAS E ABREVIAÇÕES}

ABRAMAN Associação Brasileira de Manutenção e Gestão de Ativos

ANEEL Agência Nacional de Energia Elétrica

CENELEC European Committee for Electrotechnical Standardization

ERP Enterprise Resource Planning

IBGE Instituto Brasileiro de Geografia e Estatística

IEC International Electrotechnical Commission

MAEC Método de Análise por Esforço de Componentes

MCC Método de Contagem de Componentes

MMIC Circuito Integrado Monolítico de Micro-ondas (Monolithic Microwave Integrated Circuit)

MTBF Tempo Médio entre Falhas (Mean Time Between Failures)

MTTF Tempo Médio para Falhar (Mean Time To Failure)

MTTR Tempo Médio para Reparar (Mean Time To Repair)

MSS Multi-state System

Pnad Pesquisa Nacional por Amostra de Domicílios

RIAC Reliability Information Analysis Center

SAW Onda Acústica de Superfície (Surface Acoustic Wave)

SIL Safety Integrity Level

TMR Triple Modular Redundancy

VHSIC Circuitos Integrados de Altíssima Velocidade (Very High Speed Integrated Circuit) 



\section{SUMÁRIO}

1. INTRODUCÃO

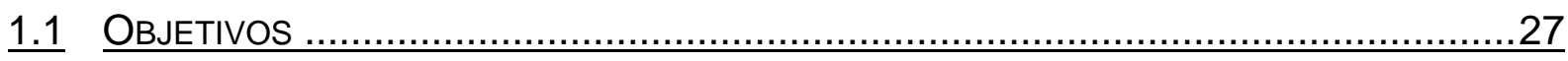

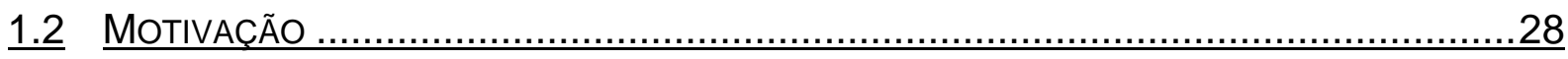

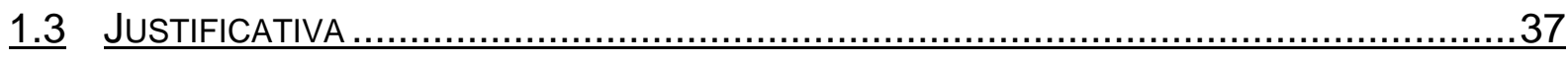

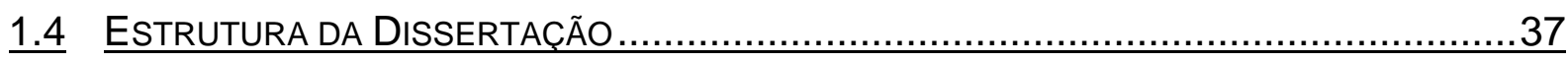

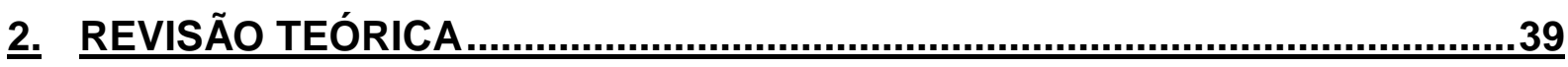

2.1 Panorama Científico do Estado-da-ARTE da ManUtenç̃̃o Preditiva ................39

2.2 CONSIDERACC̃̃ES GERAIS SOBRE SISTEMAS CRÍTICOS ........................................54

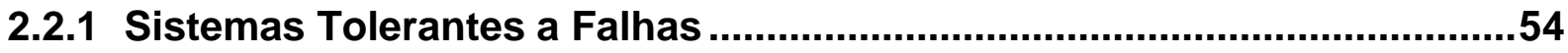

2.2.2 Falhas, Erros e Disfunções em Sistemas Críticos ...................................59

2.2.3 Filosofias de Projeto para Combater Falhas ..........................................62

2.2.4 Funções Confiabilidade, Disponibilidade e Segurança Crítica (Safety) de Sistemas Elétricos, Eletrônicos e Programáveis .................................................66

2.3 MOdELOS DE CÁlCULO dE CONFIABILIDADE DE SISTEMAS ELÉTRICOS, ElETRÔNICOS E PROGRAMÁVEIS ........................................................................................... 72

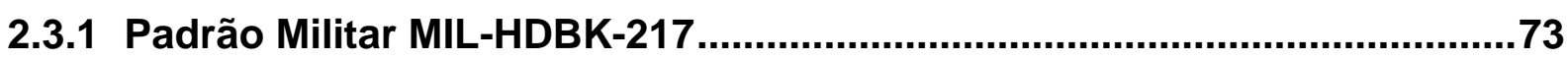

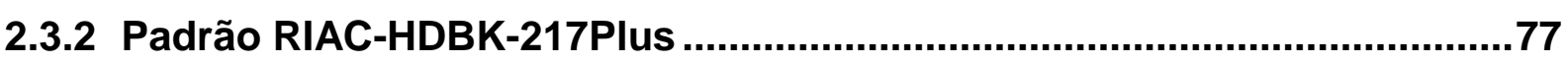

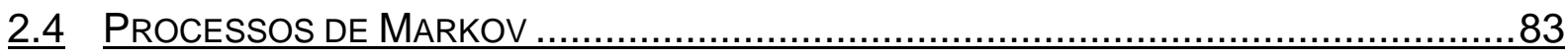

2.4.1 Classificação dos Modelos de Markov na Área de Dependabilidade ........84

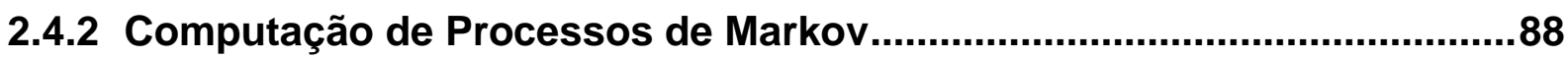

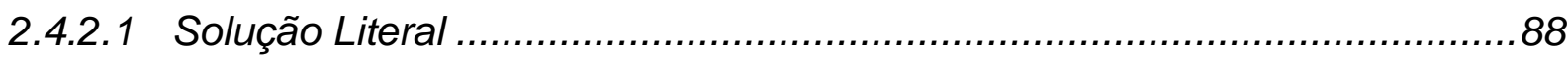

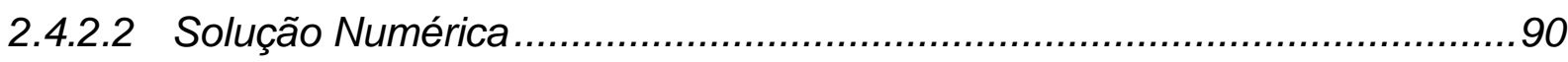

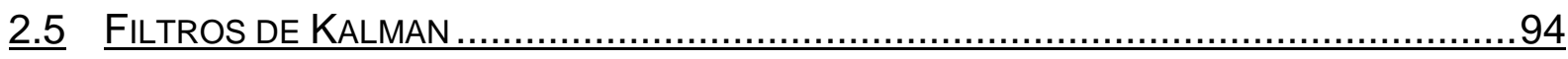

2.5.1 Formulação Matemática dos Filtros de Kalman ......................................97

2.6 CONSIDERACCÕES FINAIS DO CAPÍTULO ...........................................................102

3. PROPOSTA DE MODELO DE PREVISÃO DE FALHAS BASEADO EM PROCESSOS ESTOCÁSTICOS E FILTRAGEM KALMAN PARA SUPORTE $\dot{A}$ MANUTENCÃO PREDITIVA DE SISTEMAS ELÉTRICOS, ELETRÔNICOS E PROGRAMÁVEIS.

3.1 PANORAMA GERAL DO MOdELO PROPOSTO ……….......................................103

3.2 DetalHAMENTO dOS "DADOS DO AMBIENTE DE OPERAÇÃO DO SISTEMA" ..............109

3.3 Detalhamento do Bloco "CÁlCulo das taXas de falHas e dE Reparos CONDICIONADAS AO HISTÓRICO DE OPERACCÃO" ........................................................114 
3.4 Detalmamento do Bloco "Cálculos matemáticos do Modelo de Markov ESTENDIDO" ............................................................................................. 121

3.5 Detalmamento do Bloco "Detector de Comportamento e Filtro de Kalman" 122

3.6 Detalhamento das Categorias de Resultados Produzidos pelo Modelo

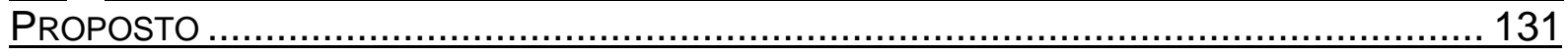

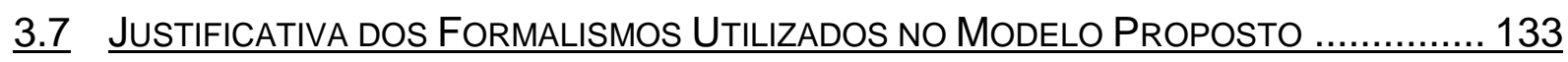

$\underline{3.8}$ CONSIDERAÇÕES FINAIS DO CAPÍTULO …………......................................... 134

4. AMBIENTE DE DESENVOLVIMENTO E ENSAIO DO MODELO PROPOSTO 135

4.1 Características Principals do Ambiente de Desenvolvimento e Ensaio do

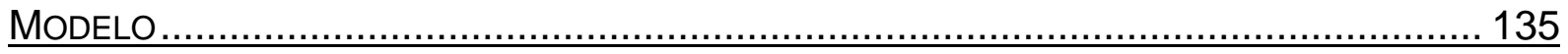

4.2 DeTALHAMENTO DO MÓDULO "LEITURA DA ESPECIFICACÃO DO SISTEMA" ...............139

4.3 DETALHAMENTO DO MÓDULO "SIMULADOR DE DADOS DE ENTRADA" ..................... 141

4.3.1 Detalhamento da Função historicoSorteioTempoFalhar () ..................146

4.3.2 Detalhamento da Função historicoSorteioReparoOuSubstituicao () .. 154

4.3.3 Detalhamento da Função historicoSorteioTempoInicioManut () ........ 156

4.3.4 Detalhamento da Função historicoSorteioT empoReparar ()................. 161

4.3.5 Detalhamento da Função historicoSorteioTempoSubstituir () .............169

4.4 Detalhamento do Módulo "Computação de Processos de Markov com HISTÓRICO DE OPERAÇÃO" ............................................................................ 178

4.5 Detalmamento do Módulo "TRatamento Estocástico e Filtragem Kalman PARA PREDICÃO DE FALHAS" ........................................................................... 179

4.6 CONSIDERAC̄ÕES FINAIS DO CAPÍTULO ……................................................ 183

5. ESTUDOS DE CASO E ANÁLISE DOS RESULTADOS OBTIDOS ...............185

5.1 PANORAMA GERAL DOS CASOS ESTUDADOS ................................................ 185

5.2 AVALIAÇÃO DE UM SISTEMA SIMPLES ...................................................... 186

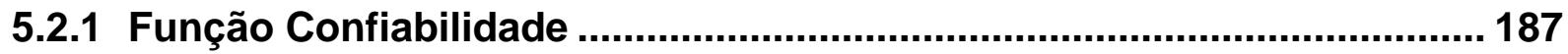

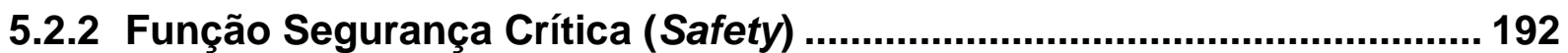

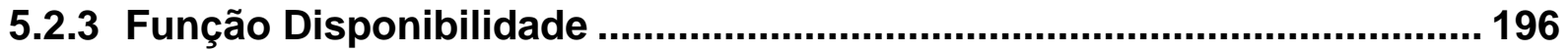

5.3 AVALIACÃ̃ DE UM SISTEMA SÉRIE COM DOIS COMPONENTES ……...................... 208

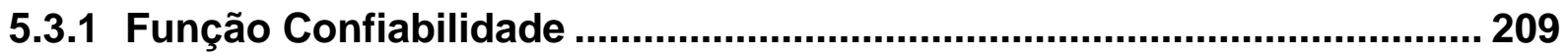

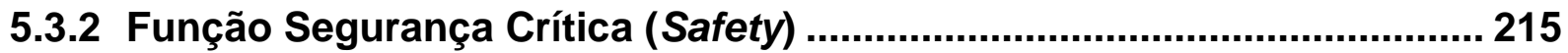

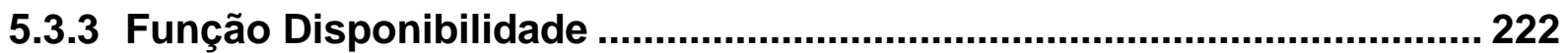

5.4 AvaliaçÃo de UM Sistema PaRAlelo com DoIs Componentes Redundantes . 237

5.4.1 Função Confiabilidade ..................................................................... 238

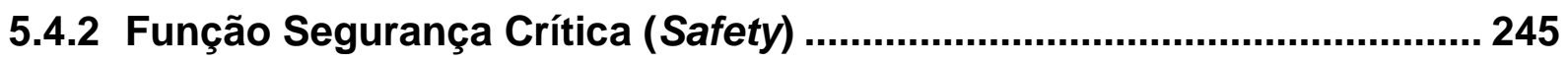




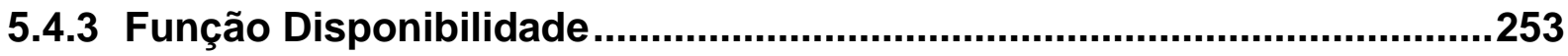

5.5 SUMÁRIO DOS RESULTADOS OBTIDOS ……………….....................................268

5.6 CONSIDERACCÕES FINAIS DO CAPÍTULO ………….......................................271

6. CONSIDERACÕES FINAIS

6.1 ConCLUSÕES DA PESQUISA DO MESTRADO ………........................................273

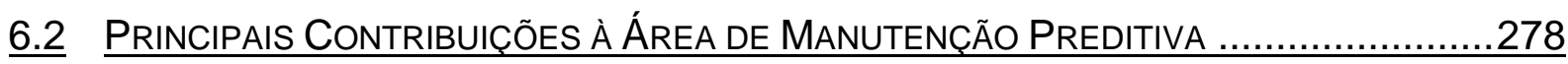

$\underline{6.3}$ SUGESTÕES PARA TRABALHOS FUTUROS ………......................................279

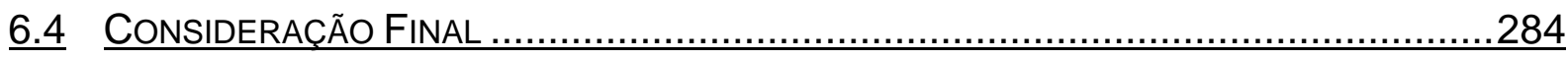

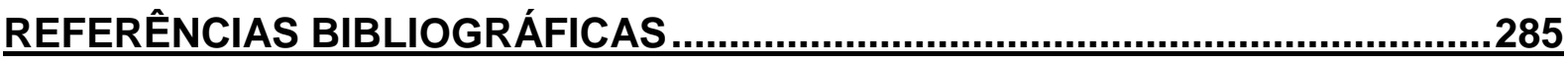

APÊNDICE A - HISTÓRICOS OPERACIONAIS UTILIZADOS NOS ESTUDOS DE

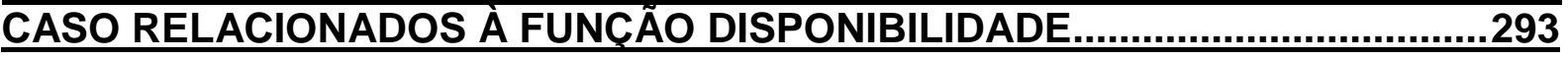

APÊNDICE A.1 - HISTÓRICOS OPERACIONAIS DO SISTEMA SIMPLES ……....................293 APÊNDICE A.2 - HISTÓRICOS OPERACIONAIS DO SISTEMA SÉRIE DE DOIS COMPONENTES .294

APÊNDICE A.3 - HISTÓRICOS OperacionaIS do Sistema PARALELO DE DOIS COMPONENTES............................................................................................... 



\section{INTRODUÇÃO}

Este capítulo da dissertação apresenta o escopo do presente estudo, abordando os objetivos, a motivação e as justificativas da proposta defendida neste trabalho. Além disso, também é explorada no presente capítulo a estrutura geral desta dissertação.

\subsection{OBjetivos}

O presente trabalho científico apresenta como objetivo principal propor um modelo que permita avaliar, por meio do uso de dados de histórico de operação, os impactos das condições de operação de um sistema formado por componentes elétricos, eletrônicos e programáveis sobre os índices de dependabilidade de seus elementos.

As condições de operação de um sistema podem ser compreendidas como um conjunto de fatores que afetam, direta ou indiretamente, seu funcionamento ao longo de seu respectivo tempo de missão. $O$ presente trabalho de pesquisa visa responder, sobretudo, as seguintes questões, que relacionam as condições de operação de um sistema elétrico, eletrônico e programável sobre seus níveis de confiabilidade, disponibilidade e segurança crítica (safety):

a) Quais são os efeitos de um contexto de operação adverso (por exemplo, devido a uma sobretensão de alimentação ou a um fenômeno de derating, em que há capacidade reduzida de dissipação de calor) sobre as taxas de falha dos componentes de um sistema?

b) Quais são os impactos dos fatores humanos dos atores envolvidos na utilização de um sistema, tais como usuários e equipes de instalação, manutenção e operação, sobre as taxas de falha e de reparo dos elementos que compõem o sistema?

Uma possível abordagem para que as questões prévias possam ser respondidas consiste em se considerar que os aspectos considerados nelas (contextos de operação adversos e ação humana) podem ser indiretamente avaliados a partir dos eventos de falhas e manutenções já manifestados em um sistema ao longo de um período de tempo. 
Ao se utilizar essa abordagem, torna-se possível, ainda, considerar um segundo objetivo principal para o presente estudo: a possibilidade de se avaliar como os eventos de falhas e manutenções anteriormente executados sobre os componentes de um sistema podem ser utilizados para que suas respectivas falhas futuras possam ser previstas antecipadamente.

Com base na capacidade de presciência de comportamento considerada nesse segundo objetivo, considera-se que o modelo proposto pode ser utilizado para dar suporte à manutenção preditiva de sistemas, visto que se espera que ele permita prever quando procedimentos de manutenção devem ser executados para se evitar uma falha ou uma degradação indesejada do sistema. Desse modo, as políticas de manutenção prescritas para um sistema poderiam ser complementadas ou adaptadas a partir do embasamento matemático produzido pelo modelo defendido neste trabalho de pesquisa.

\subsection{Motivação}

No mundo contemporâneo, o ser humano tem se tornado cada vez mais dependente de serviços prestados por meio do uso de sistemas elétricos, eletrônicos e programáveis. O uso progressivamente mais difundido de sistemas computacionais para se executar diversas tarefas básicas do cotidiano é o principal responsável por essa mudança de paradigma, tal como se pode constatar, no caso do Brasil, por meio do "Suplemento da Pesquisa Nacional por Amostra de Domicílios (Pnad) 2008 sobre Acesso à Internet e Posse de Telefone Móvel Celular para Uso Pessoal', publicado pelo IBGE em 2009.

Por meio desse estudo, foi possível detectar que o percentual da população brasileira de dez ou mais anos de idade que acessou a Internet pelo menos uma vez na vida passou de 20,8\% em 2005 para 34,6\% em 2008 (IBGE, 2009). Esse índice revela um aumento de $75,3 \%$ no número de brasileiros que já acessou a Internet, que atinge a marca de 56 milhões de habitantes (IBGE, 2009).

Além desse aspecto, o Pnad 2008 também foi responsável por traçar o perfil das atividades executadas pelo brasileiro na Internet (IBGE, 2009). O resultado obtido, apresentado na Figura 1, permite verificar que as principais atividades 
executadas pelo brasileiro na Internet estão relacionadas ao lazer e à comunicação com outras pessoas.

Figura 1 - Distribuição das Principais Atividades Executadas na Internet em 2008 pela População Brasileira com 10 ou mais Anos de Idade

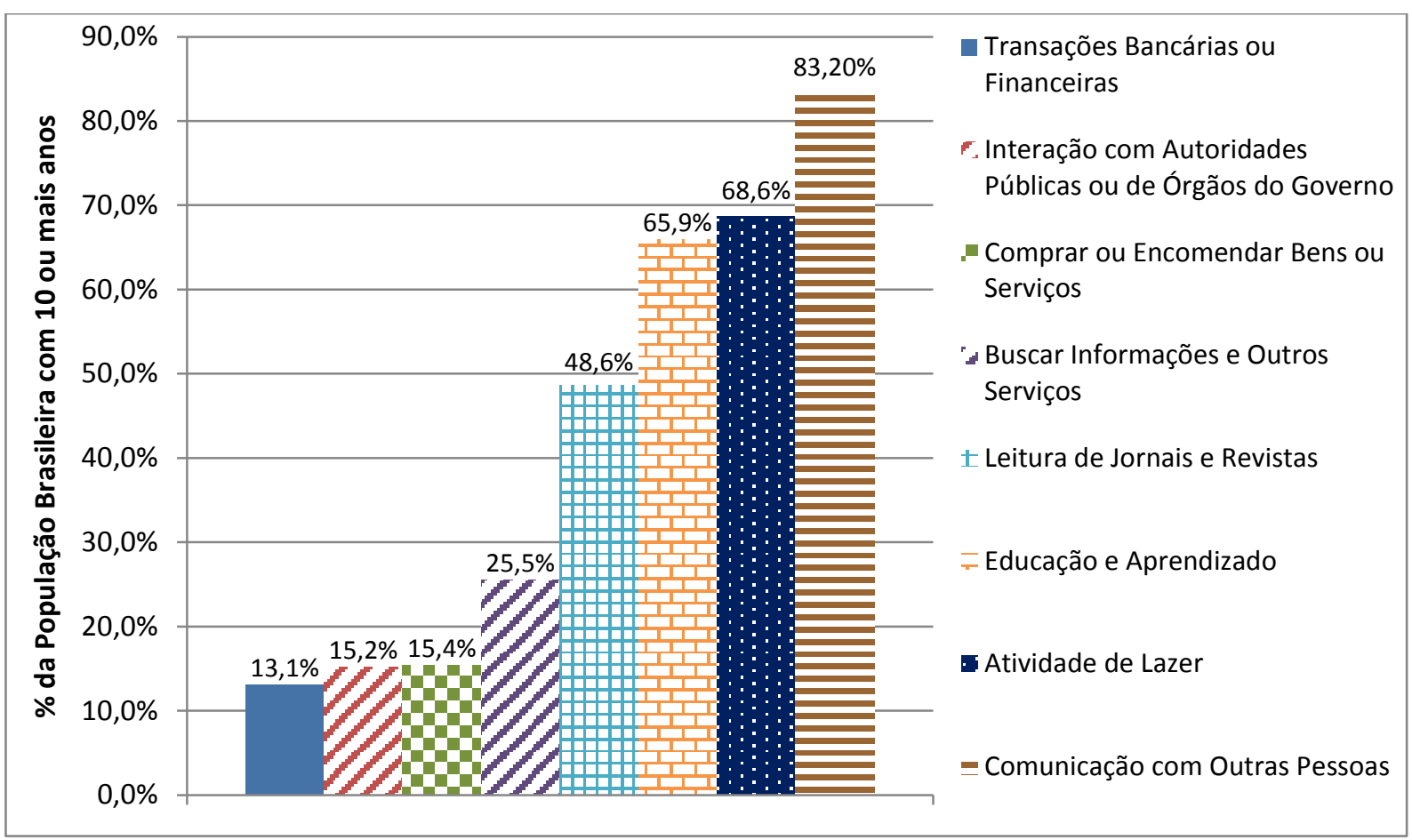

Fonte: adaptado de IBGE (2009)

Embora com índices menos expressivos, tarefas como transações bancárias e financeiras, interações com autoridades públicas e aquisições de bens e serviços também apresentam representatividade significativa, afetando diretamente de 6 a 8 milhões de brasileiros segundo os dados levantados pelo Pnad 2008. Ao contrário das atividades de lazer, as tarefas relacionadas anteriormente normalmente necessitam ser executadas em prazos específicos, e eventuais perdas financeiras ou retaliações judiciais podem ocorrer quando elas não podem ser cumpridas dentro de seus respectivos limites temporais.

Por esse motivo, é fundamental que as empresas que proveem acesso à Internet mantenham seus respectivos sistemas disponíveis pelo maior período de tempo possível, sob a pena de pagarem multas se os serviços concedidos não se mantiverem de acordo com os níveis de qualidade acordados em contrato. No Brasil, um dos exemplos mais emblemáticos de problemas de acesso à Internet ocorreu no 
ano de 2008, quando pelo menos 3500 empresas e diversos clientes residenciais da empresa espanhola Telefonica ficaram sem acesso banda larga à Internet por 5 dias consecutivos devido à ocorrência de falhas em roteadores (FOLHA ONLINE, 2010). Em decorrência de compensações por indisponibilidade de serviço e do pagamento de multas e indenizações a pessoas físicas e jurídicas que foram lesadas, estima-se que o prejuízo sofrido pela Telefonica na ocasião tenha superado $\mathrm{R} \$ 24$ milhões (FOLHA ONLINE, 2010).

Os índices de disponibilidade também são extensivamente utilizados no setor de distribuição de energia elétrica como métricas do nível de qualidade dos serviços prestados aos consumidores. No Brasil, cabe à ANEEL avaliar se os índices de disponibilidade (também denominados indicadores de continuidade de serviço) das distribuidoras de energia elétrica estão dentro de patamares aceitáveis, e caso eles não sejam considerados adequados pelo órgão regulador, as empresas concessionárias podem ser penalizadas com o pagamento de multas.

Os indicadores avaliados pela ANEEL podem ser divididos em duas categorias distintas (ANEEL, 2012):

a) Indicadores Coletivos: São índices acompanhados pela ANEEL por meio da coleta de dados de subdivisões de uma distribuidora denominadas Conjuntos Elétricos (ANEEL, 2012). Os dois indicadores coletivos utilizados são os seguintes:

i. DEC (Duração Equivalente de Interrupção por Unidade Consumidora): Sinaliza o período de tempo (em horas) em que um consumidor fica, em média, sem fornecimento de energia elétrica durante um intervalo de tempo de observação de um mês ou um ano (ANEEL, 2012).

ii. FEC (Frequência Equivalente de Interrupção por Unidade Consumidora): Representa o número de vezes em que um consumidor fica, em média, sem fornecimento de energia elétrica durante um intervalo de tempo de observação de um mês ou um ano (ANEEL, 2012). 
b) Indicadores Individuais: São índices acompanhados pela ANEEL em cada unidade consumidora particular (ANEEL, 2012). Os três indicadores individuais utilizados são os seguintes:

i. DIC (Duração de Interrupção por Unidade Consumidora): Sinaliza o período de tempo (em horas) em que um consumidor específico fica sem fornecimento de energia elétrica durante um intervalo de tempo de observação de um mês ou um ano (ANEEL, 2012).

ii. FIC (Frequência de Interrupção por Unidade Consumidora): Representa o número de vezes em que um consumidor específico fica sem fornecimento de energia elétrica durante um intervalo de tempo de observação de um mês ou um ano (ANEEL, 2012).

iii. DMIC (Duração Máxima de Interrupção por Unidade Consumidora): Simboliza o máximo período de tempo em que um consumidor específico fica sem fornecimento de energia elétrica durante um intervalo de tempo de observação de um mês ou um ano (ANEEL, 2012).

Nas aplicações mencionadas anteriormente (uso de Internet para execução de tarefas do cotidiano e fornecimento de energia elétrica), a ocorrência de falhas em componentes dos sistemas envolvidos leva, essencialmente, à degradação dos níveis de qualidade dos serviços prestados aos usuários finais devido à indisponibilidade. Salvo em situações patológicas nas quais não existem mecanismos secundários de mitigação de falhas (por exemplo, grupos geradores movidos à queima de combustível orgânico para manter a energização de equipamentos médicos de terapia intensiva), nenhuma das situações previamente abordadas leva a situações potencialmente perigosas, que podem resultar em desastres ambientais ou em mortes.

Quando esses cenários potencialmente perigosos podem se manifestar em decorrência de uma ou mais falhas dos componentes de um sistema, este é considerado um sistema crítico com relação à segurança (safety), e a aplicação à qual ele se destina é definida como uma aplicação crítica com relação à segurança (safety). Nesses casos, a ocorrência de falhas inseguras que expõem o sistema ou o ambiente a situações potencialmente perigosas deve ser evitada ao 
máximo, sobretudo por meio da adoção de técnicas de projeto que evitem que falhas simples ou múltiplas de componentes levem o sistema a operar em uma situação insegura com uma probabilidade superior a um limiar máximo definido para a aplicação.

É por esse motivo que os sistemas críticos com relação à segurança (safety) devem ser desenvolvidos de forma aderente a normas que prescrevem técnicas e métodos a serem usados para que os Níveis de Integridade de Segurança (SIL Safety Integrity Level) desejados para a aplicação possam ser atingidos. Além de normas e padrões específicos de cada domínio (por exemplo, normas CENELEC da série $501 x x$ para sistemas metroferroviários), é recomendável que o projeto de sistemas elétricos, eletrônicos e programáveis de aplicação crítica siga a norma internacional IEC 61508, que considera as características de segurança crítica (safety) necessárias para todas as fases do ciclo de vida de um sistema elétrico, eletrônico e programável (incluindo hardware e software) utilizado em uma aplicação crítica com relação à segurança (safety) (IEC, 2010).

Mesmo em sistemas críticos com relação à segurança, a ocorrência de falhas em alguns de seus componentes é um fenômeno que, embora passível de mitigação por meio de técnicas de projeto que preveem resiliência, não pode ser contido. Para se evitar a manifestação de situações potencialmente inseguras devido à ocorrência de falhas simples ou múltiplas (mesmo que cada uma delas seja isoladamente segura), é importante que pelo menos as falhas que afetem negativamente a segurança crítica (safety) de um sistema sejam detectáveis. Nessas condições, a manifestação de uma falha exerce algum impacto sobre o funcionamento do sistema, e tal alteração comportamental é passível de reconhecimento e de um eventual tratamento mitigatório.

Se todas as falhas de um sistema forem detectáveis, procedimentos de manutenção corretiva apropriados poderão ser disparados. Nesse caso, a manutenção corretiva serve apenas para corrigir uma falha que já ocorreu (e que, portanto, não pode ser mais evitada).

Dependendo das necessidades impostas pelo grau de criticidade da aplicação, procedimentos de manutenção periódica sobre um dado sistema podem 
ser executados independentemente da ocorrência de uma falha de seus componentes. Essa categoria de manutenção, que visa evitar a manifestação de potenciais falhas dos componentes de um sistema, é classificada como preventiva.

Quando dados referentes à operação dos componentes de um sistema estão disponíveis ${ }^{1}$, eles podem ser utilizados para se prever, com um grau de precisão determinado pelas técnicas de interpretação dos dados de histórico e pelo nível de detalhamento e precisão das informações disponíveis, quando novas falhas podem ocorrer. Nesse caso, apenas os componentes que forem constatados como potencialmente sujeitos a uma falha em um futuro suficientemente próximo é que serão submetidos a um procedimento de manutenção apropriado. Como tais procedimentos de manutenção são baseados na predição de falhas futuras, diz-se que a manutenção executada é preditiva.

Como a manutenção preditiva é embasada em dados que refletem fielmente (com determinado grau de confiança) o histórico de uso dos componentes de um sistema, uma de suas principais vantagens frente à manutenção preventiva é a maior efetividade, que pode ser traduzida, em longo prazo, em uma redução dos custos de manutenção e em um aumento nos índices de disponibilidade e segurança crítica (safety) associados ao sistema. Segundo Almeida (2012a), existem pesquisas que indicam que um terço de todos os custos de manutenção em uma planta industrial é desperdiçado como resultado de manutenção desnecessária ou inadequadamente realizada. Como, ainda de acordo com Almeida (2012a), os custos de manutenção em uma planta industrial respondem por $15 \%$ a $30 \%$ de todos os seus custos operacionais, manutenções desnecessárias ou inadequadas são responsáveis por $5 \%$ a $10 \%$ de todos os custos operacionais da empresa.

Nos setores de geração de energia elétrica, papel e celulose, processamento alimentício, têxtil, metalurgia, siderurgia e em outras indústrias de manufatura ou de processo, um levantamento realizado em 1988 sobre uma amostra de indústrias dos Estados Unidos, do Canadá, da Grã-Bretanha, da França e da Austrália revelou uma série de benefícios financeiros após a adoção com sucesso de técnicas de

\footnotetext{
1 Pelo menos dos componentes mais críticos do sistema, identificados com base no uso do conhecimento adquirido pelas equipes de projeto, operação e manutenção acerca do sistema.
} 
manutenção preditiva (ALMEIDA, 2012b). O panorama geral das melhorias alcançadas pelas empresas que participaram do estudo é sumarizado na Tabela 1.

Tabela 1 - Melhorias Tangíveis com a Adoção de um Programa Eficiente de Gerência de Manutenção Preditiva

\begin{tabular}{|l|c|}
\hline \multicolumn{1}{|c|}{ Benefício Alcançado } & Percentual \\
\hline Redução dos custos de manutenção & De $50 \%$ a $80 \%$ \\
\hline Redução de falhas nas máquinas & De $50 \%$ a $60 \%$ \\
\hline Redução de estoque de sobressalentes & De $20 \%$ a $30 \%$ \\
\hline Redução de horas extras para manutenção & De $20 \%$ a $50 \%$ \\
\hline Redução do tempo de parada das máquinas & De $50 \%$ a $80 \%$ \\
\hline Aumento na vida das máquinas & De $20 \%$ a $40 \%$ \\
\hline Aumento da produtividade & De $20 \%$ a $30 \%$ \\
\hline Aumento dos lucros & De $25 \%$ a $60 \%$ \\
\hline
\end{tabular}

Fonte: Almeida (2012b)

Desde o ano de 1985, a ABRAMAN (Associação Brasileira de Manutenção e Gestão de Ativos) realiza e divulga bienalmente um levantamento sobre os indicadores do desempenho da manutenção em diversos setores de produtos e serviços da economia brasileira (ABRAMAN, 2011). Na última edição da pesquisa, conduzida e lançada em 2011, 145 empresas de 20 diferentes áreas de atuação foram consultadas sobre diversas características de seus procedimentos de manutenção por meio de um questionário (ABRAMAN, 2011). Os principais setores econômicos das empresas consultadas no levantamento da ABRAMAN em 2011 estão relacionados na Tabela 2.

Tabela 2 - Principais Setores Econômicos das Empresas Consultadas pela ABRAMAN em 2011

\begin{tabular}{|c|c|}
\hline Setor da Economia & Número de Empresas \\
\hline Prestação de Serviços & 18 \\
\hline Transportes e Portos & 17 \\
\hline Metalúrgico & 14 \\
\hline Siderúrgico & 11 \\
\hline
\end{tabular}




\begin{tabular}{|c|c|}
\hline Setor da Economia & Número de Empresas \\
\hline Automotivo & 9 \\
\hline Energia Elétrica & 7 \\
\hline
\end{tabular}

Fonte: ABRAMAN (2011)

Entre todos os resultados obtidos na pesquisa realizada pela ABRAMAN em 2011, é importante salientar o perfil dos procedimentos de manutenção aplicados pelas empresas consultadas. Pelos dados apresentados na Figura 2 e na Tabela 3, é possível notar que as manutenções corretiva e preventiva respondem por aproximadamente $65 \%$ de todos os esforços de manutenção executados pelas empresas consultadas, ao passo que as manutenções preditivas não atingem 20\% de todos os esforços gastos com procedimentos de manutenção. Além desse aspecto, também é possível inferir que, salvo pequenas variações locais entre os levantamentos bienais, essa tendência se mantém praticamente inalterada desde 1995.

Figura 2 - Percentual de Homem-hora por Tipo de Manutenção

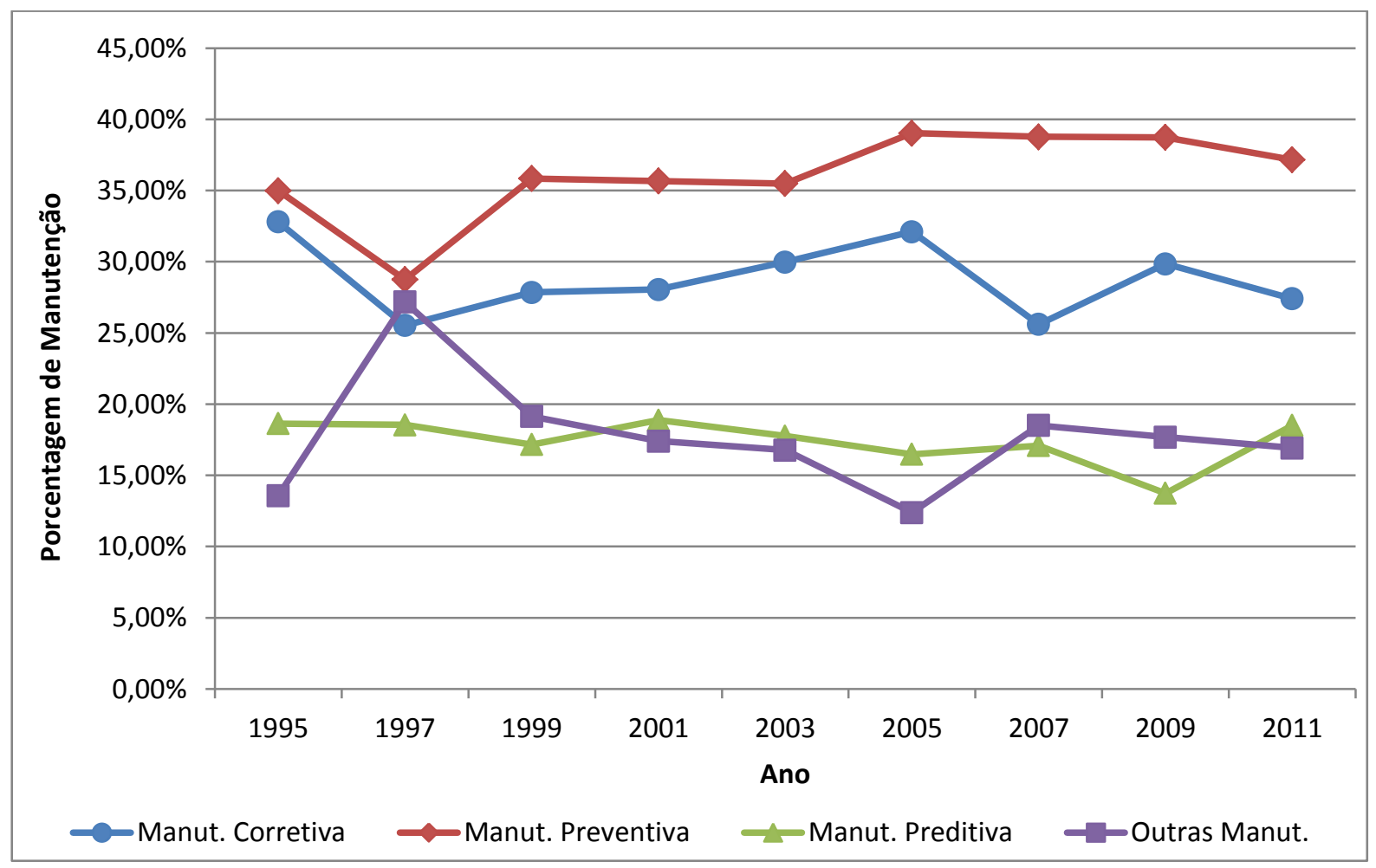

Fonte: ABRAMAN (2011) 
Tabela 3 - Valores dos Percentuais da Figura 2

\begin{tabular}{|c|c|c|c|c|}
\cline { 2 - 5 } \multicolumn{1}{c|}{} & $\begin{array}{c}\text { Manutenção } \\
\text { Corretiva }\end{array}$ & $\begin{array}{c}\text { Manutenção } \\
\text { Preventiva }\end{array}$ & $\begin{array}{c}\text { Manutenção } \\
\text { Preditiva }\end{array}$ & $\begin{array}{c}\text { Outras } \\
\text { Manutenções }\end{array}$ \\
\hline $\mathbf{1 9 9 5}$ & $32,80 \%$ & $35,00 \%$ & $18,64 \%$ & $13,56 \%$ \\
\hline $\mathbf{1 9 9 7}$ & $25,53 \%$ & $28,75 \%$ & $18,54 \%$ & $27,18 \%$ \\
\hline $\mathbf{1 9 9 9}$ & $27,85 \%$ & $35,84 \%$ & $17,17 \%$ & $19,14 \%$ \\
\hline $\mathbf{2 0 0 1}$ & $28,05 \%$ & $35,67 \%$ & $18,87 \%$ & $17,41 \%$ \\
\hline $\mathbf{2 0 0 3}$ & $29,98 \%$ & $35,49 \%$ & $17,76 \%$ & $16,77 \%$ \\
\hline $\mathbf{2 0 0 5}$ & $32,11 \%$ & $39,03 \%$ & $16,48 \%$ & $12,38 \%$ \\
\hline $\mathbf{2 0 0 7}$ & $25,61 \%$ & $38,78 \%$ & $17,09 \%$ & $18,51 \%$ \\
\hline $\mathbf{2 0 0 9}$ & $29,85 \%$ & $38,73 \%$ & $13,74 \%$ & $17,68 \%$ \\
\hline $\mathbf{2 0 1 1}$ & $27,40 \%$ & $37,17 \%$ & $18,51 \%$ & $16,92 \%$ \\
\hline
\end{tabular}

Fonte: ABRAMAN (2011)

Em vista da argumentação apresentada, é possível inferir que um programa de manutenção preditiva pode contribuir com a introdução de benefícios de diversas naturezas que, via de regra, podem ser traduzidos em redução de custos para as empresas e em aumento de qualidade de produtos e serviços para os usuários finais. Nesse caso, a diminuição dos custos operacionais para as empresas pode ser dividida em duas componentes:

a) Redução direta, relacionada à diminuição dos gastos da empresa com peças, equipamentos e equipes de manutenção;

b) Redução indireta, associada à diminuição de pagamentos de multas e ressarcimentos decorrentes do aumento global da qualidade dos produtos fornecidos ou dos serviços prestados pela empresa.

Para empresas que atuam especificamente em aplicações críticas com relação à segurança (safety), a manutenção preditiva mostra-se como uma alternativa que permite, ao mesmo tempo, reduzir custos operacionais com manutenção (devido à maior eficiência da manutenção preditiva quando comparada com procedimentos usuais de manutenção preventiva) e aumentar os níveis de segurança crítica (safety) de um sistema, algo necessário considerando-se, sobretudo, as recentes demandas de mercado em domínios de aplicação crítica 
como as áreas metroferroviária e de transporte aéreo (SILVA NETO; CUGNASCA, 2013).

\subsection{JUSTIFICATIVA}

Pretende-se estabelecer o modelo proposto no presente estudo como parte integrante de um programa de manutenção preditiva de sistemas elétricos, eletrônicos e programáveis voltados a quaisquer aplicações. Ao atuar como um elemento que apoia o disparo de procedimentos de manutenção preditiva, espera-se que os seguintes benefícios, detalhadamente abordados na seção 1.2, podem ser atingidos mediante adoção do modelo defendido neste trabalho científico:

a) Os custos diretos e indiretos associados à recuperação de falhas e aos períodos de indisponibilidade de um sistema podem ser reduzidos;

b) As probabilidades de ocorrência de falhas que levem à indisponibilidade de um serviço ou a uma situação potencialmente perigosa podem ser minorados, uma vez que eventos indesejados decorrentes da degradação (parcial ou total) de um sistema poderão ser previstos antecipadamente e com maior precisão do que as políticas e heurísticas usualmente utilizadas;

c) A possibilidade de se prever, com um grau de confiança preestabelecido, os instantes de tempo em que eventos de falha e de indisponibilidade podem ocorrer permite otimizar a alocação de recursos humanos e financeiros para se desempenhar procedimentos de manutenção. Esse aspecto se deve ao fato de que, ao se conhecer com maior precisão os subsistemas que devem ser preventivamente reparados e os instantes de tempo mais prováveis para os mesmos falharem, as equipes de manutenção a serem convocadas podem ser dimensionadas com maior adequação para as necessidades constatadas, sobretudo com relação à quantidade de pessoas envolvidas e às especialidades técnicas das mesmas.

\subsection{Estrutura da Dissertação}

A presente dissertação está estruturada com base em seis capítulos. 
Os principais conceitos utilizados no modelo proposto neste trabalho científico são expostos de forma sumarizada no Capítulo 2. Nesse caso, é inicialmente apresentado o panorama da evolução tecnológica da manutenção preditiva e, em seguida, são explorados aspectos gerais aplicáveis a sistemas tolerantes a falhas e as principais características dos modelos de cálculo de confiabilidade de sistemas elétricos, eletrônicos e programáveis preconizados nos padrões internacionais MILHDBK-217 e RIAC-HDBK-217Plus. Por fim, são detalhados os conceitos básicos e métodos de simulação de Processos de Markov, bem como as características gerais dos Filtros de Kalman.

No Capítulo 3, por sua vez, explora-se com detalhes o modelo proposto no presente estudo, sendo apresentadas as características de um histórico de operação de um sistema elétrico, eletrônico e programável e os algoritmos que permitem incorporá-lo aos Processos de Markov e gerar as previsões de falhas futuras por meio de filtragem Kalman. Também são apresentados nesse capítulo os principais indicadores e resultados que podem ser obtidos por intermédio do modelo proposto.

No Capítulo 4, são abordados os principais aspectos do ambiente computacional utilizado para desenvolver e avaliar o modelo proposto no presente estudo. Dessa maneira, pertencem ao escopo do Capítulo 4 tanto o simulador de dados de histórico de operação de sistemas quanto os softwares que implementam os modelos conceituais e algoritmos apresentados no Capítulo 3.

Aborda-se, no Capítulo 5, a análise dos resultados obtidos pela aplicação do modelo proposto no Capítulo 3 (mediante uso das ferramentas documentadas no Capítulo 4) a três estudos de caso distintos, concebidos com o propósito de promover a discussão das diferenças dos resultados produzidos mediante aplicação de abordagens clássicos e do modelo proposto neste trabalho.

Por fim, apresentam-se no Capítulo 6, as considerações finais do presente estudo científico, com as conclusões sobre o modelo proposto e sugestões para eventuais trabalhos futuros em extensões do modelo e em áreas de conhecimento correlatas. 


\section{REVISÃO TEÓRICA}

Este capítulo da dissertação aborda os principais aspectos dos fundamentos que embasam o modelo proposto no presente estudo. Após se expor o panorama da evolução científica recente das técnicas de manutenção preditiva, abordam-se generalidades conceituais relacionadas a sistemas tolerantes a falhas, os padrões atuais de determinação de confiabilidade de sistemas elétricos, eletrônicos e programáveis e os fundamentos dos Processos de Markov e dos Filtros de Kalman.

\subsection{Panorama Científico do Estado-da-ARTe da Manutenção Preditiva}

Com o aumento da demanda produtiva e o acirramento da competitividade pelo mercado, a manutenção passou a assumir uma função essencial não só para o processo produtivo, mas também para garantir a entrega de serviços essenciais ao conforto dos usuários e clientes envolvidos (MARQUES et al., 2006). Segundo Pinto, Xavier e Baroni (2002) ${ }^{2}$ apud Marques et al. (2006), a missão fundamental da manutenção é "garantir a disponibilidade da função dos equipamentos e instalações de modo a atender a um processo de produção ou de serviço, com confiabilidade, segurança, preservação do meio ambiente e custos adequados".

De acordo com Pinto e Xavier (2007), a evolução da manutenção compreende três etapas:

a) Primeira Geração de Manutenção: Abrange o período antes da Segunda Guerra Mundial, durante o qual a indústria era pouco mecanizada e os equipamentos eram simples e, em sua maioria, superdimensionados (PINTO; XAVIER, 2007). Nessa geração, a manutenção executada era essencialmente corretiva e compreendia apenas serviços de limpeza, lubrificação e reparo após uma disfunção se manifestar (PINTO; XAVIER, 2007).

\footnotetext{
2 PINTO, A. K.; XAVIER, J. A. N.; BARONI, T. Gestão da Manutenção e Técnicas Preditivas. Rio de Janeiro: Ed. Qualitymark: ABRAMAN, 2002.
} 
Quando a manutenção corretiva não é planejada, os custos operacionais globais tendem a ser maiores, e perdas de produção e danos em equipamentos tornam-se mais frequentes;

b) Segunda Geração de Manutenção: Engloba o período que vai da Segunda Guerra Mundial até o final da década de 1960, durante o qual as indústrias, ao almejar aumentar a produtividade, aumentaram a mecanização, a complexidade das instalações industriais e os graus dos índices de confiabilidade e disponibilidade que necessitavam ser alcançados (PINTO; XAVIER, 2007). Como, nesse período, a indústria manteve-se bastante dependente do bom funcionamento de suas máquinas, esse aspecto levou à ideia de que falhas dos equipamentos poderiam (e deveriam) ser evitadas, culminando no surgimento do conceito de manutenção preventiva (PINTO; XAVIER, 2007). Esta, por sua vez, é definida por Pinto e Xavier (2007) como sendo "a atuação realizada de forma a reduzir ou evitar a falha ou queda no desempenho, obedecendo a um plano previamente elaborado, baseado em intervalos definidos de tempo";

c) Terceira Geração de Manutenção: A partir da década de 1970, o aumento da automação empresarial levou a um aumento nos custos relacionados a paralisações e problemas de qualidade nos produtos e serviços disponibilizados pelas empresas. Consequentemente, esse cenário impulsionou uma mudança no perfil das manutenções para que fosse possível se manter a capacidade competitiva (PINTO; XAVIER, 2007).

Nesse contexto, surge a manutenção preditiva, que pode ser compreendida como "a manutenção que prediz o tempo de vida útil dos componentes das máquinas e equipamentos e as condições para que esse tempo seja bem aproveitado" (MARQUES et al., 2006). A manutenção preditiva deve ser amparada por meio de "qualquer atividade de monitoramento que seja capaz de fornecer dados suficientes para uma análise de tendências, emissão de diagnóstico e tomada de decisão". 
Desde então, diversos estudos têm sido conduzidos com o intuito de melhorar a eficiência dos procedimentos de manutenção preditiva e reduzir o custo associado à sua implementação continuada. Um dos primeiros estudos publicados é abordado em Bendell e Humble (1978), que apresenta, por meio de expressões matemáticas respaldadas na teoria de probabilidades, uma técnica destinada ao levantamento da predisposição de ocorrência de falhas em unidades de um sistema com base em seus respectivos históricos de utilização. O modelo proposto deve ser alimentado com quatro categorias de dados de histórico (BENDELL; HUMBLE, 1978):

a) Tempo de calendário transcorrido no ensaio;

b) Tempo acumulado de funcionamento de cada componente;

c) Duração do período de tempo de operação atual;

d) Características aleatórias do ambiente no qual o sistema em estudo está inserido.

Apesar do pioneirismo na abordagem dos efeitos das condições operacionais de um sistema sobre suas tendências de falhas e degradações futuras, o trabalho exposto em Bendell e Humble (1978) possui algumas limitações. As principais restrições percebidas são as seguintes:

a) Não se consideram, nos modelos concebidos para avaliar as tendências de falhas e degradações, eventuais procedimentos de manutenção previamente executados sobre o sistema em estudo. Nessas condições, o comportamento previsto para o sistema a partir dos modelos matemáticos pode não ser suficientemente abrangente;

b) O número máximo de modos de falha considerados plausíveis para cada componente do sistema em estudo é limitado em três unidades. Essa hipótese simplificadora restringe, por exemplo, a utilização do modelo proposto em Bendell e Humble (1978) para abordar componentes eletrônicos como transistores, diodos, LEDs e acopladores ópticos, que possuem mais que três modos de falha plausíveis segundo CENELEC (2003);

c) Os modelos matemáticos concebidos requerem que o nível quantitativo de degradação do sistema em estudo seja utilizado como uma entrada. Como a quantificação desse parâmetro não é usualmente trivial em sistemas de médio e grande porte utilizados em aplicações práticas, eventuais estimativas 
realizadas podem comprometer o grau de confiança associado aos resultados produzidos a partir dos modelos defendidos em Bendell e Humble (1978).

Um panorama geral sobre a implantação de um programa extensivo de manutenção preditiva em um ambiente empresarial é tratado em Trodd (1998). A abordagem utilizada consiste em apresentar as condições que levam a manutenção preditiva a ser economicamente viável em diversos contextos distintos, discutindose, nesse caso, as ações que devem ser tomadas e os benefícios e resultados que podem ser atingidos após a implantação do programa de manutenção preditiva. Para ilustrar e suportar a argumentação, o autor expõe três estudos de casos sobre experiências reais; no entanto, vale ressaltar que nenhum detalhe técnico relacionado aos modelos utilizados nos estudos de caso abordados é apresentado.

Um levantamento recente sobre o estado-da-arte da área de manutenção preditiva é apresentado em Hashemian e Bean (2011). As contribuições mais significativas dessa referência relacionam-se a dois aspectos distintos: os perfis das funções que descrevem as taxas de falhas aplicáveis a diversas categorias de equipamentos ao longo do tempo e as principais modalidades de técnicas de manutenção preditiva utilizadas em algumas aplicações específicas.

Segundo apresentado em Hashemian e Bean (2011), estudos realizados conjuntamente pela empresa aérea United Airlines e pelo Departamento de Defesa Norte-Americano (DoD) na década de 1970, publicados em Nowlan e Heap (1978), ainda podem ser considerados importantes para se qualificar a evolução da taxa de falhas de diversas categorias de componentes usualmente aplicados em diversas aplicações. De acordo com Nowlan e Heap (1978), os ensaios realizados pela United Airlines para avaliar quanto o envelhecimento dos componentes estudados afeta a probabilidade de eles falharem permitiram observar que componentes usualmente utilizados em aeronaves seguem uma entre seis curvas de probabilidades condicionais de ocorrência de falhas. Os perfis detectados, juntamente com os respectivos percentuais de componentes aderentes a cada um deles, são ilustrados na Figura 3. 
Figura 3 - Perfis das Curvas de Taxa de Falha

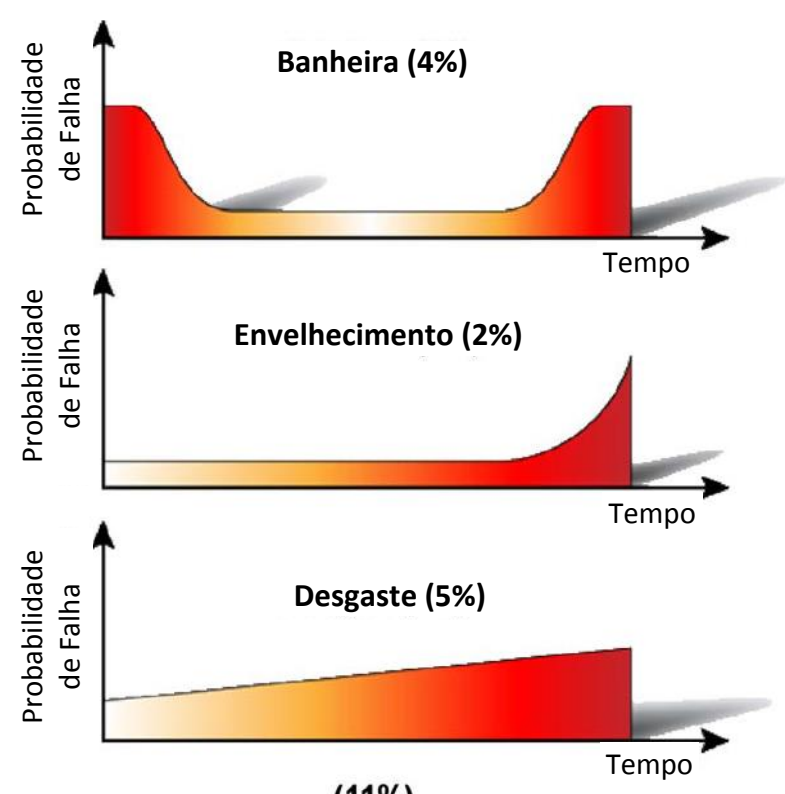

(11\%)

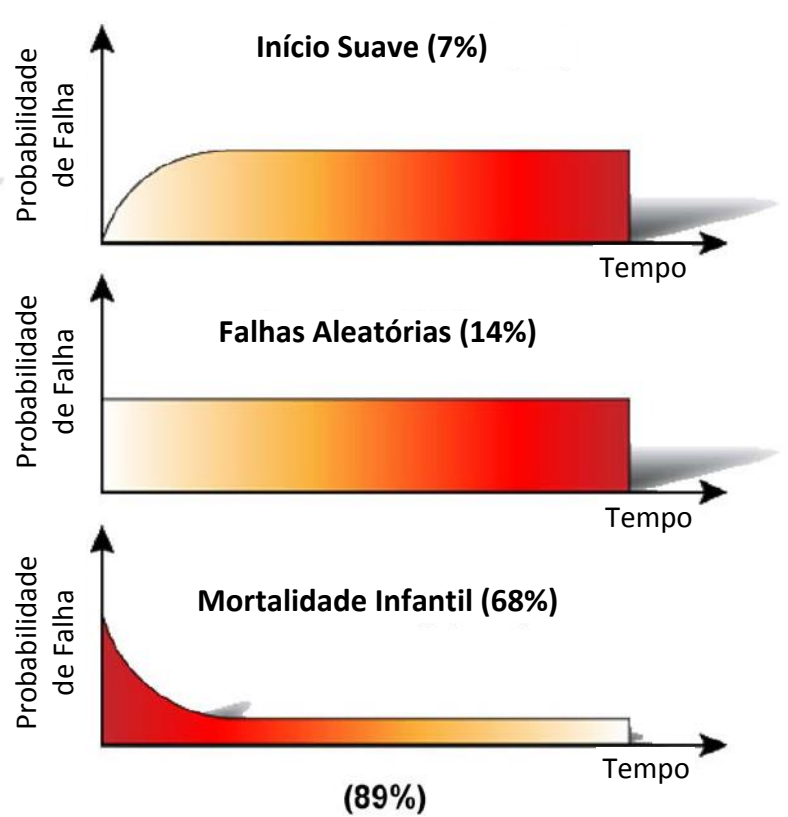

$(89 \%)$

Fonte: adaptado de Hashemian e Bean (2011)

Como se pode observar a partir da Figura 3, há dois padrões de curvas de taxas de falhas que possuem regiões bem definidas de aumento pronunciado da probabilidade de manifestação de uma falha devido ao envelhecimento de um componente: a curva da banheira e a curva de envelhecimento. Esses padrões comportamentais de taxas de falhas foram constatados apenas em $6 \%$ dos componentes considerados nos estudos realizados pela United Airlines, o que contradiz as previsões intuitivas de que diversas categorias de componentes tendem a falhar mais à medida que envelhecem (HASHEMIAN; BEAN, 2011). Segundo Nowlan e Heap (1978), os principais elementos cujas taxas de falhas seguem as curvas da banheira ou de envelhecimento foram pneus, cilindros de motores de movimento alternado (baseados em pistões), pastilhas de freio, lâminas de compressores e todas as partes estruturais das aeronaves.

Também de acordo com a Figura 3, é possível notar que as taxas de falhas de $5 \%$ dos componentes avaliados em Nowlan e Heap (1978) são aderentes à curva de desgaste, caracterizada por um aumento gradual da probabilidade de um componente falhar à medida que ele envelhece. A principal diferença entre as curvas de envelhecimento e de desgaste relaciona-se exatamente à taxa de crescimento da probabilidade de ocorrência de falhas de um componente: enquanto 
a curva de envelhecimento prevê que existe um instante de tempo notável a partir do qual a tendência de o elemento em estudo falhar aumenta abruptamente, a curva de desgaste prescreve que a taxa de falhas cresce de forma homogênea desde a fabricação do componente em estudo. Segundo Nowlan e Heap (1978), os motores das turbinas das aeronaves são os principais elementos cujas taxas de falhas podem ser descritas apropriadamente pela curva de desgaste.

As taxas de falhas de todas as demais categorias de componentes que foram consideradas no estudo apresentado em Nowlan e Heap (1978) seguem uma das seguintes curvas:

a) Início Suave: Os elementos cujas taxas de falhas são aderentes à curva de início suave são caracterizados por possuírem reduzida probabilidade de falharem no início de seus respectivos períodos de vida. Uma vez transcorrido esse intervalo de tempo introdutório, a taxa de falhas do componente aumenta e atinge um patamar que se mantém constante independentemente de seu tempo de utilização.

De acordo com a Figura 3, 7\% dos componentes considerados no estudo documentado em Nowlan e Heap (1978) seguem o padrão comportamental representado pela curva de início suave. É importante ressaltar, no entanto, que nenhuma informação adicional sobre as categorias de componentes enquadradas nesta classificação foi fornecida em Nowlan e Heap (1978).

b) Falhas Aleatórias: Quando a taxa de falhas de um componente segue a curva de falhas aleatórias, a probabilidade de ocorrência de uma falha do elemento em estudo é essencialmente a mesma ao longo de todo o seu período de vida (desde a fabricação até o descarte).

Com base na Figura 3, o perfil de falhas aleatórias descreve o comportamento da taxa de falhas de $11 \%$ dos componentes avaliados no estudo publicado em Nowlan e Heap (1978). Assim como no caso anterior, não houve detalhamento em Nowlan e Heap (1978) acerca dos tipos de componentes avaliados que foram classificados desta forma; 
c) Mortalidade Infantil: Os elementos cujas taxas de falhas seguem o perfil de mortalidade infantil são caracterizados por possuírem elevada probabilidade de falharem no início de seus respectivos períodos de vida. Uma vez transcorrido esse intervalo de tempo introdutório, a taxa de falhas do componente decai e atinge um patamar que se mantém constante independentemente de seu tempo de utilização.

A partir da Figura 3, é possível notar que o comportamento prescrito pela curva de mortalidade infantil foi dominante nos ensaios realizados no estudo, uma vez que $68 \%$ dos componentes considerados puderam ser comportamentalmente descritos por ela. De acordo com Nowlan e Heap (1978), os principais elementos enquadrados em tal categoria são os equipamentos eletrônicos.

Segundo Nowlan e Heap (1978), a principal característica compartilhada entre os componentes que seguem as curvas de início suave, falhas aleatórias e mortalidade infantil relaciona-se ao fato de que não há uma tendência de a probabilidade de falhas aumentar com o envelhecimento do componente. Por esse motivo, torna-se difícil prever com precisão o período efetivo de vida útil de elementos cujas taxas de falhas seguem uma dessas curvas, visto que essa característica pode variar tanto entre amostras de uma mesma categoria de componente quanto de acordo com as condições em que os equipamentos são utilizados (HASHEMIAN; BEAN, 2011). Nessas situações, a abordagem mais indicada para orientar a substituição de componentes em uso deve agregar aos processos operacionais já existentes mecanismos que permitam executar a manutenção preditiva dos sistemas (HASHEMIAN; BEAN, 2011).

No caso específico de sistemas elétricos e eletrônicos, apresentam-se em Hashemian e Bean (2011) três abordagens de monitoramento operacional que dão suporte à manutenção preditiva de equipamentos. Maiores informações sobre as técnicas enumeradas subsequentemente podem ser obtidas em Hashemian e Bean (2011). 
a) Uso de dados de operação coletados a partir dos próprios sensores do processo;

b) Uso de dados de operação coletados a partir de sensores de teste (incluindo sensores sem fio);

c) Uso de sinais elétricos de teste baseados, por exemplo, no método de resposta do sistema a um degrau de corrente elétrica e em testes de refletometria de domínio temporal e de indutância-capacitância-resistência.

A tendência principal das pesquisas acadêmicas recentes relacionadas à área de manutenção preditiva relaciona-se à proposição de arcabouços, métodos e modelos que podem ser aplicados especificamente em uma ou mais áreas de atuação. Em Grall et al. (2002), por exemplo, é apresentada a proposta de um modelo de manutenção preditiva para sistemas que se deterioram gradualmente. Em vez de prever observação constante do sistema, o modelo defendido combina monitoramentos periódicos com manutenções corretivas, sendo estas executadas apenas quando o grau de degradação do sistema supera um limiar aceitável para seu funcionamento. Para defender a viabilidade do modelo, os autores mostram, por meio de alguns estudos de caso, que o custo global da manutenção obtido pela aplicação do modelo é inferior ao da manutenção preditiva tradicional (com observação constante dos parâmetros de funcionamento do sistema avaliado).

Um método de validação similar, também baseado na avaliação do custo global da manutenção de um sistema, é utilizado no estudo exposto em Zhou, Xi e Lee (2007). Nesse trabalho de pesquisa, é proposto um modelo que integra manutenções preventivas executadas periodicamente com manutenções preditivas de modo que o custo global das manutenções possa ser minimizado mediante combinação das duas técnicas. O custo ótimo é traduzido em um indicador de degradação global do sistema sob estudo, que é empregado como parâmetro de determinação do tipo de manutenção a ser executado: quando o índice de degradação passa a superar o limiar de custo ótimo, uma manutenção preventiva é executada sobre o sistema.

É importante ressaltar que críticas sobre conceitos e o raciocínio matemático utilizados em Zhou, Xi e Lee (2007) foram publicadas um ano depois em Wu (2008). Em resposta a esses comentários, o modelo inicialmente proposto em Zhou, Xi e 
Lee (2007) é defendido em Zhou (2008), em que se expõem erros e imprecisões nos fundamentos das críticas de Wu (2008). Após essa interação, não há registro de outras publicações relacionadas diretamente ao trabalho iniciado em Zhou, Xi e Lee (2007).

No entanto, dois dos autores de Zhou, Xi e Lee (2007) participaram do estudo apresentado em Zhou, Lu e Xi (2012), que aborda técnicas de otimização de procedimentos de manutenção preventiva aplicados a sistemas de múltiplos componentes utilizados em linhas de produção. A ideia central do modelo produzido pelos pesquisadores envolvidos no estudo consiste em se conceber uma política de manutenção preventiva capaz de minimizar os custos operacionais dos procedimentos de reparo do sistema utilizado para automatizar a linha de produção. Para tanto, propõe-se que as atividades de manutenção do sistema devem ser planejadas de tal forma a se otimizar o uso dos períodos de tempo nos quais a linha de produção está inativa para que os procedimentos de reparo sejam executados.

No estudo apresentado em Fan et al. (2011), é proposta uma abordagem que visa à otimização de procedimentos de manutenção preditiva aplicados a sistemas reparáveis cujos modos de falha plausíveis são dependentes entre si (isto é, a probabilidade de ocorrência de um modo de falha depende do acontecimento de outros modos de falhas). A solução discutida no artigo se baseia na modelagem de uma função de custo global de manutenção, determinada, por sua vez, a partir da evolução da taxa de falhas associada ao sistema em estudo e de sua respectiva "idade efetiva", determinada a partir da cronologia de eventos notáveis que ocorrem durante a operação do sistema. Entre as principais contribuições apresentadas em Fan et al. (2011), é possível salientar a capacidade de se considerar impactos de manutenções imperfeitas (isto é, que não levam o sistema a comportar-se tal como quando "novo") sobre a evolução de sua taxa de falhas e de sua "idade efetiva", o que permite realizar uma modelagem do sistema mais fidedigna à realidade.

Já no estudo publicado em Ming Tan e Raghavan (2008), é proposto um arcabouço genérico de suporte à manutenção preditiva de sistemas de múltiplos estados (MSSs - Multi-state Systems) que emprega estimativas de instantes para ocorrência de falhas coletadas a partir de medições do grau de degradação do sistema. O modelo apresentado no artigo pode ser adaptado, dependendo da 
necessidade, às características específicas dos sistemas empresariais que devem ser monitorados para fins de manutenção preditiva (MING TAN; RAGHAVAN, 2008).

O estudo exposto em Ming Tan e Raghavan (2008) também foi objeto de questionamentos levantados em Liu e Huang (2009), no qual são sugeridas correções e melhorias para o modelo de Ming Tan e Raghavan (2008). A resposta dos autores de Ming Tan e Raghavan (2008) aos comentários recebidos é apresentada no artigo Ming Tan e Raghavan (2009), que detalha as limitações e as hipóteses consideradas no modelo defendido em Liu e Huang (2009). Após essa interação, não há registro de outras publicações relacionadas diretamente ao trabalho iniciado em Ming Tan e Raghavan (2008).

Em Kaiser e Gebraeel (2009), a manutenção preditiva é abordada por intermédio de um modelo que permite estimar o tempo de vida útil de um sistema a partir de algumas variáveis sensorialmente aferidas durante sua operação e de dados estatísticos de confiabilidade determinados a partir de ensaios realizados com uma população de sistemas com características análogas à do elemento em estudo. Um dos aspectos mais críticos do modelo proposto relaciona-se ao intervalo de tempo ótimo que deve ser utilizado para coletar dados operacionais do sistema em avaliação, uma vez que, se poucos dados forem adquiridos, a amostra pode não ser suficientemente significativa e, consequentemente, as previsões produzidas pelo modelo podem ser excessivamente conservadoras, levando a falsas indicações de necessidade de procedimentos de manutenção.

Por intermédio de simulações computacionais de uma manufatura composta por cinco estações de trabalho paralelas, verificou-se no estudo publicado em Kaiser e Gebraeel (2009) que os custos associados à política de manutenção preditiva proposta no estudo são inferiores aos de outras abordagens de manutenção preditiva que desconsideram os impactos dos dados operacionais sobre 0 comportamento do sistema em estudo. Segundo Kaiser e Gebraeel (2009), o trabalho apresentado dá margem a trabalhos futuros que visem investigar a aplicação do modelo em sistemas mais sofisticados que o considerado no artigo, sobretudo com o propósito de avaliar dois aspectos: a possibilidade de utilizar o modelo proposto como uma ferramenta de otimização de peças de reposição em estoques e os efeitos da degradação dos sensores utilizados para coletar dados 
operacionais do sistema em estudo sobre as previsões de manutenção produzidas por meio do modelo. Além desses aspectos, questões referentes à influência das condições de armazenamento de sobressalentes, à obsolescência tecnológica dos equipamentos utilizados nas linhas de produção e habilidade das equipes de manutenção sobre as estimativas de tempo de vida útil dos componentes de um sistema também podem ser investigadas em eventuais trabalhos correlatos com base nas contribuições providas por Kaiser e Gebraeel (2009).

Outra abordagem para se prever o tempo de vida útil de um sistema baseada no uso conjunto de dados operacionais e de parâmetros estatísticos levantados por meio da análise de uma população de sistemas similares ao objeto do estudo é apresentada no estudo publicado em You et al. (2010). O principal objetivo do modelo desenvolvido pelos autores do artigo é o de permitir que o planejamento de longo prazo de uma política de manutenção preditiva, usualmente baseado apenas em dados estatísticos de confiabilidade, seja aprimorado ao se também considerar as condições operacionais do sistema em estudo, que podem ser continuamente monitoradas.

A viabilidade do modelo apresentado é defendida por intermédio de simulações, que mostram que a abordagem proposta, quando comparada com métodos tradicionais baseados apenas nas distribuições probabilísticas dos tempos de vida útil de sistemas, leva a uma melhoria na disponibilidade global do sistema, além de permitir prever com razoável precisão o seu respectivo tempo de vida residual após uma manutenção preditiva (YOU et al., 2010). Um aspecto importante que merece ser salientado relaciona-se à grande similaridade na temática dos trabalhos apresentados em Kaiser e Gebraeel (2009) e em You et al. (2010), uma vez que ambos relacionam-se a modelos matemáticos que visam melhorar as previsões dos tempos de vida útil de um sistema por meio da combinação de dados estatísticos de confiabilidade com dados funcionais levantados durante um período de operação. Essa proximidade entre ambos os estudos é explorada em You et al. (2010), em que se cita o trabalho exposto em Kaiser e Gebraeel (2009) no levantamento bibliográfico realizado pelos autores.

Em Araiza (2004), faz-se uso de métodos formais (no caso, método Z) para se propor a especificação de um sistema de manutenção preditiva inteiramente 
baseado em software. O uso de métodos formais na especificação foi motivado pela possibilidade de se provar matematicamente a correção da especificação do sistema e de sua própria implementação (desde que o processo de implementação tenha sido feito de forma completamente aderente à especificação) (ARAIZA, 2004).

É importante ressaltar, no entanto, que métodos formais são falíveis e não conseguem garantir que um sistema projetado esteja livre de erros (HALL, 1990). Essa característica decorre do fato de que algumas características do sistema (tais como aspectos não funcionais) não podem ser formalmente provadas e que as provas matemáticas conduzidas sobre uma especificação formal podem ser desenvolvidas incorretamente (HALL, 1990). No estudo apresentado em Jaspan et al. (2009), em que são apresentados os resultados da reavaliação de todas as observações feitas em Hall (1990) de forma a adequá-las aos avanços científicos e tecnológicos atingidos desde a data de tal publicação, ratifica-se que qualquer especificação formal que não é verificada ou que fica restrita a porções isoladas de um sistema não é suficiente para garantir a correção de todo o sistema projetado.

No estudo publicado em Li, Chun e Ching (2005), é apresentada a proposta de um sistema multiagentes destinado ao gerenciamento remoto da manutenção preditiva de uma empresa globalizada por meio de uma plataforma Web. Primeiramente, o modelo é inicialmente apresentado para suporte a um único equipamento; depois, é gradualmente estendido para os domínios de uma unidade da empresa e, por fim, para a empresa toda (com todas as suas unidades integradas). Segundo os autores, o modelo havia sido apenas parcialmente implementado e testado com base em dados experimentais na época da publicação (LI; CHUN; CHING, 2005), e não há registro de nenhuma outra publicação que relate a continuidade da pesquisa.

Já no estudo abordado em Groba et al. (2007), por sua vez, são apresentadas propostas de requisitos e da arquitetura básica de um arcabouço que permite integrar políticas automatizadas de manutenção preditiva de diversos sistemas diferentes a um Sistema de Gestão Empresarial (ERP). Por adotar uma arquitetura de sistema aberto (e, portanto, munida de interoperabilidade e portabilidade), o arcabouço proposto possibilita a integração de qualquer ferramenta de apoio à manutenção preditiva (GROBA et al., 2007). 
No trabalho de pesquisa exposto em Kumar e Srivastava (2012), é proposto um modelo de manutenção preditiva para equipamentos de escavação utilizando sistemas especialistas, redes neurais e algoritmos genéticos. A combinação dessas técnicas permite, segundo os autores do estudo, avaliar dados de histórico de operação dos componentes do sistema de modo a se identificar, detectar e localizar eventuais falhas. De posse dos resultados dessa avaliação, os níveis de integridade dos componentes do sistema são iterativamente reavaliados e, dependendo dos resultados obtidos, ações de manutenção são sugeridas (KUMAR; SRIVASTAVA, 2012).

Um aspecto notável relacionado ao trabalho apresentado em Kumar e Srivastava (2012) que deve ser destacado é o de que a arquitetura conceitual do modelo desenvolvido pode ser também utilizada em outros domínios de aplicação. Entretanto, vale ressaltar que, ao terem sido particularizadas para as categorias de componentes utilizados em equipamentos de escavação, as funções lógicomatemáticas que descrevem os sistemas especialistas, as redes neurais e os algoritmos genéticos abordados no artigo necessitariam ser adaptadas a fim de possibilitar estudos do modelo conceitual proposto em Kumar e Srivastava (2012) em outras áreas de atuação.

Em Silva et al. (2012), por sua vez, aborda-se uma metodologia para monitorar as condições de isolamento de uma linha de transmissão de alta potência, de modo a se permitir o disparo de ações de manutenção preditiva antes de o fornecimento de energia ser interrompido. Para tanto, a variação da corrente de fuga na linha de transmissão em estudo é avaliada no domínio do tempo e faz-se uso de uma rede neural para a tomada de decisão sobre eventuais procedimentos de manutenção preditiva que se mostrarem necessários.

Um dos mais recentes trabalhos relacionados à área de manutenção preditiva foi publicado em Hong et al. (2013), o qual versa sobre uma técnica para otimizar a manutenção preditiva de equipamentos mecânicos que sofrem degradação causada por fenômenos físico-químicos. As principais categorias de componentes que pertencem ao escopo do modelo apresentado no estudo são caixas de marchas e bombas utilizadas em indústrias químicas e canos utilizados em oleodutos, gasodutos e em usinas nucleares (HONG et al., 2013). 
No modelo concebido pelos autores do estudo, funções de distribuição de probabilidade específicas são utilizadas para representar tanto os níveis de degradação dos componentes considerados quanto o grau de dependência (acoplamento) entre eles (HONG et al., 2013). A partir dessas representações matemáticas, as regras a serem adotadas para minimizar o custo associado às manutenções recomendadas são definidas com base em índices determinados por meio de padrões estocásticos que descrevem os riscos de cada possível alternativa de manutenção que pode ser executada (HONG et al., 2013). Com base nos resultados obtidos nos estudos de caso hipotéticos considerados no trabalho, afirma-se em Hong et al. (2013) que a adoção de tais padrões estocásticos para modelar os riscos das possíveis manutenções que devem ser executadas é a principal contribuição científica do estudo.

Em adição aos trabalhos já abordados, que caracterizam de forma bastante abrangente a evolução científica na área de manutenção preditiva, existem três outras publicações que merecem destaque especial por se relacionarem mais intimamente com o estudo apresentado nesta dissertação. A principal similaridade entre os modelos desenvolvidos em todos esses trabalhos relaciona-se ao uso de algoritmos de filtragem sobre amostras de dados que descrevem o histórico de operação de um sistema para que uma previsão de seu comportamento futuro possa ser gerada de tal forma a se orientar uma política de manutenção preditiva.

O primeiro estudo diretamente relacionado a essa abordagem é apresentado em Christer, Wang e Sharp (1997), em que se aborda uma técnica para orientar a substituição de indutores de fornos industriais por meio do monitoramento contínuo da condutância do componente. A partir dos dados coletados, o comportamento futuro da condutância do indutor sob avaliação é estimado por meio de um filtro de Kalman, e a tendência determinada é empregada para se definir quando um procedimento de manutenção do equipamento deve ser executado.

Por intermédio de um estudo de caso baseado no uso de dados reais coletados durante a operação de um forno industrial, verificou-se que o modelo proposto em Christer, Wang e Sharp (1997) é adequado para uso em aplicações práticas e que há margem para que ele seja estendido ou adaptado de tal forma a 
poder ser empregado também em outros domínios (CHRISTER; WANG; SHARP, 1997).

No trabalho exposto em Lu, Tu e Lu (2007), por sua vez, é apresentado um modelo que permite orientar procedimentos de manutenção preditiva de sistemas que se deterioram continuamente a partir do uso de um conjunto de dados experimentais que permitem avaliar o perfil de degradação de desempenho do elemento em estudo. Dependendo da aplicação à qual o sistema sob avaliação se destina, parâmetros como corrente elétrica, vibração mecânica, temperatura e pressão podem ser usados com essa finalidade.

Prevê-se, no modelo idealizado em Lu, Tu e Lu (2007), que os valores experimentais da variável de interesse para o estudo sejam aproximados por uma função matemática que descreva a evolução estimada do parâmetro de interesse ao longo do tempo do ensaio. Eventuais ruídos inerentes às aferições realizadas experimentalmente são extraídos por meio de um modelo de transições aleatórias integradas (integrated random walk model), e os dados não ruidosos produzidos nessa etapa são utilizados em um filtro de Kalman com a finalidade de se determinar a tendência futura de degradação do sistema sob avaliação (LU; TU; LU, 2007).

Por fim, o estudo apresentado em Cadini, Zio e Avram (2009) versa sobre um modelo de suporte à manutenção preditiva de sistemas baseado no uso de um filtro probabilístico denominado filtro de partículas. De acordo com Cadini, Zio e Avram (2009), a principal vantagem dessa abordagem sobre as alternativas baseadas em filtros de Kalman reside na capacidade de ela representar mais fielmente processos cujos ruídos seguem funções de distribuição de probabilidade diferentes do padrão Gaussiano, usualmente presentes em aplicações nos domínios nuclear, aeroespacial e químico.

O foco do trabalho apresentado em Cadini, Zio e Avram (2009) está na modelagem de uma política de manutenção preditiva aplicável a componentes cujo desgaste decorre de esforços aplicados ciclicamente, algo comum, por exemplo, aos elementos que situam-se nas fronteiras de pressão de uma usina nuclear (CADINI; ZIO; AVRAM, 2009). A avaliação do modelo proposto em Cadini, Zio e Avram (2009) é executada com base em dados numéricos representativos da evolução da 
profundidade de uma rachadura em uma estrutura hipotética, que são utilizados de tal forma que se possa prever o instante da ocorrência de uma fratura no elemento em estudo por intermédio do modelo desenvolvido no trabalho científico.

\subsection{Considerações Gerais Sobre Sistemas Críticos}

A presente seção deste trabalho científico destina-se à apresentação dos principais termos e conceitos relacionados a sistemas e aplicações críticas, sobretudo com o intuito de se introduzir o vocabulário usual da área, que será empregado ao longo dos demais Capítulos desta dissertação.

\subsubsection{Sistemas Tolerantes a Falhas}

Conceitualmente, um sistema pode ser definido um conjunto ou uma combinação de partes que formam um todo complexo ou unitário (MICHAELIS, 2012). Em vista da grande generalidade de tal acepção, o vocábulo "sistema" pode ser usado em diversos contextos, entre os quais é possível destacar os sistemas biológicos que compõem o corpo humano, os sistemas de governo adotados nos países do mundo e os sistemas construídos com respaldo da Engenharia.

Todo sistema, independentemente de ser natural ou de ter sido concebido pelo homem, expõe o ambiente em que ele está inserido a alguma espécie de risco (ALMEIDA JR., 2003). Muitos sistemas de Engenharia, inclusive, são concebidos com o intuito de minimizar os riscos de outro sistema, tal como ocorre com os Sistemas de Previsão Meteorológica, que auxiliam o ser humano a prever antecipadamente a ocorrência de fenômenos naturais gerados pelo "sistema climático da Terra" para se tentar minimizar os impactos de grandes catástrofes naturais.

Grande parte dos riscos oferecidos pelos sistemas de Engenharia está relacionada às situações em que o sistema desempenha suas funções de forma inapropriada devido, por exemplo, à ocorrência de uma ou mais falhas de seus componentes. Nos denominados Sistemas Críticos, um evento de funcionamento anormal pode levar a consequências socialmente inaceitáveis, que afetam tanto os 
envolvidos com o sistema quanto o ambiente no qual o sistema está inserido (VISMARI, 2007).

Para se reduzir a probabilidade de manifestação de cenários indesejados, a tolerância a falhas é uma característica recomendada para sistemas críticos. Um sistema tolerante a falhas é capaz de manter o correto desempenho de suas funcionalidades mesmo na presença de falhas de hardware e erros de software (JOHNSON, 1989). O grau de tolerância a falhas de um sistema deve ser prescrito por meio de requisitos não funcionais que quantificam os seguintes índices:

a) Confiabilidade (Reliability): A confiabilidade de um sistema, simbolizada por $R(t)$, é uma função do tempo definida como a probabilidade condicional de o sistema desempenhar corretamente suas funcionalidades em um intervalo de tempo $\left[t_{0} ; t\right]$ considerando-se que o sistema estava plenamente operacional no instante $t_{0}$ (JOHNSON, 1989). A confiabilidade é usualmente empregada para caracterizar o grau de tolerância a falhas de sistemas que não podem ser reparados (JOHNSON, 1989), permitindo quantificar a probabilidade de um sistema estar funcionando após determinado período de operação na ausência de qualquer espécie de reparo corretivo ou preventivo.

b) Disponibilidade (Availability): A disponibilidade de um sistema, simbolizada por $A(t)$, é uma função do tempo definida como a probabilidade de um sistema estar operacional no instante de tempo $t$, que representa a fração de tempo durante a qual o sistema permanece em funcionamento em relação ao tempo total de operação (JOHNSON, 1989).

Vale ressaltar que, embora aparentemente similares, a confiabilidade e a disponibilidade são conceitos diferentes: enquanto a confiabilidade avalia a probabilidade de funcionamento em um intervalo de tempo, a disponibilidade quantifica a probabilidade de funcionamento em um instante de tempo (JOHNSON, 1989). Por esse motivo, um sistema com alto índice de ocorrência de falhas (e, portanto, pouco confiável) pode apresentar elevada disponibilidade se os respectivos tempos de manutenção forem suficientemente baixos (JOHNSON, 1989). 
c) Segurança Crítica (Safety): A segurança crítica de um sistema, simbolizada por $S(t)$, é uma função do tempo definida como a probabilidade condicional de o sistema desempenhar, em um período de tempo $\left[t_{0} ; t\right]$, suas funções corretamente ou descontinuá-las sem causar mortes, danos à saúde, destruição de propriedades, perda de missão ou impactos ao meio ambiente (CAMARGO JR., 2002). Assim como no caso da confiabilidade, a função segurança crítica é definida de tal forma que o sistema esteja funcionando corretamente no instante inicial de observação $\left(t_{0}\right)$ (JENS, 2006).

Em sistemas críticos com relação à segurança (safety), os riscos associados às falhas inseguras, que levam o sistema a situações potencialmente perigosas, devem ser minimizados. Uma das formas de tal mitigação de riscos ser adequadamente incorporada ao projeto de sistemas críticos com relação à segurança consiste no princípio ALARP (As Low As Reasonably Possible), preconizado na norma internacional IEC61508 e responsável pela avaliação do balanço entre o grau de redução de um risco e o custo associado à implantação das respectivas medidas mitigatórias. De acordo com a Figura 4 (IEC, 2010), os níveis de um risco podem ser classificados em uma das três categorias a seguir:

i. Riscos Intoleráveis: Um risco é considerado intolerável quando sua manutenção não puder ser plausivelmente justificada, exceto em casos extraordinários;

ii. Riscos Toleráveis: Um risco é dito tolerável quando mecanismos mitigatórios mostrarem-se impraticáveis ou quando a redução do risco representar um ganho inferior ao custo necessário para tal rebaixamento;

iii. Riscos Aceitáveis: Um risco é considerado aceitável quando sua manutenção puder ser plausivelmente justificada e quando tem pouco efeito sobre os níveis de integridade do sistema. 
Figura 4 - Regiões de Risco e ALARP

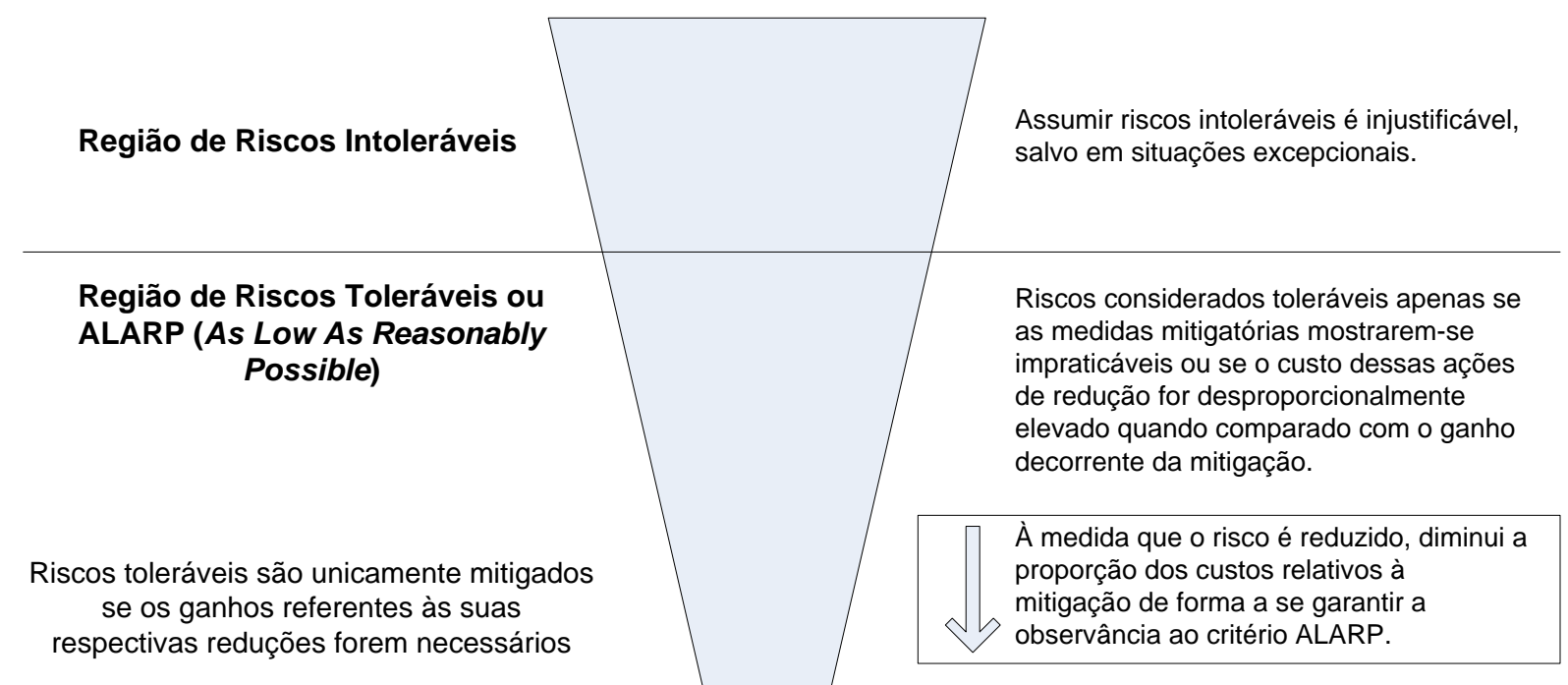

Região de Riscos Aceitáveis

É necessário monitorar continuamente os riscos aceitáveis para se garantir que os mesmos permaneçam neste nível.

Riscos Desprezíveis

Fonte: adaptado de IEC (2010)

d) Funcionabilidade (Performability): A funcionabilidade de um sistema, representada por $P(L, t)$, é uma função do tempo definida como a probabilidade de um sistema funcionar com um nível de integridade $L$ em um dado instante de tempo $t$ (JOHNSON, 1989). O nível de integridade $L$ de um sistema reflete a capacidade de o mesmo ser mantido em operação degradada, na qual uma parte de suas funcionalidades está comprometida.

A característica de tolerância a falhas está diretamente relacionada à funcionabilidade por intermédio da adoção de técnicas de degradação suave (do inglês, graceful degradation) em projetos de sistemas. A degradação suave permite a um sistema reduzir automaticamente seu respectivo nível de integridade - por exemplo, mediante desligamento de componentes detectados como falhos - para que o sistema possa ser mantido parcialmente operacional com um grau de degradação aceitável para as funcionalidades mantidas (JOHNSON, 1989). 
e) Manutenibilidade (Maintainability): A manutenibilidade de um sistema, simbolizada por $M(t)$, é uma função do tempo que indica a probabilidade de um sistema falho ser restaurado para um estado operacional em um dado período de tempo $t$ (JOHNSON, 1989). A manutenibilidade é uma característica de fundamental importância em sistemas nos quais vidas humanas, equipamentos ou o meio-ambiente podem estar expostos a riscos enquanto um procedimento de reparo é executado (JOHNSON, 1989).

Especialmente nesses casos de maior criticidade, a adoção de técnicas de diagnóstico automático no projeto de sistemas é recomendada com o intuito de se melhorar os índices de manutenibilidade (JOHNSON, 1989). Tal melhoria está relacionada ao fato de o diagnóstico automático minimizar o gasto temporal associado à determinação da origem de uma falha, que tende a ser a etapa mais custosa de um procedimento de manutenção manual (JOHNSON, 1989).

f) Testabilidade (Testability): A testabilidade pode ser definida como a habilidade de se avaliar a existência e a qualidade dos atributos de um sistema por intermédio de testes (JOHNSON, 1989). Em muitos sistemas nos quais é necessário garantir níveis elevados de confiabilidade, disponibilidade ou segurança crítica (safety), é comum utilizar testes automatizados, que são executados periodicamente com o propósito de avaliar se as funcionalidades críticas dos respectivos sistemas estão íntegras.

Com a tendência cada vez mais significativa do uso de sistemas computacionais para aplicação crítica, a adoção de testes automatizados tem se tornado mais viável. A importância dos testes automatizados torna-se ainda maior em sistemas baseados em componentes COTS (Commercial OffThe-Shelf), que, devido às necessidades de barateamento e diminuição do tempo de comissionamento dos projetos, passam a ser usados em funcionalidades críticas mesmo sem terem sido projetados para tal categoria de aplicação.

g) Dependabilidade (Dependability): A dependabilidade é a propriedade de um sistema que justifica a confiança de alguém nele (STOREY, 1996). A 
quantificação da dependabilidade de um sistema, que reflete a qualidade de serviço por ele disponibilizada, é feita por meio dos índices de confiabilidade, disponibilidade, segurança crítica (safety), funcionabilidade, manutenibilidade e testabilidade (JOHNSON, 1989).

\subsubsection{Falhas, Erros e Disfunções em Sistemas Críticos}

Independentemente do grau de criticidade da aplicação, todo sistema está sujeito à ocorrência de falhas de seus componentes ou à aquisição de entradas impróprias - isto é, dados de entrada potencialmente não íntegros e diferentes das condições normais para as quais o sistema foi projetado. Em sistemas críticos com relação à segurança (safety), por exemplo, é importante que tanto os modos de falha de seus componentes quanto a leitura de entradas impróprias sejam tratados de tal forma que o sistema ingresse em um estado seguro, no qual não existe nenhuma exposição a uma situação potencialmente perigosa.

O processo de manifestação da falha de um componente na saída de um sistema pode ser dividido em três etapas, ilustradas na Figura 5.

Figura 5 - Manifestação de Falhas, Erros e Disfunções em um Sistema

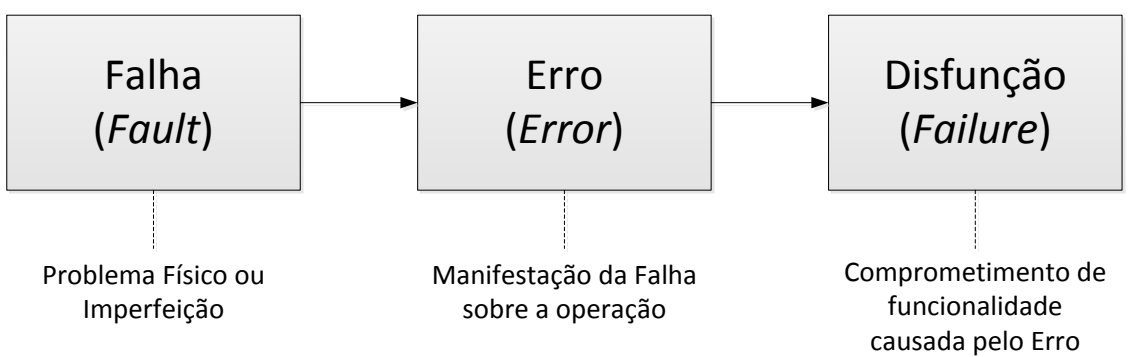

Fonte: adaptado de Johnson (1989)

Como se evidencia na Figura 5, uma falha corresponde a um problema intrínseco de determinado componente de hardware ou software e normalmente decorre das propriedades físico-químicas dos materiais utilizados em sua fabricação ou da falta de efetividade dos mecanismos de controle de qualidade aplicados ao seu projeto. Quando ocorre uma falha em um dado componente, o bloco funcional do sistema no qual o componente falho está inserido sofre uma alteração em seu 
comportamento, e essa modificação comportamental local, por sua vez, é denominada erro.

Quando essa mudança de comportamento é pouco significativa, a operação global do sistema não é impactada e, portanto, não existe nenhum reflexo da falha do componente sobre as saídas geradas pelo sistema. Por outro lado, quando 0 efeito de um erro é localmente expressivo, as saídas globais do sistema podem ser alteradas, levando ao comprometimento das funcionalidades do sistema. Quando as funções desempenhadas pelo sistema são alteradas, diz-se que uma disfunção manifestou-se.

Seja o circuito elétrico da Figura 6, que gera um sinal elétrico na saída OUT de acordo com as condições de polarização do transistor bipolar Q1. Em condições normais de operação, o transistor Q1 está saturado e a tensão de saída no coletor (referência OUT) é fixada em aproximadamente $100 \mathrm{mV}$.

Figura 6 - Circuito Elétrico de Polarização do Transistor Bipolar Q1

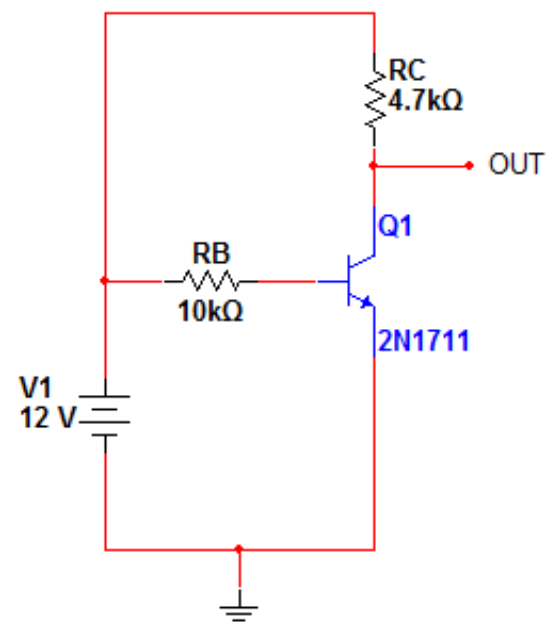

Fonte: Autor

De acordo com a constituição física de um resistor, determinada pelos materiais utilizados em sua fabricação e pela qualidade dos processos produtivos aplicados, a norma internacional EN50129:2003 preconiza que é plausível que tal componente manifeste um dos modos de falha subsequentes (CENELEC, 2003). Tais modos de falha podem se manifestar, por exemplo, devido ao envelhecimento 
do dispositivo ou ao uso do mesmo em condições operacionais adversas (fora da faixa de operação nominal para a qual o componente se destina):

- Curto-circuito entre terminais;

- Terminais em aberto;

- Aumento da resistência elétrica;

- Diminuição da resistência elétrica;

- Curto-circuito entre o componente e a sua carcaça.

Os quatro primeiros modos de falha apresentados em CENELEC (2003) também são abordados no padrão militar norte-americano MIL-STD-338B:1998. Tal referência expõe, inclusive, as probabilidades de ocorrência de cada modo de falha de acordo com as diferentes constituições físicas de resistores disponíveis para uso em projetos (resistores bobinados, resistores de filme de carbono, resistores de filme metálico, resistores de carbono aglomerado, redes de resistores e resistores variáveis) (DoD, 1998).

No caso do circuito elétrico da Figura 6, a manifestação de qualquer um dos modos de falha anteriormente relacionados no resistor RB provoca uma alteração na corrente de base do transistor bipolar Q1, que pode ser interpretada como um erro que afeta a precisão operacional do circuito elétrico. Dependendo do modo de falha que o resistor RB exibe, tal erro pode "afetar significativamente a tensão de saída na referência OUT", levando à manifestação de uma disfunção do circuito elétrico da Figura 6.

O gráfico da Figura 7 apresenta os efeitos da variação da resistência elétrica do resistor RB sobre a tensão de saída na referência OUT. Por meio dessa ilustração, verifica-se que, se a resistência elétrica do resistor RB tornar-se superior a aproximadamente $400 \mathrm{k} \Omega$, as condições de polarização do transistor Q1 serão alteradas (à medida que a resistência de RB aumenta, Q1 passa para os modos ativo e de corte) e a tensão de saída na referência OUT torna-se maior do que o valor nominal (determinado para $\mathrm{RB}=10 \mathrm{k} \Omega$ ).

Considerando-se, para efeito ilustrativo, que a operação do circuito elétrico da Figura 6 é considerada aceitável para valores de tensão em OUT menores ou iguais 
a 0,5V, a análise comportamental da Figura 7 permite inferir que o modo de falha aumento da resistência elétrica de $R B$, que provoca localmente um erro de diminuição da corrente de base do transistor Q1, leva à manifestação de uma disfunção no circuito elétrico da Figura 6 apenas quando a resistência elétrica de RB é superior a aproximadamente $420 \mathrm{k} \Omega$.

Figura 7 - Estudo de Sensibilidade da Saída OUT do Circuito Elétrico da Figura 6 devido à Variação da Resistência Elétrica de RB

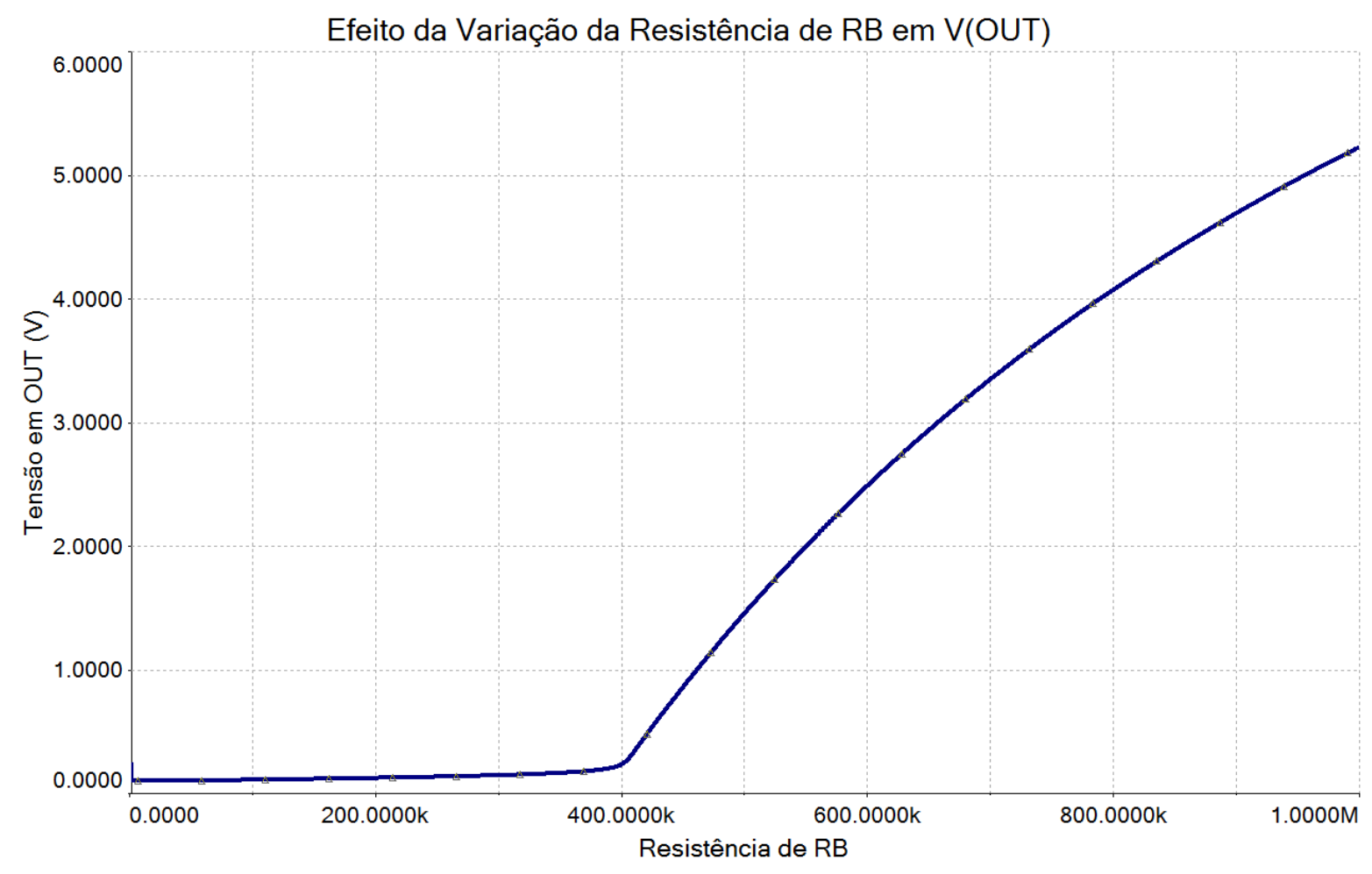

Fonte: Autor

\subsubsection{Filosofias de Projeto para Combater Falhas}

As falhas podem resultar de diversos eventos que ocorrem internamente a um dispositivo eletrônico ou computacional, externamente ao componente ou durante 0 projeto do componente ou do sistema que o utiliza (JOHNSON, 1989). Dessa forma, as causas de uma falha podem estar associadas a problemas de especificação, problemas de implementação, problemas intrínsecos aos componentes do sistema e interferências de fatores externos.

Os problemas de especificação compreendem todas as inadequações incorporadas a um sistema durante as etapas de concepção lógica do projeto. Os 
problemas de especificação incluem o uso de algoritmos incorretos e a definição de arquiteturas e requisitos de sistema, de hardware e de software inadequados para as necessidades reais do sistema a ser projetado (adaptado de JOHNSON, 1989).

Os problemas de implementação, por sua vez, estão associados a ações inapropriadas no processo de transformação das especificações de hardware e software nos respectivos produtos finais que devem compor o sistema idealizado (equipamentos de hardware e código executável) (JOHNSON, 1989). A etapa de implementação pode introduzir falhas devido a deficiências técnicas de projeto, à seleção inapropriada de componentes a serem incorporados ao projeto, a problemas na construção do sistema ou à codificação incorreta do software pertencente ao projeto, que introduz erros na lógica de funcionamento do sistema (JOHNSON, 1989). Em suma, os problemas de implementação refletem a manifestação de ocorrências de negligência, imprudência ou imperícia da equipe de projeto.

Os problemas intrínsecos aos componentes do sistema são normalmente considerados a fonte mais comum das falhas que ocorrem em um sistema, e eles podem refletir tanto deficiências nos processos produtivos dos componentes quanto o desgaste decorrente das condições de operação dos componentes no sistema (JOHNSON, 1989). Como a manifestação de grande parte das falhas de componentes elétricos, eletrônicos e programáveis é um evento aleatório, é usual que componentes eletrônicos manifestem comportamentos erráticos repentinamente (adaptado de JOHNSON, 1989).

Por fim, as interferências de fatores externos englobam quaisquer perturbações que um sistema sofre devido à ação do ambiente que o cerca. As principais categorias de fatores externos que podem influenciar o funcionamento de um sistema são as seguintes (adaptado de JOHNSON, 1989):

- Presença de radiação;

- Presença de interferência eletromagnética;

- Ocorrência de impactos mecânicos;

- Ocorrência de atuações indevidas dos operadores e usuários do sistema;

- Existência de variação nas características ambientais, tais como temperatura, pressão e tensão de alimentação. 
Dependendo do grau de criticidade da aplicação, diferentes técnicas de projeto podem ser utilizadas e combinadas com o intuito de evitar falhas, evitar erros ou evitar disfunções. A Figura 8 apresenta a contextualização dos três tipos de técnicas de combate a falhas na sequência lógica das causas de uma disfunção.

\section{Figura 8 - Técnicas de Combate a Falhas Contextualizadas na Sequência Lógica das Causas de uma Disfunção}

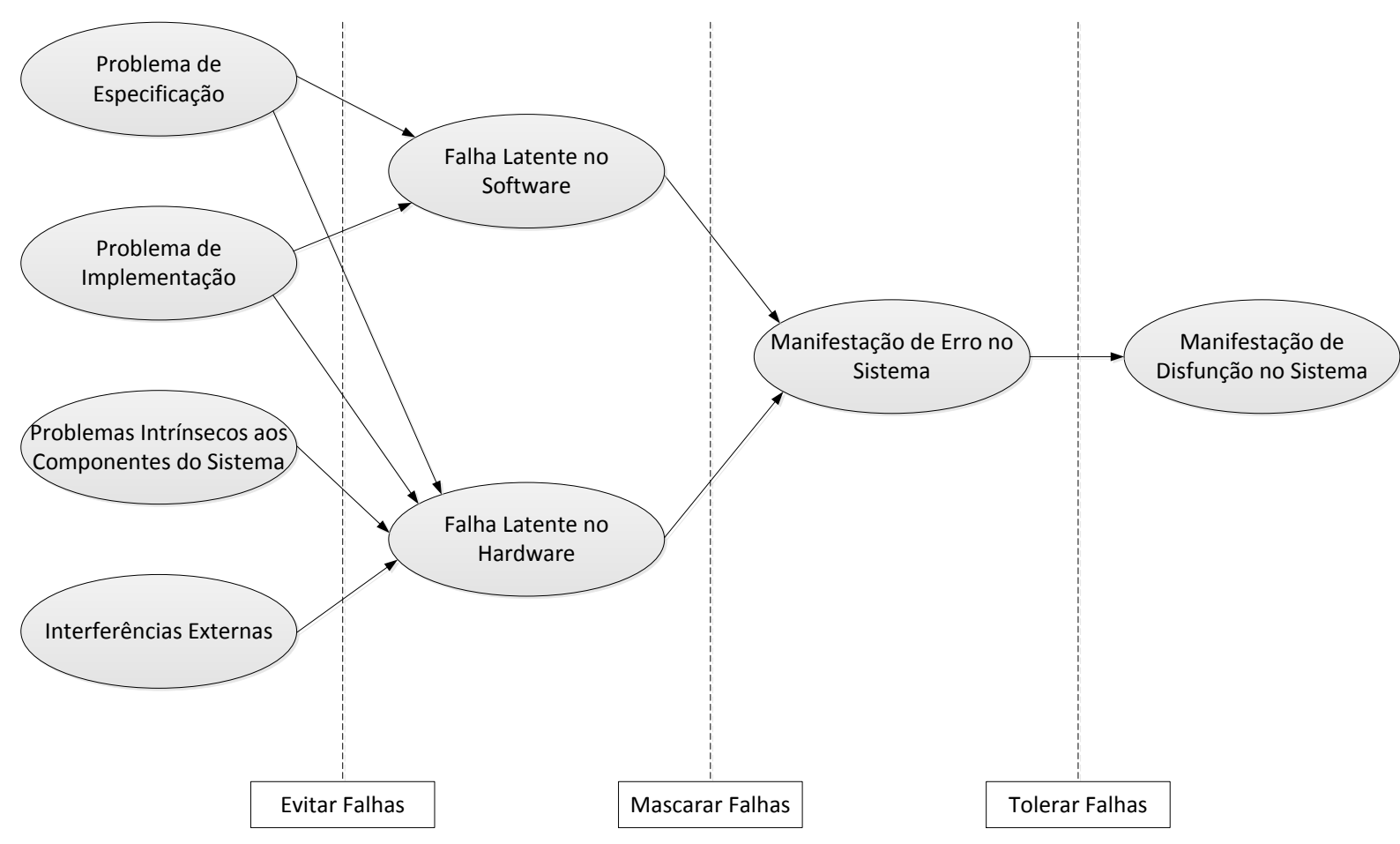

Fonte: Johnson (1989)

Todas as técnicas desenvolvidas para se evitar falhas servem para impedir que falhas estejam presentes em um sistema. As principais abordagens utilizadas com tal intuito são as seguintes (adaptado de JOHNSON, 1989):

- Revisões de projeto (por exemplo, Design Reviews);

- Pré-seleção (screening) de componentes;

- Testes $^{3}$;

${ }^{3}$ Devido ao fato de os sistemas contemporâneos serem complexos - sobretudo em virtude do elevado grau de acoplamento entre seus módulos internos - a execução de testes exaustivos torna-se impraticável. Dessa maneira, como apenas parte do universo de testes possíveis é executada, os resultados gerados apenas atestam cobertura de correto funcionamento das funcionalidades testadas, e não do sistema inteiro. 
- Métodos de controle de qualidade (tanto de processo quanto de produto);

- Blindagem, para minimizar os efeitos de interferências do ambiente externo.

Nas situações em que erros devem ser evitados no sistema, abordagens de mascaramento de falhas são utilizadas com a finalidade de se impedir a manifestação de alterações comportamentais em blocos funcionais de determinado sistema (adaptado de JOHNSON, 1989). As principais técnicas de mascaramento de falhas são as seguintes (adaptado de JOHNSON, 1989):

- Códigos de detecção e correção de erro (tais como paridade e código de hamming);

- Votação majoritária das saídas de módulos redundantes.

Quando se almeja evitar a manifestação de disfunções de um sistema, devem ser utilizadas técnicas de tolerância a falhas. Como as disfunções são diretamente causadas por erros, os termos "tolerância a falhas" e "tolerância a erros" são considerados sinônimos e, portanto, podem ser utilizados indiscriminadamente (JOHNSON, 1989).

As duas principais categorias de abordagens de tolerância a falhas são as seguintes (JOHNSON, 1989):

- Uso de técnicas de mascaramento de falhas (códigos de correção de erro e votação majoritária);

- Reconfiguração do sistema, com o intuito de recuperá-lo de uma falha detectada por intermédio da inibição do módulo falho. O processo de reconfiguração é composto por quatro etapas:

i. Detecção da falha, que determina o nível de cobertura da reconfiguração;

ii. Localização da falha, que determina o bloco funcional do sistema no qual a falha ocorreu;

iii. Contenção da falha, que serve para isolar a falha previamente detectada e localizada a fim de se evitar que os efeitos da falha sejam propagados para o restante do sistema, podendo transformar-se em uma disfunção; 
iv. Recuperação da falha, que define as ações a serem tomadas para que o sistema seja recolocado em um estado operacional mesmo após a ocorrência da falha já detectada, localizada e contida;

\subsubsection{Funções Confiabilidade, Disponibilidade e Segurança Crítica (Safety) de Sistemas Elétricos, Eletrônicos e Programáveis}

As funções confiabilidade, disponibilidade e segurança crítica (safety) são, usualmente, os elementos mais utilizados para mensurar quantitativamente atributos de dependabilidade dos sistemas utilizados em aplicações críticas. O uso de métodos quantitativos de determinação dos atributos de dependabilidade permite, por meio de modelos conceituais, comparar sistemas distintos ou até mesmo diferentes alternativas de implementação de um sistema.

A determinação das funções confiabilidade, disponibilidade e segurança crítica (safety) especificamente para sistemas elétricos, eletrônicos e programáveis depende de três variáveis:

a) Taxa de Falhas $(\lambda)$ : A taxa de falhas de um sistema indica o número de falhas que podem ocorrer no sistema em um dado período de tempo (SHOOMAN, 1990). No caso específico de sistemas elétricos, eletrônicos e programáveis, a taxa de falhas assume um valor constante igual a $\lambda$ (JOHNSON, 1989).

A ausência de variação temporal da taxa de falhas dos sistemas elétricos, eletrônicos e programáveis deve-se à constatação, por meio de experimentos práticos, de que tais sistemas comportam-se de acordo com a curva da banheira, ilustrada na Figura 9 (JOHNSON, 1989). Por intermédio dessa ilustração, nota-se a existência de três faixas de comportamento da taxa de falhas dos sistemas elétricos, eletrônicos e programáveis ao longo do tempo: 
Figura 9 - Curva da Banheira para Sistemas Elétricos, Eletrônicos e Programáveis

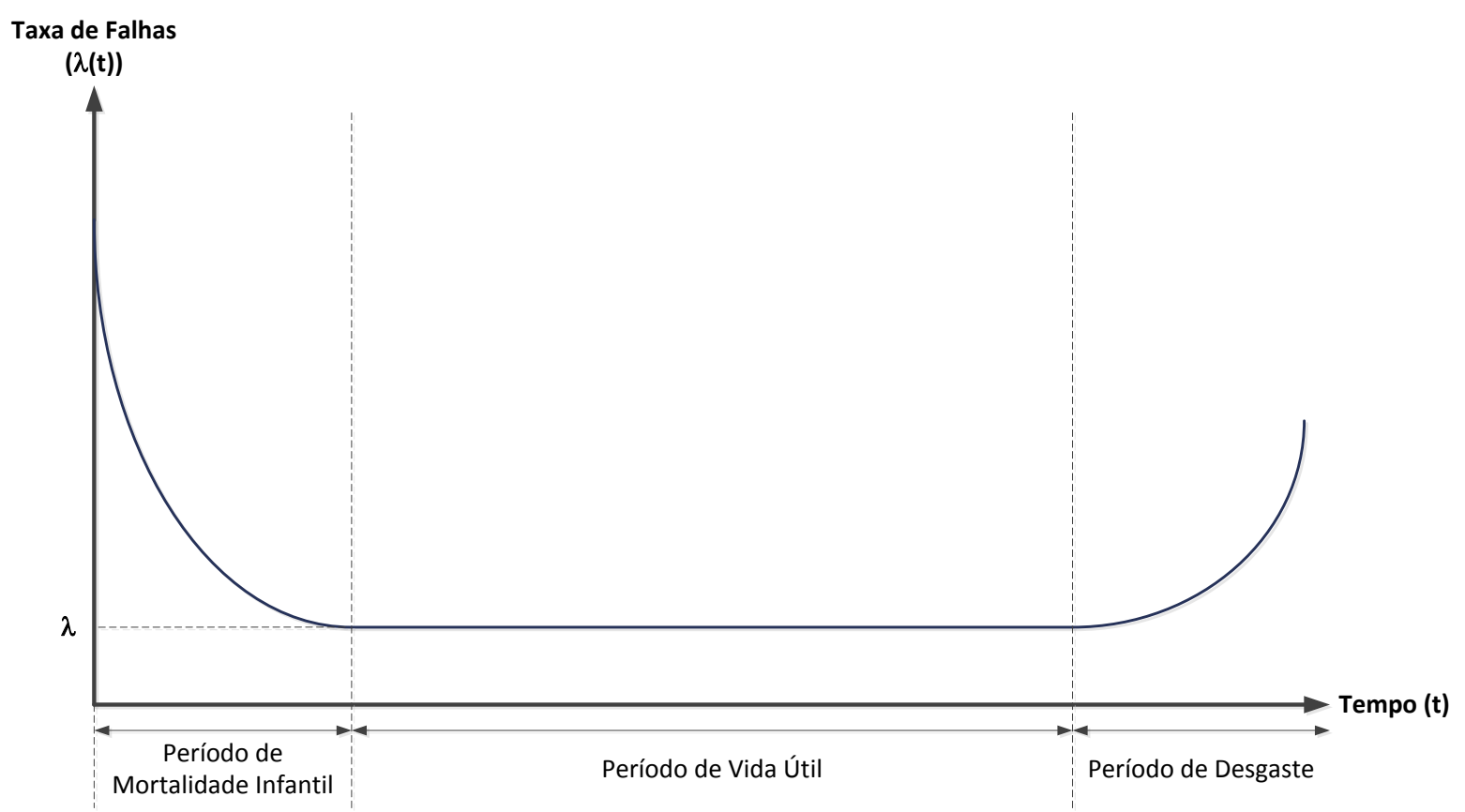

Fonte: Johnson (1989)

i. Na etapa inicial, denominada de Período de Mortalidade Infantil, a taxa de falhas de um sistema elétrico, eletrônico ou programável iniciase com um valor elevado e decai progressivamente até atingir um limiar $\lambda$ que praticamente não varia com o tempo. Normalmente associado à manifestação de falhas iniciais que refletem problemas nos processos produtivos aplicados a determinado sistema elétrico, eletrônico ou programável, o período de mortalidade infantil é usualmente ultrapassado, na prática, por intermédio do uso de técnicas de screening (sob o ponto de vista dos fabricantes) e burn-in (sob o ponto de vista dos usuários), que visam acelerar a operação de um sistema para que apenas componentes "sadios" (sem problemas significativos em seus processos produtivos) possam sobreviver;

ii. Na etapa intermediária, denominada de Período de Vida Útil, a taxa de falhas de um sistema elétrico, eletrônico ou programável praticamente não varia com o tempo e é mantida em um patamar $\lambda$ que representa a menor taxa de falhas que o sistema irá manifestar até o seu descarte. Esse comportamento simboliza que determinado componente irá prover serviços mais previsíveis e confiáveis aos seus 
usuários exatamente em seu respectivo período de vida útil (JOHNSON, 1989).

Sob o ponto de vista prático, a taxa de falhas no período de vida útil cresce sensivelmente com o tempo, tal como apresentado na Figura 10, adaptada de Wang, Hsu e Liu (2002). Como esse crescimento é pouco significativo, é usual aproximá-lo por uma constante para simplificar os cálculos dos parâmetros de dependabilidade com razoável precisão.

Figura 10 - Curva da Banheira com Crescimento da Taxa de Falhas no Período de Vida Útil

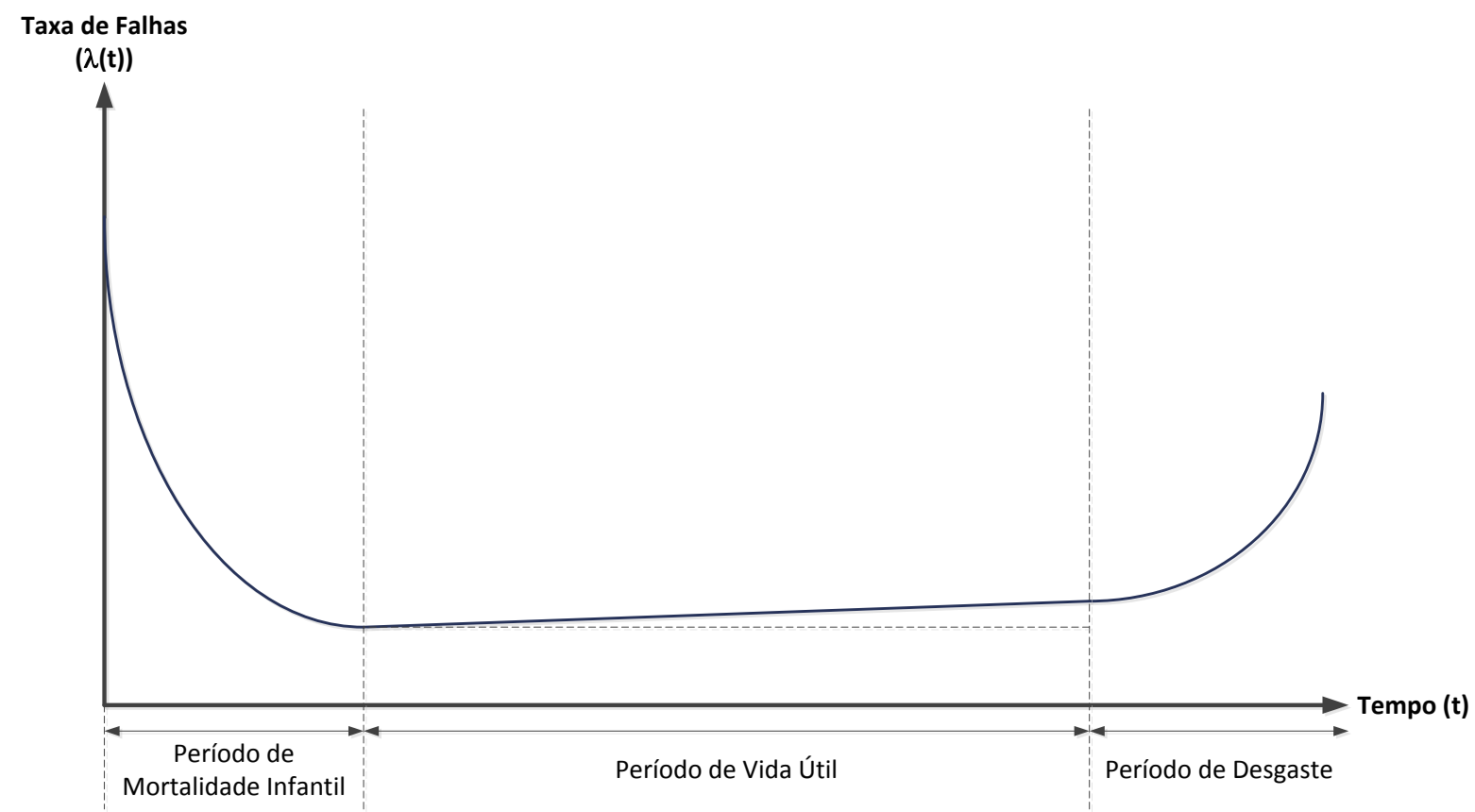

Fonte: adaptado de Wang, Hsu e Liu (2002)

iii. Na etapa final, denominada de Período de Desgaste, a taxa de falhas de um sistema elétrico, eletrônico ou programável passa a assumir um comportamento crescente muito mais significativo como reflexo da maior probabilidade de ocorrência de falhas devido ao desgaste e ao envelhecimento naturais.

Quando a taxa de falhas de um sistema pode ser aproximada por uma constante, a função confiabilidade segue a lei exponencial expressa na equação (1). A demonstração completa do raciocínio que conduz à equação 
(1) é apresentada em Johnson (1989) e não pertence ao escopo deste trabalho.

$$
R(t)=e^{-\lambda t}
$$

O Tempo Médio para Falhar (MTTF) de um sistema simboliza o tempo esperado de operação de um sistema antes da ocorrência de sua primeira falha (JOHNSON, 1989). Ele é algebricamente definido, segundo demonstrações apresentadas em Johnson (1989), por meio da equação (2).

$$
M T T F=\int_{0}^{\infty} R(t) d t
$$

Nas condições em que a função confiabilidade assume o comportamento da equação (1), o MTTF pode ser reduzido à equação (3). Essa expressão mostra que o MTTF de um sistema elétrico, eletrônico ou programável é igual ao inverso de sua taxa de falhas.

$$
M T T F=\frac{1}{\lambda}
$$

Um aspecto que vale ser ressaltado é o de que há estudos científicos, tal como o apresentado em Hashemian e Bean (2011), que defendem que a adoção da curva da banheira para representar a taxa de falhas de componentes elétricos, eletrônicos e programáveis é um conceito intuitivo, com pouco embasamento científico na área de engenharia e majoritariamente determinado a partir de conhecimento empírico e do senso comum.

Uma das principais evidências de que a taxa de falhas de equipamentos elétricos, eletrônicos e programáveis pode ser representada por uma função diferente da curva da banheira é a exposta em NOWLAN; HEAP, 1978 ${ }^{4}$, que versa sobre um estudo cujos resultados permitem inferir que componentes elétricos e eletrônicos são desprovidos de um período de desgaste. No entanto, mesmo se esse modelo for adotado, ainda é possível aproximar a taxa de falhas de sistemas elétricos, eletrônicos e programáveis por um valor

\footnotetext{
4 Maiores detalhes sobre a referência Nowlan e Heap (1978) podem ser obtidos na revisão bibliográfica explorada na seção 2.1 desta dissertação.
} 
constante $\lambda$, que fica vigente a partir do instante de tempo em que o período de mortalidade infantil esperado para o elemento em estudo seja transcorrido.

b) Taxa de Reparos $(\mu)$ : A taxa de reparos de um sistema representa a quantidade média de procedimentos de reparo ou manutenção que podem ocorrer sobre um determinado sistema por unidade de tempo (JOHNSON, 1989). A taxa de reparos de um sistema está diretamente relacionada ao seu Tempo Médio para Reparar (MTTR), que representa o tempo médio requerido para reparar um sistema após a ocorrência de uma falha (JOHNSON, 1989). A relação algébrica entre a taxa de reparos e o MTTR é apresentada na equação (4).

$$
\operatorname{MTTR}=\frac{1}{\mu}
$$

A estimativa do valor do MTTR de um sistema é usualmente coletada experimentalmente injetando-se seguidamente falhas em um sistema, de tal forma que apenas uma falha esteja ativa por ensaio, e avaliando-se o tempo requerido para que tal falha seja apropriadamente corrigida (JOHNSON, 1989). Em geral, a qualidade da estimativa é melhorada ao se utilizar, para cada tipo de falha injetada no sistema, diferentes equipes de manutenção por ensaio, de tal forma que as diferenças nas habilidades e nas capacidades dessas equipes de manutenção possam ser estatisticamente consideradas nas estimativas colhidas (JOHNSON, 1989).

De posse dos valores de MTTF e MTTR de um sistema, é possível estimar sua disponibilidade assintótica (com tempo tendendo ao infinito) por intermédio da equação (5) (STOREY, 1996). Essa equação evidencia que a disponibilidade assintótica representa a fração do tempo de operação de sistema no qual ele se mantém plenamente operacional (STOREY, 1996).

$$
A=\frac{M T T F}{M T T F+M T T R}
$$

Esse resultado pode ser compreendido com auxílio da Figura 11, que mostra o comportamento cíclico de um sistema com a alternância entre períodos de 
operação normal e períodos no qual o sistema está submetido a reparos que visam restaurar suas condições de funcionamento normal.

Figura 11 - Relacionamento entre MTTF, MTTR e MTBF

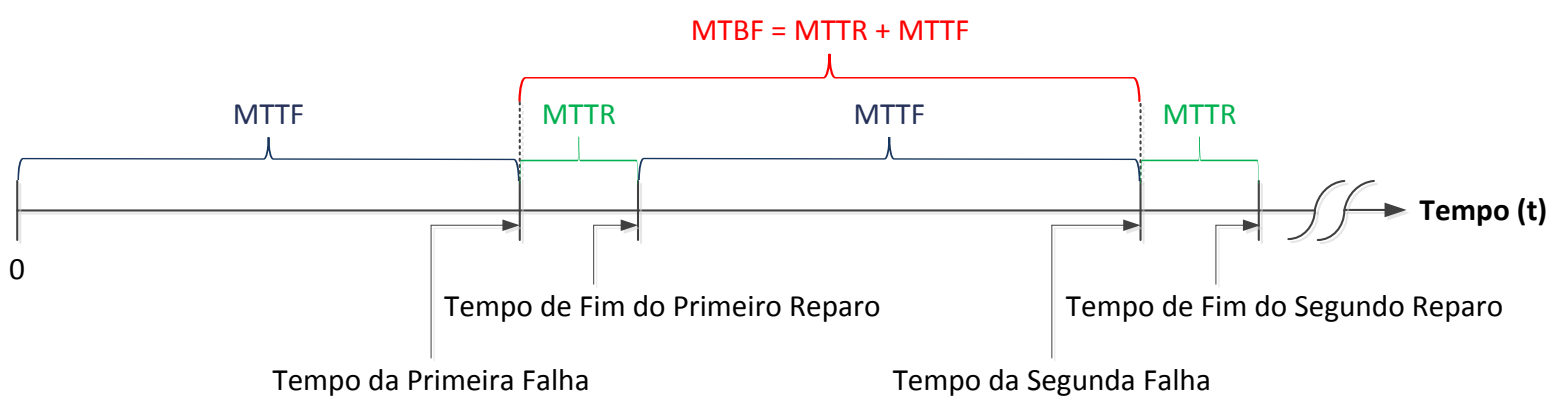

Fonte: adaptado de Johnson (1989) e Jens (2006)

O denominador da equação (5), replicado na equação (6), é definido como o Tempo Médio entre Falhas (MTBF) de um sistema. Por meio da Figura 11, é possível compreender que o MTBF compreende, na média, o tempo transcorrido entre duas falhas consecutivas de um sistema.

$$
M T B F=M T T F+M T T R
$$

c) Taxa de Falhas Inseguras $\left(\lambda_{u}\right)$ : As falhas ocorrentes em um sistema podem ser divididas em duas categorias: as falhas seguras e as falhas inseguras, que levam o sistema a um estado de operação no qual ele está exposto a situações que podem levar a mortes, danos à saúde, destruição de propriedades, perda de missão ou impactos ao meio ambiente. Por analogia à taxa de falhas, é possível conceituar a taxa de falhas inseguras de um sistema como sendo o número de falhas inseguras que podem ocorrer no sistema em um dado período de tempo.

O Tempo Médio para Falhar Inseguramente (MTTUF) de um sistema simboliza o tempo esperado de operação de um sistema antes da ocorrência de sua primeira falha insegura. Por analogia com o MTTF, ele pode ser representado por meio da equação (7).

$$
M T T U F=\int_{0}^{\infty} S(t) d t
$$


Em resumo, as equações relacionadas na Tabela 4 podem ser utilizadas nos cálculos dos índices de confiabilidade, disponibilidade e segurança crítica (safety) de sistemas elétricos, eletrônicos e programáveis.

Tabela 4 - Resumo das Equações dos Índices de Confiabilidade, Disponibilidade e Segurança Crítica (Safety) de Sistemas Elétricos, Eletrônicos e Programáveis

\begin{tabular}{|c|c|}
\hline Função Confiabilidade & $R(t)=e^{-\lambda t}$ \\
\hline Tempo Médio para Falhar & $M T T F=\frac{1}{\lambda}$ \\
\hline Tempo Médio para Reparar & $M T T R=\frac{1}{\mu}$ \\
\hline Tempo Médio entre Falhas & $M T B F=M T T F+M T T R$ \\
\hline Disponibilidade Assintótica & $A=\frac{M T T F}{M T B F}$ \\
\hline Tempo Médio para Falhar Inseguramente & $M T T U F=\int_{0}^{\infty} S(t) d t$ \\
\hline
\end{tabular}

2.3 Modelos de CÁlculo de Confiabilidade de Sistemas ElÉtricos, Eletrônicos E PROGRAMÁvEIS

Como se apresentou na seção 2.2.4, o cálculo da função confiabilidade de um sistema elétrico, eletrônico ou programável em um dado intervalo de tempo depende do conhecimento prévio da taxa de falhas aproximada de um sistema durante seu Período de Vida Útil.

Embora a taxa de falhas de um componente elétrico, eletrônico ou programável possa ser estimada por meio de cálculos estatísticos aplicados a uma amostra de uma população de componentes com características similares, esse tipo de procedimento pode ter duas consequências negativas: o custo elevado, dado que uma quantidade significativa de componentes de uso comercial é desperdiçada em ensaios destrutivos, e a produção de resultados imprecisos em caso de a amostra utilizada nos ensaios não refletir fidedignamente o comportamento real da população que ela representa. 
Por esse motivo, o Departamento de Defesa Norte-Americano (DoD) publicou um padrão militar denominado Military Handbook 217 (MIL-HDBK-217), que prescreve modelos para a predição das taxas de falhas de diversas famílias de componentes elétricos, eletrônicos e programáveis a partir de características típicas da tecnologia utilizada, do grau de maturidade de seu projeto e das condições do ambiente em que tais componentes serão utilizados.

Posteriormente, após o projeto do MIL-HDBK-217 ter sido abandonado pelo governo norte-americano em 1995 (RIAC, 2012), o padrão preconizado no MILHDBK-217 passou para o comando do Reliability Information Analysis Center (RIAC), que é um centro de pesquisa ligado ao DoD e que conta com a participação de empresas e universidades norte-americanas (RIAC, 2013). Sob o comando do RIAC, o padrão MIL-HDBK-217 foi revisado e, como resultado dessa reavaliação, foi publicado o padrão internacional RIAC-HDBK-217Plus, cuja última versão oficial data de Maio de 2006.

As principais características técnicas dos padrões MIL-HDBK-217 e RIACHDBK-217Plus serão abordadas nas duas seções subsequentes.

\subsubsection{Padrão Militar MIL-HDBK-217}

O padrão militar MIL-HDBK-217 visa estabelecer e manter métodos consistentes e uniformes para se estimar os índices de confiabilidade de equipamentos e sistemas eletrônicos de propósito militar (DOD, 1991). Ele estabelece uma base de conhecimento comum para se comparar e avaliar predições de confiabilidade de projetos similares ou competidores, e serve, portanto, como uma ferramenta que visa dar suporte ao aumento dos índices de confiabilidade de um equipamento sendo projetado (DOD, 1991).

As diretrizes de predição de confiabilidade preconizadas no padrão militar MIL-HDBK-217 baseiam-se na análise do melhor conjunto de dados possível que representa o projeto do sistema sob avaliação (DOD, 1991). Para que os modelos de predição de confiabilidade previstos no padrão MIL-HDBK-217 passem a ser ferramentas úteis para a condução de um projeto, é fundamental entender as suas limitações (DOD, 1991). 
A primeira limitação de um modelo de predição de confiabilidade diz respeito ao fato de os modelos que permitem estimar a taxa de falhas de um componente eletrônico representarem estimativas pontuais baseadas apenas em um conjunto de dados disponíveis no momento do cálculo (DOD, 1991). Por esse motivo, as estimativas podem ser consideradas válidas apenas nas condições em que os dados de entrada foram colhidos e apenas para os dispositivos cobertos por esses dados (DOD, 1991).

Mesmo quando utilizados em ambientes similares, as diferenças entre as aplicações de um sistema podem afetar significativamente as predições de confiabilidade feitas, de tal forma que os índices previstos tendam a ser mais próximos do comportamento real do sistema em alguns ambientes específicos do que em outros (DOD, 1991). Também é importante ressaltar que a taxa de falhas de um componente também é impactada por aspectos como os cenários operacionais, as características dos operadores envolvidos, as práticas de manutenção utilizadas, as técnicas de medida e coleta de dados aplicadas e até mesmo em diferenças na definição de uma falha (DOD, 1991). Por essa razão, nunca se deve assumir que um índice de confiabilidade previsto a partir de modelos matemáticos representa fielmente a confiabilidade medida em campo com base no funcionamento de um sistema (DOD, 1991).

O padrão MIL-HDBK-217 prevê a existência de dois métodos de predição de confiabilidade distintos, cuja aplicação prática depende diretamente do grau de maturidade do projeto a ser avaliado:

a) Método de Análise por Esforço de Componentes (Parts Stress Analysis Method): O Método de Análise por Esforço de Componentes (MAEC) é o principal método de predição de confiabilidade preconizado no padrão MILHDBK-217 e deve ser aplicado sobre projetos com maior grau de maturidade, cujos dispositivos de hardware e circuitos elétricos já estão sendo efetivamente projetados (DOD, 1991).

O MAEC prevê, em resumo, que a taxa de falhas de um componente eletrônico discreto pode ser prevista com base na expressão matemática apresentada na equação (8) (DOD, 1991). 


$$
\lambda_{p}=\lambda_{b} \pi_{Q} \pi_{E} \pi_{T} \pi_{A} \pi_{R} \pi_{S} \pi_{C}
$$

Na equação (8):

- $\lambda_{p}$ é a taxa de falhas prevista para o componente;

- $\lambda_{b}$ é a taxa de falhas base para o componente, usualmente expressa por um modelo que relaciona a influência de esforços elétrico e térmico sobre o componente;

- $\pi_{Q}$ é o fator de qualidade associado ao componente, que expressa o grau de qualidade aplicado à fabricação e ao projeto do componente. $O$ fator de qualidade $\pi_{Q}$ aumenta à medida que menos qualidade está associada a seu projeto;

- $\pi_{E}$ é o fator ambiental associado ao componente, que expressa o efeito do ambiente em que o componente está inserido sobre sua taxa de falhas. Ambientes que deixam o componente mais susceptível à ocorrência de falhas apresentam valores de $\pi_{E}$ maiores;

- Os demais fatores $\pi_{i}$ estão relacionados a outros aspectos que afetam o funcionamento dos componentes eletrônicos, a exemplo da temperatura (parâmetro $\pi_{T}$ ).

Para componentes microeletrônicos e programáveis, a equação (8) é ligeiramente alterada com 0 intuito de se incorporar as particularidades desses dispositivos. Não pertence ao escopo deste trabalho apresentar os modelos que regem o comportamento de tais componentes e recomenda-se ao leitor consultar o Capítulo 5 do padrão MIL-HDBK-217 (DOD, 1991) para maiores informações.

b) Método de Contagem de Componentes (Parts Count Method): O Método de Contagem de Componentes (MCC) é uma abordagem alternativa de predição de confiabilidade preconizado no padrão MIL-HDBK-217 recomendado para componentes cujos projetos estão em etapas iniciais de concepção ou quando não existe uma base de dados suficientemente abrangente para a aplicação do MAEC (DOD, 1991). A aplicação do MCC 
requer a presença de três tipos de dados: os tipos genéricos dos componentes (incluindo complexidade) e as suas respectivas quantidades, os níveis de qualidade associados aos componentes e as características do ambiente no qual os componentes irão operar (DOD, 1991).

De posse dessas informações, é possível estimar a taxa de falhas de um equipamento formado por componentes eletrônicos a partir da expressão matemática apresentada na equação (9) (DOD, 1991).

$$
\lambda_{E Q U I P}=\sum_{i=1}^{n} N_{i}\left(\lambda_{g} \pi_{Q}\right)_{i}
$$

Na equação (9):

- $\lambda_{E Q U I P}$ é a taxa de falhas prevista para um equipamento formado por componentes eletrônicos;

- $\lambda_{g}$ é a taxa de falhas genérica para o i-ésimo tipo de componente que compõe o equipamento;

- $\pi_{Q}$ é o fator de qualidade associado ao i-ésimo tipo de componente, que expressa o grau de qualidade aplicado à fabricação e ao projeto do componente.

- $N_{i}$ representa o número de componentes do i-ésimo tipo de componente que compõem o equipamento sob avaliação;

- $n$ representa a quantidade de tipos diferentes de componentes que compõem o equipamento sob avaliação.

Em geral, a aplicação do MCC leva a resultados mais pessimistas (com maiores taxas de falhas) do que os gerados por intermédio da aplicação do MAEC sobre um mesmo sistema formado por componentes eletrônicos (DOD, 1991).

As categorias de componentes elétricos, eletrônicos e programáveis cobertos no padrão militar MIL-HDBK-217 são os seguintes (DOD, 1991):

- Dispositivos lógicos programáveis e microprocessadores;

- Memórias; 
- Circuitos integrados de altíssima velocidade (VHSICs) e similares;

- Circuito integrado monolítico de micro-ondas (MMIC) de arseneto de gálio (GaAs) e dispositivos digitais;

- Dispositivos híbridos;

- Dispositivos de onda acústica de superfície (SAW);

- Memórias de bolha magnética;

- Semicondutores discretos;

- Tubos;

- Lasers;

- Resistores;

- Capacitores;

- Dispositivos indutivos;

- Relés;

- Chaves;

- Conectores;

- Peças de interconexão;

- Conexões;

- Medidores;

- Cristais de quartzo;

- Lâmpadas;

- Filtros eletrônicos;

- Fusíveis;

- Componentes diversos.

Para maiores informações sobre o conteúdo da norma MIL-HDBK-217, é sugerida consulta à referência DOD, 1991.

\subsubsection{Padrão RIAC-HDBK-217Plus}

O padrão RIAC-HDBK-217Plus representa uma evolução dos modelos de predição de confiabilidade apresentados no padrão militar MIL-HDBK-217. Além de incluir modelos para cálculo de confiabilidade de outros elementos básicos que não foram abordados no padrão militar MIL-HDBK-217, o padrão RIAC-HDBK-217Plus também incorpora uma metodologia que permite estimar a confiabilidade de um 
sistema ou produto formado por componentes elétricos, eletrônicos e programáveis elementares.

Os elementos básicos contemplados no padrão RIAC-HDBK-217Plus são os seguintes:

- Capacitores;

- Diodos;

- Circuitos integrados com encapsulamento plástico;

- Circuitos integrados hermeticamente fechados;

- Indutores;

- Transformadores;

- Dispositivos óptico-eletrônicos;

- Chaves;

- Relés;

- Conectores;

- Resistores;

- Tiristores;

- Transistores;

- Software.

A metodologia prescrita no padrão RIAC-HDBK-217Plus pontua que a confiabilidade de um sistema, simbolizada por sua taxa de falhas, pode ser prevista se, inicialmente, forem determinadas as estimativas das taxas de falhas de todos os seus componentes (RIAC, 2006). Uma vez conhecidos tais valores, a taxa de falhas global de dado sistema pode ser calculada pela soma de todas as taxas de falhas de seus componentes e, dependendo da disponibilidade de dados adicionais, pela incorporação ao cálculo de parâmetros adicionais que refletem efeitos sistêmicos da interação entre os componentes elementares (RIAC, 2006).

O objetivo primário dos modelos de predição de confiabilidade apresentados no padrão RIAC-HDBK-217Plus é permitir estimar a "taxa de ocorrência de falhas" e os fatores acelerantes dos mecanismos primários de falha de um componente com um grau de exatidão apropriado (RIAC, 2006). Para que esse objetivo pudesse ser 
atingido, os modelos preconizados no padrão RIAC-HDBK-217Plus foram concebidos de tal forma a serem apropriadamente sensíveis a características como as condições de operação e os esforços do sistema sob avaliação, de tal forma a permitir ao usuário dos modelos efetuar análises de compromisso (tradeoff) entre tais variáveis (RIAC, 2006).

A visão geral do modelo de predição de confiabilidade da taxa de falhas de um sistema segundo o padrão RIAC-HDBK-217Plus é apresentado na Figura 12. A abordagem específica que deve ser usada na avaliação de determinado sistema depende de vários aspectos, entre os quais é possível ressaltar os seguintes (RIAC, 2006):

a) Existência de dados em sistemas predecessores: Um sistema é dito predecessor a outro mais novo quando ele é baseado em tecnologias similares e usa técnicas de projeto e desenvolvimento parecidas com as do sistema mais recente, cujos índices de confiabilidade se deseja estimar (RIAC, 2006). Se o sistema sob análise é uma evolução de um sistema predecessor, o conhecimento de campo acumulado sobre este pode ser utilizado e modificado com o propósito de se avaliar as diferenças entre 0 sistema mais recente e o seu predecessor (RIAC, 2006);

b) Quantidade de dados empíricos disponíveis sobre o sistema sob análise: Caso dados empíricos (de teste, de operação em campo ou de ambos) referentes ao sistema sob análise estejam disponíveis, estes podem ser combinados com a estimativa inicial de confiabilidade para originar a melhor estimativa possível da taxa de falhas do sistema (RIAC, 2006). A combinação dos dados empíricos ocorre por meio de uma abordagem Bayesiana, e à medida que mais dados empíricos estão disponíveis, a taxa de falhas estimada pela abordagem Bayesiana é dominada pela componente formada pelos dados empíricos. Na Figura 12, o resultado Bayesiano de combinação dos dados empíricos é simbolizado pela taxa de falhas final, denominada $\lambda_{2}$;

c) Possibilidade de 0 analista decidir avaliar os processos utilizados no desenvolvimento do sistema. 
Figura 12 - Modelo de Cálculo de Taxa de Falhas de Sistemas segundo RIAC-HDBK-217Plus

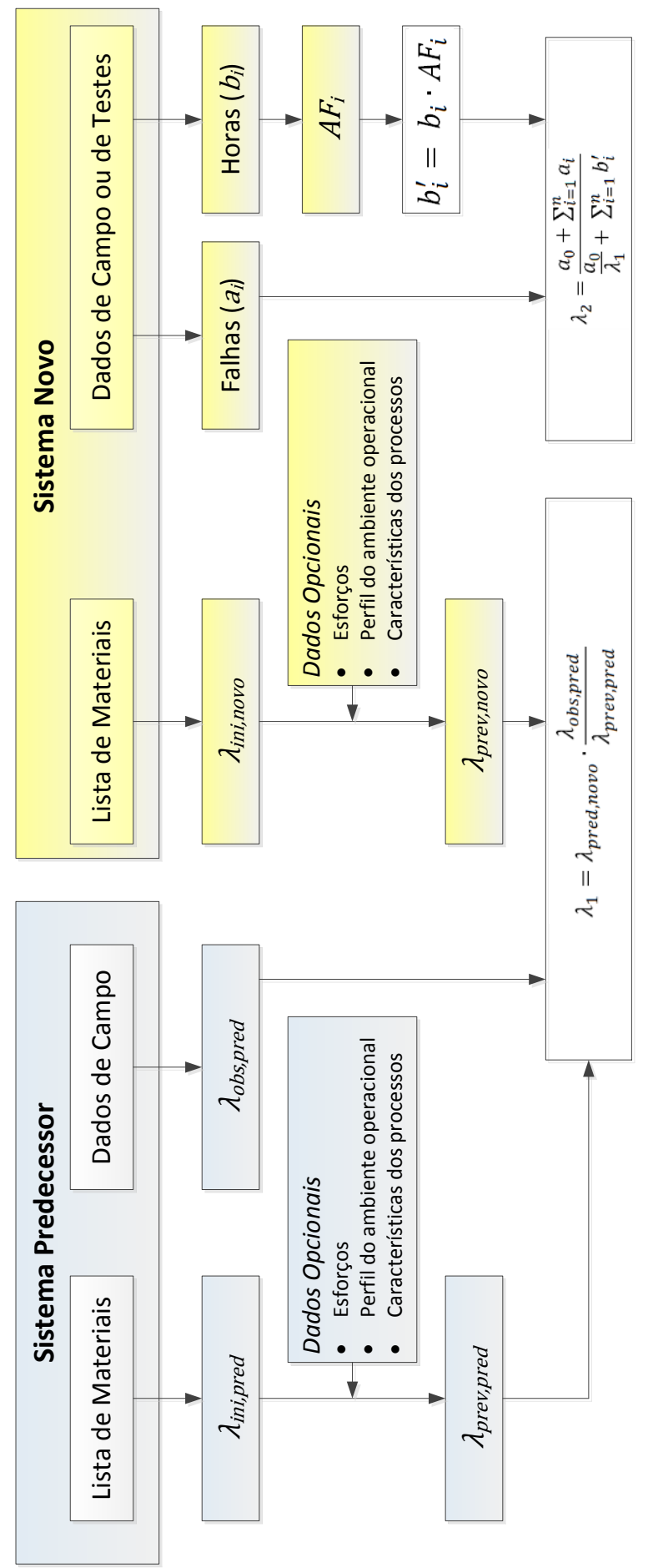

Fonte: adaptado de RIAC (2006)

Cada um dos elementos representados no arcabouço ilustrado na Figura 12 é detalhado nos itens subsequentes (RIAC, 2006). 
- $\lambda_{\text {ini,pred }}$ : Refere-se ao valor inicial da taxa de falhas do sistema predecessor. Ele corresponde à soma das taxas de falhas previstas para os seus componentes, estimadas com auxílio das técnicas de predição de taxas de falha preconizadas no padrão RIAC-HDBK-217Plus para componentes eletrônicos ou com base em dados provindos de outras fontes;

- $\lambda_{\text {obs,pred }}$ : Refere-se à taxa de falhas do sistema predecessor observada na prática com base em dados de operação de campo. Seu valor é calculado dividindo-se o número de falhas observadas pelo número de horas cumulativas de operação;

- Dados Opcionais: Dados opcionais são utilizados para melhorar as estimativas de taxa de falhas de um sistema por meio da incorporação de esforços ambientais, fatores relacionados ao perfil de utilização e características dos processos aplicados ao sistema. O padrão RIAC-HDBK217Plus apresenta valores de referência para serem considerados, mas, se valores reais forem conhecidos para um sistema, o uso destes é recomendado.

- $\lambda_{\text {prev,pred }}$ : Corresponde ao valor final da taxa de falhas prevista para o sistema predecessor, resultante da combinação da estimativa inicial $\lambda_{\text {ini,pred }}$ com os dados opcionais;

- $\lambda_{\text {ini,novo: }}$ : Corresponde ao valor inicial da taxa de falhas do sistema novo. Assim como $\lambda_{\text {ini,pred }}$, corresponde à soma das taxas de falhas previstas para os seus componentes, estimadas com auxílio das técnicas de predição de taxas de falha preconizadas no padrão RIAC-HDBK-217Plus para componentes eletrônicos ou com base em dados provindos de outras fontes;

- $\lambda_{\text {prev,novo: }}$ Corresponde a um valor intermediário da taxa de falhas prevista para o sistema novo, resultante da combinação da estimativa inicial com os dados opcionais. Na ausência destes, $\lambda_{\text {prev,novo }}$ é igual a $\lambda_{\text {ini,novo }}$;

- $\lambda_{1}$ : Refere-se à estimativa da taxa de falhas do sistema novo que resulta da combinação de $\lambda_{\text {prev,novo }}$ com as informações acumuladas para o sistema predecessor. Na equação (10), que mostra como $\lambda_{1}$ é calculado, o quociente $\lambda_{\text {obs,pred }} / \lambda_{\text {prev,pred }}$ contabiliza as diferenças entre as taxas de falhas prevista e observada para o sistema predecessor, estendendo-a proporcionalmente também ao sistema novo. 


$$
\lambda_{1}=\lambda_{\text {pred,novo }} \cdot \frac{\lambda_{\text {obs }, \text { pred }}}{\lambda_{\text {prev }, \text { pred }}}
$$

- $\quad \boldsymbol{a}_{\boldsymbol{i}}$ : Cada valor de $a_{i}$ indica a quantidade de falhas ocorrentes sobre o sistema novo referente ao i-ésimo conjunto de dados disponíveis sobre esse sistema.

- $\quad \boldsymbol{b}_{\boldsymbol{i}}$ : Cada valor de $b_{i}$ indica a quantidade cumulativa de horas de operação do sistema novo referente ao i-ésimo conjunto de dados disponíveis sobre esse sistema.

- $\quad \boldsymbol{A} \boldsymbol{F}_{\boldsymbol{i}}$ : Consiste no fator de aceleração associado ao i-ésimo conjunto de dados disponíveis sobre o sistema novo. Se os dados são coletados nas mesmas condições da operação de campo do sistema, sobre a qual se deseja estimar a taxa de falhas do sistema, o fator de aceleração referente ao ensaio é igual a 1. Se, por outro lado, o i-ésimo ensaio sobre o sistema novo é executado em condições de teste ou em um ambiente de campo diferente daquele para o qual se deseja estimar a taxa de falhas do sistema, o fator de aceleração deve ser estimado com base em cálculos de predição de confiabilidade nas condições de teste e de uso final do sistema. Não pertence ao escopo deste trabalho detalhar esses cálculos, que são descritos em RIAC (2006).

- $\boldsymbol{b}_{\boldsymbol{i}}^{\prime}$ : Cada valor de $b_{i}^{\prime}$ indica a quantidade cumulativa de horas efetivas de operação do sistema novo referente ao i-ésimo conjunto de dados disponíveis sobre esse sistema. Os valores efetivos são calculados mediante multiplicação de $b_{i}$ pelo respectivo fator de aceleração $A F_{i}$, conforme apresentado na equação (11).

$$
b_{i}^{\prime}=b_{i} \cdot A F_{i}
$$

- $\boldsymbol{a}_{0}$ : Representa o número efetivo de falhas associadas à taxa de falhas prevista. Se esse parâmetro for desconhecido, deve-se usar o valor padrão 0,5; caso contrário, o parâmetro $a_{0}$ pode ser calculado nos casos em que existem dados previstos e observados suficientes no sistema predecessor. Não pertence ao escopo deste trabalho detalhar os cálculos associados ao parâmetro $a_{0}$, que são descritos em RIAC (2006).

- $\lambda_{2}$ : Representa a melhor estimativa possível da taxa de falhas do sistema novo usando-se a maior quantidade possível de dados e informações disponíveis tanto do sistema novo quanto de seu predecessor. O cálculo de 
$\lambda_{2}$ é efetuado por meio de uma combinação Bayesiana de $\lambda_{1}$ com os dados de histórico de operação do sistema novo. A expressão que permite determinar $\lambda_{2}$ é apresentada na equação (12).

$$
\lambda_{2}=\frac{a_{0}+\sum_{i=1}^{n} a_{i}}{\frac{a_{0}}{\lambda_{1}}+\sum_{i=1}^{n} b_{i}^{\prime}}
$$

Pela equação (12), é possível notar que, na ausência de dados empíricos de teste ou de operação em campo do sistema novo (situação na qual $\sum_{i=1}^{n} a_{i} \mathrm{e}$ $\sum_{i=1}^{n} b_{i}^{\prime}$ são iguais a zero), $\lambda_{2}$ iguala-se a $\lambda_{1}$.

Para maiores informações sobre o conteúdo do padrão RIAC-HDBK-217Plus, é sugerida consulta à referência RIAC (2006).

\subsection{PROCESSOS DE MARKOV}

Entre todos os métodos de avaliação dos índices de dependabilidade de sistemas, a análise Markoviana é uma das mais poderosas técnicas de modelagem conhecidas (JENS, 2006). Os processos de Markov permitem o tratamento de processos estocásticos contínuos no tempo, que podem ser definidos como famílias de variáveis aleatórias que descrevem o funcionamento de um processo ao longo do tempo (JENS, 2006). Por esse motivo, os processos de Markov mostram-se importantes na área de dependabilidade, pois os parâmetros de entrada para o cálculo de índices como a confiabilidade, a disponibilidade e a segurança crítica (safety) são variáveis aleatórias (JENS, 2006).

Os dois principais elementos que constam em um modelo de Markov são os estados do sistema e as transições entre estados (JOHNSON, 1989). O estado de um sistema representa todas as características que devem ser conhecidas para descrever o sistema modelado em qualquer instante de tempo (JOHNSON, 1989). Para modelos de confiabilidade e disponibilidade, por exemplo, cada estado de um processo de Markov representa uma combinação distinta de módulos falhos e operacionais, e é comum assumir nas avaliações dos modelos de Markov que o sistema modelado está plenamente operacional como condição inicial (JOHNSON, 1989). 
As transições entre estados, por sua vez, regem as mudanças de estado que ocorrem em um sistema, refletindo a ocorrência de falhas e reconfigurações sobre o sistema sob avaliação à medida que o tempo passa (JOHNSON, 1989). Todas as transições entre estados em um processo de Markov são caracterizadas por uma probabilidade de ocorrência, que reflete os valores associados às taxas de falhas $e$ de reparos dos componentes de um sistema (JOHNSON, 1989). Por se tratarem de probabilidades, a soma de todas as transições que entram em um estado e saem dele deve ser sempre igual a 1.

\subsubsection{Classificação dos Modelos de Markov na Área de Dependabilidade}

Os modelos de Markov utilizados na área de dependabilidade podem ser divididos em três categorias principais:

a) Modelos de Confiabilidade: Os modelos de confiabilidade permitem obter a confiabilidade de um sistema a partir da determinação das funções que descrevem as probabilidades de falha de cada um de seus componentes. A principal característica construtiva de um modelo de confiabilidade é a existência de um estado absorvente, que não apresenta nenhuma transição de saída. Esse estado absorvente, que sempre representará a configuração na qual todos os módulos do sistema sob estudo estão falhos, reflete a tendência natural de qualquer sistema sempre falhar após um tempo suficientemente elevado desde sua ativação.

Um exemplo de modelo de confiabilidade para um sistema formado por um único componente é apresentado na Figura 13. Nessa ilustração, verifica-se que a probabilidade de ocorrência de uma falha sobre o sistema enquanto ele está operacional é igual a $1-e^{-\lambda . \Delta t}$ para um intervalo $\Delta t$ de estudo, ao passo que a probabilidade de ele se manter operacional é dada pela probabilidade complementar $e^{-\lambda . \Delta t}$. A partir do momento que o sistema assume comportamento falho, ele se mantém indefinidamente nesse estado, dado que a probabilidade de permanência nele é igual a 1. 
Figura 13 - Modelo de Markov da Confiabilidade de um Sistema Simples

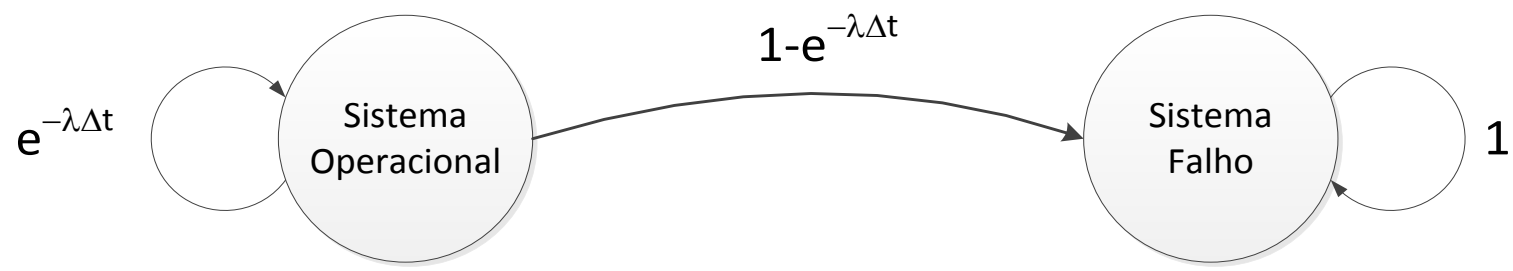

Fonte: Autor

b) Modelos de Disponibilidade: Os modelos de disponibilidade permitem obter a disponibilidade de um sistema a partir da determinação das funções que descrevem as probabilidades de falha de cada um de seus componentes. A principal característica construtiva de um modelo de disponibilidade é a inexistência de estados absorventes, visto que qualquer componente pode estar sujeito a um reparo quando ele (ou o sistema, no caso de falhas não detectáveis) estiver falho. Essa característica de ausência de estados absorventes permite inferir que o sistema está sempre disponível exceto durante os períodos de tempo nos quais o sistema está nos estados em que o sistema encontra-se falho e ainda não se concluiu o seu processo de reparo.

Um exemplo de modelo de disponibilidade para um sistema formado por um único componente é apresentado na Figura 14. Nessa ilustração, verifica-se que, em oposição ao que ocorre no modelo de confiabilidade da Figura 13, é possível efetuar a transição do estado falho para o estado operacional com uma probabilidade igual a $1-e^{-\mu . \Delta t} \mathrm{em}$ um intervalo de estudo igual a $\Delta t$. Dessa maneira, a probabilidade de o sistema simples se manter falho após a ocorrência de uma primeira falha é igual ao valor complementar $e^{-\mu . \Delta t}$. 
Figura 14 - Modelo de Markov da Disponibilidade de um Sistema Simples

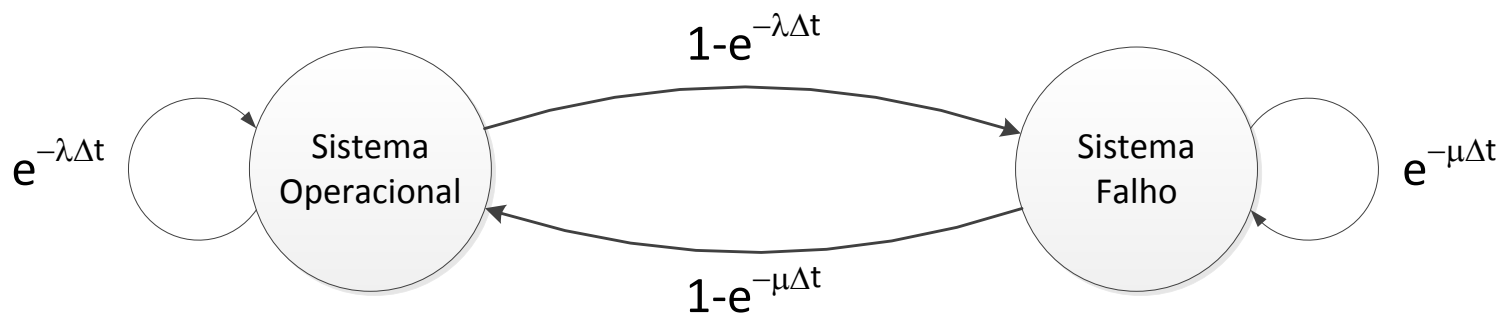

Fonte: Autor

c) Modelos de Segurança Crítica (Safety): Os modelos de segurança crítica (safety) são similares aos modelos de confiabilidade no que diz respeito à presença de um estado absorvente, mas a interpretação física deste é diferente. Nos modelos de segurança crítica, existem duas categorias de estados absorventes: os estados que remetem à ocorrência de falhas seguras e os estados que estão associados à ocorrência de falhas inseguras sobre o sistema.

Um exemplo de modelo de segurança crítica (safety) para um sistema formado por um único componente é apresentado na Figura 15. Para compreendê-la, é inicialmente necessário considerar que a taxa de falhas de um sistema genérico pode ser descrita pela combinação de duas componentes: a taxa de falhas seguras $\left(\lambda_{s}\right)$ e a taxa de falhas inseguras $\left(\lambda_{u}\right)$. Considerando-se que uma porcentagem $\mathbf{C}$ das falhas ocorrentes no sistema sob avaliação sejam seguras, é possível utilizar as expressões apresentadas na equação (13) e na equação (14) para a montagem do Modelo de Markov.

$$
\begin{gathered}
\lambda_{s}=\lambda \cdot C \\
\lambda_{u}=\lambda \cdot(1-C)
\end{gathered}
$$


Figura 15 - Modelo de Markov da Segurança Crítica (Safety) de um Sistema Simples

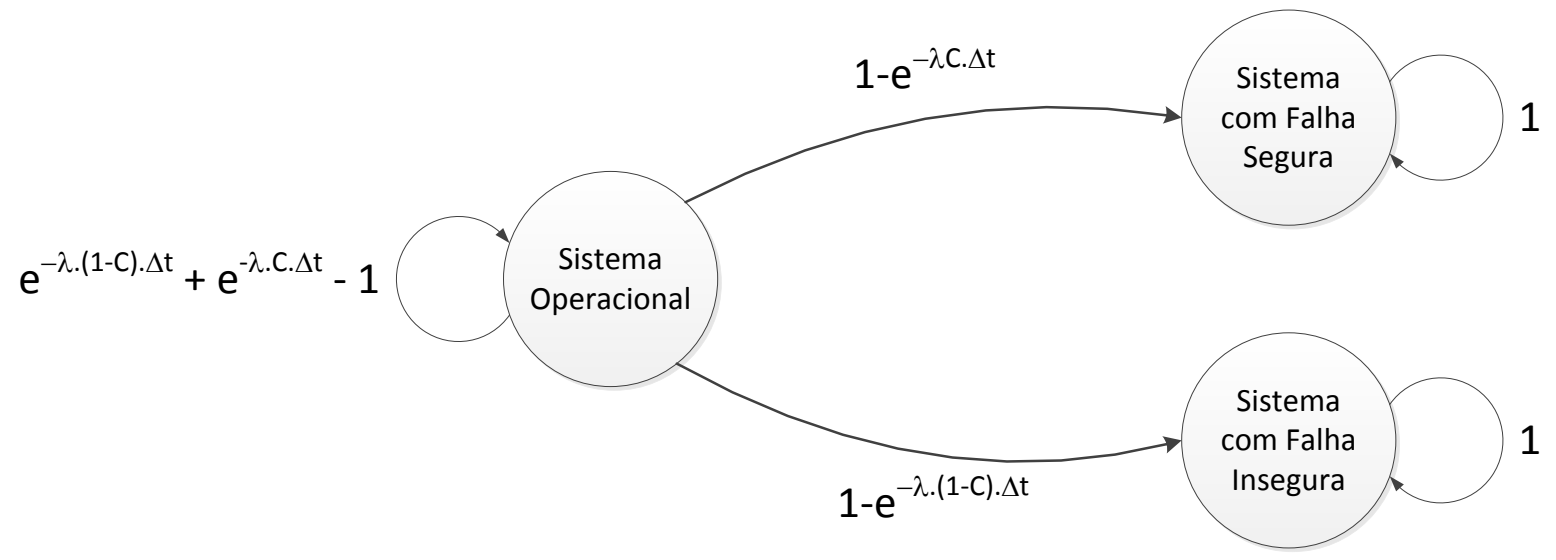

\section{Fonte: Autor}

Pela Figura 15, é possível notar que, quando o sistema está em condições operacionais, ele poderá assumir, depois de um intervalo de tempo $\Delta t$, um entre três comportamentos distintos: ou ele falhará de modo seguro com uma probabilidade $1-e^{-\lambda . c . \Delta t}$, ou ele falhará inseguramente com uma probabilidade $1-e^{-\lambda \cdot(1-C) . \Delta t}$, ou ele se manterá operacional com a probabilidade complementar $e^{-\lambda . c . \Delta t}+e^{-\lambda .(1-c) . \Delta t}-1$. A partir do momento que o sistema assumir comportamento falho (independentemente de a falha ocorrida ter sido segura ou insegura), ele se manterá indefinidamente no respectivo estado atingido com probabilidade 1.

Em todos os casos, é comum considerar que o intervalo de tempo $\Delta t$ entre duas observações consecutivas do funcionamento do sistema representado pelo modelo de Markov é suficientemente pequeno. Nessas condições, é possível aproximar as funções exponenciais do tipo $e^{-\lambda . \Delta t}$ pelos seus respectivos polinômios de Taylor de primeira ordem no entorno do ponto $\lambda . \Delta t=0$. Aplicando-se a expressão geral dos polinômios de Taylor de primeira ordem no entorno do ponto $\lambda . \Delta t=0$, apresentada na equação (15), é possível obter a aproximação da equação (16), que lineariza a função exponencial $e^{-\lambda . \Delta t}$.

$$
\begin{gathered}
P(\lambda . \Delta t)=f(0)+\frac{d[f(\lambda . \Delta t)]}{d(\lambda . \Delta t)} \cdot \lambda \cdot \Delta t \\
P(\lambda . \Delta t)=1-\lambda . \Delta t \quad(16)
\end{gathered}
$$




\subsubsection{Computação de Processos de Markov}

A determinação das funções temporais que descrevem a distribuição das probabilidades de permanência nos estados de um processo de Markov é feita por intermédio da resolução de um sistema de equações diferenciais cuja solução é composta por funções de uma única variável real: o tempo (t). Dessa maneira, qualquer abordagem utilizada para resolver sistemas de equações diferenciais pode ser empregada para se obter a solução das funções que regem um modelo de Markov.

Entre as abordagens mais tradicionais utilizadas na área de dependabilidade, é possível salientar as apresentadas nos itens subsequentes.

\subsubsection{Solução Literal}

Para sistemas representados por modelos de Markov com número reduzido de estados, é praticável obter algebricamente a solução do sistema de equações diferenciais que o rege por intermédio do uso de técnicas como as Transformadas de Laplace. Para que essa abordagem possa ser utilizada, basta considerar que os intervalos de tempo $\Delta t$ considerados nos modelos sejam suficientemente pequenos e, no limite, se aproximem de zero.

No modelo de Markov da Figura 14, por exemplo, a aproximação feita na equação (16) conduz ao modelo de Markov da Figura 16. A partir deste, é possível descrever o comportamento das probabilidades de permanência nos estados do modelo de Markov por intermédio das equações (17) e (18):

Figura 16 - Modelo de Markov da Figura 14 com a Aproximação da Equação (16)

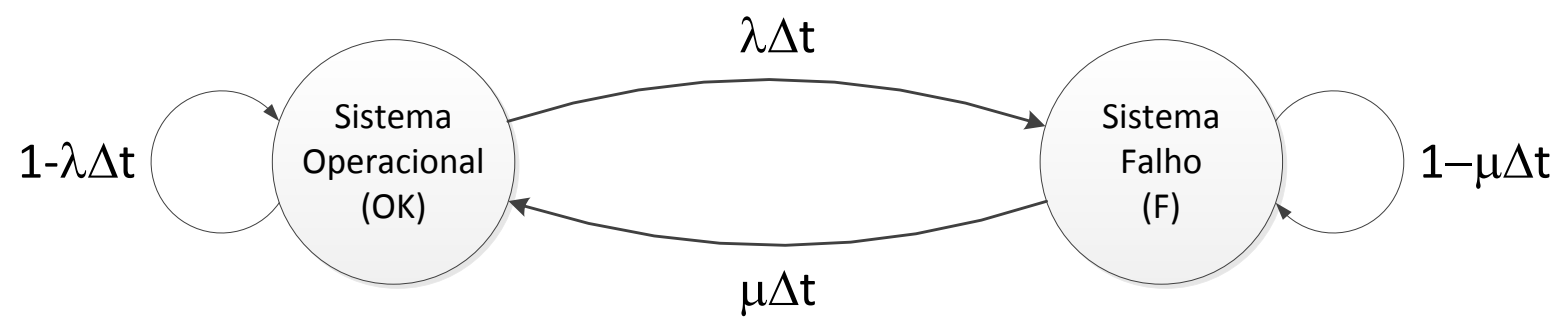




$$
\left\{\begin{array}{l}
p_{O K}(t+\Delta t)=(1-\lambda \Delta t) p_{O K}(t)+(\mu \Delta t) p_{F}(t) \\
p_{F}(t+\Delta t)=(\lambda \Delta t) p_{O K}(t)+(1-\mu \Delta t) p_{F}(t)
\end{array}\right.
$$

Reordenando ambos os termos das equações (17) e (18), é possível obter as equações (19) e (20):

$$
\left\{\begin{array}{l}
\frac{p_{O K}(t+\Delta t)-p_{O K}(t)}{\Delta t}=-\lambda \cdot p_{O K}(t)+\mu \cdot p_{F}(t) \\
\frac{p_{F}(t+\Delta t)-p_{F}(t)}{\Delta t}=\lambda \cdot p_{O K}(t)-\mu \cdot p_{F}(t)
\end{array}\right.
$$

Considerando-se a condição limítrofe em que o intervalo de tempo $\Delta t$ aproxima-se de zero, as equações (19) e (20) passam para a forma diferencial apresentada nas equações (21) e (22):

$$
\left\{\begin{array}{l}
\frac{d\left[p_{O K}(t)\right]}{d t}=-\lambda \cdot p_{O K}(t)+\mu \cdot p_{F}(t) \\
\frac{d\left[p_{F}(t)\right]}{d t}=\lambda \cdot p_{O K}(t)-\mu \cdot p_{F}(t)
\end{array}\right.
$$

Aplicando-se às equações (21) e (22) a transformada de Laplace, obtêm-se as equações (23) e (24), nas quais $P_{O K}(s)$ e $P_{F}(s)$ representam, respectivamente, as transformadas de Laplace das funções $p_{O K}(t)$ e $p_{F}(t)$. Também é importante considerar que os valores iniciais das probabilidades $p_{O K}(0)$ e $p_{F}(0)$ são respectivamente iguais a 1 e 0 , visto que se considera que o sistema está inicialmente em estado operacional no instante $t=0$.

$$
\left\{\begin{array}{l}
s . P_{O K}(s)-p_{O K}(0)=-\lambda \cdot P_{O K}(s)+\mu \cdot P_{F}(s) \\
s . P_{F}(s)-p_{F}(0)=\lambda \cdot P_{O K}(s)-\mu \cdot P_{F}(s)
\end{array}\right.
$$

A resolução do sistema de equações no domínio da frequência encaminha aos resultados finais apresentados nas equações (25) e (26).

$$
\begin{gathered}
P_{O K}(s)=\frac{1}{s+(\lambda+\mu)}+\frac{\mu}{s \cdot[s+(\lambda+\mu)]} \\
P_{F}(s)=\frac{\lambda}{s \cdot[s+(\lambda+\mu)]}
\end{gathered}
$$


Por fim, os resultados apresentados nas equações (25) e (26) podem ser submetidos à transformada inversa de Laplace, que conduz às funções que descrevem, no domínio do tempo, as probabilidades de falha e de operação correta do sistema simples. Essas funções são expostas nas equações (27) e (28).

$$
\begin{gathered}
p_{O K}(t)=e^{-(\lambda+\mu) t}+\frac{\mu}{\lambda+\mu}\left(1-e^{-(\lambda+\mu) t}\right) \\
p_{F}(t)=\frac{\lambda}{\lambda+\mu}\left(1-e^{-(\lambda+\mu) t}\right)
\end{gathered}
$$

Pelas equações (27) e (28), é possível notar que as seguintes observações são válidas:

- No instante de tempo $t=0$, a probabilidade de o sistema estar operacional é igual a 1, ao passo que a probabilidade de ele estar falho é zero;

- Quando $t \rightarrow \infty$, a probabilidade de o sistema estar operacional tende à disponibilidade assintótica expressa pela equação (5), ao passo que a probabilidade de o sistema estar falho aproxima-se do valor complementar ao gerado pela equação (5), denominado indisponibilidade assintótica;

- A soma das funções $p_{O K}(t)$ e $p_{F}(t)$ resulta em 1.

\subsubsection{Solução Numérica}

Com o uso extensivo de recursos computacionais, as abordagens de solução numérica para os modelos de Markov mostram-se interessantes, visto que elas permitem obter resultados próximos aos determinados por meio da solução literal de forma algorítmica.

A abordagem mais tradicional de solução numérica aplicada aos modelos de Markov utilizados na área de dependabilidade parte da forma discreta do sistema de equações discretas que descreve o modelo de Markov a ser estudado. Com base no exemplo literal apresentado na seção 2.4.2.1, verifica-se que é possível escrever o sistema de equações que rege o comportamento discretizado (a cada $\Delta t$ unidades de tempo) de um modelo de Markov na forma matricial exposta na equação (29). Nessa expressão, $P(t+\Delta t)$ representa 0 vetor coluna com os valores das probabilidades de permanência nos estados do modelo de Markov no instante de 
tempo $t+\Delta t, P(t)$ simboliza o vetor coluna com os valores das probabilidades de permanência nos estados do modelo de Markov no instante de tempo $t$ e $A$ representa a matriz que contém as transições entre cada par de estados do modelo de Markov.

$$
P(t+\Delta t)=A \cdot P(t)
$$

Assumindo-se um valor inicial para o vetor de probabilidades $P(0)$, o valor de $P(\Delta t)$ pode ser calculado, com base na equação (29), fazendo-se $P(\Delta t)=A \cdot P(0)$ (JOHNSON, 1989). Analogamente, o valor do vetor de probabilidades no instante de tempo $t=2 \Delta t$ pode ser determinado por meio da equação (29) fazendo-se $P(2 \Delta t)=$ A.P $P(\Delta t)$ (JOHNSON, 1989). Como, no entanto, $P(\Delta t)=A . P(0)$, o cálculo de $P(2 \Delta t)$ pode ser reescrito na forma $P(2 \Delta t)=A^{2} . P(0)$, que mostra dependência exclusiva com os valores conhecidos de $P(0)$ e de $A$ (JOHNSON, 1989).

Por indução, esse raciocínio pode ser estendido de tal forma a se obter o caso geral apresentado na equação (30) (JOHNSON, 1989).

$$
P(n \Delta t)=A^{n} \cdot P(0)
$$

Ao se considerar valores de $\Delta t$ suficientemente pequenos, a equação (30) pode ser utilizada para se obter estimativas numéricas precisas das probabilidades de permanência nos estados de um modelo de Markov para qualquer instante de tempo múltiplo de $\Delta t$ por meio de multiplicações sucessivas da matriz de transições associada ao modelo de Markov. A escolha do valor de $\Delta t$ a ser utilizado em um cálculo numérico orientado por computador deve levar em conta dois aspectos básicos e compromissados entre si: a precisão desejada e o esforço computacional demandado para os cálculos. À medida que o valor de $\Delta t$ diminui, a precisão dos resultados numéricos produzidos no ensaio aproxima-se cada vez mais dos valores reais gerados pela solução literal, mas o esforço necessário para gerar tais resultados aumenta.

Tipicamente, para valores de taxas de falhas e de reparos usualmente empregados em projetos reais $\left(10^{-9}\right.$ falhas $/ h<\lambda<10^{-3}$ falhas $/ h$ e $10^{-2}$ reparos $/$ 
$h<\mu<2$ reparos $/ h$ ), valores de $\Delta t$ situados entre 10 minutos e 30 minutos representam um bom balanceamento entre precisão e esforço computacional.

Outro aspecto que pode ser ressaltado relaciona-se à convergência do método numérico baseado nas multiplicações matriciais sucessivas da equação (30). Segundo apresentado em Burkardt (2012), o cálculo de sucessivos produtos de uma matriz $M$ quadrada por ela mesma converge para uma matriz $K$ constante e de mesma ordem se ela for semiconvergente.

A propriedade de semiconvergência de uma matriz $M$ está relacionada à avaliação de seu raio espectral $\rho(M)$, que corresponde ao módulo do maior autovalor de $M$ (BURKARDT, 2012). Diz-se que uma matriz $M$ é semiconvergente quando seu raio espectral for menor ou igual a 1, e no caso específico de o raio espectral ser igual a 1, o único autovalor com módulo igual a 1 deve ser positivo e semisimples (isto é, apresentar multiplicidade algébrica 1) (BURKARDT, 2012).

Quando o raio espectral de uma matriz $M$ semiconvergente é menor do que 1, o cálculo de $\lim _{n \rightarrow \infty} M^{n}$ converge para a matriz $K$ nula; caso contrário, $\lim _{n \rightarrow \infty} M^{n}$ converge para uma matriz $K$ constante não nula (isto é, com pelo menos um elemento diferente de zero) (BURKARDT, 2012).

As matrizes de transições utilizadas nos modelos de Markov da área de dependabilidade apresentam elementos representativos de probabilidades e, portanto, são munidas de duas propriedades que as particularizam:

- Todos os elementos das matrizes de transições apresentam valores pertencentes ao intervalo $[0 ; 1]$;

- A soma de todos os elementos de uma linha das matrizes de transições sempre resulta em 1, visto que tal soma corresponde à combinação de probabilidades de eventos mutuamente excludentes e complementares.

Pelas propriedades apresentadas anteriormente, é possível demonstrar que as matrizes de transições típicas dos modelos de Markov da área de dependabilidade são semiconvergentes, de tal forma que o limite $\lim _{n \rightarrow \infty} A^{n}$ sempre tende para uma matriz $K$ constante não nula. Essa matriz apresentará as 
probabilidades estacionárias de permanência nos estados do modelo de Markov para um instante de tempo suficientemente elevado, que tende ao infinito.

Por fim, é importante salientar a existência de outros métodos numéricos para a resolução matemática de modelos de Markov. A proposta apresentada em Ghaderi, Haghifam e Mostafa Abedi (2010) é a de conjugar uma abordagem estocástica baseada no método de Monte Carlo com os modelos de Markov. A motivação para o estudo apresentado pelos autores é a de que, em sistemas representados por modelos de Markov mais sofisticados, a técnica de multiplicações matriciais apresentada anteriormente pode tornar-se muito custosa, sendo mais vantajoso utilizar métodos alternativos que permitem obter boas aproximações para os resultados esperados utilizando-se, para tanto, um esforço computacional inferior ao demandado por intermédio do uso da abordagem matricial (GHADERI; HAGHIFAM; MOSTAFA ABEDI, 2010).

O algoritmo proposto em Ghaderi, Haghifam e Mostafa Abedi (2010) é apresentado na Figura 17. Ele é baseado na execução de diversos experimentos de amostragem da evolução dos estados de operação de um sistema representado por seu modelo de Markov até que ocorra convergência das probabilidades de permanência em cada um dos estados previstos no modelo estudado. 
Figura 17 - Algoritmo de Cálculo de Modelos de Markov

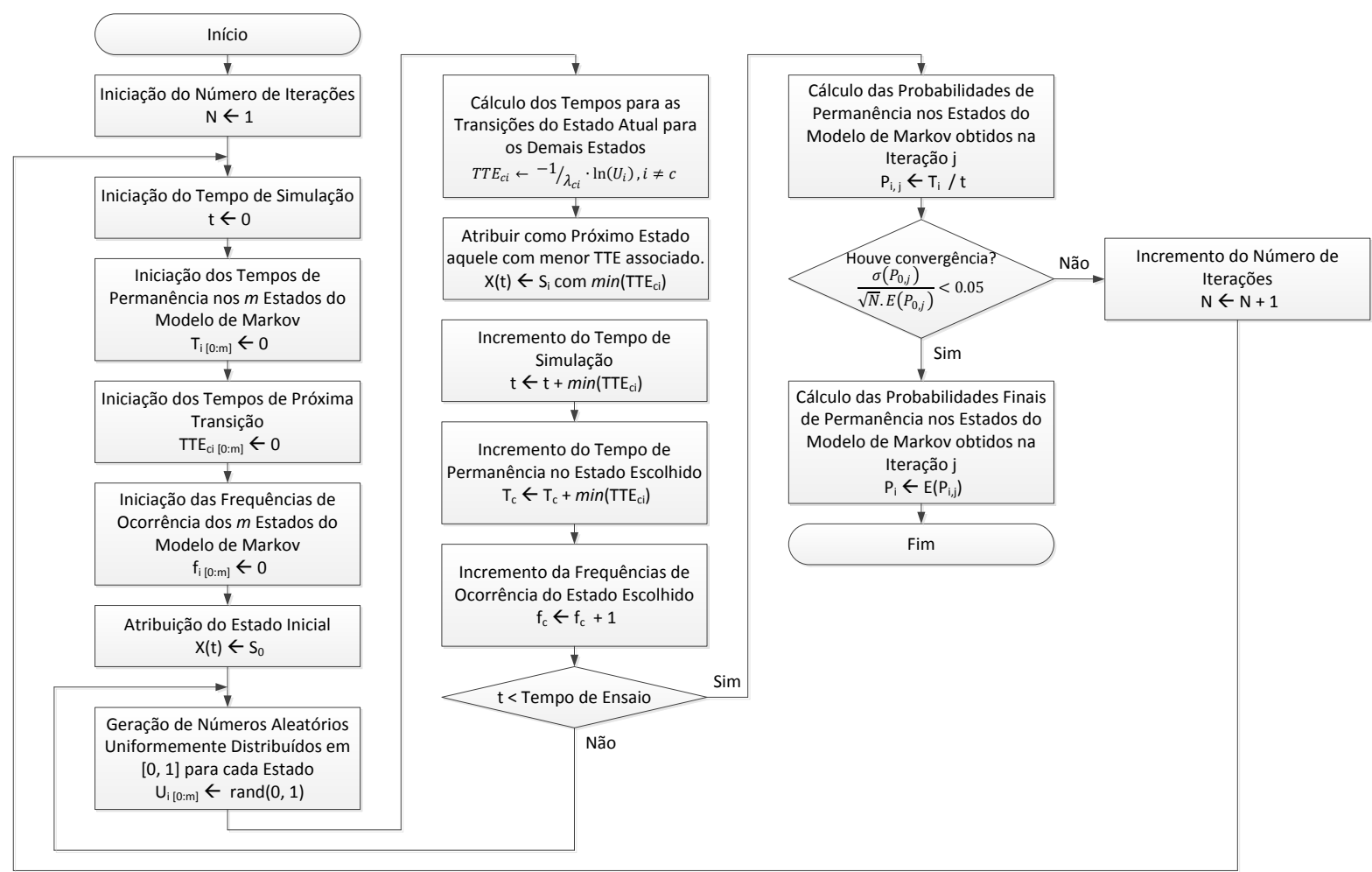

Fonte: adaptado de Ghaderi, Haghifam e Mostafa Abedi (2010)

É importante ressaltar que, devido ao fato de os estudos apresentados em Ghaderi, Haghifam e Mostafa Abedi (2010) ainda serem preliminares, o modelo proposto nessa referência não será utilizado na presente pesquisa de Mestrado.

\subsection{FILTROS DE KALMAN}

Um filtro de Kalman é um algoritmo ótimo e recursivo de processamento de dados que é utilizado, essencialmente, para se estimar o estado de um sistema a partir do uso de três categorias básicas de informações de entrada (MAYBECK, 1979) (KLEINBAUER, 2004):

a) A dinâmica de funcionamento do sistema em estudo e dos dispositivos de medição conectados a ele;

b) A descrição estatística dos ruídos introduzidos no sistema, dos erros nas medições realizadas sobre ele e das incertezas na dinâmica dos modelos matemáticos utilizados para descrevê-lo;

c) As condições iniciais das variáveis de interesse ao estudo. 
Um cenário típico de aplicação de um filtro de Kalman configura-se quando se deseja estimar o estado de um sistema a partir de dados ruidosos coletados por múltiplos instrumentos de medição conectados a ele. Na situação representada na Figura 18, por exemplo, um filtro de Kalman é introduzido para determinar a velocidade exibida no velocímetro de um automóvel (variável de interesse do estudo) considerando aferições realizadas simultaneamente por dois sensores: um tacômetro e um acelerômetro.

Figura 18 - Aplicação de um Filtro de Kalman no Controle de um Velocímetro Automotivo

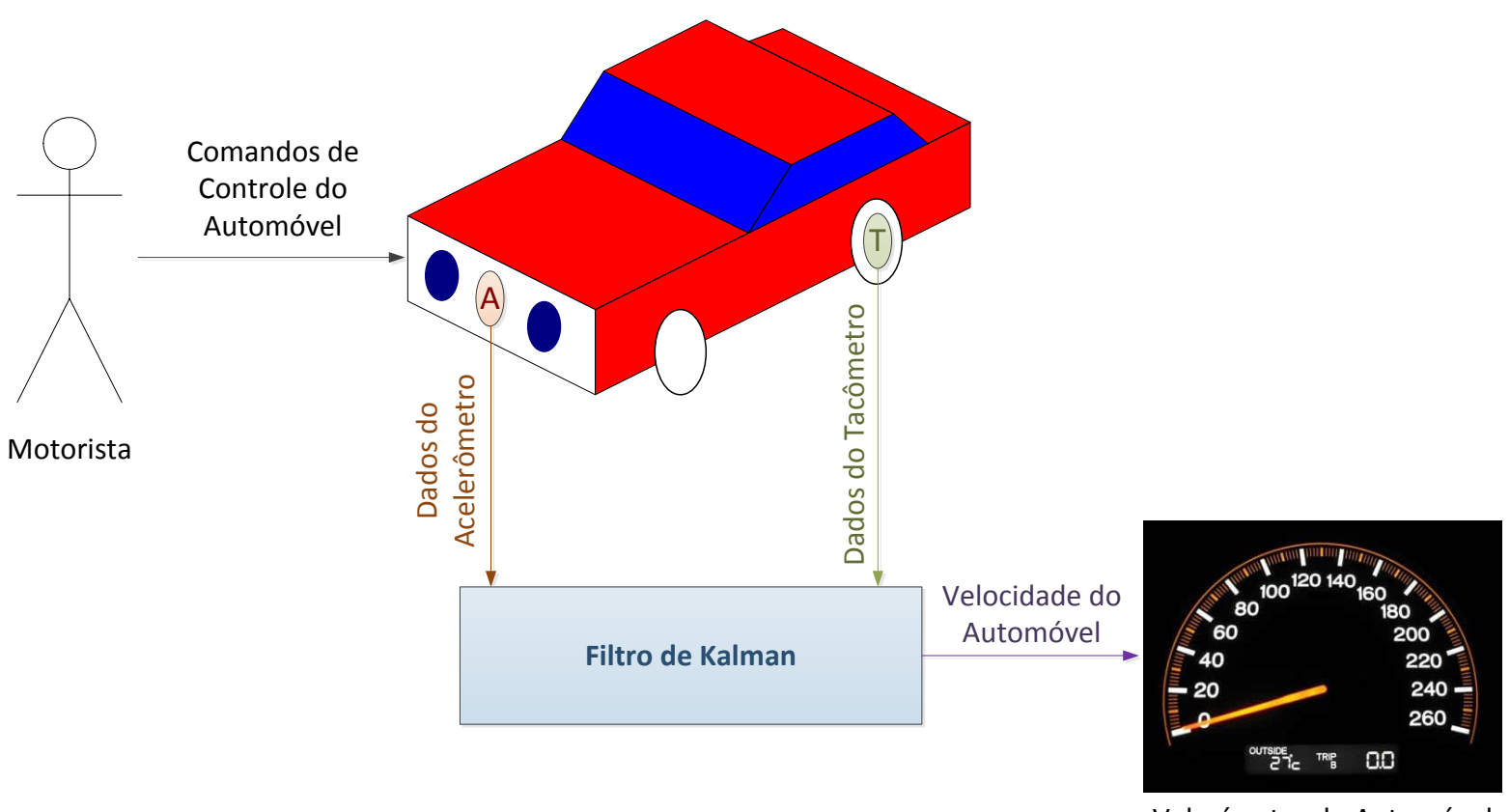

Velocímetro do Automóvel

Fonte: Autor

Considerando-se que as medidas fornecidas pelos sensores do sistema (no caso do exemplo da Figura 18, o acelerômetro e o tacômetro) podem sofrer degradações devido a imprecisões inerentes aos próprios dispositivos e a eventuais ruídos externos, as aferições proporcionadas por eles podem desviar-se das variáveis monitoradas. Para que a degradação nas leituras realizadas pelos sensores possa ser reduzida (ou filtrada), cabe ao filtro de Kalman processar os dados fornecidos pelos equipamentos de medição de tal forma a minimizar o erro estatístico associado a eles. 
A abordagem utilizada por um filtro de Kalman para atingir o objetivo de minimização do erro estatístico de um conjunto de dados ruidosos baseia-se no uso de funções de distribuição de probabilidades que condicionam as variáveis a serem monitoradas aos dados extraídos pelos sensores do sistema. No caso do exemplo da Figura 18, o filtro de Kalman construído para determinar a velocidade do automóvel (a ser exibida no velocímetro do veículo) deve prever que essa variável pode ser calculada por meio de uma função de distribuição de probabilidades condicionada às leituras realizadas pelo tacômetro e pelo acelerômetro.

Um aspecto que deve ser salientado é que um filtro de Kalman pode ser considerado a melhor solução para se minimizar o erro estatístico de um conjunto de dados ruidosos apenas se duas hipóteses forem verdadeiras (MAYBECK, 1979):

a) As funções matemáticas que descrevem o modelo físico que relaciona a variável a ser monitorada e os dados produzidos pelos sensores que monitoram o funcionamento do sistema em estudo devem ser lineares;

b) O ruído inerente às medições realizadas pelos sensores deve ser branco e seguir uma função Gaussiana (normal) de distribuição probabilística. Nessas condições, o ruído associado aos dados produzidos pelos sensores do sistema não tem correlação temporal (isto é, não é possível conhecer o valor do ruído em um instante de tempo $t$ supondo que ele seja conhecido em outros instantes de tempo), é equipotente em todo o espectro da frequência de operação do sistema em estudo e o valor assumido por ele em um instante de tempo $t$ segue uma distribuição de probabilidades normal com média $\mu \mathrm{e}$ desvio padrão $\sigma$.

Uma das principais vantagens proporcionadas pelos filtros de Kalman é a de que, ao se assumir uma distribuição de probabilidades Gaussiana para descrever os ruídos associados às medições realizadas pelos sensores do sistema em estudo, apenas dois parâmetros (média $\mu$ e desvio padrão $\sigma$ ) necessitam ser conhecidos para que o sistema possa ser algebricamente modelado. Em outros algoritmos de filtragem, por sua vez, é comum que mais parâmetros estatísticos (pelo menos três) sejam conhecidos para que a representação algébrica do sistema a ser estudado possa ser completada (MAYBECK, 1979). 
Por esse motivo, os filtros de Kalman são passíveis de serem aplicados em cenários nos quais não se pode estender significativamente o conhecimento acerca da dinâmica interna de funcionamento do sistema a ser estudado ou dos sensores conectados a ele com o propósito de monitorá-lo. Em aplicações práticas nas quais o conhecimento sobre o sistema em estudo é limitado, aponta-se em Maybeck (1979) que é usual assumir que o ruído inerente às medições realizadas pelos sensores do sistema siga uma distribuição Gaussiana de probabilidades, uma vez que estimativas da média $\mu$ e do desvio padrão $\sigma$ das distribuições de probabilidades dos dados coletados pelos sensores do sistema em estudo podem ser trivialmente obtidos.

\subsubsection{Formulação Matemática dos Filtros de Kalman}

Sob o ponto de vista formal, as interfaces de entrada e saída de um filtro de Kalman podem ser representadas por meio do diagrama da Figura 19.

Figura 19 - Interfaces de Entrada e Saída de um Filtro de Kalman

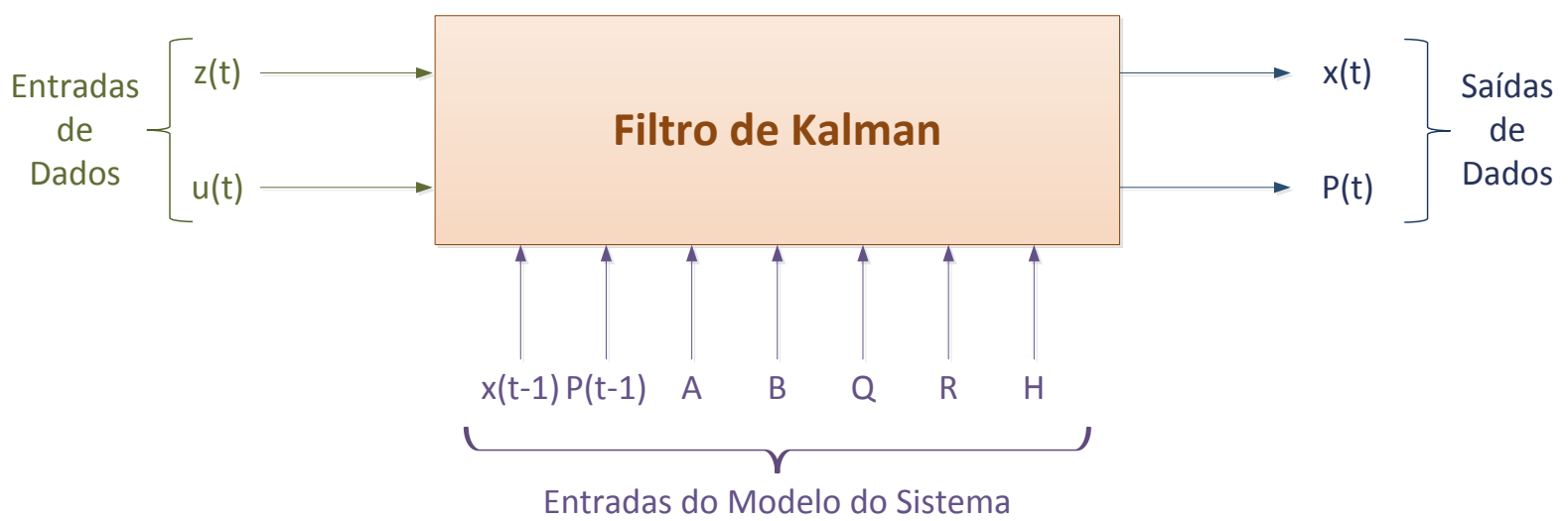

Fonte: Autor

A partir da Figura 19, verifica-se que as interfaces de entrada e saída de um filtro de Kalman podem ser subdivididas em três subconjuntos:

a) Entradas de Dados: As entradas de dados de um filtro de Kalman relacionam-se às informações extraídas do sistema em estudo em um instante de tempo $t$. As duas entradas de dados de um filtro de Kalman são as seguintes: 
i. $\quad z(t)$ : Corresponde a um vetor coluna de dimensão $n$ que apresenta as medições realizadas pelos $n$ sensores de monitoramento do sistema em estudo no instante de tempo $t$;

ii. $u(t)$ : Representa um vetor coluna de dimensão $k$ que indica os valores do comportamento de $k$ eventuais variáveis de controle do sistema em estudo no instante de tempo $t$.

b) Entradas do Modelo do Sistema: As entradas do modelo do sistema relacionam-se aos parâmetros matemáticos dependentes das equações matemáticas que descrevem os fenômenos físicos do sistema em estudo. As seis entradas do modelo do sistema consideradas por um filtro de Kalman são as seguintes:

i. $\quad x(t-1)$ : É um vetor coluna de dimensão $m$ que apresenta os valores iniciais (no instante de tempo $t-1$ ) das $m$ variáveis do sistema cujo comportamento se deseja prever;

ii. $\quad P(t-1)$ : Corresponde à matriz quadrada de ordem $m$ que apresenta os valores iniciais (no instante de tempo $t-1$ ) das covariâncias entre todas as $m$ variáveis do sistema cujo comportamento se deseja prever. Os elementos da diagonal principal de $P(0)$ quantificam a variância de cada uma das variáveis do processo, ao passo que os demais elementos quantificam a covariância entre cada par de variáveis do processo;

iii. A: É uma matriz quadrada de ordem $m$ que descreve, de forma matricial, o sistema de equações matemáticas do modelo físico do sistema em estudo que permite obter os valores das variáveis de interesse do sistema em estudo no instante de tempo $t+1(x(t+1))$ a partir dos valores vigentes no instante $t(x(t))$;

iv. $B$ : É uma matriz de dimensão $m \times k$ que descreve, de forma matricial, o sistema de equações matemáticas do modelo físico do sistema em estudo que relaciona os valores das $m$ variáveis de interesse do sistema em estudo no instante de tempo $t(x(t))$ às suas $k$ variáveis de controle no instante $t(u(t))$;

v. Q: É uma matriz quadrada de ordem $m$ que descreve, de forma matricial, a covariância associada ao modelo do processo representado 
pelo filtro de Kalman. Os elementos da diagonal principal de $Q$ quantificam a variância de cada uma das variáveis do processo, ao passo que os demais elementos quantificam a covariância entre cada par de variáveis do processo;

vi. R: É uma matriz quadrada de ordem $n$ que descreve, de forma matricial, a covariância associada às medições realizadas pelos $n$ sensores de monitoramento do sistema em estudo. Os elementos da diagonal principal de $R$ quantificam a variância das medições efetuadas pelos sensores do processo, ao passo que os demais elementos quantificam a covariância entre cada par de sensores do sistema;

vii. $\quad H$ : É uma matriz de dimensão $n \times m$ que descreve, de forma matricial, o sistema de equações matemáticas do modelo físico do sistema em estudo que relaciona as $m$ variáveis de interesse do sistema às $n$ medições realizadas pelos sensores.

c) Saídas de Dados: As saídas de dados relacionam-se aos valores previstos para as variáveis de interesse do estudo no instante de tempo $t+1$ com base nas entradas de dados coletadas no instante de tempo $t$. As duas saídas de dados de um filtro de Kalman são as seguintes:

i. $\quad x(t)$ : É um vetor coluna de dimensão $m$ que apresenta os valores previstos para as $m$ variáveis do sistema no instante de tempo $t$ com base nos dados de entrada coletados no instante de tempo $t-1$;

ii. $\quad P(t)$ : Corresponde à matriz quadrada de ordem $m$ que apresenta os valores previstos para as covariâncias entre todas as $m$ variáveis do sistema no instante de tempo $t$ com base nos dados de entrada coletados no instante de tempo $t-1$. Os elementos da diagonal principal de $P(t)$ quantificam a variância de cada uma das variáveis do processo, ao passo que os demais elementos quantificam a covariância entre cada par de variáveis do processo.

A obtenção dos valores de $x(t)$ e $P(t)$ a partir das Entradas de Dados e das Entradas de Modelo de um filtro de Kalman decorre da utilização sequencial das sete equações apresentadas subsequentemente. Nas expressões seguintes, $I_{m}$ é a matriz identidade de ordem $m, A^{t}$ e $H^{t}$ representam o resultado da transposição das 
matrizes $A$ e $H$, respectivamente, e $S^{-1}$ simboliza o resultado da inversão da matriz $S$.

$$
\left\{\begin{array}{l}
x_{\text {pred }}(t)=A \cdot x(t-1)+B \cdot u(t) \\
P_{\text {pred }}(t)=A \cdot P(t-1) \cdot A^{t}+Q \\
\tilde{y}(t)=z(t)-H \cdot x_{\text {pred }}(t) \\
S(t)=H \cdot P_{\text {pred }}(t) \cdot H^{t}+R \\
K(t)=P_{\text {pred }}(t) \cdot H^{t} \cdot S(t)^{-1} \\
x(t)=x_{\text {pred }}(t)+K(t) \cdot \tilde{y}(t) \\
P(t)=\left(I_{m}-K \cdot H\right) \cdot P_{\text {pred }}(t)
\end{array}\right.
$$

Nas equações (31) a (37), é possível verificar que há cinco variáveis intermediárias que são calculadas para que as saídas $x(t)$ e $P(t)$ possam ser determinadas:

a) $x_{\text {pred }}(t)$ : É um vetor coluna de dimensão $m$ correspondente à estimativa do valor de $x(t)$ considerando-se apenas a regra matemática (do modelo teórico do sistema sob avaliação) que relaciona $x(t)$ às variáveis de interesse no instante $t-1(x(t-1))$ e às eventuais $k$ variáveis de controle;

b) $P_{\text {pred }}(t)$ : É uma matriz quadrada de ordem $m$ que expressa a estimativa do valor de $x(t)$ considerando-se apenas a regra matemática (do modelo teórico do sistema sob avaliação) que relaciona $x(t)$ às variáveis de interesse no instante $t-1(x(t-1))$ e às eventuais $k$ variáveis de controle;

c) $\tilde{y}(t)$ : É um vetor coluna de dimensão $n$ que indica o quanto cada uma das medições realizadas pelos $n$ sensores de monitoramento do sistema no instante de tempo $t$ se distancia dos valores teóricos estimados para cada uma das medições, obtidos pelo produto entre a matriz $H$ e $x_{\text {pred }}(t)$;

d) $S(t)$ : É uma matriz quadrada de ordem $n$ que indica a covariância ponderada das medições realizadas pelos $n$ sensores de monitoramento do sistema em estudo. A ponderação é feita considerando-se as covariâncias estimadas conceitualmente para as medições (expressas na matriz $R$ ) com as previstas utilizando-se a regra matemática (do modelo teórico do sistema sob avaliação), obtida pelo produto entre a matriz $H$, a variável intermediária $P_{\text {pred }}(t)$ e a matriz transposta $H^{t}$; 
e) $K(t)$ : É uma matriz de ordem $m \times n$ que indica o grau de influência dos parâmetros $\tilde{y}$ e $x_{\text {pred }}(t)$ na saída $x(t)$ e o grau de influência dos parâmetros $R$ e $P_{\text {pred }}(t)$ em $P(t)$. Quando a matriz de covariância $R$ predomina sobre a matriz de covariância $P_{\text {pred }}(t)$ (situação essa indicativa de que as medições realizadas sobre o sistema são menos confiáveis do que as estimativas calculadas mediante utilização das expressões matemáticas do modelo teórico do sistema), a matriz $K$ aproxima-se da matriz nula e, consequentemente, a saída $x(t)$ é dominada pela variável $x_{p r e d}(t)$ e a saída $P(t)$ é majoritariamente determinada por $P_{\text {pred }}(t)$.

Por outro lado, quando a matriz de covariância $P_{\text {pred }}(t)$ predomina sobre a matriz de covariância $R$ (situação essa indicativa de que as medições realizadas sobre o sistema são mais confiáveis do que as estimativas calculadas mediante utilização das expressões matemáticas do modelo teórico do sistema), a matriz $K$ aproxima-se da inversa da matriz $H\left(H^{-1}\right)$. Nessas condições, a saída $x(t)$ é dominada pelo produto $z \cdot H^{-1}$ (indicativo dos valores das variáveis de interesse obtidos mediante conversão das leituras do sensores do sistema) e a saída $P_{\text {pred }}(t)$ aproxima-se da matriz nula.

Um aspecto que deve ser ressaltado nos filtros de Kalman é o de que eles podem ser utilizados de forma recursiva, de tal forma que as saídas $x(t)$ e $P(t)$ geradas em uma iteração sejam utilizadas como entradas para o processamento das novas saídas $x(t+1)$ e $P(t+1)$. No exemplo da Figura 20, um filtro de Kalman configurado com os mesmos parâmetros de modelo $A, B, Q, R$ e $H$ é utilizado para gerar estimativas de $x(2)$ e $P(2)$ a partir das entradas de dados $z(1), z(2), u(1)$ e $u(2)$ e das entradas iniciais de modelo $x(0)$ e $P(0)$. Para a determinação de $x(2)$ e $P(2)$, as saídas $x(1)$ e $P(1)$ geradas pela primeira aplicação do filtro de Kalman são utilizadas como entradas de modelo da segunda iteração de uso do filtro. 
Figura 20 - Exemplo de Utilização Recursiva de um Filtro de Kalman

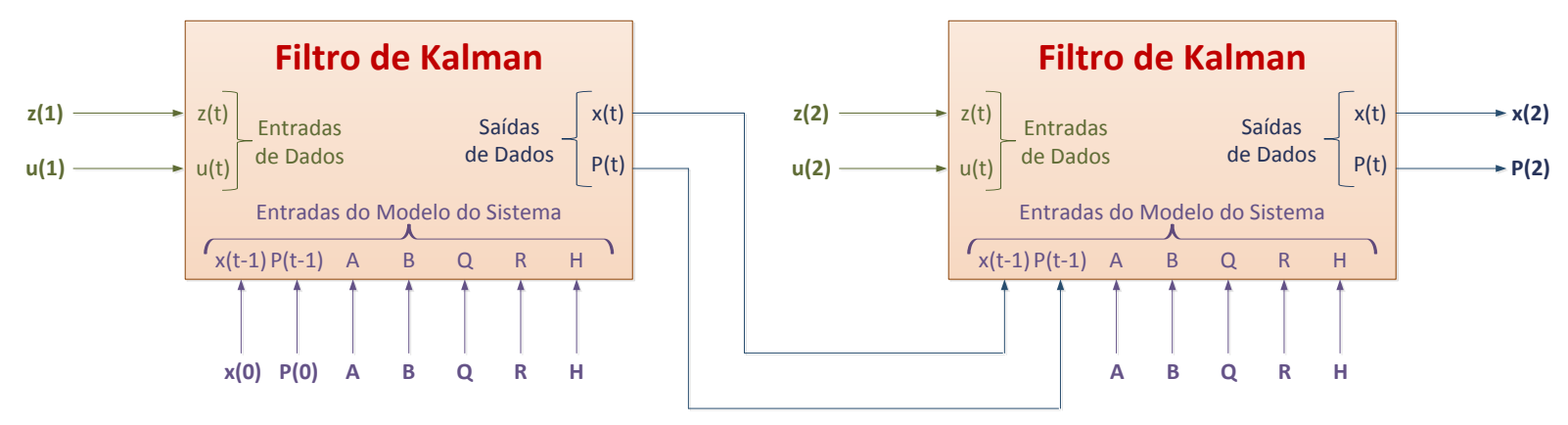

Fonte: Autor

Sob o ponto de vista da implementação, uma das principais vantagens dos filtros de Kalman com relação a algoritmos de filtragem mais sofisticados (que demandam conhecimento de mais parâmetros estatísticos do sistema em estudo) é o de que não há necessidade de se utilizar uma infraestrutura computacional sofisticada para implementá-los. Por meio das equações (31) a (37), a solução de um filtro de Kalman envolve apenas operações de soma, subtração, transposição, multiplicação e inversão de matrizes.

Para maiores informações sobre filtros de Kalman, sugere-se consultar as referências Kalman (1960), Maybeck (1979), Welsh e Bishop (2006) e Simon (2010).

\subsection{Considerações FinaIS do CaPítulo}

Foram apresentados, no presente capítulo, os principais aspectos dos fundamentos que embasam o modelo proposto neste trabalho científico. Foram abordados um panorama da evolução tecnológica relacionada à área da manutenção preditiva, os aspectos gerais aplicáveis aos sistemas tolerantes a falhas, as principais características dos modelos de cálculo de confiabilidade de sistemas elétricos, eletrônicos e programáveis preconizados nos padrões internacionais MIL-HDBK-217 e RIAC-HDBK-217Plus, os conceitos básicos e métodos de cálculo de Processos de Markov e uma introdução aos filtros de Kalman. Todo esse conhecimento será utilizado nos demais Capítulos da presente Dissertação de Mestrado como infraestrutura básica para o entendimento do modelo proposto neste estudo. 


\section{PROPOSTA DE MODELO DE PREVISÃo DE FALHAS BASEAdO EM PROCESSOS ESTOCÁSTICOS E FILTRAGEM KALMAN PARA SUPORTE À MANUTENÇÃO PREDITIVA DE SISTEMAS ELÉTRICOS, ELETRÔNICOS E PROGRAMÁVEIS}

Este capítulo da Dissertação de Mestrado reúne os formalismos já abordados com o propósito de se apresentar o cerne desta pesquisa científica. A exposição do modelo concebidos neste trabalho é introduzida com a definição de uma arquitetura que contextualiza o modelo proposto em um ambiente de operação de um sistema hipotético. A partir dessa arquitetura inicial, cada um de seus elementos é detalhado, e, por fim, são apresentados os principais índices que podem ser obtidos após a integração dos elementos básicos propostos nesta pesquisa.

\subsection{Panorama Geral do Modelo Proposto}

Sabe-se, pelo conteúdo já exposto no Capítulo 2, que a utilização de uma taxa de falhas constante para representar o comportamento de componentes elétricos, eletrônicos e programáveis é uma aproximação que permite, entre outros motivos, utilizar formalismos matemáticos simplificados para a determinação dos índices de dependabilidade associados a determinado sistema.

Sob o ponto de vista prático, a assunção da hipótese de taxa de falhas constante impede que algumas características dos sistemas reais sejam incorporadas aos cálculos de dependabilidade. As principais limitações impostas por essa simplificação são as seguintes:

a) A variação natural da taxa de falhas entre componentes análogos (pertencentes a uma mesma família), decorrente dos processos industriais aplicados às etapas de fabricação, estocagem, distribuição e instalação;

b) O crescimento natural da taxa de falhas dos componentes elétricos, eletrônicos e programáveis com o tempo, apresentado na Figura 10, é desconsiderado nos cálculos dos índices de dependabilidade dos sistemas. Por esse motivo, as estimativas geradas com base nas simplificações tendem a ser mais otimistas do que o comportamento real esperado para dado sistema; 
c) Os efeitos das dependências (estruturais e funcionais) entre os componentes de um sistema são desconsiderados nos cálculos de seus respectivos índices de dependabilidade. Como as taxas de falhas dos componentes do sistema são consideradas constantes com o tempo, os reflexos da manifestação da falha de um componente sobre os demais componentes do sistema (sobretudo no que diz respeito à probabilidade condicional de ocorrência de uma falha sobre um componente íntegro dado que outro componente falhou) não podem ser contabilizados.

Limitações similares ocorrem com relação às taxas de reparos dos componentes elétricos, eletrônicos e programáveis, que são usualmente aproximadas por valores constantes no tempo. Essa aproximação desconsidera, por exemplo, a variação natural dos tempos necessários para reparar um sistema em pelo menos três situações usuais e emblemáticas:

a) Para determinado componente de um sistema, o tempo necessário para uma ação de reparo pode variar em função da dificuldade do procedimento a ser executado. Pode ser natural, por exemplo, que uma ação de conserto demande mais tempo para ser concluída do que uma atuação que vise apenas substituir um componente falho por um equivalente íntegro;

b) Para uma mesma ação de reparo de determinado componente de um sistema, o tempo demandado para que diferentes equipes de manutenção executem-na pode variar em função da experiência adquirida pela equipe.

c) Uma mesma equipe de manutenção nem sempre irá executar uma ação de reparo sempre no mesmo período de tempo. Essas variações temporais, que podem ser reduzidas por meio de treinamentos e de acúmulo de experiência em campo, são inerentes à própria natureza humana.

Para que um programa de manutenção preditiva suficientemente efetivo possa ser implantado, é importante que existam formalismos que permitam descrever conceitualmente o sistema a ser estudado mantendo-se um grau aceitável de fidelidade entre sua representação conceitual e seu comportamento real. Por esse motivo, o modelo proposto na presente pesquisa foi concebido com o intuito de minimizar as limitações de tratamento das taxas de falhas e de reparos apresentadas anteriormente, de tal forma a permitir que as estimativas dos índices 
de dependabilidade e dos instantes de ocorrência de falhas dos componentes do sistema em estudo sejam suficientemente críveis em aplicações práticas.

Para tanto, o modelo proposto neste estudo foi estruturado de acordo com a arquitetura apresentada na Figura 21, que o contextualiza em um ambiente usual para a operação de um sistema hipotético.

Figura 21 - Arquitetura do Modelo da Pesquisa Contextualizado em um Ambiente de Operação de um Sistema Hipotético

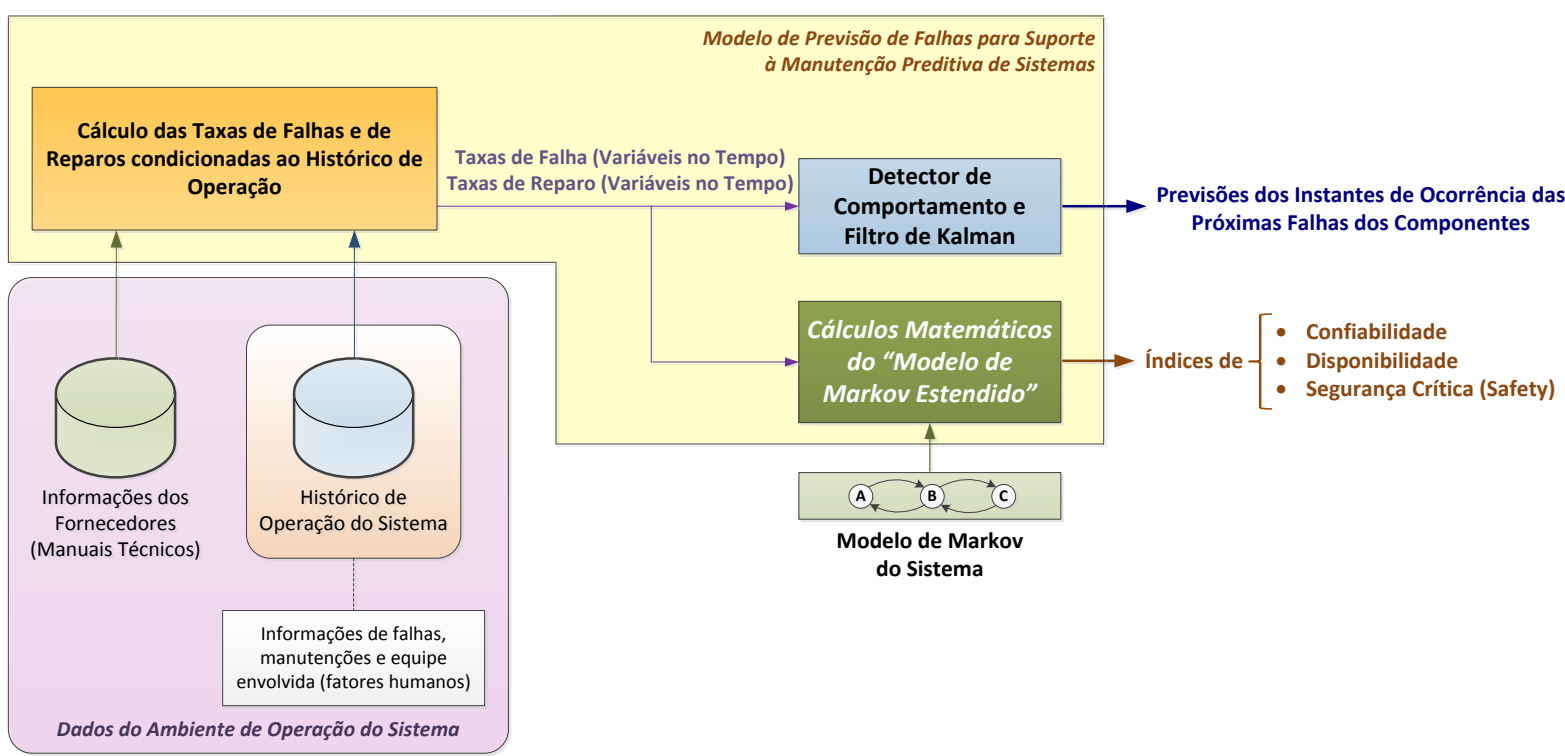

Fonte: Autor

Pela Figura 21, é possível observar que o modelo proposto neste trabalho científico pode atuar como uma ferramenta que permite determinar índices de confiabilidade, disponibilidade e segurança crítica (safety) de um sistema a partir de duas fontes básicas de dados de origem, oriundas do ambiente de operação do sistema em estudo (representado, na Figura 21, pelo bloco denominado "Dados do Ambiente de Operação do Sistema"):

a) Os manuais técnicos dos componentes do sistema são responsáveis por fornecer as estimativas iniciais das respectivas taxas de falhas esperadas para cada um dos componentes do sistema, determinadas sob condições operacionais especificadas pelos fabricantes;

b) O histórico de operação do sistema é responsável por fornecer os registros dos eventos de falha e de manutenção efetuados sobre cada componente do 
sistema. Essas informações possibilitam que o comportamento dos componentes do sistema em suas reais condições de uso possa ser inferido por meio do modelo proposto.

O funcionamento do modelo da Figura 21 pode ser subdividido em três etapas distintas, representadas de forma sumarizada no fluxograma da Figura 22.

Figura 22 - Fluxograma do Funcionamento do Modelo da Figura 21

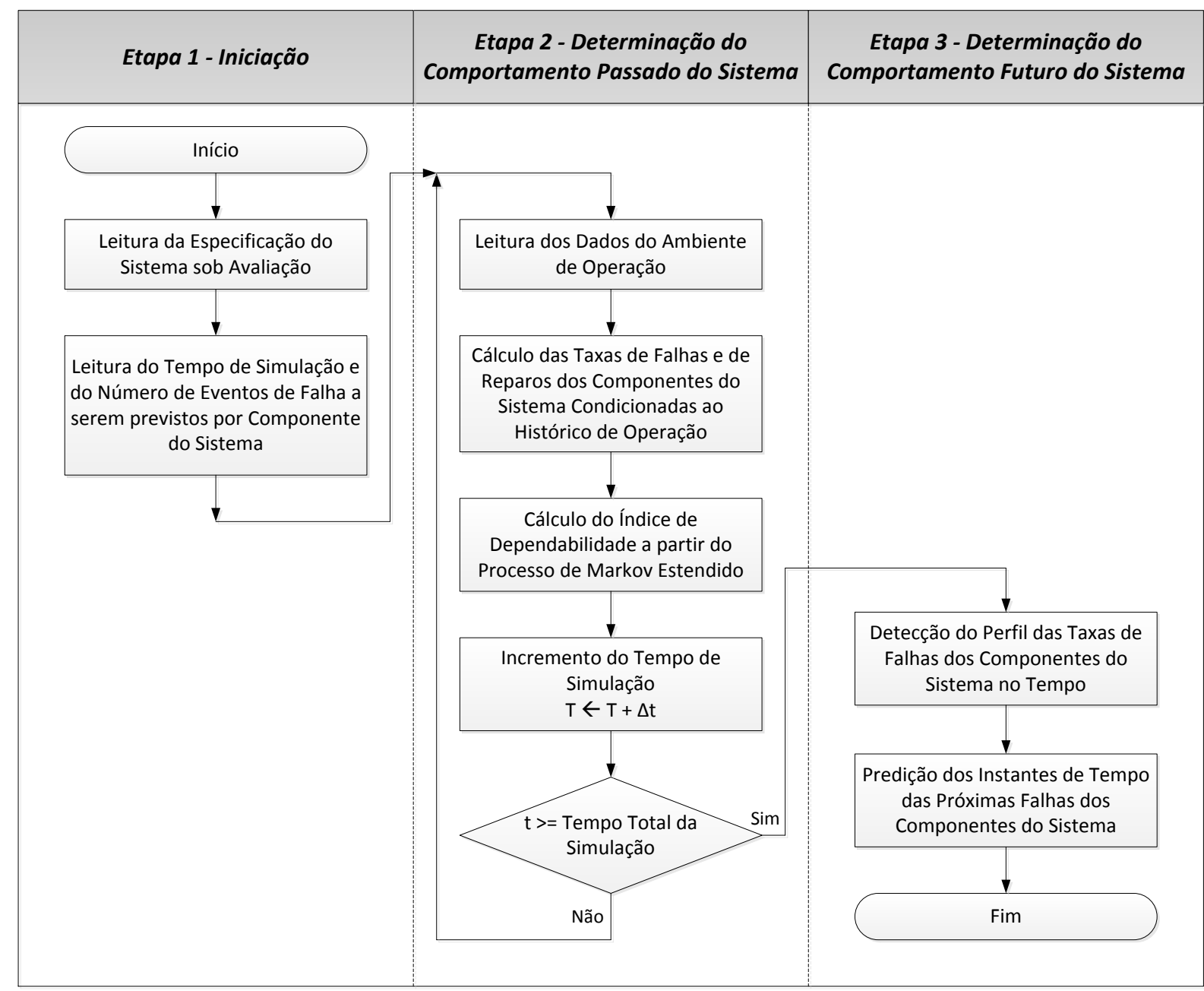

Fonte: Autor

A seguir, são expostas as descrições de cada uma das três etapas de funcionamento representadas no fluxograma da Figura 22. 


\section{a) Etapa 1: Iniciação}

Atribui-se à primeira fase do funcionamento do modelo da Figura 21 a funcionalidade de estabelecer as condições iniciais para que um sistema possa ser estudado. Para tanto, o ambiente de simulação comportamental do modelo da Figura 21 deve ser iniciado com a leitura das características do sistema a ser avaliado, que compreendem a configuração do processo de Markov que o rege (número de componentes, códigos de identificação dos estados e expressões literais de todas as transições entre estados), do período de tempo durante o qual foram coletados dados operacionais do sistema em estudo (representado, na Figura 22, pelo "Tempo de Simulação") e da quantidade de eventos de falhas futuras que devem ser previstas para cada componente do sistema.

\section{b) Etapa 2: Determinação do Comportamento Passado do Sistema Estudado}

A segunda etapa do funcionamento do modelo da Figura 21 é responsável por determinar o perfil comportamental da dependabilidade do sistema em estudo com base no uso dos "Dados do Ambiente de Operação do Sistema" desde o instante em que o sistema foi habilitado até o final do período de tempo durante o qual foram coletados registros operacionais do sistema (adquirido como entrada do modelo na "Etapa 1").

Essa fase de funcionamento do modelo da Figura 21 opera de forma iterativa, de tal forma que cada iteração de funcionamento represente o transcurso de um intervalo de tempo $\Delta t$ no funcionamento do sistema representado pelo seu respectivo modelo de Markov. A escolha do valor do intervalo de tempo $\Delta t$ utilizado em um ensaio depende do compromisso entre precisão de resultados e demanda de esforço computacional, conforme abordado na seção 2.4.2.2.

A primeira etapa de cada iteração compreende a leitura dos dados originados dos manuais técnicos e do histórico de operação do sistema. Essa aquisição de dados, desempenhada pelo bloco "Cálculo das Taxas de Falhas e de Reparos condicionadas ao Histórico de Operação" da Figura 21, é responsável por determinar periodicamente novas estimativas para as taxas de falhas e de reparos envolvidas 
no modelo de Markov em estudo com base nos modelos de predição de confiabilidade preconizados no padrão RIAC-HDBK-217Plus. Os cálculos são executados considerando-se a leitura do histórico desde seu início até último registro gerado até o tempo de simulação corrente.

Quando os valores referentes à iteração atual já foram gerados pelo bloco "Cálculo das Taxas de Falhas e de Reparos condicionadas ao Histórico de Operação" da Figura 21, os resultados previamente produzidos são encaminhados como entradas para o bloco "Cálculos Matemáticos do "Modelo de Markov Estendido", também representado na Figura 21. Esse bloco é responsável por estimar, com base nos valores das taxas de falhas e de reparos da respectiva iteração, o novo valor do índice de dependabilidade (confiabilidade, disponibilidade ou segurança crítica (safety)) na iteração executada.

Ao término dessa etapa, verifica-se se o tempo de simulação já atingiu o final do período de tempo de funcionamento do sistema, adquirido como entrada do modelo na "Etapa 1". Se esse valor não foi atingido, uma nova iteração de processamento da "Etapa 2" é iniciada; caso contrário, dá-se início à "Etapa 3" do funcionamento do modelo da Figura 21.

\section{c) Etapa 3: Determinação do Comportamento Futuro do Sistema Estudado}

Quando o tempo de simulação atinge o instante de tempo no qual o histórico de operação termina, o modelo proposto responsabiliza-se por efetuar a predição do comportamento futuro do sistema, estimando os próximos eventos de falhas que deverão ocorrer sobre cada um de seus componentes.

A partir dos dados determinados pelo bloco "Cálculo das Taxas de Falhas e de Reparos Condicionadas ao Histórico de Operação" da Figura 21, é possível se prever uma tendência para a evolução das funções que descrevem as taxas de falhas de cada um dos componentes do sistema, com o propósito de orientar a execução de procedimentos de manutenção preditiva sobre o sistema com um grau de confiança mais aceitável que o das políticas e heurísticas usualmente utilizadas. Essa predição é desempenhada pelo bloco "Detector de Comportamento e Filtro de Kalman" da Figura 21, que gera, por meio de regressão polinomial e de um filtro de 
Kalman, o comportamento previsto para todas as funções envolvidas com as taxas de falhas dos componentes do sistema em estudo.

As seções subsequentes apresentam o detalhamento das características de cada um dos blocos do modelo conceitual apresentado na Figura 21.

\subsection{Detalhamento dos "Dados do Ambiente de OperaçÃo do Sistema”}

Os "Dados do Ambiente de Operação do Sistema" são utilizados com o propósito de descreverem as características dos componentes do sistema. Tais dados estão divididos em duas categorias: os dados coletados de manuais técnicos e os dados de histórico de operação do sistema, que são gerados durante o seu funcionamento sob condições normais de utilização.

Em sistemas reais, as taxas de falhas aproximadas de seus componentes podem ser extraídas de manuais técnicos disponibilizados pelos respectivos fabricantes. Essas estimativas são, geralmente, determinadas pelos fabricantes considerando-se um conjunto de condições específicas de operação para cada componente (por exemplo, um valor específico de temperatura) e que, nem sempre, pode ser respeitado na prática quando o mesmo componente é posto em funcionamento dentro de um sistema.

Por esse motivo, o uso de dados que reflitam o histórico de operação do sistema mostra-se interessante para que as estimativas das taxas de falhas e de reparos dos seus componentes possam ser estimadas de modo mais fiel às reais condições de utilização do sistema. Para que um histórico possa ser utilizado de forma efetiva, é importante que ele seja construído de tal forma a enumerar todos os eventos de falha e de manutenção que são executados sobre todos os componentes do sistema.

Dessa forma, o modelo proposto no presente trabalho científico foi construído considerando-se que o histórico de operação de um sistema formado por $n$ componentes contemple os seguintes tipos de eventos: 
a) Evento de Início de Histórico de Operação (L): Esse tipo de evento é responsável por registrar o instante de tempo em que se iniciou a operação do sistema. Sob o ponto de vista do modelo conceitual proposto neste trabalho de pesquisa, o "Evento de Início de Histórico de Operação" é tratado sempre no instante de tempo $t=0$, que marca o início do estudo de qualquer sistema;

b) Evento de Ocorrência de Falha no i-ésimo Componente do Sistema $\left(F_{i}\right)$ : Esse tipo de evento é responsável por informar o instante de tempo, contabilizado a partir do início da operação do sistema, em que foi detectada uma falha em um de seus componentes. A partir dos registros das falhas de todos os componentes, é determinada a evolução das funções temporais que descrevem as suas respectivas taxas de falhas;

c) Evento de Ocorrência de Início de Reparo (em Laboratório) no i-ésimo Componente do Sistema $\left(\mathbf{R l}_{\mathbf{i}}\right)$ : Esse tipo de evento é responsável por informar o instante de tempo, contabilizado a partir do início da operação do sistema, em que foi iniciada uma ação de reparo em laboratório de um de seus componentes. Quando esse estado é atingido, a hipótese assumida é a de que o componente defeituoso é retirado de seu ambiente operacional (sem ser substituído por um componente sobressalente) para que ele seja reparado em laboratório. A diferença entre os instantes de tempo de ocorrência de um evento de início de reparo (em laboratório) de um componente do sistema e do respectivo evento de falha indica o intervalo de tempo que foi necessário para mobilizar a equipe de manutenção para solucionar o problema;

d) Evento de Ocorrência de Final de Reparo (em Laboratório) no i-ésimo Componente do Sistema $\left(\mathbf{R F}_{\mathrm{i}}\right)$ : Esse tipo de evento é responsável por informar o instante de tempo, contabilizado a partir do início da operação do sistema, em que foi concluída uma ação de reparo (em laboratório) de um de seus componentes. A diferença entre os instantes de tempo de ocorrência de um evento de fim de reparo (em laboratório) de um componente do sistema e do respectivo evento de falha é utilizada para se determinar a evolução das funções temporais que descrevem as taxas de reparo dos componentes do sistema;

e) Evento de Ocorrência de Início de Substituição (Reparo em Campo) do iésimo Componente do Sistema $\left(\mathbf{S I}_{\mathrm{i}}\right)$ : Sob o ponto de vista do presente 
trabalho de pesquisa, os eventos registrados no histórico de operação de um sistema preveem a diferenciação entre as operações de reparo (em laboratório) e de substituição (reparo em campo) de um componente. Essa diferenciação foi considerada no presente trabalho de pesquisa porque os procedimentos de reparo (em laboratório) e de substituição (reparo em campo) serão tratados de forma diferenciada na determinação das estimativas das taxas de reparos dos componentes do sistema executadas pelo bloco "Cálculo das Taxas de Falhas e de Reparos condicionadas ao Histórico de Operação", como se abordará na seção 3.3.

Quando o estado de início de substituição (reparo em campo) é atingido, a hipótese assumida é a de que o componente defeituoso é retirado do sistema e substituído por um componente sobressalente. A diferença entre os instantes de tempo de ocorrência de um evento de início de substituição (reparo em campo) de um componente do sistema e do respectivo evento de falha indica o intervalo de tempo que foi necessário para mobilizar a equipe de manutenção para solucionar o problema;

f) Evento de Ocorrência de Final de Substituição (Reparo em Campo) no iésimo Componente do Sistema $\left(\mathbf{S F}_{\mathrm{i}}\right)$ : Esse tipo de evento é responsável por informar o instante de tempo, contabilizado a partir do início da operação do sistema, em que foi concluída uma ação de substituição (reparo em campo) de um de seus componentes. A diferença entre os instantes de tempo de ocorrência de um evento de fim de substituição de um componente do sistema e do respectivo evento de falha é utilizada para se determinar a evolução das funções temporais que descrevem as taxas de reparo dos componentes do sistema;

g) Evento de Final de Histórico de Operação (D): Responsável por registrar o instante de tempo em que a observação dos dados de histórico do sistema foi concluída. A finalização do histórico de operação pode representar duas situações distintas: a interrupção da coleta de dados de diagnóstico do sistema em um instante de tempo predefinido pela sua equipe de operação ou a tangência do instante de tempo atual, em que o sistema ainda está em 
operação e não retornou mais dados para a interface de diagnóstico que se responsabiliza pela manutenção do histórico operacional.

O encadeamento dinâmico entre os tipos de eventos relacionados anteriormente pode ser representado graficamente pelo diagrama de transição de estados apresentado na Figura 23. Por simplicidade de notação, o "Evento de Final de Histórico de Operação" foi omitido da Figura 23 porque ele pode ser atingido a partir de qualquer outro tipo de evento.

Figura 23 - Encadeamento Dinâmico dos Eventos de Histórico de Operação de um Sistema

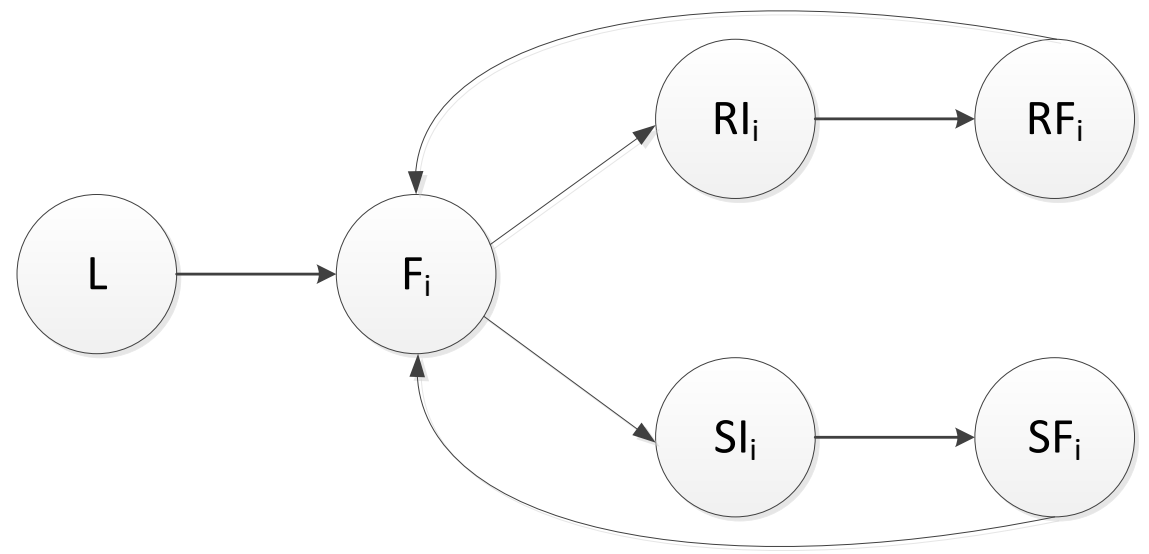

\section{Fonte: Autor}

Pelo diagrama da Figura 23, é possível observar que, a partir do instante em que o histórico de operação é iniciado, o primeiro tipo de evento esperado para um componente relaciona-se à ocorrência de uma falha $\left(\mathbf{F}_{\mathbf{i}}\right)$. Após a efetivação de tal evento, dois caminhos distintos são possíveis: ou o componente é reparado (eventos $\mathbf{R}_{\mathbf{i}}$ e $\mathbf{R F}_{\mathbf{i}}$ ), ou o componente é substituído (eventos $\mathbf{S l}_{\mathbf{i}}$ e $\mathbf{S F}_{\mathbf{i}}$ ). Por fim, com o término do ato de manutenção (reparo ou substituição), é esperada uma nova falha no componente.

Ainda com relação ao diagrama apresentado na Figura 23, um aspecto que deve ser ressaltado é o de que, no modelo proposto no presente estudo, um componente é considerado defeituoso (atingindo o estado $\mathbf{F}_{\mathbf{i}}$ ) assim que uma falha tenha ocorrido nele. Dessa maneira, se outras falhas afetarem o componente sob avaliação enquanto ele ainda não tiver sido reparado, tais eventos de falha não serão considerados no modelo. 
Sob o ponto de vista prático, a definição da granularidade dos componentes abordados no histórico de operação do sistema depende de um compromisso entre duas características conflitantes: o custo associado à provável necessidade de implementação de um subsistema acessório de diagnóstico do sistema em estudo, que será responsável por gerar e manter os dados de histórico de operação, e o grau de conhecimento que se deseja ter sobre cada elemento que compõe o sistema.

A contextualização do subsistema de diagnóstico no ambiente do sistema em estudo é apresentada na Figura 24. Nessa ilustração, o termo "componente" deve ser interpretado de acordo com o grau de granularidade de informações que devem ser conhecidas para se avaliar o sistema em estudo de forma satisfatória. Dessa maneira, deve-se considerar que um "componente" pode ser tanto um dispositivo elétrico, eletrônico ou programável elementar (resistor, capacitor, transistor ou circuito integrado, por exemplo) quanto um subsistema que agrupa mais de um desses dispositivos básicos.

Figura 24 - Contextualização do Subsistema de Diagnóstico

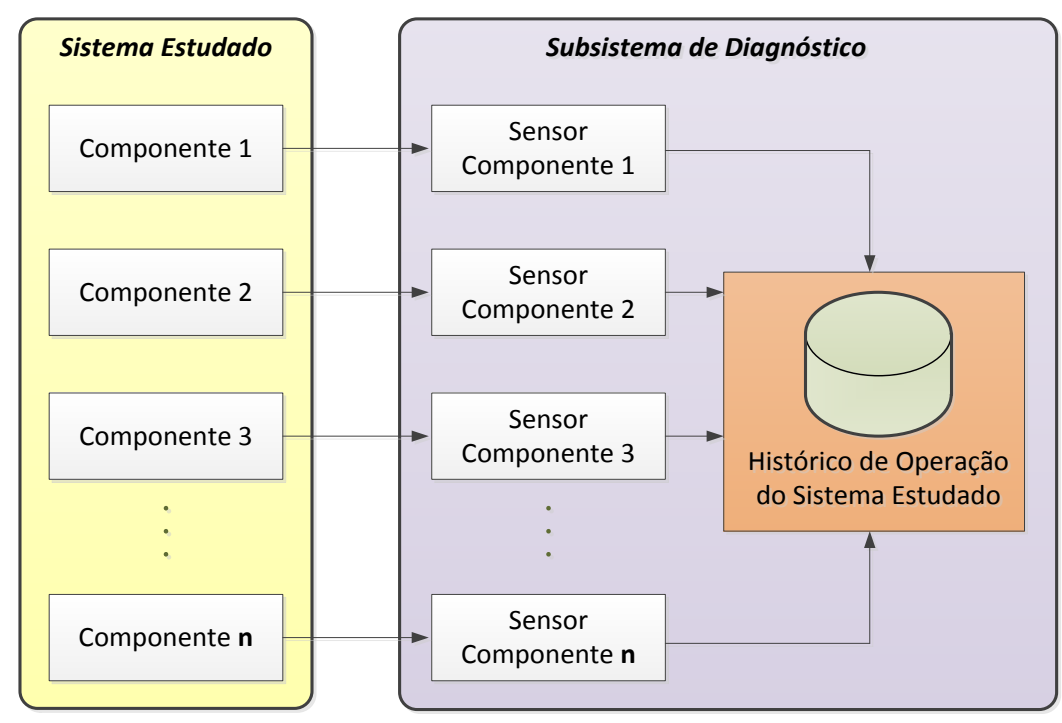

Fonte: Autor

Em sistemas críticos com relação à segurança (safety), nos quais a ocorrência de determinados tipos de falhas pode levar a consequências catastróficas, pode ser interessante que os módulos mais críticos do sistema sejam monitorados com elevado grau de granularidade (por exemplo, monitorando-se o 
funcionamento de cada componente de hardware que compõe o sistema em estudo, tais como resistores, capacitores, transistores e circuitos integrados). Esse conhecimento detalhado sobre a operação do sistema, por sua vez, seria traduzido na elevação dos custos de fabricação e manutenção do sistema, visto que seria necessário manter em funcionamento um subsistema de diagnóstico suficientemente confiável que se responsabilizasse pela geração e pela manutenção dos dados de histórico.

Em sistemas com menor grau de criticidade com relação a qualquer índice de dependabilidade, por sua vez, pode não ser necessário monitorar todos os componentes de hardware que integram o sistema, mas apenas avaliar o funcionamento de alguns de seus módulos na forma de caixas-pretas. Nessa abordagem, o subsistema de geração e manutenção dos dados de histórico seria mais simples e menos custoso, uma vez que ele apenas monitoraria as interfaces de entrada e saída dos módulos que necessitariam ser estudados.

Os algoritmos utilizados na implementação da proposta apresentada nesta seção são detalhados no Capítulo 4 da presente Dissertação de Mestrado.

\subsection{Detalhamento do Bloco "Cálculo das taxas de falhas e de Reparos CONDICIONADAS AO HISTÓRICO DE OPERAÇÃO"}

Considerando-se que os "Dados do Ambiente de Operação do Sistema" estão disponíveis, é de responsabilidade do bloco "Cálculo das Taxas de Falhas e de Reparos condicionadas ao Histórico de Operação" determinar iterativamente, a cada intervalo $\Delta t$ de simulação, os valores atualizados das taxas de falhas e de reparos de todos os componentes que integram o sistema em estudo.

Os cálculos das taxas de falhas dos componentes do sistema em estudo são executados considerando-se o modelo de predição de confiabilidade prescrito no padrão RIAC-HDBK-217Plus e apresentado detalhadamente na seção 2.3.2. No caso específico deste trabalho científico, as seguintes simplificações são consideradas: 
a) Nenhum conhecimento específico acerca do histórico de utilização de sistemas predecessores é empregado nos cálculos, de tal forma que os valores dos parâmetros $\lambda_{\text {obs,pred }}$ e $\lambda_{\text {prev,pred }}$ da Figura 12 possam ser considerados iguais. Nessas condições, pela equação (10), o parâmetro $\lambda_{1}$ do modelo da Figura 12 passa a ser igual a $\lambda_{\text {pred,novo; }}$

b) Assume-se que o parâmetro $\lambda_{\text {pred,novo }}$ da Figura 12 corresponde à taxa de falhas nominal de um componente do sistema em estudo, extraída dos manuais técnicos disponibilizados pelo fabricante. Nessas condições, $\lambda_{\text {pred,novo }}$ passa a ser uma constante única para cada componente do sistema em estudo;

c) Considerando-se que o histórico de operação do sistema corresponda a uma única base de dados coletada em tempo de funcionamento real (isto é, sem fatores de aceleração), os conjuntos de valores $a_{i}$ e $b_{i}$ da Figura 12 são unitários $\left(a_{1}\right.$ e $\left.b_{1}\right)$ e o fator de aceleração $A F_{1}$ associado a $b_{1}$ é igual a 1 ;

d) O parâmetro $a_{0}$ da Figura 12 é fixado no valor padrão recomendado pelo padrão RIAC-HDBK-217Plus, igual a 0,5.

e) Com base nas simplificações apresentadas nos itens anteriores, a equação (12) pode ser reescrita. A versão simplificada da equação (12) aplicável ao bloco "Cálculo das Taxas de Falhas e de Reparos condicionadas ao Histórico de Operação" é apresentada na equação (38).

$$
\lambda_{2}=\frac{0,5+a_{1}}{\frac{0,5}{\lambda_{\text {pred,novo }}}+b_{1}}
$$

A equação (38), que produz em $\lambda_{2}$ uma estimativa para a taxa de falhas de um componente do sistema com base no histórico de operação acumulado até o instante de tempo sobre o qual se executa o respectivo cálculo, é reavaliada iterativamente no modelo proposto no presente estudo, em que cada iteração corresponde ao transcurso de um intervalo de tempo $\Delta t$. Ao final de cada iteração de tratamento do bloco "Cálculo das Taxas de Falhas e de Reparos condicionadas ao Histórico de Operação", os valores determinados para as taxas de falhas são fornecidos ao bloco "Cálculos Matemáticos do 'Modelo de Markov Estendido" para que ele possa atualizar os índices de dependabilidade aplicáveis ao sistema em estudo. 
Com base na equação (38), é possível inferir que a variação temporal da taxa de falhas $\lambda_{2}$ é aderente ao seguinte princípio qualitativo:

a) No intervalo de tempo compreendido entre o início do funcionamento do componente e a ocorrência de uma falha nele, ou ainda no período de tempo compreendido entre duas falhas consecutivas de um mesmo componente, o parâmetro $a_{1}$ da equação (38) mantém-se constante e o parâmetro $b_{1}$ aumenta com o tempo. Como, nessas condições, apenas o denominador da equação (38) eleva-se com o tempo, a taxa de falhas $\lambda_{2}$ é gradualmente reduzida enquanto o componente mantém-se operacional;

b) Com a ocorrência de uma falha do componente, o parâmetro $a_{1}$ da equação (38) é incrementado em uma unidade e o parâmetro $b_{1}$ mantém-se constante até que o procedimento de reparo associado à falha prévia seja concluído. Como, nessas condições, apenas o numerador da equação (38) eleva-se com o tempo, a taxa de falhas $\lambda_{2}$ cresce quando ocorre um evento de falha relacionado ao componente.

Devido à inexistência de um modelo de predição análogo ao apresentado no padrão internacional RIAC-HDBK-217Plus para modelar a evolução da taxa de reparos de um componente elétrico, eletrônico ou programável e ao fato de que não pertence ao escopo imediato do presente trabalho preencher tal lacuna por meio da proposição de um modelo matemático com essa finalidade, uma hipótese simplificadora considerada na presente pesquisa é a de que o arcabouço preconizado no padrão internacional RIAC-HDBK-217Plus para cálculo das taxas de falhas de componentes elétricos, eletrônicos e programáveis será estendido para ser usado de forma a se determinar a evolução temporal das taxas de reparos a partir dos dados do histórico de operação de cada componente. Por meio dessa abordagem, características que podem ser utilizadas para explicar variações nos tempos de procedimentos de manutenção, tais como variações de experiência de equipes de manutenção diferentes e variações de dificuldade de procedimentos de manutenção de acordo com os tipos de disfunções manifestadas por um mesmo componente, passam a ser contempladas pelo modelo proposto.

A versão análoga do arcabouço da norma RIAC-HDBK-217Plus estendida para as taxas de reparos de componentes elétricos, eletrônicos e programáveis para 
o propósito do presente trabalho de pesquisa é apresentada na Figura 25. Por intermédio desse esquema, é possível notar que a taxa de reparos do sistema predecessor influencia a taxa de reparos do sistema novo (componente em estudo) por intermédio da razão $\mu_{o b s, p r e d} / \mu_{\text {prev,pred }}$, que estende proporcionalmente ao sistema novo as diferenças entre as taxas de reparos observada $\left(\mu_{\text {obs,pred }}\right)$ e prevista $\left(\mu_{\text {prev,pred }}\right)$ para o sistema predecessor. Esses valores são respectivamente coletados considerando-se o histórico de operação e as políticas usuais de manutenção aplicadas ao sistema predecessor.

Para que o histórico do sistema novo (componente em estudo) possa ser considerado na determinação de sua taxa de reparos efetiva, são considerados, de maneira análoga à proposta pelo padrão RIAC-HDBK-217Plus para as taxas de falhas, os parâmetros $a_{i}$ e $b_{i}$. No caso específico das taxas de reparo, esses parâmetros representam, respectivamente, o número de procedimentos de reparo executados sobre o sistema novo e o tempo acumulado gasto com todos os reparos acumulados ao longo do tempo de geração do histórico de funcionamento do sistema. 
Figura 25 - Adaptação do Cálculo de Taxas de Falhas do Padrão RIAC-HDBK-217Plus à Determinação de Taxas de Reparos a partir de Histórico de Operação de Sistemas Elétricos, Eletrônicos e Programáveis

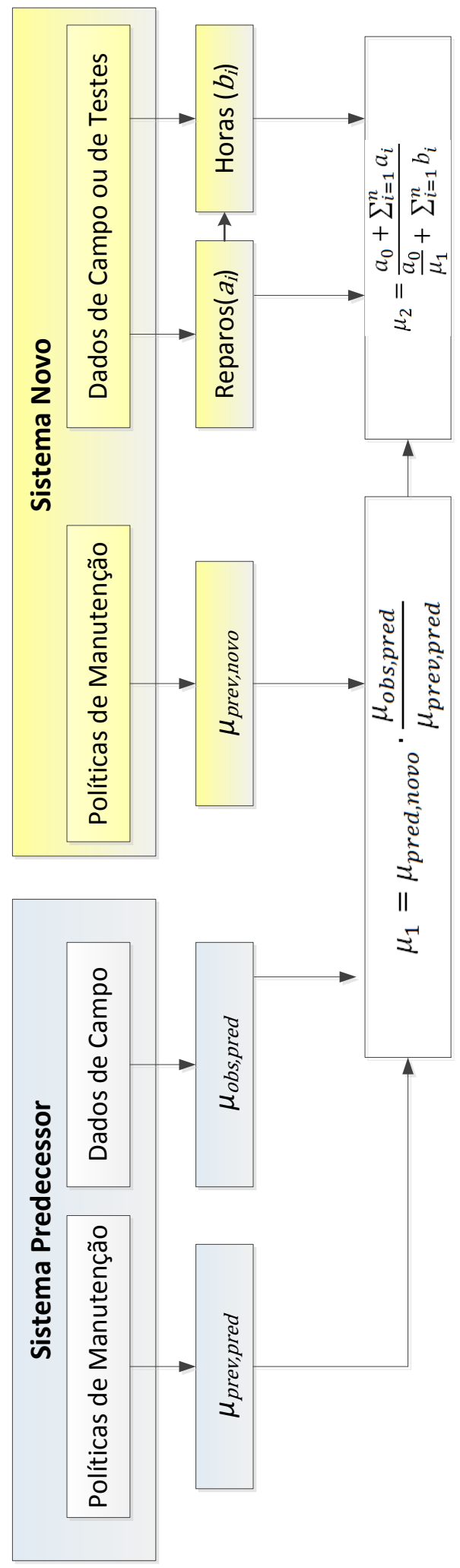

Fonte: Autor 
É importante salientar que não foi considerada plausível a hipótese de se adotar os fatores de aceleração $A F_{i}$ no tratamento das taxas de reparos de componentes elétricos, eletrônicos e programáveis. Essa decisão foi tomada com base no fato de que não é usual executar conscientemente procedimentos de "reparo acelerado" ou de "reparo prolongado" sobre tais componentes, o que força os fatores de aceleração a assumirem sempre valor 1 .

Com relação ao parâmetro $a_{0}$ - que, por analogia ao texto original do padrão RIAC-HDBK-217Plus sobre os cálculos de taxas de falhas, representaria o número efetivo de reparos associados à taxa de reparos prevista para o componente também foi considerado que ele deve assumir o valor padrão 0,5 .

Com base em toda a argumentação prévia, a estimativa da taxa de reparos de um componente elétrico, eletrônico ou programável determinada de forma condicionada ao seu histórico de funcionamento pode ser determinada pela aplicação das equações (39) e (40). Na equação (39), o parâmetro $\mu_{\text {prev,novo }}$ representa a taxa de reparos nominal do componente, determinada apenas considerando-se as políticas de manutenção usuais a serem aplicadas sobre o mesmo.

$$
\begin{gathered}
\mu_{1}=\mu_{\text {pred }, \text { novo }} \cdot \frac{\mu_{\text {obs }, \text { pred }}}{\mu_{\text {prev }, \text { red }}} \\
\mu_{2}=\frac{a_{0}+\sum_{i=1}^{n} a_{i}}{\frac{a_{0}}{\mu_{1}}+\sum_{i=1}^{n} b_{i}^{\prime}}
\end{gathered}
$$

No caso específico do modelo proposto na presente pesquisa para o bloco "Cálculo das Taxas de Falhas e de Reparos condicionadas ao Histórico de Operação", hipóteses simplificadoras análogas às já apresentadas para as taxas de falhas também podem ser consideradas para o tratamento das taxas de reparo. As simplificações adotadas foram as seguintes:

a) Nenhum conhecimento específico acerca do histórico de utilização de sistemas predecessores é empregado nos cálculos, de tal forma que os 
valores de $\mu_{\text {obs,pred }}$ e $\mu_{\text {prev,pred }}$ possam ser considerados iguais. Nessas condições, pela equação (32), o parâmetro $\mu_{1}$ passa a ser igual a $\mu_{\text {pred,novo }}$;

b) Considerando-se que o histórico de operação do sistema corresponda a uma única base de dados, os conjuntos de valores $a_{i}$ e $b_{i}$ são unitários $\left(a_{1}\right.$ e $\left.b_{1}\right)$;

c) O parâmetro $a_{0}$ é fixado no valor padrão igual a 0,5;

d) Com base nas simplificações apresentadas nos itens anteriores, a equação (40) pode ser reescrita. A versão simplificada da equação (40) aplicável ao bloco "Cálculo das Taxas de Falhas e de Reparos condicionadas ao Histórico de Operação" é apresentada na equação (41).

$$
\mu_{2}=\frac{0,5+a_{1}}{\frac{0,5}{\mu_{\text {pred,novo }}}+b_{1}}
$$

Juntamente com as taxas de falhas, as taxas de reparos calculadas por meio da equação (41) para cada componente do sistema em estudo são reavaliadas iterativamente e, ao final de cada iteração de tratamento do bloco "Cálculo das Taxas de Falhas e de Reparos condicionadas ao Histórico de Operação", os valores determinados para as taxas de reparos também são fornecidos ao bloco "Cálculos Matemáticos do "Modelo de Markov Estendido" para que ele possa atualizar os índices de dependabilidade aplicáveis ao sistema em estudo.

É importante ressaltar que cabe ao bloco "Cálculo das Taxas de Falhas e de Reparos condicionadas ao Histórico de Operação" efetuar o tratamento diferenciado aos eventos de reparo (conserto) e de substituição de um componente defeituoso no sistema. A diferença entre ambos está no critério de atualização da taxa de falhas do componente, que é reiniciada com o valor nominal (extraído dos manuais técnicos dos fabricantes) apenas quando houver a conclusão do procedimento de substituição.

Os algoritmos utilizados na implementação da proposta apresentada nesta seção são detalhados no Capítulo 4 da presente Dissertação de Mestrado. 


\subsection{Detalhamento do Bloco "Cálculos matemáticos do Modelo de Markov ESTENDIDO"}

Como se apresentou na seção 3.3, os valores das taxas de falhas e de reparos dos componentes do sistema em estudo são iterativamente atualizadas, em intervalos de tempo $\Delta t$, pelo bloco "Cálculo das Taxas de Falhas e de Reparos condicionadas ao Histórico de Operação" com base nos dados de histórico de operação coletados do sistema.

Ao final de cada iteração, os valores das taxas de falhas e de reparos produzidos pelo bloco "Cálculo das Taxas de Falhas e de Reparos condicionadas ao Histórico de Operação" são utilizados como entrada do modelo de Markov do sistema em estudo, que gera, também de forma iterativa, uma estimativa do índice de dependabilidade representado pelo modelo de Markov referente ao mesmo instante de tempo múltiplo de $\Delta t$.

Os cálculos associados à computação do modelo de Markov são efetuados mediante utilização da solução numérica baseada em sucessivas multiplicações da matriz de transições do modelo de Markov, apresentada nas equações (29) e (30) da seção 2.4.2.2. A única diferença em relação ao método tradicional equacionado nas equações (29) e (30) relaciona-se ao fato de a matriz de transições alterar-se ligeiramente entre uma transição e outra devido à atualização das taxas de falhas e de reparos pelo bloco "Cálculo das Taxas de Falhas e de Reparos condicionadas ao Histórico de Operação".

Dessa maneira, é possível afirmar que, no contexto do modelo conceitual proposto no presente estudo e apresentado na Figura 21, a matriz de transições do modelo de Markov de qualquer sistema estudado varia com o tempo. Considerandose essa característica, a equação (29) pode ser reescrita na seguinte forma:

$$
P(\mathrm{t}+\Delta t)=A(\mathrm{t}+\Delta t) \cdot P(t)
$$

Aplicando-se o mesmo raciocínio indutivo utilizado na seção 2.4.2.2, também é possível reescrever a equação (30) na forma apresentada na equação (43). 


$$
P(n \Delta t)=\left(\prod_{i=1}^{n} A(i . \Delta t)\right) \cdot P(0)
$$

É importante ressaltar que as alterações nos valores da matriz de transições do modelo de Markov a cada iteração de cálculo são pequenas e não levam à alteração das propriedades numéricas apresentadas na seção 2.4.2.2 no que diz respeito às características dos valores de seus elementos. Por esse motivo, 0 produto $\prod_{i=1}^{n} A(i . \Delta t)$, embora deixe de convergir para uma matriz $K$ constante, atingirá um valor relativamente próximo a ela.

Um aspecto que deve ser ressaltado é o de que, conceitualmente, os processos Markovianos podem ser utilizados apenas para descrever fenômenos estocásticos cujos modelos de transição de estados são munidos de probabilidades de transição constantes ao longo do tempo. Quando essa propriedade matemática deixa de ser respeitada, é necessário utilizar abordagens mais genéricas, tais como os processos Semi-Markovianos.

No caso específico do presente trabalho de pesquisa, uma hipótese simplificadora considerada foi a de que, como as alterações nos valores das probabilidades de todas as transições de estados são pequenas entre cada iteração de cálculo, seria possível obter resultados relevantes com razoável precisão utilizando-se uma abordagem Markoviana tradicional. A principal motivação relacionada a essa simplificação relaciona-se ao fato de que, em decorrência da maior complexidade dos modelos Semi-Markovianos frente aos modelos Markovianos, o desempenho computacional de um algoritmo que implementa a modelagem matemática de um processo Semi-Markov é inferior ao de um algoritmo que implementa a modelagem matemática de um processo de Markov.

\subsection{Detalhamento do Bloco "Detector de Comportamento e Filtro de KalmaN"}

O bloco "Detector de Comportamento e Filtro de Kalman" é o responsável por determinar estimativas para os instantes de ocorrência das falhas futuras de todos os componentes do sistema em estudo. Para tanto, os eventos de falhas registrados no Histórico Operacional do sistema são utilizados como entradas para os cálculos de predição que são executados. 
Cada componente do sistema sob avaliação é avaliado de forma independente dos demais pelo bloco "Detector de Comportamento e Filtro de Kalman". Para cada um dos componentes do sistema, cabe ao bloco "Detector de Comportamento e Filtro de Kalman" executar os seguintes passos de processamento:

a) Inicialmente, o bloco "Detector de Comportamento e Filtro de Kalman" consulta o Histórico Operacional do sistema com o propósito de filtrar os instantes de tempo dos $f$ eventos de falha do componente sob avaliação $\left(t_{\lambda}\right)$ e organizá-los em ordem crescente;

b) Em seguida, um índice numérico $\beta$ inteiro e variante de 1 a $f$ é associado, também em ordem crescente, a cada um dos instantes de tempo dos eventos de falha detectados para o componente sob avaliação. Ao final dessa etapa, os índices numéricos $\beta$ e os instantes de tempo $t_{\lambda}$ dos eventos de falha passam a ser organizados em uma matriz similar à exemplificada na Tabela 5.

Tabela 5 - Exemplo de Matriz de Relacionamento entre Índice Numérico $\beta$ e Instantes de Tempo $t_{\lambda}$ das Falhas de um Componente

\begin{tabular}{|c|c|}
\hline $\boldsymbol{\beta}$ & $\boldsymbol{t}_{\boldsymbol{\lambda}}(\mathbf{h})$ \\
\hline 1 & 12.358 \\
\hline 2 & 21.959 \\
\hline 3 & 33.215 \\
\hline 4 & 44.023 \\
\hline 5 & 50.987 \\
\hline 6 & 63.259 \\
\hline 7 & 71.460 \\
\hline
\end{tabular}

\section{Fonte: Autor}

c) A matriz elaborada na etapa b) pode ser interpretada como uma relação de pontos em um plano cartesiano bidimensional, no qual o eixo das abscissas é representado por $\boldsymbol{\beta}$ e o eixo das ordenadas é simbolizado por $\boldsymbol{t}_{\lambda}$. Com base nessa interpretação, é possível obter uma expressão matemática aproximada para a função $f(\beta)=t_{\lambda}$ mediante uso de uma técnica de regressão. 
Após a execução de alguns ensaios preliminares durante a presente pesquisa de Mestrado, constatou-se que o uso de uma regressão linear permite obter resultados satisfatórios para a modelagem matemática da função $f(\beta)=t_{\lambda}$, que pode, dessa maneira, ser escrita na forma $f(\beta)=t_{\lambda}=a . \beta+l$, sendo os coeficientes $a$ e $l$ determinados matematicamente. Uma justificativa relacionada a essa escolha é a de que, supondo-se que os procedimentos de manutenção executados sobre todos os componentes do sistema em estudo sejam perfeitos - isto é, todos os componentes do sistema são restaurados aos mesmos estados que eles assumiam quando eram novos - é possível considerar que o tempo médio para ele manifestar uma falha aproxime-se de seu MTTF nominal. Por esse motivo, uma primeira aproximação (mais grosseira) para a função $f(\beta)$ é a de que ela pode ser representada pela expressão $\beta * M T T F$, correspondente a uma reta com coeficiente linear nulo e coeficiente angular igual ao MTTF do componente.

Outro aspecto a ser ressaltado é o de que, como o processo de regressão linear requer a existência de pelo menos três pontos de dados de origem para que as variâncias associadas aos coeficientes angular e linear sejam finitas, o modelo de predição de falhas idealizado para o bloco "Detector de Comportamento e Filtro de Kalman" é aplicável se houver pelo menos três registros de falhas passadas no histórico operacional do componente em estudo;

d) Uma vez determinados os valores dos coeficientes angular (a) e linear $(l)$ da função $f(\beta)$, uma primeira estimativa dos instantes de tempo em que as próximas falhas do componente irão ocorrer pode ser obtida atribuindo-se à variável $\beta$ da função $f(\beta)=a$. $\beta+l$ valores inteiros superiores ao número de falhas $f$ extraído do Histórico Operacional.

No entanto, um aspecto que deve ser ressaltado é o de que esse método consiste, essencialmente, em se extrapolar a função $f(\beta)$ além do intervalo $[1, \beta]$ utilizado para construí-la pela regressão linear do conjunto de pontos extraídos do Histórico Operacional. Dessa maneira, os resultados gerados pelo procedimento de extrapolação podem deixar de ser relevantes se o 
"fenômeno físico da ocorrência de falhas de um componente" não puder ser razoavelmente descrito pela função algébrica aproximada $f(\beta)=a \cdot \beta+l$ (com os valores dos coeficientes angular $(a)$ e linear $(l)$ obtidos pelo procedimento de regressão) para valores de $\beta$ superiores a $f$.

Para que esse problema seja minimizado, a abordagem proposta no presente estudo consiste em se utilizar um filtro de Kalman para ajustar os valores dos coeficientes angular $(a)$ e linear $(l)$ da função $f(\beta)$ considerando-se a ponderação entre "os valores dos instantes de tempo de ocorrência das próximas falhas do componente resultantes da extrapolação da função $f(\beta)$ considerando-se os valores originais de a e l mesmo para valores de $\beta$ superiores a $f$ " e "um conjunto de valores de instantes de tempo de ocorrência das próximas falhas do componente gerados pseudoaleatoriamente a partir de seu MTTF nominal'. Tais valores pseudoaleatórios são produzidos com o propósito de simular o funcionamento do componente sob avaliação no futuro, de tal forma que, no filtro de Kalman, eles exerçam o papel das "medições realizadas pelos sensores conectados ao sistema em estudo" (correspondentes às entradas de dados $z(t)$ da introdução teórica apresentada na seção 2.5).

Com base nessa abordagem, as equações básicas consideradas na construção do filtro de Kalman são as seguintes:

i. Equações de Próximo Estado do Componente: Em condições ideais, o comportamento esperado para a próxima falha do componente é o de que ele seja aderente à função afim $f(\beta)=a \cdot \beta+l$ e que os coeficientes angular $(a)$ e linear $(l)$ da função $f(\beta)$ não se alterem ao se introduzir os instantes de ocorrência das falhas futuras do componente (relacionadas a quaisquer valores de $\beta$ superiores a $f$ ).

Sob o ponto de vista matemático, essas condições podem ser traduzidas no seguinte sistema de equações: 


$$
\left\{\begin{array}{l}
a(\beta+1)=a(\beta) \\
l(\beta+1)=l(\beta)
\end{array}\right.
$$

ii. Equação de Relacionamento entre o Estado do Componente e o Instante de Ocorrência de sua Próxima Falha: Considerando-se que o filtro de Kalman não altera o perfil polinomial de primeiro grau da função $f(\beta)$, é possível descrever o instante teórico em que a próxima falha do componente em estudo ocorrerá por meio da equação (46):

$$
t_{\lambda}(\beta+1)=a(\beta+1) \cdot(\beta+1)+l(\beta+1)
$$

Com base nas equações (44), (45) e (46), os valores dos coeficientes angular (a) e linear $(l)$ da função $f(\beta)$ a serem considerados na determinação da $(\beta+1)$ ésima falha do componente em estudo a partir das $\beta$ falhas anteriores podem ser determinados com auxílio do filtro de Kalman representado na Figura 26.

Figura 26 - Filtro de Kalman Utilizado no Modelo Proposto na Pesquisa

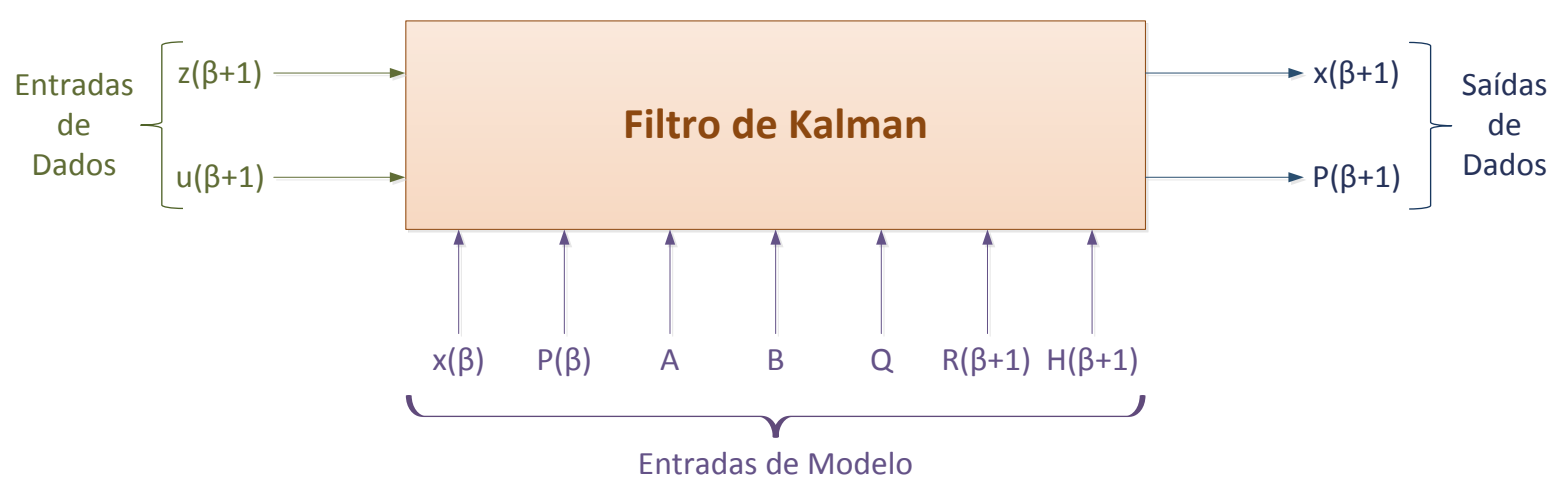

Fonte: Autor

As entradas de dados do filtro de Kalman da Figura 26 são as seguintes:

i. $z(\beta+1)$ : Representa 0 instante de tempo pseudoaleatoriamente determinado para a ocorrência da $(\beta+1)$-ésima falha do componente em estudo a partir do valor de seu MTTF nominal. O detalhamento do algoritmo utilizado com essa finalidade é exposto na seção 4.5 desta dissertação;

ii. $u(\beta+1)$ : Representa eventuais entradas de controle adicionais que podem influenciar sobre os valores dos coeficientes angular $(a)$ e linear 
(l) da função $f(\beta)$. Por simplicidade, as entradas $u(\beta+1)$ serão consideradas nulas no presente estudo para qualquer valor de $\beta$ superior ao número de falhas $f$ registradas no Histórico Operacional do componente.

As entradas de modelo do filtro de Kalman da Figura 26 são as seguintes:

i. $x(\beta)$ : Como $x(\beta)$ deve conter os valores iniciais das variáveis cujos valores devem ser previstos, tal entrada de modelo consiste em um vetor coluna munido de dois elementos: o coeficiente angular $a(\beta)$ e o coeficiente linear $l(\beta)$. A representação matemática de $x(\beta)$ é exposta na equação (47):

$$
x(\beta)=\left(\begin{array}{l}
a(\beta) \\
l(\beta)
\end{array}\right)
$$

ii. $\quad P(\beta)$ : Considerando-se que a entrada $x(\beta)$ seja representada pela equação (47), a matriz $P(\beta)$ é uma matriz quadrada de ordem 2 cujos elementos da diagonal principal são iguais às variâncias (Var) associadas aos coeficientes angular $a(\beta)$ e linear $l(\beta)$ e cujos elementos da diagonal secundária correspondem à covariância $(\mathrm{Cov})$ entre esses dois coeficientes. A representação matemática de $P(\beta)$ é exposta na equação (48):

$$
P(\beta)=\left(\begin{array}{cc}
\operatorname{Var}_{a(\beta)} & \operatorname{Cov}_{a(\beta), l(\beta)} \\
\operatorname{Cov}_{a(\beta), l(\beta)} & \operatorname{Var}_{l(\beta)}
\end{array}\right)
$$

Para $\beta=f$, as variâncias associadas aos coeficientes angular $a$ e linear $l$ dependem exclusivamente do processo de regressão linear aplicado ao conjunto de pares ordenados $\left(\beta, t_{\lambda}\right)$. Nessas condições, as equações (49), (50) e (51) devem ser utilizadas para se obter os valores de $\operatorname{Var}_{a(f)}$ e $\operatorname{Var}_{l(f)}$ :

$$
\sigma=\sqrt{\frac{\sum_{\beta=1}^{f}\left\{t_{\lambda}(\beta)-[a \cdot \beta+l]\right\}^{2}}{f-2}}
$$




$$
\begin{gathered}
\operatorname{Var}_{a(f)}=\frac{f \cdot \sigma^{2}}{\left(f \cdot \Sigma_{\beta=1}^{f} \beta^{2}\right)-\left(\sum_{\beta=1}^{f} \beta\right)^{2}} \\
\operatorname{Var}_{l(f)}=\operatorname{Var}_{a(f)} \cdot \frac{\sum_{\beta=1}^{f} \beta^{2}}{f}
\end{gathered}
$$

Por simplicidade, a covariância inicial (para $\beta=f$ ) entre os coeficientes angular $a$ e linear $l$ será considerada nula no presente estudo.

iii. A: Considerando-se as equações (44) e (45), que descrevem que os coeficientes angular $a$ e linear $l$ se mantêm constantes para qualquer valor de $\beta$, a matriz $A$ corresponde à matriz identidade de ordem 2 , conforme apresentado na equação (52):

$$
A=\left(\begin{array}{ll}
1 & 0 \\
0 & 1
\end{array}\right)
$$

iv. $B$ : Como a entrada de controle $u(\beta+1)$ será considerada nula, o valor assumido pela matriz $B$ não exercerá influência sobre 0 comportamento do filtro de Kalman desenvolvido na presente pesquisa.

v. $Q$ : Por simplicidade, será considerada a hipótese de que o modelo matemático que aproxima a ocorrência das falhas de um componente por uma função afim não possui incertezas associadas. Em decorrência dessa limitação, a matriz $Q$ do filtro de Kalman corresponde à matriz nula de ordem 2, exibida na expressão (53):

$$
Q=\left(\begin{array}{ll}
0 & 0 \\
0 & 0
\end{array}\right)
$$

vi. $\quad R(\beta+1)$ : Como a entrada de dados $z(\beta+1)$ é composta por um só elemento, a matriz $R$ também apresentará apenas um elemento. $O$ valor assumido pela matriz $R$ corresponde à variância do número pseudoaleatório $z(\beta+1)$, conforme apresentado na expressão (54):

$$
R=\left(\operatorname{Var}_{z(\beta+1)}\right)
$$


O detalhamento das distribuições de probabilidade utilizadas no processo de geração dos valores pseudoaleatórios da entrada de dados $z(\beta+1)$ será explorado na seção 4.5. Por esse motivo, os cálculos necessários para que $\operatorname{Var}_{z(\beta+1)}$ também serão expostos apenas nessa ocasião.

vii. $H(\beta+1)$ : Considerando-se a equação (46), que relaciona os coeficientes angular $a$ e linear $l$ aos tempos de ocorrência das falhas futuras do componente em estudo, a matriz $H$ corresponde à matriz de dimensão $1 \times 2$ representada na expressão (55):

$$
H=(\beta+1 \quad 1)
$$

As saídas de dados produzidas pelo filtro de Kalman da Figura 26 são as seguintes:

i. $x(\beta+1)$ : A saída $x(\beta+1)$ consiste em um vetor coluna munido de dois elementos: o coeficiente angular $a(\beta+1)$ e o coeficiente linear $l(\beta+1)$ a serem considerados na determinação do instante de tempo da próxima falha do componente sob avaliação. A representação matemática de $x(\beta+1)$ é exposta na equação (56):

$$
x(\beta+1)=\left(\begin{array}{l}
a(\beta+1) \\
l(\beta+1)
\end{array}\right)
$$

ii. $P(\beta+1)$ : A matriz $P(\beta+1)$ é uma matriz quadrada de ordem 2 cujos elementos da diagonal principal são iguais às variâncias (Var) associadas aos coeficientes angular $a(\beta+1)$ e linear $l(\beta+1)$ e cujos elementos da diagonal secundária correspondem à covariância $(\mathrm{Cov})$ entre esses dois coeficientes. A representação matemática de $P(\beta+1)$ é exposta na equação (57):

$$
P(\beta+1)=\left(\begin{array}{cc}
\operatorname{Var}_{a(\beta+1)} & \operatorname{Cov}_{a(\beta+1), l(\beta+1)} \\
\operatorname{Cov}_{a(\beta+1), l(\beta+1)} & \operatorname{Var}_{l(\beta+1)}
\end{array}\right)
$$

A partir dos valores das células da matriz $P(\beta+1)$, é possível estimar a variância de $x(\beta+1)$ aplicando-se o princípio de propagação de incertezas 
da equação (58) à função afim $f(\beta+1)=a \cdot(\beta+1)+l$. O resultado dessa operação é apresentado na equação (59).

$$
\begin{aligned}
& \operatorname{Var}_{x(\beta+1)}=\left(\frac{\partial f}{\partial a}\right)^{2} \cdot \operatorname{Var}_{a(\beta+1)}+\left(\frac{\partial f}{\partial l}\right)^{2} \cdot \operatorname{Var}_{l(\beta+1)}+2 \cdot\left(\frac{\partial f}{\partial a}\right) \cdot\left(\frac{\partial f}{\partial l}\right) \cdot \operatorname{Cov}_{a(\beta+1), l(\beta+1)} \\
& \operatorname{Var}_{x(\beta+1)}=(\beta+1)^{2} \cdot \operatorname{Var}_{a(\beta+1)}+\operatorname{Var}_{l(\beta+1)}+2 \cdot(\beta+1) \cdot \operatorname{Cov}_{a(\beta+1), l(\beta+1)}
\end{aligned}
$$

Com base na notação apresentada anteriormente, o sistema de equações apresentado na seção 2.5 (formado pelas equações (31) a (37)) para descrever as generalidades de um filtro de Kalman pode ser reescrito conforme exposto nas equações (60) a (66).

$$
\left\{\begin{array}{l}
x_{\text {pred }}(\beta+1)=A \cdot x(\beta)+B \cdot u(\beta+1) \\
P_{\text {pred }}(\beta+1)=A \cdot P(\beta) \cdot A^{t}+Q \\
\tilde{y}(\beta+1)=z(\beta+1)-H(\beta+1) \cdot x_{\text {pred }}(\beta+1) \\
S(\beta+1)=H(\beta+1) \cdot P_{\text {pred }}(\beta+1) \cdot H(\beta+1)^{t}+R(\beta+1) \\
K(\beta+1)=P_{\text {pred }}(\beta+1) \cdot H(\beta+1)^{t} \cdot S(\beta+1)^{-1} \\
x(\beta+1)=x_{\text {pred }}(\beta+1)+K(\beta+1) \cdot \tilde{y}(\beta+1) \\
P(\beta+1)=\left(I_{2}-K(\beta+1) \cdot H(\beta+1)\right) \cdot P_{\text {pred }}(\beta+1)
\end{array}\right.
$$

Considerando-se que uma quantidade $k$ de falhas posteriores às $f$ falhas já extraídas do Histórico Operacional do componente em estudo devam ser previstas, o Filtro de Kalman da Figura 26 deve ser recursivamente empregado conforme apresentado na Figura 27. É importante salientar que tal esquema de recursividade segue a mesma lógica do exemplo apresentado na Figura 20 da seção 2.5:

$>$ As entradas de modelo $A, B$ e $Q$ são as mesmas em todas as iterações executadas;

> As entradas de dados $z(f+1)$ a $z(f+k)$ são independentes entre si;

> Para toda iteração $i=\{1, \ldots, k-1\}$, as saídas de dados $x(f+i) \mathrm{e}$ $P(f+i)$ são utilizadas como entradas de modelo da iteração $i+1$;

> Como as entradas de modelo $R$ e $H$ dependem, respectivamente, da entrada de dados $z(f+i)$ e da iteração $i$, seus valores são recalculados antes de cada iteração. 
Figura 27 - Utilização Recursiva do Filtro de Kalman da Figura 26 na Determinação de Múltiplas Falhas Futuras de um Componente

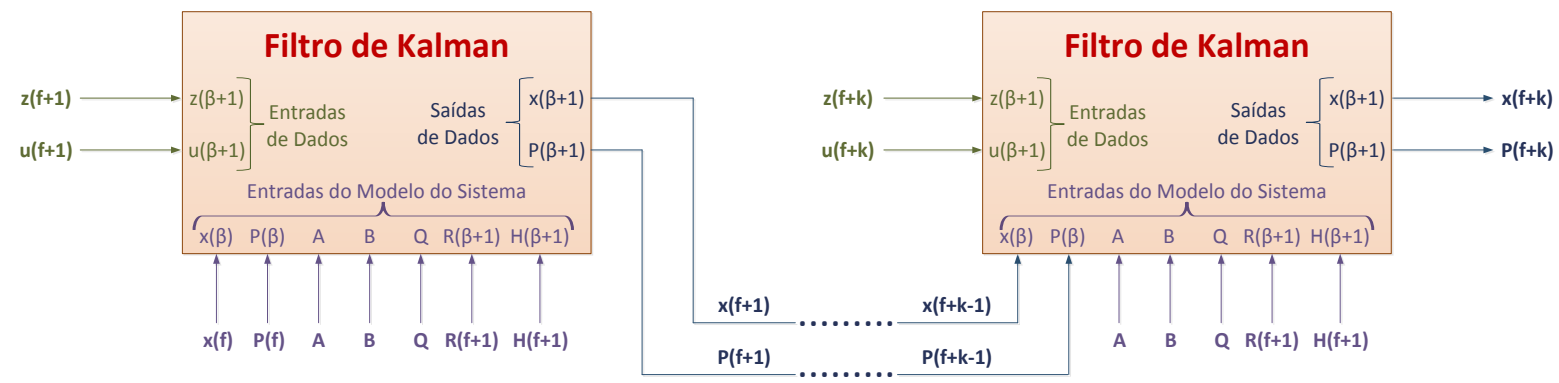

Fonte: Autor

\subsection{Detalhamento das Categorias de Resultados Produzidos Pelo Modelo PROPOSTO}

Considerando-se as descrições apresentadas nas seções anteriores, é possível observar que o modelo proposto no presente estudo produz os seguintes resultados finais acerca do comportamento de um sistema:

a) Computação dos Índices de Dependabilidade do Sistema: $O$ bloco "Cálculos Matemáticos do Modelo de Markov Estendido" é responsável por gerar, de acordo com a natureza do modelo de Markov que the é fornecido como entrada externa, a curva que descreve a evolução de uma das três funções básicas da área de dependabilidade: confiabilidade, disponibilidade ou segurança crítica (safety) até o final do período de tempo durante o qual já foi observado o comportamento do sistema em estudo.

É importante salientar que não pertence ao escopo do modelo proposto no presente estudo deduzir, a partir da análise do perfil e das características do modelo de Markov fornecido como entrada, qual o tipo de índice de dependabilidade que será determinado. Considerando-se que o modelo proposto pode ser implementado por meio de uma ferramenta computacional, e que cabe ao usuário dessa ferramenta projetar e fornecer como entrada o modelo de Markov que representa o comportamento dinâmico do sistema a ser estudado, também fica delegada ao usuário a capacidade de discernir o índice de dependabilidade produzido na saída da ferramenta computacional que implementa o modelo proposto nesta pesquisa. 
Um exemplo de saída gerada pelo bloco "Cálculos Matemáticos do Modelo de Markov Estendido" é apresentado na Figura 28, que simboliza a disponibilidade prevista para um sistema hipotético determinada de forma dependente dos seus dados de histórico operacional e sem predição de comportamento futuro pelo bloco "Detector de Comportamento e Filtro de Kalman".

Figura 28 - Exemplo de Saída da Disponibilidade de um Sistema Gerada pelo Bloco "Cálculos Matemáticos do Modelo de Markov Estendido"

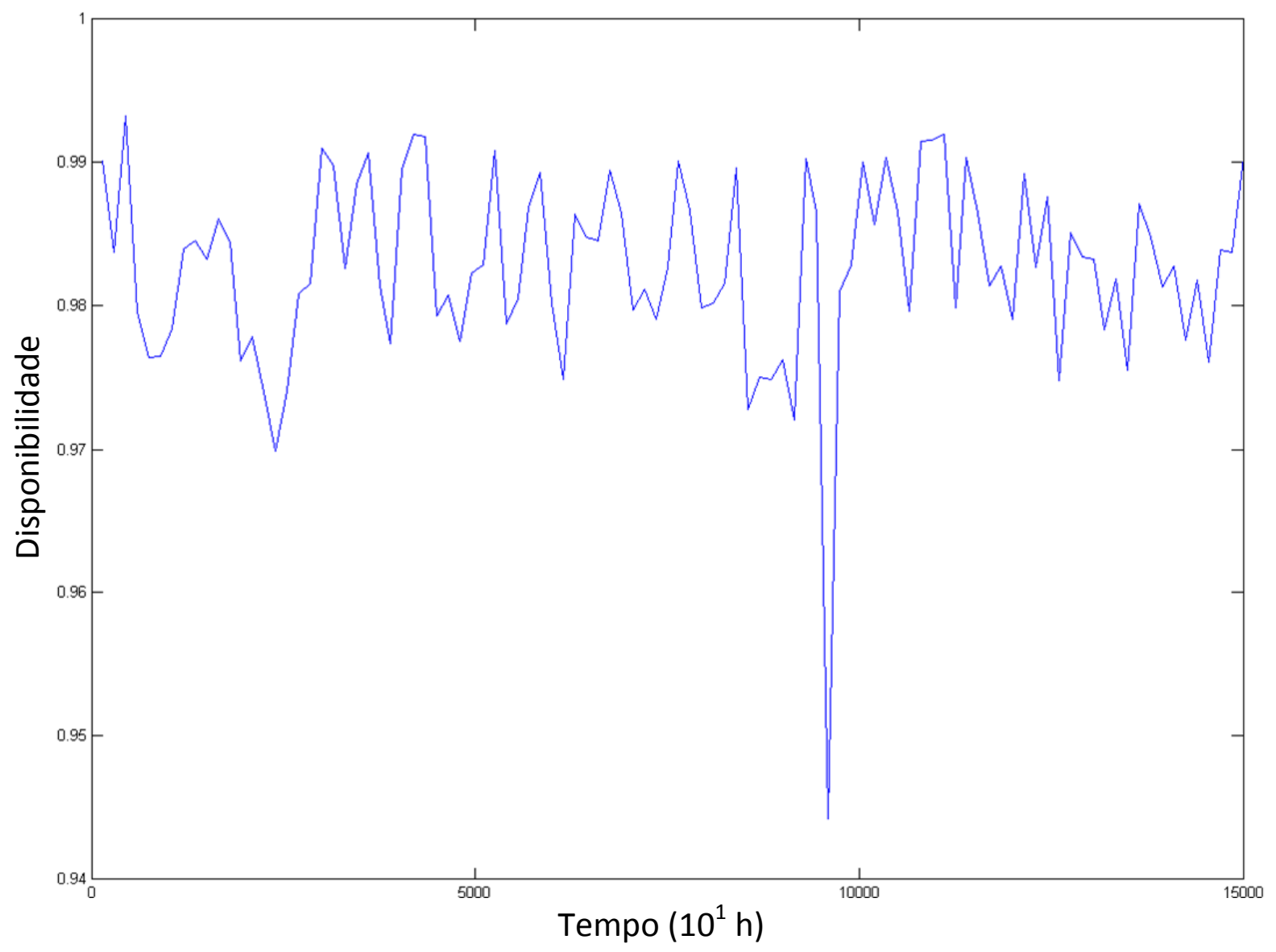

Fonte: Autor

b) Determinação de Previsões das Próximas Falhas dos Componentes do Sistema: O bloco "Detector de Comportamento e Filtro de Kalman" utiliza os registros das falhas de todos os componentes do sistema em estudo (extraídos do Histórico Operacional do sistema) e gera tabelas que contêm as previsões dos instantes de tempo das próximas falhas de cada componente do sistema. Um exemplo dessa saída é apresentado na Tabela 6. 
Tabela 6 - Exemplo de Saída Esperada do Bloco "Detector de Comportamento e Filtro de Kalman" contendo Previsões das Próximas Falhas dos Componentes de um Sistema

\begin{tabular}{|c|c|}
\hline Código do Componente & $\begin{array}{c}\text { Instantes de Tempo das Próximas } \\
\text { Falhas (em horas de operação) }\end{array}$ \\
\hline \multirow{4}{*}{ C1 } & $20595,4 \mathrm{~h}$ \\
\cline { 2 - 2 } & $27291,2 \mathrm{~h}$ \\
\cline { 2 - 2 } & $33196,8 \mathrm{~h}$ \\
\cline { 2 - 2 } & $42024,8 \mathrm{~h}$ \\
\hline \multirow{4}{*}{ C2 } & $49241,1 \mathrm{~h}$ \\
\hline & $23245,2 \mathrm{~h}$ \\
\hline & $30999,5 \mathrm{~h}$ \\
\hline & $39156,7 \mathrm{~h}$ \\
\hline & $48763,9 \mathrm{~h}$ \\
\hline
\end{tabular}

Fonte: Autor

\subsection{Justificativa dos Formalismos Utilizados no Modelo Proposto}

As abordagens de manutenção preditiva propostas nos estudos científicos recentes, abordados na seção 2.1, geralmente demandam a implantação de uma infraestrutura específica para dar suporte à coleta de dados e ao monitoramento dos componentes de um sistema. Dependendo da natureza dos dados operacionais que necessitam ser registrados e monitorados, o custo associado a essa infraestrutura pode ser excessivamente elevado, eventualmente inviabilizando a instalação de um programa de manutenção preditiva, sobretudo nas situações em que a verba disponível para tal programa é restrita (SILVA NETO; CUGNASCA, 2013).

Nos cenários específicos em que se opta pela adoção de um programa de manutenção preditiva quando já existem registros dos instantes de ocorrência das falhas e das manutenções (corretivas e preventivas) dos componentes de um sistema (contidos no bloco "Histórico de Operação do Sistema" da arquitetura da Figura 21), essas informações poderiam ser utilizadas para se tentar predizer quando as próximas falhas de cada componente irão ocorrer. Como essa abordagem não exigiria a implantação de uma infraestrutura dedicada apenas ao monitoramento de características operacionais do sistema, os custos associados à 
instalação de um programa de manutenção preditiva baseado nessa técnica seriam inferiores aos das abordagens usuais.

A utilização combinada de modelos de Markov, regressões polinomiais e filtro de Kalman permite conceber um modelo conceitual aderente à temática proposta neste trabalho por meio do uso de algoritmos computáveis de forma eficiente e a partir de bibliotecas já existentes em plataformas de desenvolvimento de ampla utilização em aplicações práticas, tais como $M A T L A B^{\Theta}$. O ambiente de desenvolvimento e ensaio do modelo proposto neste estudo é explorado com mais detalhes no Capítulo 4.

\subsection{Considerações FinaIS do CaPítulo}

Apresentou-se neste capítulo a visão geral do modelo de previsão de falhas proposto no presente estudo com o propósito de dar suporte à manutenção preditiva de sistemas elétricos, eletrônicos e programáveis. Para tanto, foi inicialmente abordada a arquitetura global do modelo proposto e, a partir desta, cada um dos blocos que compõem o modelo foi detalhado.

O próximo passo a ser abordado consiste em se expor o detalhamento das principais características dos algoritmos e das representações computacionais utilizadas na implementação do modelo proposto no presente estudo. Esses detalhes serão abordados neste trabalho com o intuito de se introduzir o ambiente sobre o qual o modelo será estudado e submetido aos ensaios que visarão validá-lo. 


\section{AMBIENTE DE DESENVOLVIMENTO E ENSAIO DO MODELO PROPOSTO}

O objetivo deste capítulo consiste em apresentar as principais características do ambiente de ensaio utilizado na implementação do modelo proposto e detalhado no Capítulo 3. Para tanto, serão detalhados os algoritmos e as estruturas de dados empregados na implementação, bem como as ferramentas adjuntas desenvolvidas com o propósito de dar suporte aos ensaios e à validação do modelo proposto.

\subsection{Características Principais do Ambiente de Desenvolvimento e Ensaio do MODELO}

O modelo proposto no presente estudo foi desenvolvido utilizando-se a versão R2009a (7.8.0.347) do aplicativo MATLAB ${ }^{\circledR}$. O software que compõe o ambiente de ensaio do modelo proposto pode ser dividido em quatro módulos principais:

a) Módulo "Leitura da Especificação do Sistema": Este módulo é o responsável pela aquisição dos valores nominais das taxas de falhas e de reparos do sistema a ser estudado, bem como do respectivo modelo de Markov que representa seu comportamento com relação ao índice de dependabilidade (confiabilidade, disponibilidade ou segurança crítica - safety) de interesse;

b) Módulo "Simulador de Dados de Entrada": Este módulo é o responsável por gerar, com base na aplicação de métodos estocásticos, registros hipotéticos do histórico de operação de um sistema a partir de suas características constitutivas elementares. O módulo "Simulador de Dados de Entrada" foi desenvolvido para permitir que a ferramenta que implementa o modelo proposto no Capítulo 3 possa ser avaliada independentemente da existência de dados reais de operação de um sistema;

c) Módulo "Tratamento Estatístico e Filtragem Kalman para Predição de Falhas": Este elemento do ambiente de ensaio do modelo é o responsável pela implementação do bloco "Detector de Comportamento e Filtro de Kalman" do modelo representado na Figura 21, cabendo a ele efetuar as predições de comportamento de cada componente do sistema em estudo com 
base nos registros das falhas que ocorreram com cada componente do sistema a partir dos respectivos dados de histórico de operação.

É importante salientar que, como as previsões produzidas pelo módulo "Tratamento Estatístico e Filtragem Kalman para Predição de Falhas" devem ser utilizadas nas estimativas dos índices de dependabilidade do sistema em estudo, as saídas produzidas por ele são realimentadas na forma de entradas para o módulo "Computação de Processos de Markov com Histórico de Operação". É por meio dessa comunicação de dados que as estimativas de predição de comportamento associadas aos índices de dependabilidade do sistema em estudo podem ser calculadas;

d) Módulo "Computação de Processos de Markov com Histórico de Operação": Este fragmento do ambiente de ensaio do modelo é responsável pela implementação dos blocos "Cálculo das Taxas de Falhas e de Reparos condicionadas ao Histórico de Operação" e "Cálculos Matemáticos do Modelo de Markov Estendido", de modo a permitir que as entradas externas referentes ao modelo de Markov do sistema em estudo e ao Histórico de Operação do sistema em estudo possam ser lidas e computadas.

Sob o ponto de vista dinâmico, os quatro módulos de software previamente mencionados são encadeados entre si de tal forma a permitir que o Ambiente de Desenvolvimento e Ensaio opere de forma aderente ao fluxograma da Figura 22, apresentado na seção 3.1. A contextualização dos módulos do Ambiente de Desenvolvimento e Ensaio na dinâmica operacional do fluxograma da Figura 22 é abordada no Diagrama Nassi-Schneiderman da Figura 29. 


\section{Figura 29 - Diagrama Nassi-Schneiderman da Dinâmica Operacional do Ambiente de Desenvolvimento e Ensaio do Modelo}

\begin{tabular}{|c|c|}
\hline \multicolumn{2}{|c|}{ Iniciação do gerador de números pseudoaleatórios do Ambiente de Desenvolvimento e Ensaio. } \\
\hline \multicolumn{2}{|c|}{$\begin{array}{l}\text { Aquisição, por meio do módulo "Leitura da Especificação do Sistema", da especificação do sistema a } \\
\text { ser estudado, do período de tempo } T \text { a ser utilizado na simulação operacional do sistema, do número } \\
\text { de falhas } k \text { a serem previstas para cada componente do sistema e do intervalo de tempo } \Delta t \text { a ser } \\
\text { transcorrido entre iterações da simulação. }\end{array}$} \\
\hline \multicolumn{2}{|c|}{ Iniciação das variáveis internas do módulo "Simulador de Dados de Entrada". } \\
\hline \multicolumn{2}{|c|}{$\begin{array}{l}\text { Geração de dados pseudoaleatórios referentes ao sistema a ser estudado por meio do módulo } \\
\text { "Simulador de Dados de Entrada". }\end{array}$} \\
\hline \multicolumn{2}{|c|}{$\begin{array}{l}\text { Iniciação das variáveis internas do módulo "Computação de Processos de Markov com Histórico de } \\
\text { Operação". }\end{array}$} \\
\hline \multirow{3}{*}{$\begin{array}{l}\text { Laço executado enquanto o } \\
\text { tempo } t \text { Sim transcorrido na } \\
\text { simulação matemática não } \\
\text { atingiu o período } T \text { de } \\
\text { simulação definido para o } \\
\text { estudo. }\end{array}$} & $\begin{array}{l}\text { Atualização, pelo módulo "Cálculos Matemáticos do Modelo de } \\
\text { Markov Estendido", dos valores das taxas de falhas e de reparos } \\
\text { dos componentes do sistema de acordo com os dados de histórico } \\
\text { produzidos pelo módulo "Simulador de Dados de Entrada". }\end{array}$ \\
\hline & $\begin{array}{l}\text { Reavaliação das probabilidades de cada estado do Modelo de } \\
\text { Markov do sistema pelo módulo "Cálculos Matemáticos do Modelo } \\
\text { de Markov Estendido". }\end{array}$ \\
\hline & $t \operatorname{Sim} \leftarrow t \operatorname{Sim}+\Delta t$ \\
\hline \multicolumn{2}{|c|}{$\begin{array}{l}\text { Iniciação das variáveis internas do módulo "Tratamento Estatístico e Filtragem Kalman para Predição } \\
\text { de Falhas". }\end{array}$} \\
\hline \multicolumn{2}{|c|}{$\begin{array}{l}\text { Avaliação do perfil da função matemática que descreva, de forma aproximada, os instantes de tempo } \\
\text { de ocorrência das falhas dos componentes do sistema por meio do módulo "Tratamento Estatístico e } \\
\text { Filtragem Kalman para Predição de Falhas". }\end{array}$} \\
\hline \multicolumn{2}{|c|}{$\begin{array}{l}\text { Determinação, por meio do módulo "Tratamento Estatístico e Filtragem Kalman para Predição de } \\
\text { Falhas", dos instantes de tempo das próximas } k \text { falhas de cada componente do sistema. }\end{array}$} \\
\hline
\end{tabular}

\section{Fonte: Autor}

A partir do diagrama da Figura 29, é possível observar que a operação do Ambiente de Desenvolvimento e Ensaio é introduzida com a iniciação da área de memória utilizada por ele (mediante uso da função clear nativa do $M A T L A B^{\circledR}$ ) e de um gerador de números pseudoaleatórios, utilizado pelo módulo "Simulador de

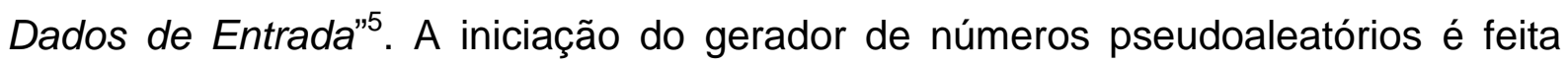
utilizando-se uma semente derivada do horário registrado no relógio do computador em que o Ambiente de Desenvolvimento e Ensaio está instalado.

\footnotetext{
${ }^{5}$ O módulo "Simulador de Dados de Entrada" será detalhado posteriormente, na seção 4.3.
} 
Depois dessa fase preliminar, o módulo "Leitura da Especificação do Sistema" é acionado com o propósito de adquirir, a partir de um arquivo externo, todos os dados necessários para permitir o estudo do sistema por meio do modelo proposto no presente estudo. Embora a relação completa dos dados lidos seja apresentada na seção 4.2, vale ressaltar que o Modelo de Markov do sistema, o período de tempo $T$ a ser utilizado na simulação operacional do sistema, o número de falhas $k$ a serem previstas para cada componente do sistema e o intervalo de tempo $\Delta t$ a ser transcorrido entre iterações da simulação são algumas das entradas coletadas pelo módulo "Leitura da Especificação do Sistema".

Com o término dessa etapa, as variáveis internas utilizadas pelo módulo "Simulador de Dados de Entrada" são iniciadas para que, em seguida, tal módulo seja acionado com o propósito de gerar aleatoriamente eventos de falhas e manutenções de todos os componentes do sistema em estudo durante o período de tempo $T$ a ser utilizado nas simulações. $O$ detalhamento interno do módulo "Simulador de Dados de Entrada" é abordado na seção 4.3.

Ao final da atuação do módulo "Simulador de Dados de Entrada", as variáveis internas utilizadas pelo módulo "Cálculos Matemáticos do Modelo de Markov Estendido" são iniciadas para que, em seguida, comece a execução sequencial das iterações responsáveis por permitir que os índices de dependabilidade do sistema em estudo possam ser calculados mediante utilização dos dados de histórico de operação produzidos pelo "Simulador de Dados de Entrada". Em cada iteração executada, cabe ao módulo "Cálculos Matemáticos do Modelo de Markov Estendido" atualizar os valores das taxas de falhas e de reparos dos componentes do sistema (utilizando o arcabouço matemático apresentado nas seções 2.3.2 e 3.3) e, a partir desses novos valores, estimar as probabilidades de permanência em cada um dos estados do modelo de Markov do sistema por meio dos cálculos apresentados nas seções 2.4.2.2 e 3.4.

A continuidade das iterações de acionamento do módulo "Cálculos Matemáticos do Modelo de Markov Estendido" ocorre enquanto os seguintes critérios forem satisfeitos: 
- A matriz de transições do modelo de Markov mantém a propriedade de semiconvergência, apresentada na seção 2.4.2.2;

- O número de iterações executadas não é suficiente para se atingir o final do período de simulação $T$ definido como entrada do ensaio e adquirido pelo módulo "Leitura da Especificação do Sistema".

Quando um dos critérios prévios deixa de ser respeitado, a utilização do módulo "Cálculos Matemáticos do Modelo de Markov Estendido" é concluída, permitindo que o processo de predição das $k$ próximas falhas dos componentes do sistema em estudo seja disparado. Nessa situação, as variáveis internas utilizadas pelo módulo "Tratamento Estatístico e Filtragem Kalman para Predição de Falhas" são iniciadas para que, em seguida, tal módulo seja acionado.

Para cada componente do sistema, o módulo "Tratamento Estatístico e Filtragem Kalman para Predição de Falhas" determina, a partir dos instantes de tempo das suas falhas (registradas no Histórico de Operação do sistema), a função polinomial de primeiro grau $f(\beta)$ (utilizando, para tanto, o algoritmo apresentado na seção 3.5) e a emprega como base para determinar os instantes de tempo das próximas falhas do componente. $\mathrm{O}$ tratamento estatístico dos valores calculados por intermédio da função aproximadora, também sob responsabilidade do módulo "Tratamento Estatístico e Filtragem Kalman para Predição de Falhas", é realizado por intermédio do Filtro de Kalman definido na seção 3.5.

O detalhamento das características de cada um dos quatro módulos de software do Ambiente de Desenvolvimento e Ensaio é feito nas seções subsequentes deste Capítulo.

\subsection{Detalhamento do Módulo "Leitura da ESPECIFICAÇÃo do SISTEMA"}

O módulo "Leitura da Especificação do Sistema" é o elemento do ambiente de desenvolvimento e ensaio responsável por efetuar a carga da especificação básica do sistema a ser estudado. Essas informações são extraídas de um arquivo externo, que é fornecido ao módulo "Leitura da Especificação do Sistema" como entrada. 
As seguintes informações devem estar presentes no arquivo de especificação encaminhado como entrada do módulo "Leitura da Especificação do Sistema":

- Quantidade $\boldsymbol{n}$ de estados do modelo de Markov do sistema representativo do índice de dependabilidade (confiabilidade, disponibilidade ou segurança crítica - safety) a ser estudado;

- Código numérico (entre 1 e $\boldsymbol{n}$ ) do estado inicial do modelo de Markov do sistema;

- Códigos numéricos (entre 1 e $\boldsymbol{n}$ ) de todos os estados de aceitação do modelo de Markov do sistema;

- Expressões literais das probabilidades de ocorrência de todas as transições do modelo de Markov, expressas em função das taxas de falhas e de reparos de todos os componentes do sistema;

- Tempo de simulação $(T)$ definido para o estudo do sistema;

- Passo de simulação $(\Delta t)$ a ser utilizado na computação do Modelo de Markov do sistema;

- Quantidade de componentes (c) que integram o sistema em estudo;

- Valores numéricos das taxas de falhas e de reparos nominais de cada um dos componentes que integram o sistema em estudo;

- Definição do tipo de cenário (otimista, normal ou pessimista) a ser considerado pelo módulo "Simulador de Dados de Histórico" no processo de geração do histórico de operação hipotético do sistema em estudo ${ }^{6}$

- Quantidade de eventos de falhas futuras $(k)$ a serem previstas para cada componente do sistema.

Para se fornecer flexibilidade ao módulo "Leitura da Especificação do Sistema" minorando-se o esforço associado à sua implementação e maximizando a utilização de bibliotecas nativamente disponibilizadas na versão R2009a (7.8.0.347) do aplicativo MATLAB, optou-se por utilizar planilhas do Microsoft Office Exce ${ }^{\circledR}$ para armazenar os dados de especificação dos sistemas a serem estudados. Tais

\footnotetext{
${ }^{6}$ A descrição dessa característica do módulo "Simulador de Dados de Entrada" será explorada de forma mais detalhada na seção 4.3.
} 
arquivos podem ser acessados pelo MATLAB por meio do uso de sua função xlsread.

\subsection{Detalhamento do Módulo "Simulador de Dados de ENTRADA"}

O módulo "Simulador de Dados de Entrada" é o elemento do ambiente de desenvolvimento do presente estudo científico destinado a gerar, com base na aplicação de técnicas estocásticas, os "Dados de Histórico de Operação" (indicados no diagrama da Figura 21) de um sistema em estudo a partir do conhecimento de suas características básicas de dependabilidade.

Essencialmente, o módulo "Simulador de Dados de Entrada" opera utilizando os seguintes dados iniciais acerca do sistema em estudo, adquiridos pelo módulo "Leitura da Especificação do Sistema":

- Número de componentes do sistema $(c)$;

- Taxas de falhas dos $n$ componentes do sistema $\left(\lambda_{i}, \forall i \in\{1,2, \ldots, c\}\right)$;

- Taxas de reparos dos $n$ componentes do sistema $\left(\mu_{i}, \forall i \in\{1,2, \ldots, c\}\right)$;

- Período de tempo desejado para a operação do sistema $(T)$;

- Indicação do tipo de cenário (otimista, normal ou pessimista) a ser considerado no processo de geração do histórico de operação hipotético do sistema em estudo.

A partir dos dados listados previamente, é de responsabilidade do módulo "Simulador de Dados de Entrada" gerar todos os eventos relevantes à operação do sistema em estudo no que diz respeito à ocorrência de falhas e procedimentos de reparo e substituição de componentes defeituosos. O algoritmo empregado para comandar o funcionamento do módulo "Simulador de Dados de Entrada" é apresentado no Diagrama Nassi-Schneiderman da Figura 30. 
Figura 30 - Diagrama Nassi-Schneiderman do Simulador de Dados de Entrada

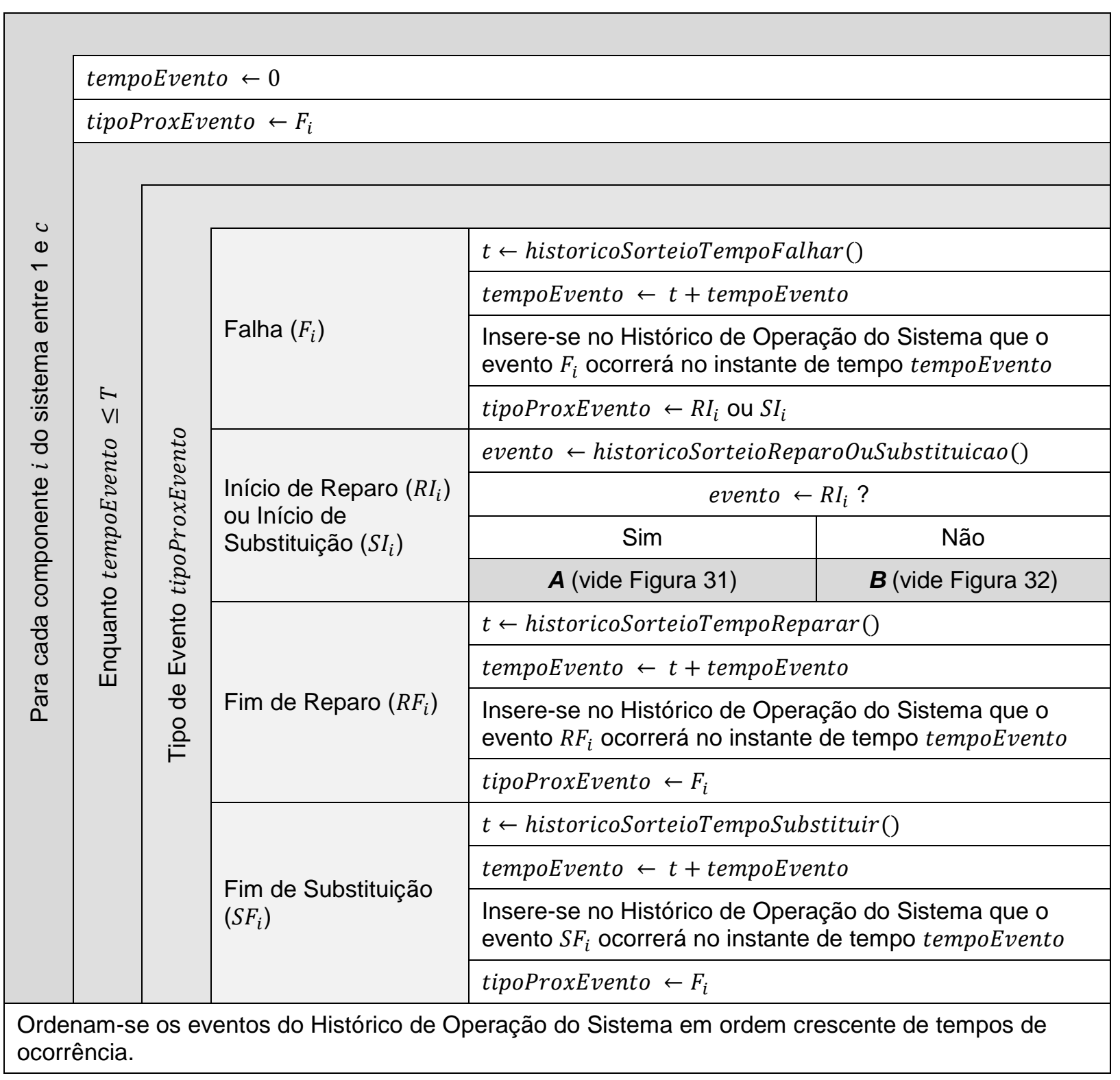

Fonte: Autor 
Figura 31 - Diagrama Nassi-Schneiderman do Bloco "A" da Figura 30

\begin{tabular}{|l|}
\hline \multicolumn{1}{|c|}{ A } \\
\hline$t \leftarrow$ historicoSorteioTempoInicioManut () \\
\hline tempoEvento $\leftarrow t+$ tempoEvento \\
\hline $\begin{array}{l}\text { Insere-se no Histórico de Operação do Sistema que o evento } R I_{i} \text { ocorrerá no instante de tempo } \\
\text { tempoEvento }\end{array}$ \\
\hline tipoProxEvento $\leftarrow R F_{i}$ \\
\hline
\end{tabular}

Fonte: Autor

Figura 32 - Diagrama Nassi-Schneiderman do Bloco "B" da Figura 30

\begin{tabular}{|l|}
\hline \multicolumn{1}{|c|}{ B } \\
\hline$t \leftarrow$ historicoSorteioTempoInicioManut () \\
\hline tempoEvento $\leftarrow t+$ tempoEvento \\
\hline $\begin{array}{l}\text { Insere-se no Histórico de Operação do Sistema que o evento } S I_{i} \text { ocorrerá no instante de tempo } \\
\text { tempoEvento }\end{array}$ \\
\hline tipoProxEvento $\leftarrow S F_{i}$ \\
\hline
\end{tabular}

\section{Fonte: Autor}

Pela Figura 30, é possível notar que o Simulador de Dados de Entrada é responsável por produzir os dados de histórico de operação associados a todos os $n$ componentes do sistema em estudo, desde o instante de tempo inicial em que 0 sistema é acionado (tempoEvento $=0$ ) até o final do intervalo de tempo desejado para a operação do sistema (tempoEvento $=T$ ). Para cada componente, o primeiro tipo de evento a ser gerado corresponde à primeira falha que ocorre imediatamente após a ativação do sistema, motivo pelo qual a variável tipoProxEvento é iniciada com o evento $F_{i}$. Depois da determinação desse primeiro evento, a progressão dos demais eventos que ocorrerão sobre cada componente do sistema é feita de forma aderente ao Diagrama de Transição de Estados apresentado na Figura 23.

O processo de geração de um evento de ocorrência de falha $\left(F_{i}\right)$ sobre um componente do sistema em estudo pode ser descrito pelas etapas subsequentes:

a) Inicialmente, se determina um tempo pseudoaleatório para a ocorrência da falha a partir da taxa de falhas nominal do componente. Essa funcionalidade foi simbolizada na Figura 30 pela função historicoSorteioTempoFalhar(), que disponibiliza o intervalo de tempo transcorrido desde o último evento 
associado ao i-ésimo componente (ativação do sistema, fim de reparo ou fim de manutenção) até a ocorrência de sua nova falha. Maiores detalhes sobre a função historicoSorteioTempoFalhar() são apresentados na seção 4.3.1;

b) Atualiza-se o tempo do evento corrente, presente na variável tempoEvento, mediante soma de seu valor anterior com o tempo calculado no item a);

c) Insere-se no Histórico de Operação do sistema o evento de falha $F_{i}$ ocorrente no instante de tempo recém-atualizado na variável tempoEvento;

d) Por fim, informa-se, na variável tipoProxEvento, que o próximo tipo de evento a ser gerado sobre o i-ésimo componente do sistema deve ser dos tipos $R I_{i}$ ou $S I_{i}$.

Para se gerar eventos de Início de Reparo $\left(R I_{i}\right)$ ou de Início de Substituição $\left(S I_{i}\right)$ relacionados ao i-ésimo componente do sistema em estudo, é prevista a execução dos seguintes passos:

a) Inicialmente, é necessário determinar o tipo de procedimento de manutenção que será executado sobre o i-ésimo componente do sistema (reparo ou substituição). Essa decisão é computada pela função historicoSorteioReparoOuSubstituicao(), que disponibiliza como saída a indicação $R I_{i}$ ou $S I_{i}$ correspondente ao evento sorteado. Maiores detalhes sobre a função historicoSorteioReparoOuSubstituicao() são apresentados na seção 4.3.2;

b) Independentemente do tipo de evento escolhido, a etapa seguinte consiste em se determinar o intervalo de tempo transcorrido entre a manifestação efetiva da falha e o início do procedimento de manutenção. Esse intervalo de tempo, que pode ser entendido como o período necessário para se detectar a falha e mobilizar a equipe de manutenção necessária para corrigi-la, é determinado pela função historicoSorteioTempoInicioManut(), que efetua os cálculos necessários a partir da taxa de reparos nominal associada ao componente. Maiores detalhes sobre essa função são explorados na seção 4.3.3;

c) Atualiza-se o tempo do evento corrente, presente na variável tempoEvento, mediante soma de seu valor anterior com o tempo calculado no item b); 
d) Insere-se no Histórico de Operação do sistema o evento sorteado $\left(R I_{i}\right.$ ou $\left.S I_{i}\right)$ ocorrente no instante de tempo recém-atualizado na variável tempoEvento;

e) Por fim, informa-se, na variável tipoProxEvento, qual deve ser o próximo tipo de evento a ser gerado sobre o i-ésimo componente do sistema. Se o evento escolhido no item a) foi $R I_{i}$, o próximo evento deve ser $R F_{i}$, ao passo que se o evento escolhido no item a) foi $S I_{i}$, o próximo evento deve ser $S F_{i}$.

O processo de geração de eventos de Fim de Reparo $\left(R F_{i}\right)$, por sua vez, é composto pelas seguintes etapas:

a) Inicialmente, é determinado um tempo pseudoaleatório para o término do procedimento de reparo a partir da taxa de reparos nominal do componente. Essa funcionalidade é desempenhada pela função historicoSorteioTempoReparar(), que computa o intervalo de tempo compreendido entre o último evento $R I_{i}$ associado ao componente e a ocorrência do final de seu reparo. Maiores detalhes sobre a função historicoSorteioTempoReparar() são apresentados na seção 4.3.4;

b) Atualiza-se o tempo do evento corrente, presente na variável tempoEvento, mediante soma de seu valor anterior com o tempo calculado no item a);

c) Insere-se no Histórico de Operação do sistema o evento de falha $R F_{i}$ ocorrente no instante de tempo recém-atualizado na variável tempoEvento;

d) Por fim, informa-se, na variável tipoProxEvento, que o próximo tipo de evento a ser gerado sobre o i-ésimo componente do sistema deve ser do tipo $F_{i}$ (associado à ocorrência de uma nova falha do componente).

O processo de geração de eventos de Fim de Substituição $\left(S F_{i}\right)$ segue uma sequência de passos análoga à apresentada anteriormente para os eventos de Fim de Reparo $\left(R F_{i}\right)$ :

a) Inicialmente, é determinado um tempo pseudoaleatório para o término do procedimento de reparo a partir da taxa de reparos nominal do componente. Essa funcionalidade é desempenhada pela função historicoSorteioTempoSubstituir(), que computa o intervalo de tempo compreendido entre o último evento $S I_{i}$ associado ao componente e a 
ocorrência do final de sua substituição. Maiores detalhes sobre a função historicoSorteioTempoSubstituir () são apresentados na seção 4.3.5;

b) Atualiza-se o tempo do evento corrente, presente na variável tempoEvento, mediante soma de seu valor anterior com o tempo calculado no item a);

c) Insere-se no Histórico de Operação do sistema o evento de falha $S F_{i}$ ocorrente no instante de tempo recém-atualizado na variável tempoEvento;

d) Por fim, informa-se, na variável tipoProxEvento, que o próximo tipo de evento a ser gerado sobre o i-ésimo componente do sistema deve ser do tipo $F_{i}$ (associado à ocorrência de uma nova falha do componente).

Ao final da geração dos eventos de Histórico de Operação para todos os componentes do sistema em estudo, o memorial de dados de Histórico é ordenado de tal forma que todos os eventos estejam apresentados em ordem crescente de tempo de ocorrência. Essa etapa é executada com o propósito de melhorar o desempenho do Software de Computação de Processos de Markov com Histórico de Operação, que utiliza o Histórico de Operação recém-gerado como entrada.

\subsubsection{Detalhamento da Função historicoSorteioTempoFalhar()}

Conforme apresentado na seção 4.3, a função historicoSorteioTempoFalhar() é responsável por computar o período de tempo transcorrido desde o último evento associado ao i-ésimo componente (ativação do sistema, fim de reparo ou fim de manutenção) até a ocorrência de sua nova falha). Para tanto, a função historicoSorteioTempoFalhar() foi desenvolvida com base no algoritmo ilustrado no Diagrama Nassi-Schneiderman da Figura 33. 
Figura 33 - Diagrama Nassi-Schneiderman da Função historicoSorteioTempoFalhar()

\begin{tabular}{|c|c|c|}
\hline \multirow{3}{*}{ 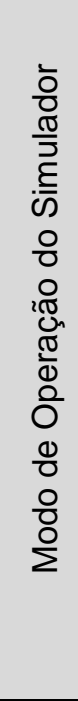 } & Otimista & $\begin{array}{l}\text { Em um cenário de ensaio otimista, define-se que há uma } \\
\text { probabilidade de } 70 \% \text { de a falha de um componente se manifestar } \\
\text { mais lentamente do que o valor nominal determinado pelo MTTF do } \\
\text { componente. } \\
\text { probPos } \leftarrow 0,7\end{array}$ \\
\hline & Normal & $\begin{array}{l}\text { Em um cenário de simulação normal, define-se que há uma } \\
\text { probabilidade de } 50 \% \text { de a falha de um componente se manifestar } \\
\text { mais lentamente do que o valor nominal determinado pelo MTTF do } \\
\text { componente. } \\
\text { probPos } \leftarrow 0,5\end{array}$ \\
\hline & Pessimista & $\begin{array}{l}\text { Em um cenário de simulação pessimista, define-se que há uma } \\
\text { probabilidade de } 10 \% \text { de a falha de um componente se manifestar } \\
\text { mais lentamente do que o valor nominal determinado pelo MTTF do } \\
\text { componente. } \\
\text { probPos } \leftarrow 0,1\end{array}$ \\
\hline \multicolumn{3}{|c|}{ num $\leftarrow$ Número aleatório uniformemente distribuído no intervalo $[0 ; 1]$} \\
\hline \multirow{2}{*}{ 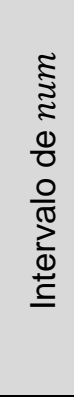 } & num $\in[0 ;$ probPos [ & $\begin{array}{l}\text { A variação do tempo da falha simulada será positiva, isto é, a falha } \\
\text { demorará mais tempo para ocorrer do que o valor nominal } \\
\text { determinado pelo MTTF do componente. } \\
\text { sinal } \leftarrow 1\end{array}$ \\
\hline & num $\in[$ probPos; 1$]$ & $\begin{array}{l}\text { A variação do tempo da falha simulada será negativa, isto é, a falha } \\
\text { demorará menos tempo para ocorrer do que o valor nominal } \\
\text { determinado pelo MTTF do componente. } \\
\text { sinal } \leftarrow-1\end{array}$ \\
\hline \multicolumn{3}{|r|}{$\boldsymbol{A}$ (vide Figura 34) } \\
\hline \multicolumn{3}{|c|}{ num $2 \leftarrow$ Número aleatório uniformemente distribuído no intervalo $[0 ; 1]$} \\
\hline \multicolumn{3}{|c|}{ B (vide Figura 35) } \\
\hline \multicolumn{3}{|c|}{ tempoNominalFalha $\leftarrow \frac{1}{\text { taxa de falhas do componente }}$} \\
\hline \multicolumn{3}{|c|}{$\begin{array}{l}\text { variacaoFalha } \leftarrow \text { sinal } * \quad \text { Número aleatório uniformemente distribuído } \\
\text { [tempoNominalFalha } * \text { fatorMult } 1 ; \text { tempoNominalFalha } * \text { fatorMult } 2]\end{array}$} \\
\hline \multicolumn{3}{|c|}{ tempoFalha $\leftarrow$ tempoNominalFalha + variacaoFalha } \\
\hline
\end{tabular}

Fonte: Autor 
Figura 34 - Diagrama Nassi-Schneiderman do Bloco "A" da Figura 33

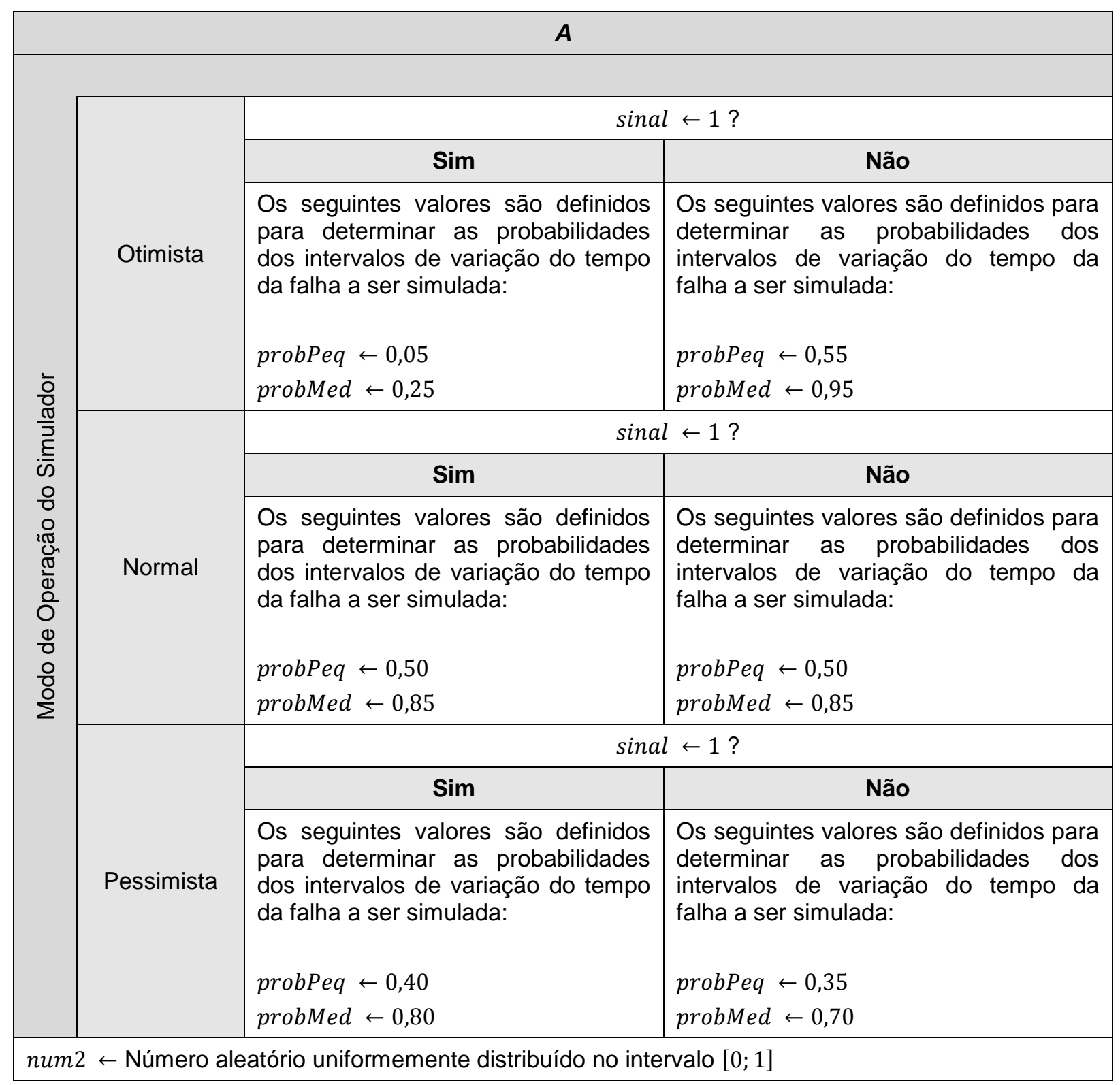

Fonte: Autor 
Figura 35 - Diagrama Nassi-Schneiderman do Bloco "B" da Figura 33

\begin{tabular}{|c|c|c|}
\hline & & $B$ \\
\hline \multirow{3}{*}{ 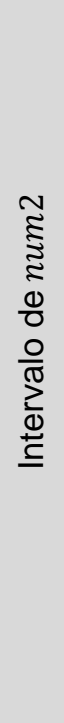 } & num $2 \in[0 ;$ probPeq [ & $\begin{array}{l}\text { A falha simulada apresentará pequeno desvio (de } 0 \% \text { a } \\
25 \% \text { do valor nominal determinado pelo MTTF do } \\
\text { componente. } \\
\text { fatorMult } 1 \leftarrow 0 \\
\text { fatorMult } 2 \leftarrow 0,25\end{array}$ \\
\hline & num $2 \in$ [probPeq;probMed [ & $\begin{array}{l}\text { A falha simulada apresentará médio desvio (de } 25 \% \text { a } \\
60 \% \text { do valor nominal determinado pelo MTTF do } \\
\text { componente. } \\
\text { fatorMult } 1 \leftarrow 0,25 \\
\text { fatorMult } 2 \leftarrow 0,6\end{array}$ \\
\hline & num $2 \in[$ probMed; 1$]$ & $\begin{array}{l}\text { A falha simulada apresentará grande desvio (de } 60 \% \text { a } \\
100 \% \text { ) do valor nominal determinado pelo MTTF do } \\
\text { componente. } \\
\text { fatorMult } 1 \leftarrow 0,6 \\
\text { fatorMult } 2 \leftarrow 1\end{array}$ \\
\hline
\end{tabular}

Fonte: Autor

A partir do diagrama da Figura 33, é possível verificar que a determinação do intervalo de tempo entre o último evento associado ao i-ésimo componente do sistema e a ocorrência de sua nova falha é feita com base na aplicação da Técnica da Roleta (Roulette Wheel Technique). Essa técnica estocástica prevê que a coleta de amostras de membros de uma população de interesse é feita por meio de sorteios sucessivos de números pseudoaleatórios uniformemente distribuídos.

O primeiro número aleatório sorteado (num) é utilizado com o intuito de se avaliar se a variação do tempo determinado para a falha com relação ao tempo nominal, expresso pelo MTTF associado ao componente, será positiva ou negativa. A regra considerada na proposta feita no presente estudo foi a seguinte:

- Para valores de num pertencentes ao intervalo [0; $\operatorname{probPos}[$, a variação no tempo nominal de falha do componente será positiva, isto é, o componente demorará mais que o tempo nominal, expresso por seu MTTF, para manifestar uma falha. Esse cenário ocorre com uma probabilidade igual a probPos;

- Para valores de num pertencentes ao intervalo [probPos; 1], a variação no tempo nominal de falha do componente será negativa, isto é, o componente 
demorará menos que o tempo nominal, expresso por seu MTTF, para manifestar uma falha. Esse cenário ocorre com uma probabilidade igual a $(1-$ probPos $)$.

Nas definições apresentadas anteriormente, o parâmetro probPos é definido com base no cenário de simulação a ser considerado no ensaio (otimista, normal ou pessimista). Os valores assumidos por probPos e as probabilidades de variação positiva e negativa dos tempos de ocorrência de falhas nos três possíveis cenários de simulação (otimista, normal e pessimista) são apresentados na Tabela 7.

Tabela 7 - Relação de Valores de probPos e das Probabilidades do Sinal da Variação dos Intervalos de Tempo para a Ocorrência de Falhas de Componentes

\begin{tabular}{|c|c|c|c|}
\hline \multirow{2}{*}{$\begin{array}{c}\text { Cenário de } \\
\text { Simulação }\end{array}$} & \multirow{2}{*}{$\begin{array}{c}\text { Valor de } \\
\text { probPos }\end{array}$} & \multicolumn{2}{|c|}{$\begin{array}{c}\text { Probabilidades de Variação dos Intervalos de Tempo } \\
\text { para Falhar }\end{array}$} \\
\cline { 3 - 4 } & & $\begin{array}{c}\text { Variação Positiva } \\
P_{F}(+)\end{array}$ & $\begin{array}{c}\text { Variação Negativa } \\
P_{F}(-)\end{array}$ \\
\hline Otimista & 0,70 & $70 \%$ & $30 \%$ \\
\hline Normal & 0,50 & $50 \%$ & $50 \%$ \\
\hline Pessimista & 0,10 & $10 \%$ & $90 \%$ \\
\hline
\end{tabular}

Fonte: Autor

O valor absoluto da variação do tempo de falha de um componente com relação ao seu valor nominal, expresso pelo MTTF associado a ele, é determinado com auxílio de um segundo número pseudoaleatório, denominado num2. A regra aplicada nesse caso é a seguinte:

- Para valores de num2 pertencentes ao intervalo [0; probPeq[, haverá uma variação pequena (de $0 \%$ a $25 \%$ ) no tempo nominal de falha do componente. Esse cenário ocorre com uma probabilidade igual a probPeq;

- Para valores de num2 pertencentes ao intervalo [probPeq; probMed[, haverá uma variação média (de $25 \%$ a $60 \%$ ) no tempo nominal de falha do componente. Esse cenário ocorre com uma probabilidade igual a (probMed probPeq);

- Para valores de num2 pertencentes ao intervalo [probMed; 1], haverá uma variação grande (de $60 \%$ a $100 \%$ ) no tempo nominal de falha do componente. Esse cenário ocorre com uma probabilidade igual a $(1-$ probMed $)$. 
Nas definições apresentadas anteriormente, os parâmetros probPeq e probMed são definidos com base no cenário de simulação a ser considerado no ensaio (otimista, normal ou pessimista) e no sinal da variação (positivo ou negativo), determinado na etapa anterior. Os valores assumidos por probPeq e probMed, bem como as probabilidades de variação pequena, média e grande dos tempos de ocorrência de falhas nos três possíveis cenários de simulação (otimista, normal e pessimista) são apresentados na Tabela 8 (para variação positiva do tempo para falhar) e na Tabela 9 (para variação negativa do tempo para falhar).

Tabela 8 - Relação de Valores de probPeq, probMed e das Probabilidades de Variação Positiva dos Intervalos de Tempo para a Ocorrência de Falhas de Componentes

\begin{tabular}{|c|c|c|c|c|c|}
\hline \multirow{2}{*}{$\begin{array}{c}\text { Cenário de } \\
\text { Simulação }\end{array}$} & \multirow{2}{*}{$\begin{array}{c}\text { Valor de } \\
\text { probPeq }\end{array}$} & $\begin{array}{c}\text { Valor de } \\
\text { probMed }\end{array}$ & \multicolumn{3}{|c|}{$\begin{array}{c}\text { Probabilidades de Variação Positiva dos } \\
\text { Intervalos de Tempo para Falhar }\end{array}$} \\
\cline { 4 - 6 } & & $\begin{array}{c}\text { Variação } \\
\text { Pequena } \\
P_{F}(P \mid+)\end{array}$ & $\begin{array}{c}\text { Variação } \\
\text { Média } \\
P_{F}(M \mid+)\end{array}$ & $\begin{array}{c}\text { Variação } \\
\text { Grande } \\
P_{F}(G \mid+)\end{array}$ \\
\hline Otimista & 0,05 & 0,25 & $5 \%$ & $20 \%$ & $75 \%$ \\
\hline Normal & 0,50 & 0,85 & $50 \%$ & $35 \%$ & $15 \%$ \\
\hline Pessimista & 0,65 & 0,95 & $65 \%$ & $30 \%$ & $5 \%$ \\
\hline
\end{tabular}

Fonte: Autor

Tabela 9 - Relação de Valores de probPeq, probMed e das Probabilidades de Variação Negativa dos Intervalos de Tempo para a Ocorrência de Falhas de Componentes

\begin{tabular}{|c|c|c|c|c|c|}
\hline \multirow{2}{*}{$\begin{array}{c}\text { Cenário de } \\
\text { Simulação }\end{array}$} & \multirow{2}{*}{$\begin{array}{c}\text { Valor de } \\
\text { probPeq }\end{array}$} & \multirow{2}{*}{$\begin{array}{c}\text { Valor de } \\
\text { probMed }\end{array}$} & \multicolumn{3}{|c|}{$\begin{array}{c}\text { Probabilidades de Variação Negativa dos } \\
\text { Intervalos de Tempo para Falhar }\end{array}$} \\
\cline { 4 - 6 } & & $\begin{array}{c}\text { Variação } \\
\text { Pequena } \\
P_{F}(P \mid-)\end{array}$ & $\begin{array}{c}\text { Variação } \\
\text { Média } \\
P_{F}(M \mid-)\end{array}$ & $\begin{array}{c}\text { Variação } \\
\text { Grande } \\
P_{F}(G \mid-)\end{array}$ \\
\hline Otimista & 0,55 & 0,95 & $55 \%$ & $40 \%$ & $5 \%$ \\
\hline Normal & 0,50 & 0,85 & $50 \%$ & $35 \%$ & $15 \%$ \\
\hline Pessimista & 0,35 & 0,70 & $35 \%$ & $35 \%$ & $30 \%$ \\
\hline
\end{tabular}

Fonte: Autor

As probabilidades definidas na Tabela 7 , na Tabela 8 e na Tabela 9 podem ser combinadas para se calcular, nos três cenários possíveis de ensaio (otimista, normal e pessimista), as seguintes probabilidades: 
a) Probabilidade de Variação Positiva de Pequeno Desvio do Tempo para Falhar com Relação ao MTTF Nominal $\left(P_{F}(P \cap+)\right)$ : Para um dado cenário de simulação (otimista, normal ou pessimista), a probabilidade $P_{F}(P \cap+)$ é expressa pelo produto da probabilidade $P_{F}(+)$ de ocorrência de variação positiva do cenário (apresentada na Tabela 7) com a probabilidade condicional $P_{F}(P \mid+)$ de ocorrência de variação pequena do cenário dado que a variação é positiva (apresentada na Tabela 8 );

b) Probabilidade de Variação Positiva de Médio Desvio do Tempo para Falhar com Relação ao MTTF Nominal $\left(P_{F}(M \cap+)\right)$ : Para um dado cenário de simulação (otimista, normal ou pessimista), a probabilidade $P_{F}(M \cap+)$ é expressa pelo produto da probabilidade $P_{F}(+)$ de ocorrência de variação positiva do cenário (apresentada na Tabela 7) com a probabilidade condicional $P_{F}(M \mid+)$ de ocorrência de variação média do cenário dado que a variação é positiva (apresentada na Tabela 8);

c) Probabilidade de Variação Positiva de Grande Desvio do Tempo para Falhar com Relação ao MTTF Nominal $\left(P_{F}(G \cap+)\right)$ : Para um dado cenário de simulação (otimista, normal ou pessimista), a probabilidade $P_{F}(G \cap+)$ é expressa pelo produto da probabilidade $P_{F}(+)$ de ocorrência de variação positiva do cenário (apresentada na Tabela 7) com a probabilidade condicional $P_{F}(G \mid+)$ de ocorrência de variação grande do cenário dado que a variação é positiva (apresentada na Tabela 8);

d) Probabilidade de Variação Negativa de Pequeno Desvio do Tempo para Falhar com Relação ao MTTF Nominal $\left(P_{F}(P \cap-)\right)$ : Para um dado cenário de simulação (otimista, normal ou pessimista), a probabilidade $P_{F}(P \cap-)$ é expressa pelo produto da probabilidade $P_{F}(-)$ de ocorrência de variação negativa do cenário (apresentada na Tabela 7) com a probabilidade condicional $P_{F}(P \mid-)$ de ocorrência de variação pequena do cenário dado que a variação é negativa (apresentada na Tabela 9);

e) Probabilidade de Variação Negativa de Médio Desvio do Tempo para Falhar com Relação ao MTTF Nominal $\left(P_{F}(M \cap-)\right)$ : Para um dado cenário de simulação (otimista, normal ou pessimista), a probabilidade $P_{F}(M \cap-$ ) é expressa pelo produto da probabilidade $P_{F}(-)$ de ocorrência de variação negativa do cenário (apresentada na Tabela 7) com a probabilidade 
condicional $P_{F}(M \mid-)$ de ocorrência de variação média do cenário dado que a variação é negativa (apresentada na Tabela 9 );

f) Probabilidade de Variação Negativa de Grande Desvio do Tempo para Falhar com Relação ao MTTF Nominal $\left(P_{F}(G \cap-)\right)$ : Para um dado cenário de simulação (otimista, normal ou pessimista), a probabilidade $P_{F}(G \cap-)$ é expressa pelo produto da probabilidade $P_{F}(-)$ de ocorrência de variação negativa do cenário (apresentada na Tabela 7) com a probabilidade condicional $P_{F}(G \mid-)$ de ocorrência de variação grande do cenário dado que a variação é negativa (apresentada na Tabela 9).

Os valores das probabilidades definidas nos itens "a)" a "f)" anteriores para os três cenários possíveis de ensaio (otimista, normal e pessimista) utilizados pelo módulo "Simulador de Dados de Entrada" estão relacionados na Tabela 10. Um aspecto que deve ser ressaltado é que, como os eventos utilizados para determinar as probabilidades $P_{F}(P \cap+), \quad P_{F}(M \cap+), \quad P_{F}(G \cap+), \quad P_{F}(P \cap-), \quad P_{F}(M \cap-)$ e $P_{F}(G \cap-)$ são complementares entre si, a soma das probabilidades prévias resulta em $1(100 \%)$ independentemente do cenário configurado no módulo "Simulador de Dados de Entrada".

Tabela 10 - Relação das Probabilidades de Todas as Combinações de Sinal e Valor Absoluto da Variação do Intervalo de Tempo para a Ocorrência de Falhas de Componentes

\begin{tabular}{|c|c|c|c|}
\hline \multirow{2}{*}{ Probabilidade } & \multicolumn{3}{|c|}{ Categoria de Cenário de Simulação } \\
\cline { 2 - 4 } & Otimista & Normal & Pessimista \\
\hline$P_{F}(P \cap+)$ & $3,5 \%$ & $25,0 \%$ & $6,5 \%$ \\
\hline$P_{F}(M \cap+)$ & $14,0 \%$ & $17,5 \%$ & $3,0 \%$ \\
\hline$P_{F}(G \cap+)$ & $52,5 \%$ & $7,5 \%$ & $0,5 \%$ \\
\hline$P_{F}(P \cap-)$ & $16,5 \%$ & $25,0 \%$ & $31,5 \%$ \\
\hline$P_{F}(M \cap-)$ & $12,0 \%$ & $17,5 \%$ & $31,5 \%$ \\
\hline$P_{F}(G \cap-)$ & $1,5 \%$ & $7,5 \%$ & $27,0 \%$ \\
\hline
\end{tabular}

Fonte: Autor

A partir das probabilidades relacionadas na Tabela 10, verifica-se que a lógica da função historicoSorteioTempoFalhar () foi desenvolvida de tal forma a priorizar, em simulações comportamentais otimistas, que as falhas de um componente do sistema em estudo ocorrerão após o transcurso de um intervalo de tempo 
significativamente maior do que o MTTF nominal estabelecido para o elemento sob avaliação. Dessa maneira, considerando-se que o módulo "Simulador de Dados de Entrada" seja configurado para gerar registros de histórico de operação do sistema em estudo representativos de seu funcionamento durante um período de tempo $T$, é esperado que os períodos de tempo durante os quais os componentes do sistema operam ser falhar em um cenário otimista sejam superiores aos observados em situações normais e pessimistas.

Analogamente, a relação de probabilidades exposta na Tabela 10 permite inferir que, em simulações comportamentais pessimistas, é mais provável que haja proeminência de que as falhas de um componente do sistema em estudo ocorrerão após o transcurso de um intervalo de tempo inferior ao MTTF nominal definido para o elemento sob avaliação. Por esse motivo, é esperado que os registros de histórico de operação produzidos pelo módulo "Simulador de Dados de Entrada" em cenários pessimistas de funcionamento do sistema em estudo indiquem que os períodos de tempo durante os quais os seus componentes operam sem falhar sejam inferiores aos gerados em situações otimistas e normais.

Por fim, uma vez conhecidos os dois parâmetros da variação do tempo para falhar (faixa de variação do valor absoluto e sinal da variação), o intervalo de tempo a ser transcorrido para a falha do componente desde o instante de ocorrência de seu último evento é determinado por meio da soma da variação do tempo para falhar com o MTTF (inverso da taxa de falhas nominal, conforme definido na equação (3)). A variação efetiva do tempo para falhar possui o sinal obtido com auxílio de num e o valor absoluto de um número pseudoaleatório sorteado com base em uma distribuição probabilística uniforme dentro da faixa de variação delimitada pelos fatores multiplicativos do MTTF nominal calculados com base em num2.

\subsubsection{Detalhamento da Função historicoSorteioReparoOuSubstituicao()}

Conforme abordado na seção 4.3, a função historicoSorteioReparoOuSubstituicao() é responsável por determinar se um evento de manutenção a ser desempenhado sobre um componente do sistema em estudo deve ser um procedimento de reparo ou uma operação de substituição do componente falho. Para tanto, a função historicoSorteioReparoOuSubstituicao() 
utiliza em seus cálculos internos as informações de histórico de operação já acumuladas a respeito do componente em avaliação e a sua respectiva taxa de falhas nominal.

O algoritmo aplicado na função historicoSorteioReparoOuSubstituicao() do Simulador de Dados de Entrada é apresentado com auxílio do Diagrama NassiSchneiderman da Figura 36.

Figura 36 - Diagrama Nassi-Schneiderman da Função historicoSorteioReparoOuSubstituicao()

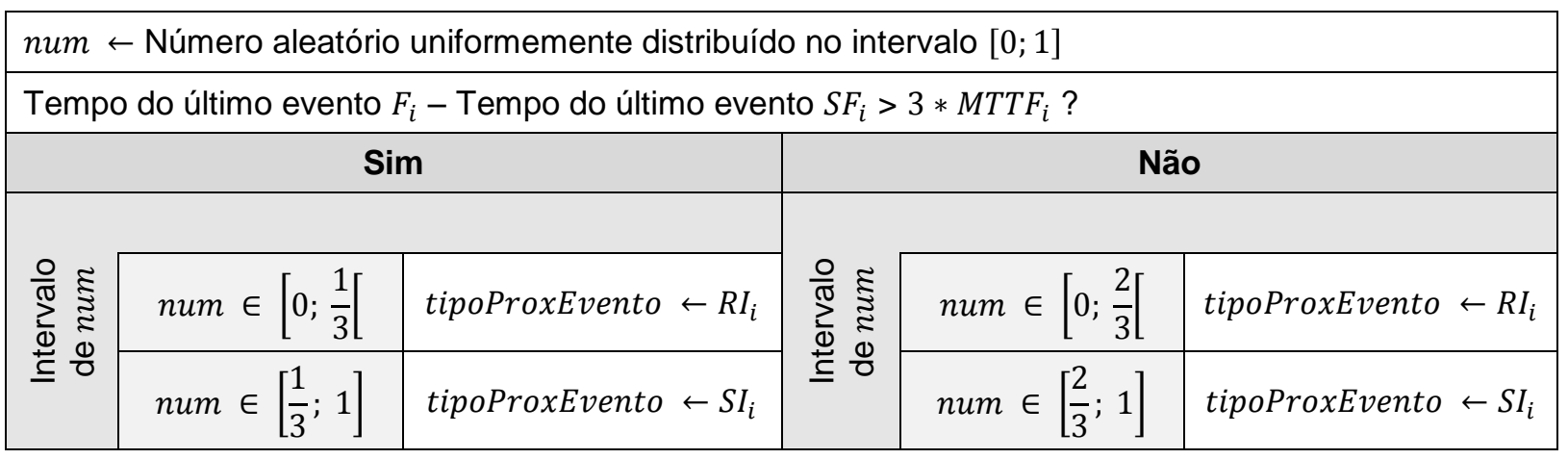

Fonte: Autor

Por intermédio do diagrama da Figura 36, é possível verificar que o algoritmo da função historicoSorteioReparoOuSubstituicao() está baseado no sorteio de um

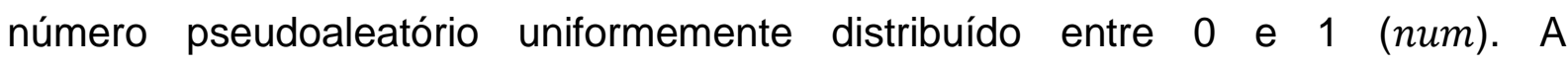
interpretação dada a esse número, feita aplicando-se a Técnica da Roleta, depende de uma verificação numérica que compreende os tempos de ocorrência dos últimos eventos $F_{i}$ e $S F_{i}$ associados ao componente e o valor nominal do seu MTTF.

A ideia que embasa essa avaliação é a de que, com o envelhecimento do componente, a substituição de um dispositivo defeituoso por outro equivalente a ele tende a tornar-se mais efetiva do que eventuais procedimentos de reparo corretivo. Por esse motivo, considera-se que, independentemente de eventuais reparos corretivos executados, a substituição de um componente torna-se mais provável à medida que o tempo transcorrido desde a sua instalação inicial ou desde a sua última substituição aumenta. No caso particular do algoritmo da função historicoSorteioReparoOuSubstituicao(), o critério empregado é o de que a probabilidade de ocorrência de uma substituição torna-se maior quando o tempo 
compreendido desde a instalação inicial do componente ou desde a sua última substituição até o seu último registro de falha for superior ao triplo do MTTF nominal.

Se essa condição for satisfeita, utiliza-se a seguinte regra para se definir qual deve ser o próximo evento de início de manutenção do componente:

- Para valores de num pertencentes ao intervalo [0;1/3[, define-se que o próximo evento associado ao i-ésimo componente do sistema em estudo é o Início de um Reparo $\left(R I_{i}\right)$. Essa decisão será tomada com uma probabilidade de $33,33 \%$;

- Para valores de num pertencentes ao intervalo $[1 / 3,1]$, define-se que o próximo evento associado ao i-ésimo componente do sistema em estudo é o Início de uma Substituição $\left(S I_{i}\right)$. Essa decisão será tomada com uma probabilidade de $66,67 \%$.

Caso não se satisfaça a condição de o tempo compreendido entre a última falha do componente e a sua última substituição ser superior ao triplo do MTTF nominal, invertem-se as probabilidades de ocorrência dos eventos $R I_{i}$ e $S I_{i}$ :

- Para valores de num pertencentes ao intervalo [0;2/3[, define-se que o próximo evento associado ao i-ésimo componente do sistema em estudo é o Início de um Reparo $\left(R I_{i}\right)$. Essa decisão será tomada com uma probabilidade de $66,67 \%$;

- Para valores de num pertencentes ao intervalo $[2 / 3,1]$, define-se que o próximo evento associado ao i-ésimo componente do sistema em estudo é o Início de uma Substituição $\left(S I_{i}\right)$. Essa decisão será tomada com uma probabilidade de $33,33 \%$.

\subsubsection{Detalhamento da Função historicoSorteioTempoInicioManut()}

Conforme tratado na seção 4.3, cabe à função historicoSorteioTempoInicioManut() determinar o intervalo de tempo transcorrido desde a detecção da falha de um componente (simbolizada pelo seu último evento $F_{i}$ ) até o início efetivo do procedimento de manutenção selecionado pela função historicoSorteioReparoOuSubstituicao() (reparo ou substituição). Esse período de 
tempo foi considerado relevante devido ao fato de ele refletir o tempo demandado para se mobilizar a equipe necessária para executar o procedimento de manutenção cabível.

O algoritmo da função historicoSorteioTempoInicioManut() é apresentado por intermédio do Diagrama Nassi-Schneiderman da Figura 37.

Figura 37 - Diagrama Nassi-Schneiderman da Função historicoSorteioTempoInicioManut()

\begin{tabular}{|c|c|c|}
\hline \multirow{3}{*}{ 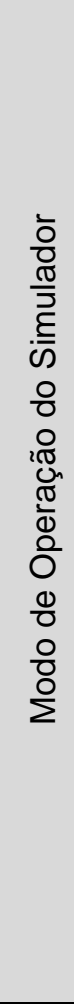 } & Otimista & $\begin{array}{l}\text { Em um cenário de ensaio otimista, os seguintes valores são } \\
\text { definidos para determinar as probabilidades dos intervalos de } \\
\text { desvio do intervalo de tempo esperado para haver a detecção } \\
\text { de uma falha. } \\
\text { probPeq } \leftarrow 0,7 \\
\text { probMed } \leftarrow 0,95 \\
\text { probGde } \leftarrow 0,99\end{array}$ \\
\hline & Normal & $\begin{array}{l}\text { Em um cenário de ensaio normal, os seguintes valores são } \\
\text { definidos para determinar as probabilidades dos intervalos de } \\
\text { desvio do intervalo de tempo esperado para haver a detecção } \\
\text { de uma falha. } \\
\text { probPeq } \leftarrow 0,5 \\
\text { probMed } \leftarrow 0,85 \\
\text { probGde } \leftarrow 0,95\end{array}$ \\
\hline & Pessimista & $\begin{array}{l}\text { Em um cenário de ensaio pessimista, os seguintes valores são } \\
\text { definidos para determinar as probabilidades dos intervalos de } \\
\text { desvio do intervalo de tempo esperado para haver a detecção } \\
\text { de uma falha. } \\
\text { probPeq } \leftarrow 0,25 \\
\text { probMed } \leftarrow 0,60 \\
\text { probGde } \leftarrow 0,90\end{array}$ \\
\hline \multicolumn{3}{|c|}{ num $\leftarrow$ Número aleatório uniformemente distribuído no intervalo $[0 ; 1]$} \\
\hline \multicolumn{3}{|r|}{$\boldsymbol{A}$ (vide Figura 38) } \\
\hline \multicolumn{3}{|c|}{ tempoNominalManut $\leftarrow \frac{1}{\text { taxa de reparos do componente }}$} \\
\hline \multicolumn{3}{|c|}{$\begin{array}{l}\text { variacaoInicioManut } \leftarrow \text { sinal } * \text { Número aleatório uniformemente distribuído no intervalo } \\
{[\text { tempoNominalManut } * \text { fatorMult } 1 ; \text { tempoNominalManut } * \text { fatorMult } 2]}\end{array}$} \\
\hline
\end{tabular}

Fonte: Autor 
Figura 38 - Diagrama Nassi-Schneiderman do Bloco "A" da Figura 37

\begin{tabular}{|c|c|c|}
\hline & & $\boldsymbol{A}$ \\
\hline \multirow{4}{*}{ 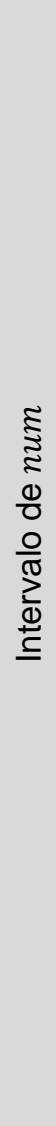 } & num $\in[0 ;$ probPeq [ & $\begin{array}{l}\text { O tempo esperado para se iniciar um procedimento de } \\
\text { manutenção após a ocorrência de uma falha poderá variar de } \\
0 \% \text { a } 25 \% \text { do valor nominal do MTTR estabelecido para o } \\
\text { componente. } \\
\text { fatorMult } 1 \leftarrow 0 \\
\text { fatorMult } 2 \leftarrow 0,25\end{array}$ \\
\hline & num $\in[$ probPeq; probMed [ & $\begin{array}{l}\text { O tempo esperado para se iniciar um procedimento de } \\
\text { manutenção após a ocorrência de uma falha poderá variar de } \\
25 \% \text { a } 60 \% \text { do valor nominal do MTTR estabelecido para o } \\
\text { componente. } \\
\text { fatorMult } 1 \leftarrow 0,25 \\
\text { fatorMult } 2 \leftarrow 0,60\end{array}$ \\
\hline & num $\in[$ probMed;probGde [ & $\begin{array}{l}\text { O tempo esperado para se iniciar um procedimento de } \\
\text { manutenção após a ocorrência de uma falha poderá variar de } \\
60 \% \text { a } 100 \% \text { do valor nominal do MTTR estabelecido para o } \\
\text { componente. } \\
\text { fatorMult } 1 \leftarrow 0,60 \\
\text { fatorMult } 2 \leftarrow 1,00\end{array}$ \\
\hline & num $\in[$ probGde; 1$]$ & $\begin{array}{l}\text { O tempo esperado para se iniciar um procedimento de } \\
\text { manutenção após a ocorrência de uma falha poderá variar de } \\
100 \% \text { a } 200 \% \text { do valor nominal do MTTR estabelecido para o } \\
\text { componente. } \\
\text { fatorMult } 1 \leftarrow 1,00 \\
\text { fatorMult } 2 \leftarrow 2,00\end{array}$ \\
\hline
\end{tabular}

Fonte: Autor

Pela Figura 37 é possível notar que o algoritmo implementado na função historicoSorteioTempoInicioManut() prevê a aplicação da Técnica da Roleta para se determinar, qualitativamente, se o tempo a ser transcorrido entre a ocorrência de um evento de falha e o início efetivo do procedimento de manutenção deve ser pequeno, médio, grande ou muito grande. Para tanto, um número pseudoaleatório (num) é sorteado de forma uniformemente distribuída no intervalo [0;1] e, de acordo com o valor numérico assumido por num, a seguinte regra é utilizada:

- Para valores de num pertencentes ao intervalo [0; probPeq[, o intervalo de tempo transcorrido entre a detecção da falha de um componente e o início do procedimento de manutenção associado será pequeno (entre $0 \%$ e $25 \%$ do MTTR nominal definido para o componente). Esse cenário ocorre com uma probabilidade igual a probPeq; 
- Para valores de num pertencentes ao intervalo [probPeq; probMed[, o intervalo de tempo transcorrido entre a detecção da falha de um componente e o início do procedimento de manutenção associado será médio (entre $25 \%$ e $60 \%$ do MTTR nominal definido para o componente). Esse cenário ocorre com uma probabilidade igual a (probMed - probPeq);

- Para valores de num pertencentes ao intervalo [probMed; probGde[, o intervalo de tempo transcorrido entre a detecção da falha de um componente e o início do procedimento de manutenção associado será grande (entre 60\% e $100 \%$ do MTTR nominal definido para o componente). Esse cenário ocorre com uma probabilidade igual a (probGde - probMed);

- Para valores de num pertencentes ao intervalo [probGde;1], o intervalo de tempo transcorrido entre a detecção da falha de um componente e o início do procedimento de manutenção associado será muito grande (entre $100 \% \mathrm{e}$ $200 \%$ do MTTR nominal definido para o componente). Esse cenário ocorre com uma probabilidade igual a $(1-$ probGde).

Nas definições apresentadas anteriormente, os parâmetros probPeq, probMed e probGde são definidos com base no cenário de simulação a ser considerado no ensaio (otimista, normal ou pessimista). Os valores assumidos por probPeq, probMed e probGde, bem como as probabilidades das quatro categorias qualitativas de valores para o intervalo de tempo transcorrido entre a detecção da falha de um componente e o início do procedimento de manutenção associado nos três possíveis cenários de simulação (otimista, normal e pessimista) são apresentados na Tabela 11. 
Tabela 11 - Relação de Valores de probPeq, probMed e probGde e das Probabilidades das Categorias Qualitativas dos Intervalos de Tempo entre Falha e Início de Manutenção

\begin{tabular}{|c|c|c|c|c|c|c|c|}
\hline & & & & \multicolumn{3}{|c|}{$\begin{array}{c}\text { Probabilidades das Categorias Qualitativas } \\
\text { dos Intervalos de Tempo entre Falha e Início } \\
\text { Cen Manutenção }\end{array}$} \\
\cline { 5 - 8 } $\begin{array}{c}\text { Cenário de } \\
\text { Simulação }\end{array}$ & \multirow{2}{*}{$\begin{array}{c}\text { Valor de } \\
\text { probPeq }\end{array}$} & \multirow{2}{*}{$\begin{array}{c}\text { Valor de } \\
\text { probMed }\end{array}$} & \multirow{2}{*}{$\begin{array}{c}\text { Valor de } \\
\text { probGde }\end{array}$} & & \multicolumn{4}{|c|}{$\begin{array}{c}\text { Variação } \\
\text { Pequena }\end{array}$} & $\begin{array}{c}\text { Variação } \\
\text { Média }\end{array}$ & $\begin{array}{c}\text { Variação } \\
\text { Grande }\end{array}$ & $\begin{array}{c}\text { Variação } \\
\text { Muito } \\
\text { Grande }\end{array}$ \\
\hline Otimista & 0,70 & 0,95 & 0,99 & $70 \%$ & $25 \%$ & $4 \%$ & $1 \%$ \\
\hline Normal & 0,5 & 0,85 & 0,95 & $50 \%$ & $35 \%$ & $10 \%$ & $5 \%$ \\
\hline Pessimista & 0,25 & 0,60 & 0,90 & $25 \%$ & $35 \%$ & $30 \%$ & $10 \%$ \\
\hline
\end{tabular}

Fonte: Autor

A partir das probabilidades relacionadas na Tabela 11, verifica-se que a lógica da função historicoSorteioTempoInicioManut () foi desenvolvida de tal forma que os intervalos de tempo transcorridos entre uma falha de um componente do sistema em estudo e o início do procedimento de manutenção associado a tal falha classificados como "pequenos" (entre $0 \%$ e $25 \%$ do valor nominal do MTTR do componente) sejam sorteados com maior probabilidade quando o módulo "Simulador de Dados de Entrada" é configurado para operar em uma situação comportamental otimista. Analogamente, a relação de probabilidades exposta na Tabela 11 permite inferir que os intervalos de tempo transcorridos entre uma falha de um componente do sistema em estudo e o início do procedimento de manutenção associado a tal falha classificados como "grandes" (entre $60 \%$ e $100 \%$ do valor nominal do MTTR do componente) e "muito grandes" (entre $100 \%$ e $200 \%$ do valor nominal do MTTR) são sorteados com maior probabilidade quando o módulo "Simulador de Dados de Entrada" é configurado para operar em uma situação comportamental pessimista.

Por fim, o valor do intervalo de tempo compreendido entre o último evento de falha do componente $\left(F_{i}\right)$ até o evento de manutenção que visa corrigi-la $\left(R I_{i}\right.$ ou $\left.S I_{i}\right)$ é calculado com base no sorteio de um número pseudoaleatório uniformemente distribuído dentro da faixa de variação (pequena, média, grande ou muito grande) delimitada pelos fatores multiplicativos do MTTR nominal calculados com base no sorteio do número pseudoaleatório num. 


\subsubsection{Detalhamento da Função historicoSorteioTempoReparar()}

Conforme abordado na seção 4.3, a função historicoSorteioTempoReparar() é responsável por calcular o período de tempo necessário para se desempenhar o reparo (conserto) de um componente defeituoso do sistema em estudo. Esse período de tempo fica compreendido entre um evento de Início de Reparo $\left(R I_{i}\right)$ e um evento de Fim de Reparo $\left(R F_{i}\right)$ do i-ésimo componente do sistema.

O algoritmo empregado na função historicoSorteioTempoReparar() é apresentado com auxílio do Diagrama Nassi-Schneiderman da Figura 39. 
Figura 39 - Diagrama Nassi-Schneiderman da Função historicoSorteioTempoReparar ()

\begin{tabular}{|c|c|c|}
\hline \multirow{3}{*}{ 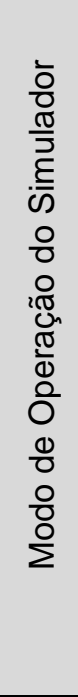 } & Otimista & $\begin{array}{l}\text { Em um cenário de ensaio otimista, define-se que há uma } \\
\text { probabilidade de } 40 \% \text { de o reparo de um componente ocorrer mais } \\
\text { lentamente do que o valor nominal determinado pelo MTTR do } \\
\text { componente. } \\
\text { probPos } \leftarrow 0,4\end{array}$ \\
\hline & Normal & $\begin{array}{l}\text { Em um cenário de ensaio normal, define-se que há uma } \\
\text { probabilidade de } 65 \% \text { de o reparo de um componente ocorrer mais } \\
\text { lentamente do que o valor nominal determinado pelo MTTR do } \\
\text { componente. } \\
\text { probPos } \leftarrow 0,65\end{array}$ \\
\hline & Pessimista & $\begin{array}{l}\text { Em um cenário de ensaio pessimista, define-se que há uma } \\
\text { probabilidade de } 92 \% \text { de o reparo de um componente ocorrer mais } \\
\text { lentamente do que o valor nominal determinado pelo MTTR do } \\
\text { componente. } \\
\text { probPos } \leftarrow 0,92\end{array}$ \\
\hline \multicolumn{3}{|c|}{ num $\leftarrow$ Número aleatório uniformemente distribuído no intervalo $[0 ; 1]$} \\
\hline \multirow{2}{*}{ 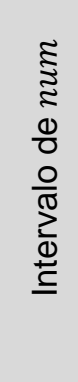 } & num $\in[0 ; \operatorname{probPos}[$ & $\begin{array}{l}\text { A variação do tempo do reparo simulado será positiva, isto é, o } \\
\text { reparo demorará mais tempo para ocorrer do que o valor nominal } \\
\text { determinado pelo MTTR do componente. } \\
\text { sinal } \leftarrow 1\end{array}$ \\
\hline & num $\in[$ probPos; 1$]$ & $\begin{array}{l}\text { A variação do tempo do reparo simulado será negativo, isto é, o } \\
\text { reparo demorará menos tempo para ocorrer do que o valor nominal } \\
\text { determinado pelo MTTR do componente. } \\
\text { sinal } \leftarrow-1\end{array}$ \\
\hline \multicolumn{3}{|r|}{$\boldsymbol{A}$ (vide Figura 40) } \\
\hline \multicolumn{3}{|c|}{ num $2 \leftarrow$ Número aleatório uniformemente distribuído no intervalo $[0 ; 1]$} \\
\hline \multicolumn{3}{|r|}{$B$ (vide Figura 41) } \\
\hline \multicolumn{3}{|c|}{ tempoNominalReparo $\leftarrow \frac{1}{\text { taxa de reparos do componente }}$} \\
\hline \multicolumn{3}{|c|}{$\begin{array}{lcr}\text { variacaoReparo } \leftarrow \text { sinal } * \quad \text { Número aleatório uniformemente distribuído no intervalo } \\
\text { [tempoNominalReparo } * \text { fatorMult } 1 ; \text { tempoNominalReparo } * \text { fatorMult } 2]\end{array}$} \\
\hline \multicolumn{3}{|c|}{ tempoReparo $\leftarrow$ tempoNominalReparo + variacaoReparo } \\
\hline
\end{tabular}

Fonte: Autor 
Figura 40 - Diagrama Nassi-Schneiderman do Bloco "A" da Figura 39

\begin{tabular}{|c|c|c|c|}
\hline \multicolumn{4}{|c|}{$A$} \\
\hline \multirow{9}{*}{ 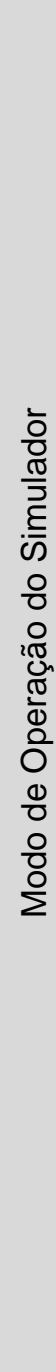 } & \multirow[b]{3}{*}{ Otimista } & \multicolumn{2}{|c|}{ sinal $\leftarrow 1 ?$} \\
\hline & & Sim & Não \\
\hline & & $\begin{array}{l}\text { Os seguintes valores são definidos } \\
\text { para determinar as probabilidades } \\
\text { dos intervalos de variação do tempo } \\
\text { do reparo a ser simulado: } \\
\text { probPeq } \leftarrow 0,80 \\
\text { probMed } \leftarrow 0,95\end{array}$ & $\begin{array}{l}\text { Os seguintes valores são definidos para } \\
\text { determinar as probabilidades dos } \\
\text { intervalos de variação do tempo do } \\
\text { reparo a ser simulado: } \\
\text { probPeq } \leftarrow 0,30 \\
\text { probMed } \leftarrow 0,70\end{array}$ \\
\hline & \multirow[b]{3}{*}{ Normal } & \multicolumn{2}{|c|}{ sinal $\leftarrow 1 ?$} \\
\hline & & Sim & Não \\
\hline & & $\begin{array}{l}\text { Os seguintes valores são definidos } \\
\text { para determinar as probabilidades } \\
\text { dos intervalos de variação do tempo } \\
\text { do reparo a ser simulado: } \\
\text { probPeq } \leftarrow 0,35 \\
\text { probMed } \leftarrow 0,80\end{array}$ & $\begin{array}{l}\text { Os seguintes valores são definidos para } \\
\text { determinar as probabilidades dos } \\
\text { intervalos de variação do tempo do } \\
\text { reparo a ser simulado: } \\
\text { probPeq } \leftarrow 0,35 \\
\text { probMed } \leftarrow 0,80\end{array}$ \\
\hline & \multirow[b]{3}{*}{ Pessimista } & \multicolumn{2}{|c|}{ sinal $\leftarrow 1 ?$} \\
\hline & & Sim & Não \\
\hline & & $\begin{array}{l}\text { Os seguintes valores são definidos } \\
\text { para determinar as probabilidades } \\
\text { dos intervalos de variação do tempo } \\
\text { do reparo a ser simulado: } \\
\text { probPeq } \leftarrow 0,15 \\
\text { probMed } \leftarrow 0,65\end{array}$ & $\begin{array}{l}\text { Os seguintes valores são definidos para } \\
\text { determinar as probabilidades dos } \\
\text { intervalos de variação do tempo do } \\
\text { reparo a ser simulado: } \\
\text { probPeq } \leftarrow 0,85 \\
\text { probMed } \leftarrow 0,99\end{array}$ \\
\hline
\end{tabular}

Fonte: Autor 
Figura 41 - Diagrama Nassi-Schneiderman do Bloco "B" da Figura 39

\begin{tabular}{|c|c|c|}
\hline & & $B$ \\
\hline \multirow{3}{*}{ 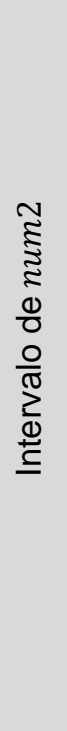 } & num $2 \in[0 ;$ probPeq [ & $\begin{array}{l}\text { O reparo simulado apresentará pequeno desvio (de } 0 \% \text { a } \\
25 \% \text { ) do valor nominal determinado pelo MTTR do } \\
\text { componente. } \\
\text { fatorMult } 1 \leftarrow 0 \\
\text { fatorMult } 2 \leftarrow 0,25\end{array}$ \\
\hline & num $2 \in$ [probPeq;probMed [ & $\begin{array}{l}\text { O reparo simulado apresentará médio desvio (de } 25 \% \text { a } \\
60 \% \text { ) do valor nominal determinado pelo MTTR do } \\
\text { componente. } \\
\text { fatorMult } 1 \leftarrow 0,25 \\
\text { fatorMult } 2 \leftarrow 0,6\end{array}$ \\
\hline & num $2 \in[$ probMed; 1$]$ & $\begin{array}{l}\text { O reparo simulado apresentará grande desvio (de } 60 \% \text { a } \\
100 \% \text { ) do valor nominal determinado pelo MTTR do } \\
\text { componente. } \\
\text { fatorMult } 1 \leftarrow 0,6 \\
\text { fatorMult } 2 \leftarrow 1\end{array}$ \\
\hline
\end{tabular}

Fonte: Autor

Pela Figura 39, é possível notar que a determinação do intervalo de tempo necessário para se reparar um componente falho é feita com base no uso de dois números pseudoaleatórios, que são avaliados utilizando-se a Técnica da Roleta. $O$ primeiro número aleatório sorteado (num) é utilizado com o intuito de se avaliar se a variação do tempo determinado para o reparo será, com relação ao tempo nominal expresso pelo MTTR associado ao componente, positiva ou negativa. A regra considerada na proposta feita no presente estudo foi a seguinte:

- Para valores de num pertencentes ao intervalo [0; $\operatorname{probPos}[$, a variação no tempo nominal de reparo do componente será positiva, isto é, o componente demorará mais que o tempo nominal de manutenção, expresso por seu MTTR, para ser consertado. Esse cenário ocorre com uma probabilidade igual a probPos;

- Para valores de num pertencentes ao intervalo [probPos,1], a variação no tempo nominal de reparo do componente será negativa, isto é, o componente demorará menos que o tempo nominal de manutenção, expresso por seu MTTR, para ser consertado. Esse cenário ocorre com uma probabilidade igual a $(1-$ probPos $)$. 
Nas definições apresentadas anteriormente, o parâmetro probPos é definido com base no cenário de simulação a ser considerado no ensaio (otimista, normal ou pessimista). Os valores assumidos por probPos e as probabilidades de variação positiva e negativa dos tempos de ocorrência de falhas nos três possíveis cenários de simulação (otimista, normal e pessimista) são apresentados na Tabela 12.

Tabela 12 - Relação de Valores de probPos e das Probabilidades do Sinal da Variação dos Intervalos de Tempo para a Execução de Reparos de Componentes

\begin{tabular}{|c|c|c|c|}
\hline \multirow{2}{*}{$\begin{array}{c}\text { Cenário de } \\
\text { Simulação }\end{array}$} & \multirow{2}{*}{$\begin{array}{c}\text { Valor de } \\
\text { probPos }\end{array}$} & \multicolumn{2}{|c|}{$\begin{array}{c}\text { Probabilidades de Variação dos Intervalos de Tempo } \\
\text { para Reparar }\end{array}$} \\
\cline { 3 - 4 } & & $\begin{array}{c}\text { Variação Positiva } \\
P_{R}(+)\end{array}$ & $\begin{array}{c}\text { Variação Negativa } \\
P_{R}(-)\end{array}$ \\
\hline Otimista & 0,40 & $40 \%$ & $60 \%$ \\
\hline Normal & 0,65 & $65 \%$ & $35 \%$ \\
\hline Pessimista & 0,92 & $92 \%$ & $8 \%$ \\
\hline
\end{tabular}

Fonte: Autor

O valor absoluto da variação do tempo de reparo de um componente com relação ao seu valor nominal, expresso pelo MTTR associado a ele, é determinado com auxílio de um segundo número pseudoaleatório, denominado num2. A regra aplicada nesse caso é a seguinte:

- Para valores de num2 pertencentes ao intervalo [0; probPeq[, haverá uma variação pequena (de $0 \%$ a $25 \%$ ) no tempo nominal de reparo do componente. Esse cenário ocorre com uma probabilidade igual a probPeq;

- Para valores de num2 pertencentes ao intervalo [probPeq; probMed[, haverá uma variação média (de $25 \%$ a $60 \%$ ) no tempo nominal de reparo do componente. Esse cenário ocorre com uma probabilidade igual a (probMed probPeq);

- Para valores de num2 pertencentes ao intervalo [probMed;1], haverá uma variação grande (de $60 \%$ a $100 \%$ ) no tempo nominal de reparo do componente. Esse cenário ocorre com uma probabilidade igual a (1probMed). 
Nas definições apresentadas anteriormente, os parâmetros probPeq e probMed são definidos com base no cenário de simulação a ser considerado no ensaio (otimista, normal ou pessimista) e no sinal da variação (positivo ou negativo), determinado na etapa anterior. Os valores assumidos por probPeq e probMed, bem como as probabilidades de variação pequena, média e grande dos tempos de execução de reparo nos três possíveis cenários de simulação (otimista, normal e pessimista) são apresentados na Tabela 13 (para variação positiva do tempo para reparar) e na Tabela 14 (para variação negativa do tempo para reparar).

Tabela 13 - Relação de Valores de probPeq, probMed e das Probabilidades de Variação Positiva dos Intervalos de Tempo de Execução de Reparos de Componentes

\begin{tabular}{|c|c|c|c|c|c|}
\hline \multirow{2}{*}{$\begin{array}{c}\text { Cenário de } \\
\text { Simulação }\end{array}$} & \multirow{2}{*}{$\begin{array}{c}\text { Valor de } \\
\text { probPeq }\end{array}$} & $\begin{array}{c}\text { Valor de } \\
\text { probMed }\end{array}$ & \multicolumn{3}{|c|}{$\begin{array}{c}\text { Probabilidades de Variação Positiva dos } \\
\text { Intervalos de Tempo para Reparar }\end{array}$} \\
\cline { 4 - 6 } & & $\begin{array}{c}\text { Variação } \\
\text { Pequena } \\
P_{R}(P \mid+)\end{array}$ & $\begin{array}{c}\text { Variação } \\
\text { Média } \\
P_{R}(M \mid+)\end{array}$ & $\begin{array}{c}\text { Variação } \\
\text { Grande } \\
P_{R}(G \mid+)\end{array}$ \\
\hline Otimista & 0,80 & 0,95 & $80 \%$ & $15 \%$ & $5 \%$ \\
\hline Normal & 0,35 & 0,80 & $35 \%$ & $45 \%$ & $20 \%$ \\
\hline Pessimista & 0,15 & 0,65 & $15 \%$ & $50 \%$ & $35 \%$ \\
\hline
\end{tabular}

Fonte: Autor

Tabela 14 - Relação de Valores de probPeq, probMed e das Probabilidades de Variação Negativa dos Intervalos de Tempo de Execução de Reparos de Componentes

\begin{tabular}{|c|c|c|c|c|c|}
\hline \multirow{2}{*}{$\begin{array}{c}\text { Cenário de } \\
\text { Simulação }\end{array}$} & \multirow{2}{*}{$\begin{array}{c}\text { Valor de } \\
\text { probPeq }\end{array}$} & \multirow{2}{*}{$\begin{array}{c}\text { Valor de } \\
\text { probMed }\end{array}$} & \multicolumn{3}{|c|}{$\begin{array}{c}\text { Probabilidades de Variação Negativa dos } \\
\text { Intervalos de Tempo para Reparar }\end{array}$} \\
\cline { 4 - 6 } & & $\begin{array}{c}\text { Variação } \\
\text { Pequena } \\
P_{R}(P \mid-)\end{array}$ & $\begin{array}{c}\text { Variação } \\
\text { Média } \\
P_{R}(M \mid-)\end{array}$ & $\begin{array}{c}\text { Variação } \\
\text { Grande } \\
P_{R}(G \mid-)\end{array}$ \\
\hline Otimista & 0,30 & 0,70 & $30 \%$ & $40 \%$ & $30 \%$ \\
\hline Normal & 0,35 & 0,80 & $35 \%$ & $45 \%$ & $20 \%$ \\
\hline Pessimista & 0,85 & 0,99 & $85 \%$ & $14 \%$ & $1 \%$ \\
\hline
\end{tabular}

Fonte: Autor

As probabilidades definidas na Tabela 12, na Tabela 13 e na Tabela 14 podem ser combinadas para se calcular, nos três cenários possíveis de ensaio (otimista, normal e pessimista), as seguintes probabilidades: 
a) Probabilidade de Variação Positiva de Pequeno Desvio do Tempo de Reparo com Relação ao MTTR Nominal $\left(P_{R}(P \cap+)\right)$ : Para um dado cenário de simulação (otimista, normal ou pessimista), a probabilidade $P_{R}(P \cap+)$ é expressa pelo produto da probabilidade $P_{R}(+)$ de ocorrência de variação positiva do cenário (apresentada na Tabela 12) com a probabilidade condicional $P_{R}(P \mid+)$ de ocorrência de variação pequena do cenário dado que a variação é positiva (apresentada na Tabela 13);

b) Probabilidade de Variação Positiva de Médio Desvio do Tempo de Reparo com Relação ao MTTR Nominal $\left(P_{R}(M \cap+)\right)$ : Para um dado cenário de simulação (otimista, normal ou pessimista), a probabilidade $P_{R}(M \cap+)$ é expressa pelo produto da probabilidade $P_{R}(+)$ de ocorrência de variação positiva do cenário (apresentada na Tabela 12) com a probabilidade condicional $P_{R}(M \mid+)$ de ocorrência de variação média do cenário dado que a variação é positiva (apresentada na Tabela 13);

c) Probabilidade de Variação Positiva de Grande Desvio do Tempo de Reparo com Relação ao MTTR Nominal $\left(P_{R}(G \cap+)\right)$ : Para um dado cenário de simulação (otimista, normal ou pessimista), a probabilidade $P_{R}(G \cap+$ ) é expressa pelo produto da probabilidade $P_{R}(+)$ de ocorrência de variação positiva do cenário (apresentada na Tabela 12) com a probabilidade condicional $P_{R}(G \mid+)$ de ocorrência de variação grande do cenário dado que a variação é positiva (apresentada na Tabela 13);

d) Probabilidade de Variação Negativa de Pequeno Desvio do Tempo de Reparo com Relação ao MTTR Nominal $\left(P_{R}(P \cap-)\right)$ : Para um dado cenário de simulação (otimista, normal ou pessimista), a probabilidade $P_{R}(P \cap-)$ é expressa pelo produto da probabilidade $P_{R}(-)$ de ocorrência de variação negativa do cenário (apresentada na Tabela 12) com a probabilidade condicional $P_{R}(P \mid-)$ de ocorrência de variação pequena do cenário dado que a variação é negativa (apresentada na Tabela 14);

e) Probabilidade de Variação Negativa de Médio Desvio do Tempo de Reparo com Relação ao MTTR Nominal $\left(P_{R}(M \cap-)\right)$ : Para um dado cenário de simulação (otimista, normal ou pessimista), a probabilidade $P_{R}(M \cap-)$ é expressa pelo produto da probabilidade $P_{R}(-)$ de ocorrência de variação negativa do cenário (apresentada na Tabela 12) com a probabilidade 
condicional $P_{R}(M \mid-)$ de ocorrência de variação média do cenário dado que a variação é negativa (apresentada na Tabela 14);

f) Probabilidade de Variação Negativa de Grande Desvio do Tempo de Reparo com Relação ao MTTR Nominal $\left(P_{R}(G \cap-)\right)$ : Para um dado cenário de simulação (otimista, normal ou pessimista), a probabilidade $P_{R}(G \cap-$ ) é expressa pelo produto da probabilidade $P_{R}(-)$ de ocorrência de variação negativa do cenário (apresentada na Tabela 12) com a probabilidade condicional $P_{R}(G \mid-)$ de ocorrência de variação grande do cenário dado que a variação é negativa (apresentada na Tabela 14).

Os valores das probabilidades definidas nos itens "a)" a "f)" anteriores para os três cenários possíveis de ensaio (otimista, normal e pessimista) utilizados pelo módulo "Simulador de Dados de Entrada" estão relacionados na Tabela 15. Um aspecto que deve ser ressaltado é que, como os eventos utilizados para determinar as probabilidades $P_{R}(P \cap+), \quad P_{R}(M \cap+), \quad P_{R}(G \cap+), P_{R}(P \cap-), \quad P_{R}(M \cap-)$ e $P_{R}(G \cap-)$ são complementares entre si, a soma das probabilidades prévias resulta em $1(100 \%)$ independentemente do cenário configurado no módulo "Simulador de Dados de Entrada".

Tabela 15 - Relação das Probabilidades de Todas as Combinações de Sinal e Valor Absoluto da Variação do Intervalo de Tempo para a Execução de Reparos de Componentes

\begin{tabular}{|c|c|c|c|}
\hline \multirow{2}{*}{ Probabilidade } & \multicolumn{3}{|c|}{ Categoria de Cenário de Simulação } \\
\cline { 2 - 4 } & Otimista & Normal & Pessimista \\
\hline$P_{R}(P \cap+)$ & $32,00 \%$ & $22,75 \%$ & $13,80 \%$ \\
\hline$P_{R}(M \cap+)$ & $6,00 \%$ & $29,25 \%$ & $46,00 \%$ \\
\hline$P_{R}(G \cap+)$ & $2,00 \%$ & $13,00 \%$ & $32,20 \%$ \\
\hline$P_{R}(P \cap-)$ & $18,00 \%$ & $12,25 \%$ & $6,80 \%$ \\
\hline$P_{R}(M \cap-)$ & $24,00 \%$ & $15,75 \%$ & $1,12 \%$ \\
\hline$P_{R}(G \cap-)$ & $18,00 \%$ & $7,00 \%$ & $0,08 \%$ \\
\hline
\end{tabular}

Fonte: Autor

A partir das probabilidades relacionadas na Tabela 15, verifica-se que a lógica da função historicoSorteioTempoReparar () foi desenvolvida de tal forma a priorizar, em simulações comportamentais otimistas, que os reparos de um componente do sistema em estudo serão executados em um intervalo de tempo menor ou apenas 
ligeiramente maior do que o MTTR nominal estabelecido para o elemento sob avaliação. Dessa maneira, considerando-se que o módulo "Simulador de Dados de Entrada" seja configurado para gerar registros de histórico de operação do sistema em estudo representativos de seu funcionamento durante um período de tempo $T$, é esperado que os períodos de tempo durante os quais os componentes do sistema estão submetidos a procedimentos de reparo em um cenário otimista sejam inferiores aos observados em situações normais e pessimistas.

Analogamente, a relação de probabilidades exposta na Tabela 15 permite inferir que, em simulações comportamentais pessimistas, é mais provável que haja proeminência de que os reparos de um componente do sistema em estudo serão desempenhados em um intervalo de tempo significativamente superior ao MTTR nominal definido para o elemento sob avaliação. Por esse motivo, é esperado que os registros de histórico de operação produzidos pelo módulo "Simulador de Dados de Entrada" em cenários pessimistas de funcionamento do sistema em estudo indiquem que os períodos de tempo durante os quais os seus componentes estão submetidos a procedimentos de reparo sejam superiores aos gerados em situações otimistas e normais.

Por fim, uma vez conhecidos os dois parâmetros da variação do tempo para reparar (faixa de variação do valor absoluto e sinal da variação), o intervalo de tempo a ser transcorrido para a execução do procedimento de reparo do componente desde o instante de ocorrência de seu último evento $R I_{i}$ é determinado por meio da soma da variação do tempo para reparar com o MTTR (inverso da taxa de reparos nominal, conforme definido na equação (4)). A variação efetiva do tempo para reparar possui o sinal obtido com auxílio de num e o valor absoluto de um número pseudoaleatório sorteado com base em uma distribuição probabilística uniforme dentro da faixa de variação delimitada pelos fatores multiplicativos do MTTR nominal calculados com base em num2.

\subsubsection{Detalhamento da Função historicoSorteioTempoSubstituir()}

Conforme abordado na seção 4.3, a função historicoSorteioTempoSubstituir () é responsável por calcular o período de tempo necessário para se desempenhar a substituição de um componente defeituoso do 
sistema em estudo. Esse período de tempo fica compreendido entre um evento de Início de Substituição $\left(S I_{i}\right)$ e um evento de Fim de Substituição $\left(S F_{i}\right)$ do i-ésimo componente do sistema.

O algoritmo empregado na função historicoSorteioTempoSubstituir() é apresentado com auxílio do Diagrama Nassi-Schneiderman da Figura 42.

Figura 42 - Diagrama Nassi-Schneiderman da Função historicoSorteioTempoSubstituir()

\begin{tabular}{|c|c|c|}
\hline \multirow{3}{*}{ 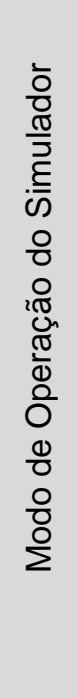 } & Otimista & $\begin{array}{l}\text { Em um cenário de ensaio otimista, define-se que há uma } \\
\text { probabilidade de } 30 \% \text { de a substituição de um componente ocorrer } \\
\text { mais lentamente do que o valor nominal determinado pelo MTTR do } \\
\text { componente. } \\
\text { probPos } \leftarrow 0,3\end{array}$ \\
\hline & Normal & $\begin{array}{l}\text { Em um cenário de ensaio normal, define-se que há uma } \\
\text { probabilidade de } 55 \% \text { de a substituição de um componente ocorrer } \\
\text { mais lentamente do que o valor nominal determinado pelo MTTR do } \\
\text { componente. } \\
\text { probPos } \leftarrow 0,55\end{array}$ \\
\hline & Pessimista & $\begin{array}{l}\text { Em um cenário de ensaio pessimista, define-se que há uma } \\
\text { probabilidade de } 85 \% \text { de a substituição de um componente ocorrer } \\
\text { mais lentamente do que o valor nominal determinado pelo MTTR do } \\
\text { componente. } \\
\text { probPos } \leftarrow 0,85\end{array}$ \\
\hline \multicolumn{3}{|c|}{ num $\leftarrow$ Número aleatório uniformemente distribuído no intervalo $[0 ; 1]$} \\
\hline \multirow{2}{*}{ 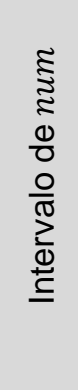 } & num $\in[0 ;$ probPos [ & $\begin{array}{l}\text { A variação do tempo da substituição simulada será positiva, isto é, a } \\
\text { substituição demorará mais tempo para ocorrer do que o valor } \\
\text { nominal determinado pelo MTTR do componente. } \\
\text { sinal } \leftarrow 1\end{array}$ \\
\hline & num $\in[$ probPos; 1$]$ & $\begin{array}{l}\text { A variação do tempo da substituição simulada será negativa, isto é, } \\
\text { o reparo demorará menos tempo para ocorrer do que o valor } \\
\text { nominal determinado pelo MTTR do componente. } \\
\text { sinal } \leftarrow-1\end{array}$ \\
\hline \multicolumn{3}{|r|}{$\boldsymbol{A}$ (vide Figura 43) } \\
\hline \multicolumn{3}{|c|}{ num $2 \leftarrow$ Número aleatório uniformemente distribuído no intervalo $[0 ; 1]$} \\
\hline \multicolumn{3}{|r|}{ B (vide Figura 44) } \\
\hline \multicolumn{3}{|c|}{ tempoNominalSubst $\leftarrow \frac{1}{\text { taxa de reparos do componente }}$} \\
\hline \multicolumn{3}{|c|}{$\begin{array}{l}\text { variacaoSubst } \leftarrow \text { sinal } * \quad \text { Número aleatório uniformemente distribuído } \\
{[\text { tempoNominalSubst } * \text { fatorMult } 1 ; \text { tempoNominalSubst } * \text { fatorMult } 2]}\end{array}$} \\
\hline \multicolumn{3}{|c|}{ tempoSubst $\leftarrow$ tempoNominalSubst + variacaoReparo } \\
\hline
\end{tabular}

Fonte: Autor 
Figura 43 - Diagrama Nassi-Schneiderman do Bloco "A" da Figura 42

\begin{tabular}{|c|c|c|c|}
\hline \multicolumn{4}{|c|}{$A$} \\
\hline \multirow{9}{*}{ 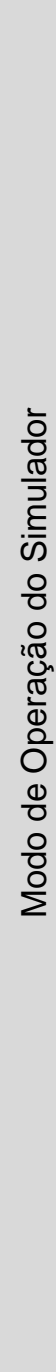 } & \multirow[b]{3}{*}{ Otimista } & \multicolumn{2}{|c|}{ sinal $\leftarrow 1 ?$} \\
\hline & & Sim & Não \\
\hline & & $\begin{array}{l}\text { Os seguintes valores são definidos } \\
\text { para determinar as probabilidades } \\
\text { dos intervalos de variação do tempo } \\
\text { da substituição a ser simulada: } \\
\text { probPeq } \leftarrow 0,85 \\
\text { probMed } \leftarrow 0,98\end{array}$ & $\begin{array}{l}\text { Os seguintes valores são definidos para } \\
\text { determinar as probabilidades dos } \\
\text { intervalos de variação do tempo da } \\
\text { substituição a ser simulada: } \\
\text { probPeq } \leftarrow 0,25 \\
\text { probMed } \leftarrow 0,60\end{array}$ \\
\hline & \multirow[b]{3}{*}{ Normal } & \multicolumn{2}{|c|}{ sinal $\leftarrow 1 ?$} \\
\hline & & Sim & Não \\
\hline & & $\begin{array}{l}\text { Os seguintes valores são definidos } \\
\text { para determinar as probabilidades } \\
\text { dos intervalos de variação do tempo } \\
\text { da substituição a ser simulada: } \\
\text { probPeq } \leftarrow 0,50 \\
\text { probMed } \leftarrow 0,85\end{array}$ & $\begin{array}{l}\text { Os seguintes valores são definidos para } \\
\text { determinar as probabilidades dos } \\
\text { intervalos de variação do tempo da } \\
\text { substituição a ser simulada: } \\
\text { probPeq } \leftarrow 0,45 \\
\text { probMed } \leftarrow 0,85\end{array}$ \\
\hline & \multirow[b]{3}{*}{ Pessimista } & \multicolumn{2}{|c|}{ sinal $\leftarrow 1 ?$} \\
\hline & & Sim & Não \\
\hline & & $\begin{array}{l}\text { Os seguintes valores são definidos } \\
\text { para determinar as probabilidades } \\
\text { dos intervalos de variação do tempo } \\
\text { da substituição a ser simulada: } \\
\text { probPeq } \leftarrow 0,20 \\
\text { probMed } \leftarrow 0,65\end{array}$ & $\begin{array}{l}\text { Os seguintes valores são definidos para } \\
\text { determinar as probabilidades dos } \\
\text { intervalos de variação do tempo da } \\
\text { substituição a ser simulada: } \\
\text { probPeq } \leftarrow 0,65 \\
\text { probMed } \leftarrow 0,95\end{array}$ \\
\hline
\end{tabular}

Fonte: Autor 
Figura 44 - Diagrama Nassi-Schneiderman do Bloco "B" da Figura 42

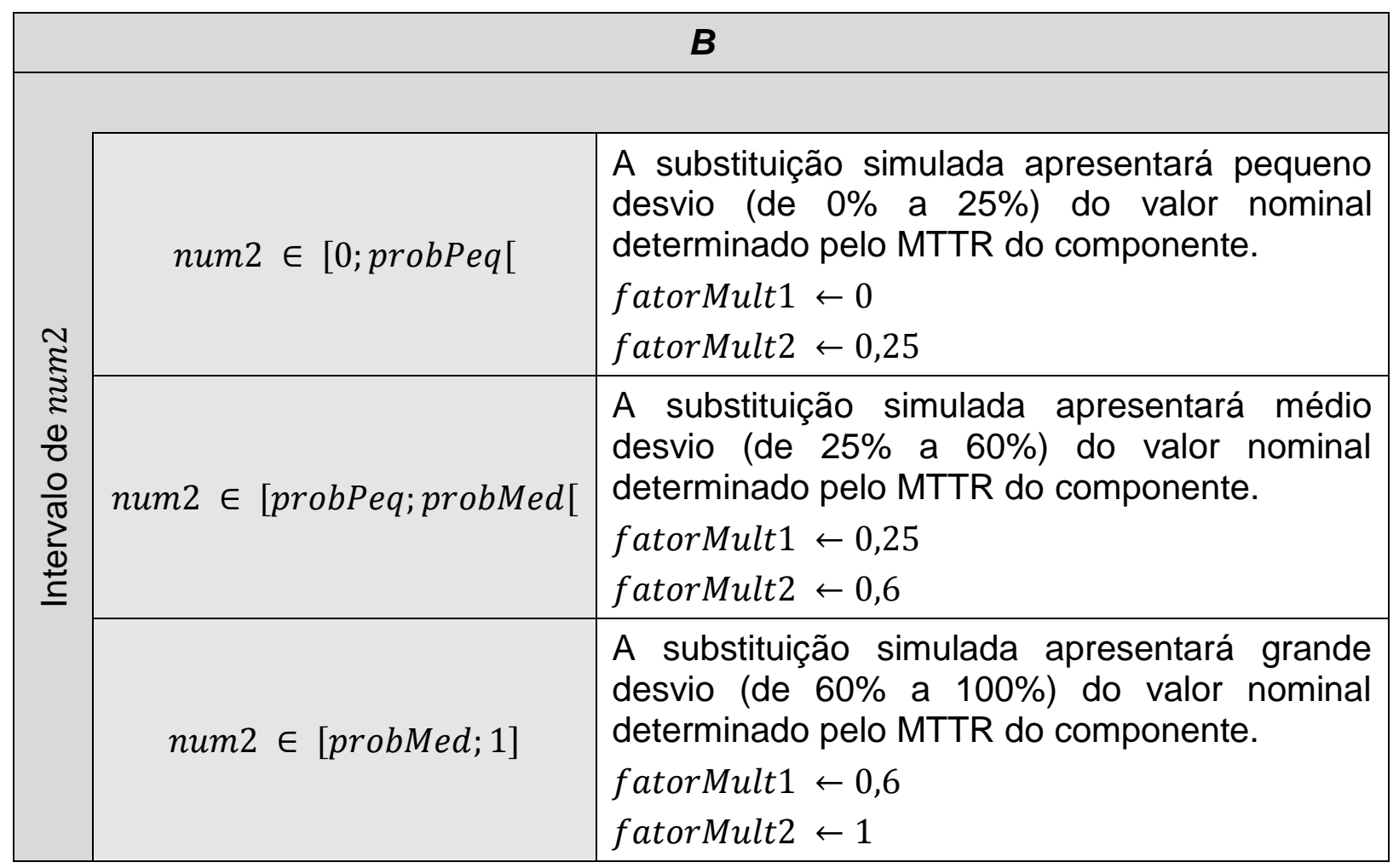

Fonte: Autor

Pela Figura 42, é possível notar que a determinação do intervalo de tempo necessário para se substituir um componente falho é feita com base no uso de dois números pseudoaleatórios, que são avaliados utilizando-se a Técnica da Roleta. O primeiro número aleatório sorteado (num) é utilizado com o intuito de se avaliar se a variação do tempo determinado para a substituição será, com relação ao tempo nominal expresso pelo MTTR associado ao componente, positiva ou negativa. A regra considerada na proposta feita no presente estudo foi a seguinte:

- Para valores de num pertencentes ao intervalo [0; $\operatorname{probPos}[$, a variação no tempo nominal de substituição do componente será positiva, isto é, o componente demorará mais que o tempo nominal de manutenção, expresso por seu MTTR, para ser substituído. Esse cenário ocorre com uma probabilidade igual a probPos;

- Para valores de num pertencentes ao intervalo [probPos, 1], a variação no tempo nominal de substituição do componente será negativa, isto é, o componente demorará menos que o tempo nominal de manutenção, expresso 
por seu MTTR, para ser substituído. Esse cenário ocorre com uma probabilidade igual a (1-probPos).

Nas definições apresentadas anteriormente, o parâmetro probPos é definido com base no cenário de simulação a ser considerado no ensaio (otimista, normal ou pessimista). Os valores assumidos por probPos e as probabilidades de variação positiva e negativa dos tempos de ocorrência de falhas nos três possíveis cenários de simulação (otimista, normal e pessimista) são apresentados na Tabela 16.

Tabela 16 - Relação de Valores de probPos e das Probabilidades do Sinal da Variação dos Intervalos de Tempo para a Execução de Substituições de Componentes

\begin{tabular}{|c|c|c|c|}
\hline \multirow{2}{*}{$\begin{array}{c}\text { Cenário de } \\
\text { Simulação }\end{array}$} & \multirow{2}{*}{$\begin{array}{c}\text { Valor de } \\
\text { probPos }\end{array}$} & $\begin{array}{c}\text { Probabilidades de Variação dos Intervalos de } \\
\text { Tempo para Substituir }\end{array}$ \\
\cline { 3 - 4 } & & $\begin{array}{c}\text { Variação Positiva } \\
P_{S}(+)\end{array}$ & $\begin{array}{c}\text { Variação Negativa } \\
P_{S}(-)\end{array}$ \\
\hline Otimista & 0,30 & $30 \%$ & $70 \%$ \\
\hline Normal & 0,55 & $55 \%$ & $45 \%$ \\
\hline Pessimista & 0,85 & $85 \%$ & $15 \%$ \\
\hline
\end{tabular}

Fonte: Autor

O valor absoluto da variação do tempo de substituição de um componente com relação ao seu valor nominal, expresso pelo MTTR associado a ele, é determinado com auxílio de um segundo número pseudoaleatório, denominado num2. A regra aplicada nesse caso é a seguinte:

- Para valores de num2 pertencentes ao intervalo [0; probPeq[, haverá uma variação pequena (de $0 \%$ a $25 \%$ ) no tempo nominal de substituição do componente. Esse cenário ocorre com uma probabilidade igual a probPeq;

- Para valores de num2 pertencentes ao intervalo [probPeq; probMed[, haverá uma variação média (de $25 \%$ a $60 \%$ ) no tempo nominal de substituição do componente. Esse cenário ocorre com uma probabilidade igual a (probMed probPeq);

- Para valores de num2 pertencentes ao intervalo [probMed; 1], haverá uma variação grande (de $60 \%$ a $100 \%$ ) no tempo nominal de substituição do 
componente. Esse cenário ocorre com uma probabilidade igual a (1probMed).

Nas definições apresentadas anteriormente, os parâmetros probPeq e probMed são definidos com base no cenário de simulação a ser considerado no ensaio (otimista, normal ou pessimista) e no sinal da variação (positivo ou negativo), determinado na etapa anterior. Os valores assumidos por probPeq e probMed, bem como as probabilidades de variação pequena, média e grande dos tempos de execução de substituição nos três possíveis cenários de simulação (otimista, normal e pessimista) são apresentados na Tabela 17 (para variação positiva do tempo para substituir) e na Tabela 18 (para variação negativa do tempo para substituir).

Tabela 17 - Relação de Valores de probPeq, probMed e das Probabilidades de Variação Positiva dos Intervalos de Tempo de Execução de Substituições de Componentes

\begin{tabular}{|c|c|c|c|c|c|}
\hline \multirow{2}{*}{$\begin{array}{c}\text { Cenário de } \\
\text { Simulação }\end{array}$} & \multirow{2}{*}{$\begin{array}{c}\text { Valor de } \\
\text { probPeq }\end{array}$} & $\begin{array}{c}\text { Valor de } \\
\text { probMed }\end{array}$ & \multicolumn{3}{|c|}{$\begin{array}{c}\text { Probabilidades de Variação Positiva dos } \\
\text { Intervalos de Tempo para Reparar }\end{array}$} \\
\cline { 4 - 6 } & & $\begin{array}{c}\text { Variação } \\
\text { Pequena } \\
P_{S}(P \mid+)\end{array}$ & $\begin{array}{c}\text { Variação } \\
\text { Média } \\
P_{S}(M \mid+)\end{array}$ & $\begin{array}{c}\text { Variação } \\
\text { Grande } \\
P_{S}(G \mid+)\end{array}$ \\
\hline Otimista & 0,85 & 0,98 & $85 \%$ & $13 \%$ & $2 \%$ \\
\hline Normal & 0,50 & 0,85 & $50 \%$ & $35 \%$ & $15 \%$ \\
\hline Pessimista & 0,20 & 0,65 & $20 \%$ & $45 \%$ & $35 \%$ \\
\hline
\end{tabular}

Fonte: Autor

Tabela 18 - Relação de Valores de probPeq, probMed e das Probabilidades de Variação Negativa dos Intervalos de Tempo de Execução de Substituições de Componentes

\begin{tabular}{|c|c|c|c|c|c|}
\hline \multirow{2}{*}{$\begin{array}{c}\text { Cenário de } \\
\text { Simulação }\end{array}$} & \multirow{2}{*}{$\begin{array}{c}\text { Valor de } \\
\text { probPeq }\end{array}$} & \multirow{2}{*}{$\begin{array}{c}\text { Valor de } \\
\text { probMed }\end{array}$} & \multicolumn{3}{|c|}{$\begin{array}{c}\text { Probabilidades de Variação Negativa dos } \\
\text { Intervalos de Tempo para Reparar }\end{array}$} \\
\cline { 4 - 6 } & & $\begin{array}{c}\text { Variação } \\
\text { Pequena } \\
P_{S}(P \mid-)\end{array}$ & $\begin{array}{c}\text { Variação } \\
\text { Média } \\
P_{S}(M \mid-)\end{array}$ & $\begin{array}{c}\text { Variação } \\
\text { Grande } \\
P_{S}(G \mid-)\end{array}$ \\
\hline Otimista & 0,25 & 0,60 & $25 \%$ & $35 \%$ & $40 \%$ \\
\hline Normal & 0,45 & 0,85 & $45 \%$ & $40 \%$ & $15 \%$ \\
\hline Pessimista & 0,65 & 0,95 & $65 \%$ & $30 \%$ & $5 \%$ \\
\hline
\end{tabular}

Fonte: Autor 
As probabilidades definidas na Tabela 16, na Tabela 17 e na Tabela 18 podem ser combinadas para se calcular, nos três cenários possíveis de ensaio (otimista, normal e pessimista), as seguintes probabilidades:

a) Probabilidade de Variação Positiva de Pequeno Desvio do Tempo de Substituição com Relação ao MTTR Nominal $\left(P_{S}(P \cap+)\right)$ : Para um dado cenário de simulação (otimista, normal ou pessimista), a probabilidade $P_{S}(P \cap+)$ é expressa pelo produto da probabilidade $P_{S}(+)$ de ocorrência de variação positiva do cenário (apresentada na Tabela 16) com a probabilidade condicional $P_{S}(P \mid+)$ de ocorrência de variação pequena do cenário dado que a variação é positiva (apresentada na Tabela 17);

b) Probabilidade de Variação Positiva de Médio Desvio do Tempo de Substituição com Relação ao MTTR Nominal $\left(P_{S}(M \cap+)\right)$ : Para um dado cenário de simulação (otimista, normal ou pessimista), a probabilidade $P_{S}(M \cap+)$ é expressa pelo produto da probabilidade $P_{S}(+)$ de ocorrência de variação positiva do cenário (apresentada na Tabela 16) com a probabilidade condicional $P_{S}(M \mid+)$ de ocorrência de variação média do cenário dado que a variação é positiva (apresentada na Tabela 17);

c) Probabilidade de Variação Positiva de Grande Desvio do Tempo de Substituição com Relação ao MTTR Nominal $\left(P_{S}(G \cap+)\right)$ : Para um dado cenário de simulação (otimista, normal ou pessimista), a probabilidade $P_{S}(G \cap$ + ) é expressa pelo produto da probabilidade $P_{S}(+)$ de ocorrência de variação positiva do cenário (apresentada na Tabela 16) com a probabilidade condicional $P_{S}(G \mid+)$ de ocorrência de variação grande do cenário dado que a variação é positiva (apresentada na Tabela 17);

d) Probabilidade de Variação Negativa de Pequeno Desvio do Tempo de Substituição com Relação ao MTTR Nominal $\left(P_{S}(P \cap-)\right)$ : Para um dado cenário de simulação (otimista, normal ou pessimista), a probabilidade $P_{S}(P \cap-)$ é expressa pelo produto da probabilidade $P_{S}(-)$ de ocorrência de variação negativa do cenário (apresentada na Tabela 16) com a probabilidade condicional $P_{S}(P \mid-)$ de ocorrência de variação pequena do cenário dado que a variação é negativa (apresentada na Tabela 18);

e) Probabilidade de Variação Negativa de Médio Desvio do Tempo de Substituição com Relação ao MTTR Nominal $\left(P_{S}(M \cap-)\right)$ : Para um dado 
cenário de simulação (otimista, normal ou pessimista), a probabilidade $P_{S}(M \cap-)$ é expressa pelo produto da probabilidade $P_{S}(-)$ de ocorrência de variação negativa do cenário (apresentada na Tabela 16) com a probabilidade condicional $P_{S}(M \mid-)$ de ocorrência de variação média do cenário dado que a variação é negativa (apresentada na Tabela 18);

f) Probabilidade de Variação Negativa de Grande Desvio do Tempo de Substituição com Relação ao MTTR Nominal $\left(P_{S}(G \cap-)\right)$ : Para um dado cenário de simulação (otimista, normal ou pessimista), a probabilidade $P_{S}(G \cap-)$ é expressa pelo produto da probabilidade $P_{S}(-)$ de ocorrência de variação negativa do cenário (apresentada na Tabela 16) com a probabilidade condicional $P_{S}(G \mid-)$ de ocorrência de variação grande do cenário dado que a variação é negativa (apresentada na Tabela 18).

Os valores das probabilidades definidas nos itens "a)" a "f)" anteriores para os três cenários possíveis de ensaio (otimista, normal e pessimista) utilizados pelo módulo "Simulador de Dados de Entrada" estão relacionados na Tabela 19. Um aspecto que deve ser ressaltado é que, como os eventos utilizados para determinar as probabilidades $P_{R}(P \cap+), \quad P_{R}(M \cap+), \quad P_{R}(G \cap+), P_{R}(P \cap-), \quad P_{R}(M \cap-)$ e $P_{R}(G \cap-)$ são complementares entre si, a soma das probabilidades prévias resulta em $1(100 \%)$ independentemente do cenário configurado no módulo "Simulador de Dados de Entrada".

Tabela 19 - Relação das Probabilidades de Todas as Combinações de Sinal e Valor Absoluto da Variação do Intervalo de Tempo para a Execução de Substituições de Componentes

\begin{tabular}{|c|c|c|c|}
\hline \multirow{2}{*}{ Probabilidade } & \multicolumn{3}{|c|}{ Categoria de Cenário de Simulação } \\
\cline { 2 - 4 } & Otimista & Normal & Pessimista \\
\hline$P_{S}(P \cap+)$ & $25,50 \%$ & $27,50 \%$ & $17,00 \%$ \\
\hline$P_{S}(M \cap+)$ & $3,90 \%$ & $19,25 \%$ & $38,25 \%$ \\
\hline$P_{S}(G \cap+)$ & $0,60 \%$ & $8,25 \%$ & $29,75 \%$ \\
\hline$P_{S}(P \cap-)$ & $17,50 \%$ & $20,25 \%$ & $9,75 \%$ \\
\hline$P_{S}(M \cap-)$ & $24,50 \%$ & $18,00 \%$ & $4,5 \%$ \\
\hline$P_{S}(G \cap-)$ & $28,00 \%$ & $6,75 \%$ & $0,75 \%$ \\
\hline
\end{tabular}

Fonte: Autor 
A partir das probabilidades relacionadas na Tabela 19, verifica-se que a lógica da função historicoSorteioTempoSubstituir() foi desenvolvida de tal forma a priorizar, em simulações comportamentais otimistas, que as substituições de um componente do sistema em estudo serão executadas em um intervalo de tempo menor ou apenas ligeiramente maior do que o MTTR nominal estabelecido para o elemento sob avaliação. Dessa maneira, considerando-se que o módulo "Simulador de Dados de Entrada" seja configurado para gerar registros de histórico de operação do sistema em estudo representativos de seu funcionamento durante um período de tempo $T$, é esperado que os períodos de tempo durante os quais os componentes do sistema estão em processo de substituição em um cenário otimista sejam inferiores aos observados em situações normais e pessimistas.

Analogamente, a relação de probabilidades exposta na Tabela 19 permite inferir que, em simulações comportamentais pessimistas, é mais provável que haja proeminência de que as substituições de um componente do sistema em estudo serão desempenhadas em um intervalo de tempo significativamente superior ao MTTR nominal definido para o elemento sob avaliação. Por esse motivo, é esperado que os registros de histórico de operação produzidos pelo módulo "Simulador de Dados de Entrada" em cenários pessimistas de funcionamento do sistema em estudo indiquem que os períodos de tempo durante os quais os seus componentes estão em processo de substituição sejam superiores aos gerados em situações otimistas e normais.

Por fim, uma vez conhecidos os dois parâmetros da variação do tempo para substituir (faixa de variação do valor absoluto e sinal da variação), o intervalo de tempo a ser transcorrido para a substituição do componente desde o instante de ocorrência de seu último evento $S I_{i}$ é determinado por meio da soma da variação do tempo para substituir com o MTTR. A variação efetiva do tempo para substituir possui o sinal obtido com auxílio de num e o valor absoluto de um número pseudoaleatório sorteado com base em uma distribuição probabilística uniforme dentro da faixa de variação delimitada pelos fatores multiplicativos do MTTR nominal calculados com base em num2. 
4.4 Detalhamento do Módulo "Computação de Processos de Markov com HISTÓRICO DE OPERAÇÃO"

O módulo "Computação de Processos de Markov com Histórico de Operação" é o responsável por efetuar os cálculos matemáticos que permitem extrair, com base no modelo proposto no Capítulo 3, os índices de dependabilidade de um sistema em estudo a partir do uso de seu histórico operacional e de um modelo de Markov que descreve o comportamento do sistema.

Com base no fluxograma apresentado na Figura 29, é possível verificar que o módulo "Computação de Processos de Markov com Histórico de Operação" é acionado iterativamente no Ambiente de Desenvolvimento e Ensaio até que se conclua a computação dos índices de dependabilidade do sistema em estudo para o período de funcionamento $T$ definido como entrada. Em cada uma das iterações executadas, cabe ao módulo "Computação de Processos de Markov com Histórico de Operação" realizar, sequencialmente, as seguintes operações:

a) A primeira etapa de funcionamento do módulo "Computação de Processos de Markov com Histórico de Operação" prevê que os valores das taxas de falhas e de reparos dos componentes do sistema em estudo sejam atualizadas com base nos dados do histórico de operação (gerados pelo módulo "Simulador de Dados de Entrada") acumulados até o instante de tempo correspondente à iteração corrente. A atualização desses valores é feita mediante aplicação dos cálculos respaldados no padrão RIAC-HDBK-217Plus de forma aderente à apresentada nas seções 2.3.2 e 3.3;

b) Os valores das taxas de falhas e de reparos atualizados na etapa "a)" são utilizados para se calcular os novos valores das transições do modelo de Markov válidas para a iteração. Esse cálculo é baseado na substituição dos valores determinados no item "a)" nas expressões literais adquiridas previamente pelo módulo "Leitura da Especificação do Sistema";

c) Após esse procedimento, as transições calculadas no passo "b)" são normalizadas considerando-se $o$ valor do intervalo de tempo $\Delta t$ entre

\footnotetext{
${ }^{7}$ Para mais detalhes acerca do módulo "Leitura da Especificação do Sistema", consultar a seção 4.2.
} 
iterações de simulação, também adquirido pelo módulo "Leitura da Especificação do Sistema".

d) Uma vez concluída a execução do passo "c)", a matriz de transição de estados do modelo de Markov aplicável à iteração corrente está pronta para ser empregada na computação dos índices de dependabilidade do sistema em estudo. Para garantir que a matriz obtida seja válida, ela é inicialmente submetida a uma avaliação de consistência que visa verificar se a sua propriedade de semiconvergência foi mantida. Para tanto, utiliza-se o critério matemático definido na seção 2.4.2.2, que prevê que a propriedade de semiconvergência é atendida se o raio espectral (maior autovalor) da matriz de transição de estados é menor ou igual a 1.

Caso a propriedade de semiconvergência não seja observada, a simulação do modelo de Markov é interrompida; caso contrário, ela prossegue normalmente.

e) Por fim, a última etapa executada pelo módulo "Computação de Processos de Markov com Histórico de Operação" em uma iteração de funcionamento do Ambiente de Desenvolvimento e Ensaio consiste no cálculo das probabilidades de permanência de cada um dos estados do modelo de Markov considerando-se os valores das transições calculadas no passo c). Esse cálculo é efetuado utilizando-se a multiplicação matricial apresentada na equação (35) da seção 3.4 .

\subsection{Detalhamento do Módulo “Tratamento Estocástico e Filtragem Kalman PARA PREDIÇÃO DE FALHAS"}

O módulo "Tratamento Estocástico e Filtragem Kalman para Predição de Falhas" é responsável por determinar os instantes de tempo em que as próximas $k$ falhas de todos os componentes do sistema em estudo irão ocorrer a partir das falhas já registradas no histórico de operação do sistema em estudo. Para tanto, o módulo "Tratamento Estocástico e Filtragem Kalman para Predição de Falhas" foi desenvolvido com base no algoritmo do bloco "Detector de Comportamento e Filtro de Kalman" do modelo proposto no presente estudo científico, documentado na seção 3.5 . 
Para cada um dos componentes do sistema, cabe ao módulo "Tratamento Estocástico e Filtragem Kalman para Predição de Falhas" realizar, sequencialmente, as seguintes operações:

a) A primeira etapa de funcionamento do módulo "Tratamento Estocástico e Filtragem Kalman para Predição de Falhas" consiste em se extrair do histórico de operação do sistema os instantes de tempo de todas as $f$ falhas que ocorreram com o componente sob avaliação. Essa tarefa é executada por meio da filtragem, a partir do histórico de operação do sistema, dos instantes de tempo associados a todos os eventos de falha associados ao componente estudado (simbolizados pelo identificador $F_{i}$, sendo o índice $i$ indicativo do código numérico de identificação do componente);

b) A partir da relação dos instantes de tempo de todas as falhas associadas ao componente em estudo (determinada na etapa a)), são executados os cálculos necessários para que a função afim $f(\beta)=t_{\lambda}=a \cdot \beta+l$ abordada na seção 3.5 seja construída.

Sob o ponto de vista da implementação, todos os cálculos relacionados à regressão linear utilizada para determinar os valores dos coeficientes angular (a) e linear $(l)$ da função $f(\beta)$, bem como de suas respectivas variâncias, foram baseados na biblioteca polyfitn para $M A T L A B^{\Theta}$. Tal biblioteca, desenvolvida por um matemático pertencente à comunidade de usuários de $M A T L A B^{\circledR}$, estende as funcionalidades de regressão polinomial multidimensional nativas do $M A T L A B^{\circledR}$ (permitindo, por exemplo, que parâmetros como as variâncias dos coeficientes de uma regressão polinomial sejam obtidos) e está gratuitamente disponível para descarga na Internet (D'ERRICO, 2012).

c) Uma vez determinados os valores iniciais dos coeficientes angular $(a)$ e linear (l) da função $f(\beta)$, passa-se ao processo de iniciação do filtro de Kalman especificado na seção 3.5 , que possui as seguintes etapas: 
i. A entrada de dados $z(f+1)$ é iniciada utilizando-se o mesmo algoritmo de geração de números pseudoaleatórios empregado na função historicoSorteioTempoFalhar() do módulo "Simulador de Dados de Entrada"8 e considerando-se, como instante da última falha associada ao componente em estudo, o tempo associado ao evento mais recente de falha $\left(F_{i}\right)$ registrado no histórico de operação do sistema.

ii. A entrada de modelo $x(f)$ assume o valor apresentado na equação (47);

iii. A entrada de modelo $P(f)$ assume o valor apresentado na equação (48);

iv. A matriz $A$ assume o valor apresentado na equação (52);

v. A matriz $Q$ assume o valor apresentado na equação (53);

vi. A matriz $H$ assume o valor apresentado na equação (55);

vii. A matriz $R$ assume, conforme definido na equação (54), o valor da variância associada à entrada de dados $z(f+1)$. Considerando-se que o valor atribuído a $z(f+1)$ depende de um número pseudoaleatório gerado a partir de uma distribuição uniforme de probabilidades no intervalo [MTTF $*$ fatorMult $1 ; M T T F *$ fatorMult 2$], \quad$ sendo fatorMult1 e fatorMult2 dois números entre 0 e 1, a variância associada à entrada $z(f+1)$ pode ser calculada por intermédio da seguinte expressão matemática:

$$
\operatorname{Var}_{z(f+1)}=\frac{[(M T T F * \text { fatorMult } 2)-(\text { MTTF } * \text { fatorMult } 1)+1]^{2}-1}{12}
$$

d) Depois de o processo de iniciação do filtro de Kalman (definido no item c)) ter sido concluído, os instantes de tempo previstos para as próximas $k$ falhas do componente sob avaliação são determinados utilizando-se recursivamente o filtro de Kalman projetado, tal como ilustrado na Figura 27. O algoritmo empregado com essa finalidade pode ser descrito por intermédio do diagrama Nassi-Schneiderman da Figura 45.

\footnotetext{
${ }^{8} \mathrm{O}$ detalhamento da função historicoSorteioTempoFalhar() pertence ao escopo da seção 4.3.1.
} 
Figura 45 - Diagrama Nassi-Schneiderman do Algoritmo Utilizado para Calcular os Instantes de Tempo das k Próximas Falhas de um Componente mediante Utilização Recursiva do Filtro de Kalman

Iniciação das variáveis utilizadas para armazenar os valores das saídas de dados $\{x(f+1), \ldots, x(f+$ $k)\}$ e $\{P(f+1), \ldots, P(f+k)\}$ referentes às próximas $k$ falhas do componente sob avaliação.

Iniciação do iterador numFalhasPred com valor 1 .

Laço executado até que o iterador numFalhasPred supere o número $k$ de falhas a serem previstas.
Determinação, mediante uso das equações (60) a (66) do filtro de Kalman, dos valores de $x(f+$ numFalhasPred $) \mathrm{e}$

$P(f+$ numFalhasPred $)$ referentes à numFalhasPred-ésima falha a ser prevista.

Determinação, a partir da equação (59), da variância de $x(f+$ numFalhasPred) a partir das variâncias e covariâncias registradas em $P(f+$ numFalhasPred $)$ para a numFalhasPred-ésima falha prevista.

Determinação, por intermédio da função

historicoSorteioTempoFalhar (), do valor pseudoaleatório a ser atribuído à entrada de dados $z(f+$ numFalhasPred +1$)$ na próxima iteração de uso do filtro de Kalman.

Determinação do valor da variância da entrada de dados $z(f+$ numFalhasPred +1$)$, que será atribuída, na próxima iteração de uso do filtro de Kalman, à entrada de controle $R(f+$ numFalhasPred +1$)$.

numFalhasPred $\leftarrow$ numFalhasPred +1

\section{Fonte: Autor}

A partir do diagrama da Figura 45, é possível notar que as primeiras etapas do algoritmo desenvolvido relacionam-se à iniciação das principais variáveis utilizadas para determinar as $k$ próximas falhas do componente do sistema sob avaliação. Ao término dessa fase, as $k$ falhas futuras do componente são calculadas iterativamente, de tal forma que, em cada rodada de processamento, o instante de ocorrência da numFalhasPred-ésima falha futura seja determinado considerando-se as (numFalhasPred -1) falhas já previstas anteriormente.

Depois do cálculo do instante de tempo em que a numFalhasPred-ésima falha futura do componente em estudo irá ocorrer, também são determinados, em cada iteração, os valores da entrada de dados $z(f+$ numFalhasPred +1$)$ e da entrada de controle $R(f+$ numFalhasPred +1$)$, que serão utilizados na iteração seguinte (numFalhasPred +1 ). $O$ cálculo da entrada de dados $z(f+$ numFalhasPred +1$)$ baseia-se no algoritmo da função historicoSorteioTempoFalhar(), detalhada na seção 4.3.1, ao passo que o 
valor a ser assumido pela entrada de controle $R(f+$ numFalhasPred +1$)$ depende de $z(f+$ numFalhasPred +1$)$ e pode ser determinado mediante uso da equação (67), aplicável para qualquer valor de $\beta$ entre $f+1$ (caso específico da equação (67)) e $f+k$.

\subsection{CONSIDERAÇÕES FINAIS DO CAPÍTULO}

Apresentou-se neste capítulo o panorama geral do ambiente utilizado na implementação e no ensaio do modelo proposto no presente estudo científico. A descrição apresentada contemplou não só as principais características funcionais dos softwares desenvolvidos, mas também a especificação dos principais algoritmos utilizados na construção do ambiente de desenvolvimento e ensaio.

No capítulo seguinte, tal ambiente é utilizado como infraestrutura para os Estudos de Caso do modelo proposto neste trabalho científico, concebidos com o propósito de permitir a discussão sobre as contribuições do modelo aos métodos tradicionais de avaliação quantitativa dos índices de confiabilidade, disponibilidade e segurança de sistemas elétricos, eletrônicos e programáveis. 


\section{ESTUDOS DE CASO E ANÁLISE DOS RESULTADOS OBTIDOS}

Este capítulo da Dissertação de Mestrado reúne os principais resultados obtidos pela aplicação do modelo proposto neste estudo científico. Após se apresentar um breve panorama sobre os Estudos de Caso que foram conduzidos, cada um deles é detalhado de forma a se apresentar os resultados gerados mediante uso do ambiente de ensaio desenvolvido e as suas respectivas discussões.

\subsection{Panorama Geral dos Casos Estudados}

Com o propósito de se avaliar as contribuições do modelo proposto no presente estudo científico e as diferenças que ele introduz quando comparado às abordagens tradicionais de avaliação dos índices de dependabilidade de sistemas elétricos, eletrônicos e programáveis, foram vislumbrados os três seguintes estudos de caso:

a) Sistema Simples: Este estudo de caso, abordado na seção 5.2, prevê a avaliação dos índices de confiabilidade, disponibilidade e segurança crítica (safety) de um sistema formado por um único componente. No caso específico do modelo de disponibilidade, também pertencem ao escopo do Estudo de Caso dois ensaios referentes às predições de falhas futuras do sistema simples:

- O primeiro ensaio realizado visa avaliar a capacidade de cinco eventos de falha do sistema serem previstos a partir de um conjunto completo de dados operacionais pseudoaleatoriamente gerados;

- O segundo ensaio realizado visa avaliar a consistência das predições de falhas futuras produzidas pelo modelo a partir do cálculo de predições para as ocorrências das três últimas falhas preexistentes nos conjunto de dados operacionais pseudoaleatoriamente gerados e utilizados no primeiro ensaio. A escolha de três registros de histórico foi balizada com base na quantidade de dados de histórico produzidos no estudo de caso. 
b) Sistema Série com Dois Componentes: Este estudo de caso, tratado na seção 5.3, prevê a avaliação dos índices de confiabilidade, disponibilidade e segurança crítica (safety) de um sistema formado por dois componentes em série. No caso específico do modelo de disponibilidade, estudos referentes às predições de falhas futuras dos dois componentes do sistema também foram realizados nos mesmos moldes de ambos os ensaios vislumbrados com essa finalidade no caso do sistema simples;

c) Sistema Paralelo com Dois Componentes Redundantes: O presente estudo de caso, apresentado na seção 5.4, prevê que seja feita a avaliação dos índices de confiabilidade, disponibilidade e segurança crítica (safety) de um sistema formado por dois componentes redundantes em paralelo. No caso específico do modelo de disponibilidade, cenários análogos aos dois ensaios utilizados para avaliar as predições de falhas do sistema simples também foram empregados para cada um dos dois componentes do sistema paralelo.

Um aspecto a ser ressaltado relaciona-se à notação utilizada para descrever os parâmetros utilizados nas simulações computacionais executadas. No texto de todas as seções deste Capítulo, os símbolos $T_{\text {sim }}$ e $\Delta t_{\text {sim }}$ serão empregados para indicar, respectivamente, o tempo máximo (final) de uma simulação e o passo temporal compreendido entre duas iterações da simulação.

Devido à existência de análises detalhadas de todos os resultados obtidos, optou-se, ainda, por se apresentar um sumário das principais tendências comportamentais observadas em todos os cenários considerados no estudo. Esse resumo dos resultados é abordado na seção 5.5.

\subsection{AVALIAÇÃo de UM Sistema SimpLes}

O estudo de um sistema simples (formado por um único componente), apresentado nesta seção da Dissertação de Mestrado, contempla a avaliação dos índices de confiabilidade, disponibilidade e segurança crítica (safety) do sistema em quatro cenários distintos, que serão apresentados e comparados: 
- Cenário 1: Resultados gerados considerando-se a abordagem clássica de tratamento de processos de Markov (sem dependência de dados de histórico de operação);

- Cenário 2: Resultados gerados aplicando-se a técnica proposta neste estudo e utilizando-se dados de histórico simulados com base em um cenário operacional normal;

- Cenário 3: Resultados gerados aplicando-se a técnica proposta neste estudo e utilizando-se dados de histórico simulados com base em um cenário operacional otimista;

- Cenário 4: Resultados gerados aplicando-se a técnica proposta neste estudo e utilizando-se dados de histórico simulados com base em um cenário operacional pessimista.

\subsubsection{Função Confiabilidade}

Considerando-se a aproximação matemática da equação (16) para linearizar as taxas exponenciais das transições entre estados, o modelo de Markov de confiabilidade do sistema simples, inicialmente apresentado na Figura 13 (seção 2.4.1), pode ser simplificado de acordo com a versão exposta na Figura 46.

Figura 46 - Modelo de Markov da Confiabilidade do Sistema Simples

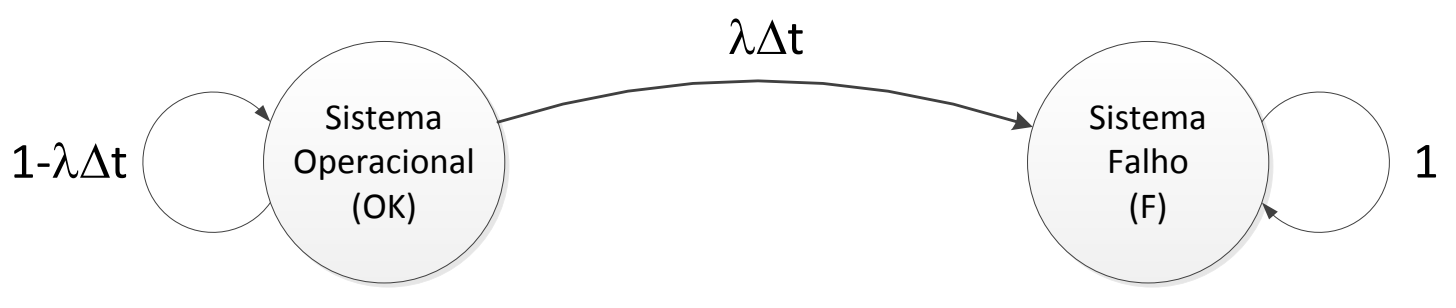

Fonte: Autor

Com base no modelo apresentado na Figura 46, a função confiabilidade do sistema simples é representada pela probabilidade de o sistema funcionar, ao longo do tempo, no estado "Sistema Operacional (OK)". Utilizando-se como parâmetros de simulação $\lambda=10^{-4}$ falhas $/ \mathrm{h}, T_{\text {sim }}=10^{5}$ horas e $\Delta t_{\text {sim }}=1$ hora, a função confiabilidade do sistema simples nos quatro cenários de estudo relacionados na seção 5.2 (abordagens sem histórico, com histórico normal, com histórico otimista e 
com histórico pessimista) pode ser representada pelos gráficos expostos na Figura 47.

Figura 47 - Gráficos da Função Confiabilidade do Sistema Simples nos Quatro Cenários Estudados

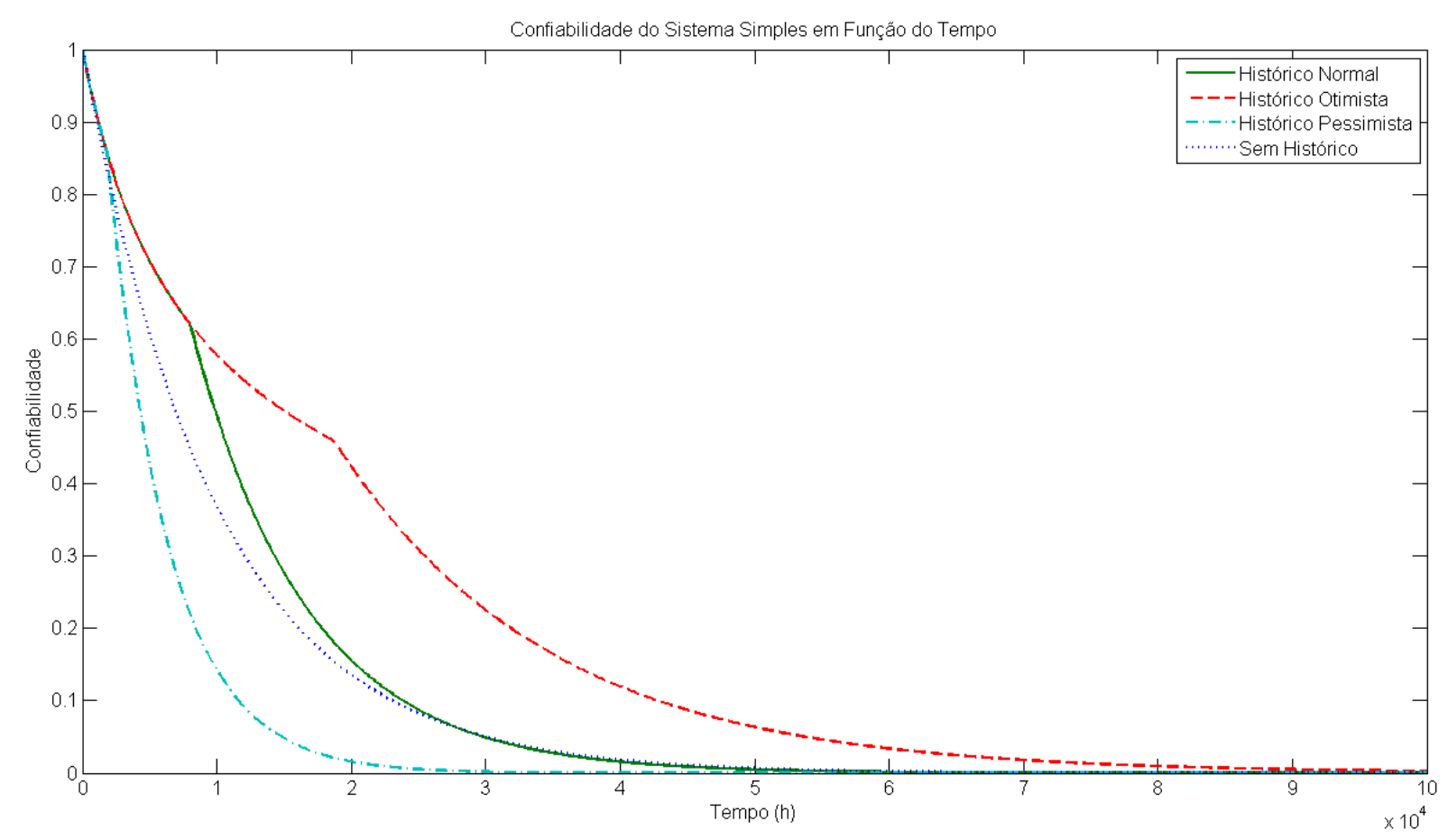

Fonte: Autor

Com base nos gráficos representados na Figura 47, verifica-se que 0 comportamento do sistema simples no cenário em que dados de histórico não são considerados é descrito pela lei exponencial $R(t)=e^{-\lambda t}$, já apresentada na seção 2.2.4. Esse resultado decorre do fato de a taxa de decaimento da confiabilidade do sistema, expressa pela taxa de falhas $\lambda$, não se alterar com o tempo.

Em todos os demais cenários considerados, a modelagem matemática definida para o bloco "Cálculo das Taxas de Falhas e de Reparos condicionadas ao Histórico de Operação" do modelo proposto, detalhada na seção 3.3 desta dissertação, promove a alteração gradual do valor da taxa de falhas $\lambda$ com o tempo de acordo com o seguinte princípio qualitativo, já explorado com maior profundidade na seção 3.3:

a) Enquanto um componente do sistema funciona normalmente, sua taxa de falhas decai gradualmente até que uma falha ocorra; 
b) Com a ocorrência de uma falha de um componente, a taxa de falhas do sistema cresce.

Considerando-se que o modelo de Markov da Figura 46 não prevê que procedimentos de manutenção sejam executados sobre o sistema simples, o módulo "Simulador de Dados de Entrada" do Ambiente de Desenvolvimento e Ensaio produziu apenas um evento de falha em cada um dos cenários estudados. A relação completa dos eventos de falha gerados pelo módulo "Simulador de Dados de Entrada" nos três ensaios que envolvem a incorporação de dados de histórico é apresentada na Tabela 20.

Tabela 20 - Eventos de Falha Gerados nos Cenários de Estudo da Confiabilidade do Sistema Simples com Histórico de Operação

\begin{tabular}{|c|c|}
\hline Ensaio Executado & Instante de Ocorrência do Evento de Falha \\
\hline Cenário 2 - Histórico Normal & $7999,326 \mathrm{~h}$ \\
\hline Cenário 3 - Histórico Otimista & $18706,382 \mathrm{~h}$ \\
\hline Cenário 4 - Histórico Pessimista & $1830,450 \mathrm{~h}$ \\
\hline
\end{tabular}

Fonte: Autor

Os instantes de tempo dos eventos de falha relacionados na Tabela 20 representam as abscissas dos "joelhos" dos gráficos da Figura 47 relacionados a cada um dos ensaios realizados. A partir desses pontos, nota-se que a taxa de decaimento da função confiabilidade dos três cenários que contemplam o uso de dados de histórico acentua-se devido ao aumento da taxa de falhas do sistema, tal como se pode observar nos gráficos da Figura 48. Tais gráficos descrevem a evolução da taxa de falhas do sistema simples nos quatro cenários considerados ao longo das primeiras 20.000 horas de estudo do sistema. Para todos os instantes de tempo posteriores a tal período inicial, a taxa de falhas do sistema manteve-se no mesmo patamar constatado ao final das primeiras 20.000 horas de avaliação. 
Figura 48 - Gráficos da Função Taxa de Falhas do Sistema Simples nos Quatro Cenários de Estudo da Função Confiabilidade

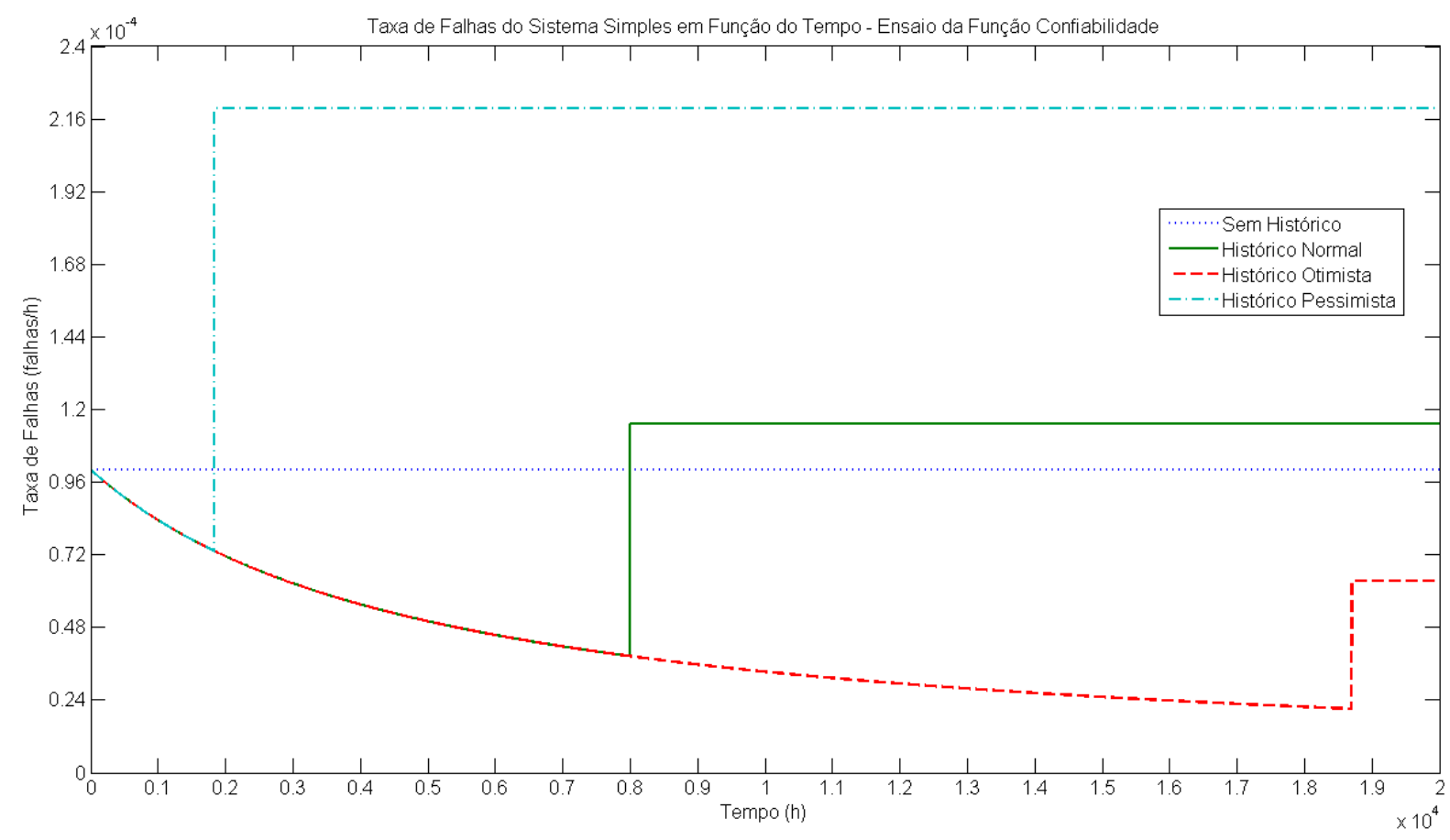

\section{Fonte: Autor}

Ao longo do intervalo de tempo $T_{\text {sim }}=10^{5}$ horas utilizado nas simulações matemáticas, é possível notar que os índices de confiabilidade observados no cenário em que se utiliza um histórico operacional otimista foram superiores aos constatados em todos os demais ensaios realizados. A obtenção desse resultado decorre do fato de o instante de ocorrência do evento de falha do sistema no ensaio com histórico otimista ter sido posterior tanto aos valores observados nas demais simulações com histórico, tal como se evidencia na Tabela 20 , quanto ao MTTF nominal do componente, que define o comportamento da confiabilidade do sistema na ausência de dados de histórico.

Esse mesmo comportamento também pode ser justificado considerando-se a taxa de falhas do sistema simples nos quatro cenários avaliados. Por intermédio da Figura 48, observa-se que a taxa de falhas do sistema na simulação em que se considera o uso de um histórico otimista é inferior à verificada em todos os demais cenários estudados. Em decorrência da menor taxa de falhas, a probabilidade de ocorrência de uma falha também diminui e, consequentemente, a confiabilidade do sistema simples observada no cenário baseado em um histórico otimista torna-se superior à constatada nos demais ensaios executados. 
A partir de aproximadamente 2000 horas de simulação, é possível notar que o cenário baseado no uso de um histórico pessimista caracterizou-se pelos menores índices de confiabilidade com relação a todos os demais ensaios realizados. Esse resultado se deve ao fato de a taxa de falhas do sistema ter sido elevada a um patamar superior ao de todos os outros cenários considerados em virtude da falha que ocorreu após aproximadamente 1830 horas de operação do sistema, tal como se pode verificar por meio dos gráficos da Figura 48.

Com relação ao cenário em que se faz uso de um histórico normal, é possível verificar, por intermédio da Figura 48, que a taxa de falhas do sistema passa a assumir um valor ligeiramente superior ao valor nominal $\lambda=10^{-4}$ falhas $/ h$ a partir de aproximadamente 8.000 horas de utilização do sistema, correspondente ao instante de tempo em que se manifesta o evento de falha apresentado na Tabela 20. A partir desse momento, o decaimento da função confiabilidade no ensaio baseado na utilização de um histórico normal passa a ocorrer mais rapidamente do que o observado na abordagem sem dados de histórico, até que, após o transcurso de um intervalo de tempo de aproximadamente 29.000 horas, a confiabilidade do sistema simples no ensaio que utiliza um histórico normal passa a ser inferior à observada no cenário sem a incorporação de registros de histórico.

Ao final do período de tempo $T_{\text {sim }}=10^{5}$ horas, as simulações executadas conduziram aos valores de confiabilidade relacionados na Tabela 21 , que ratificam a tendência comportamental apresentada anteriormente.

Tabela 21 - Confiabilidade do Sistema Simples após $T_{\text {sim }}=10^{5}$ horas

\begin{tabular}{|c|c|}
\hline Cenário Estudado & Confiabilidade do Sistema Simples \\
\hline Sem Histórico & $4,537 \cdot 10^{-5}$ \\
\hline Histórico Normal & $1,520 \cdot 10^{-5}$ \\
\hline Histórico Otimista & $2,679 \cdot 10^{-3}$ \\
\hline Histórico Pessimista & $3,704 \cdot 10^{-10}$ \\
\hline
\end{tabular}

Fonte: Autor 


\subsubsection{Função Segurança Crítica (Safety)}

Considerando-se a aproximação matemática da equação (16) para linearizar as taxas exponenciais das transições entre estados, o modelo de Markov de segurança crítica (safety) do sistema simples, inicialmente apresentado na Figura 15 (seção 2.4.1), pode ser simplificado de acordo com a versão exposta na Figura 49.

Figura 49 - Modelo de Markov da Segurança Crítica (Safety) do Sistema Simples

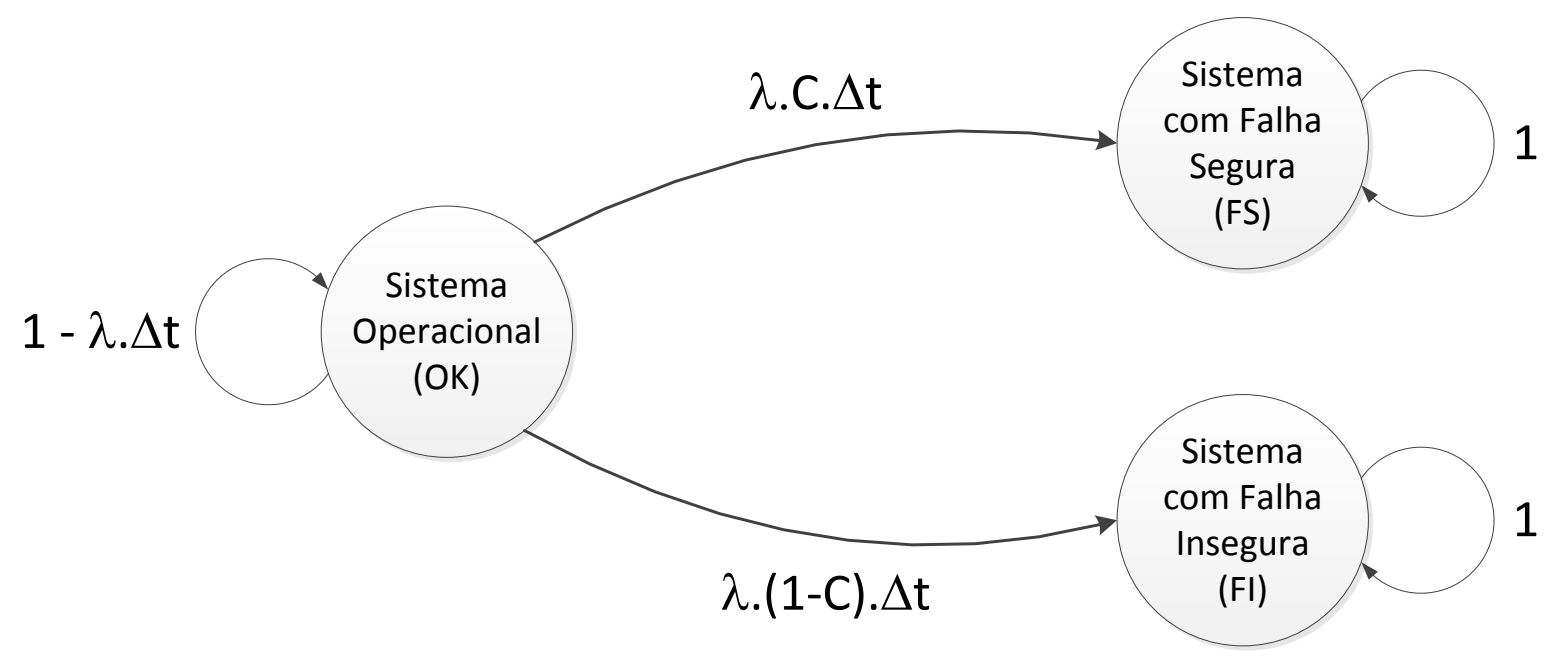

Fonte: Autor

Com base no modelo apresentado na Figura 49, a função segurança crítica (safety) do sistema simples é representada pela soma das probabilidades de 0 sistema funcionar, ao longo do tempo, nos estados "Sistema Operacional (OK)" e "Sistema com Falha Segura (FS)". Utilizando-se como parâmetros de simulação $\lambda=10^{-4}$ falhas $/ h, \quad C=0,9999, \quad T_{\text {sim }}=10^{6}$ horas e $\Delta t_{\text {sim }}=2$ horas, a função segurança crítica (safety) do sistema simples nos quatro cenários de estudo relacionados na seção 5.2 (abordagens sem histórico, com histórico normal, com histórico otimista e com histórico pessimista) pode ser representada pelos gráficos expostos na Figura 50. Com o propósito de melhorar a legibilidade dos resultados obtidos, os gráficos da Figura 50 foram plotados restringindo-se o domínio do eixo do tempo às primeiras 200.000 horas de estudo do sistema, uma vez que se constatou que, após esse intervalo de tempo inicial, os resultados obtidos alteram-se de forma pouco significativa. 
Figura 50 - Gráficos da Função Segurança Crítica (Safety) do Sistema Simples nos Quatro Cenários Estudados

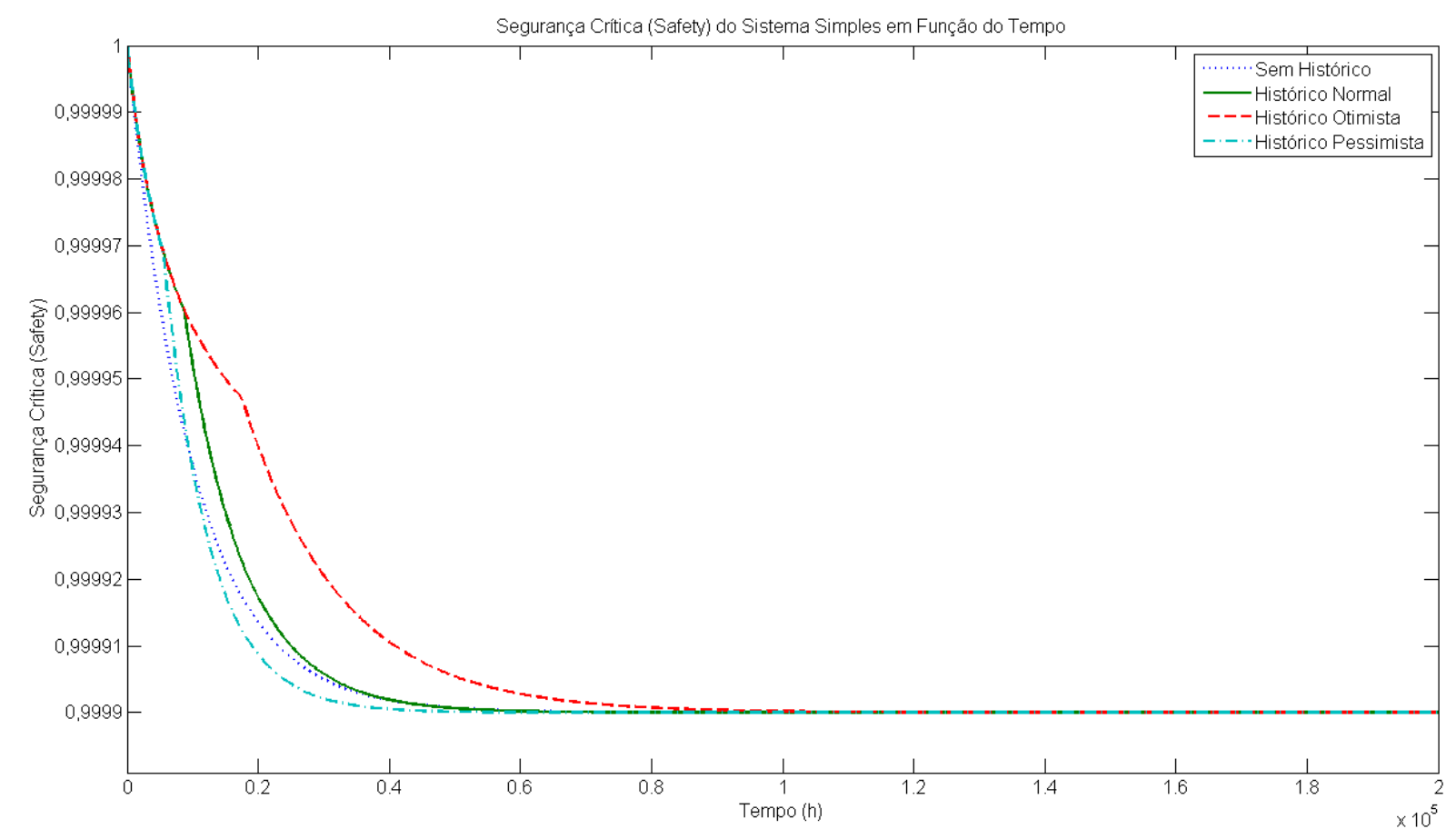

Fonte: Autor

Com base nos gráficos representados na Figura 50, é possível verificar que, em todos os ensaios considerados, a função segurança crítica (safety) do sistema simples tende a um valor assintótico que se aproxima de 0,9999, correspondente ao percentual de falhas seguras $C$. Em outras palavras, a probabilidade de ocorrência de uma falha insegura no sistema simples tende assintoticamente a $10^{-4}$, valor esse relacionado ao percentual de falhas inseguras que podem ocorrer dentro do universo de todas as falhas que podem acometer o sistema.

Ao final do tempo de simulação $T_{\text {sim }}=10^{6}$ horas, a variação relativa máxima do valor assumido pela função segurança crítica (safety) entre os quatro cenários estudados foi de apenas $2,6 \cdot 10^{-13}$, índice que pode ser considerado pouco expressivo frente ao valor absoluto 0,9999 da função segurança crítica (safety) no mesmo intervalo de tempo. Uma justificativa para esse resultado é a de que, como nenhum procedimento de manutenção foi considerado no modelo de Markov da segurança crítica (safety) do sistema, é esperado que, após um período de tempo de operação suficientemente longo, sua segurança crítica (safety) tenda ao seu percentual de falhas seguras. 
Um aspecto a ser ressaltado, no entanto, é o de que os instantes de tempo dos eventos de ocorrência de falha previstos nos três ensaios em que se faz uso de dados de histórico alteram a taxa de decaimento da função segurança crítica (safety). A relação completa dos eventos de falha gerados pelo módulo "Simulador de Dados de Entrada" nos cenários de estudo que envolvem dados de histórico é apresentada na Tabela 22.

Tabela 22 - Eventos de Falha Gerados nos Cenários de Estudo da Segurança Crítica (Safety) do Sistema Simples com Histórico de Operação

\begin{tabular}{|c|c|}
\hline Ensaio Executado & Instante de Ocorrência do Evento de Falha \\
\hline Cenário 2 - Histórico Normal & $8609,817 \mathrm{~h}$ \\
\hline Cenário 3 - Histórico Otimista & $17518,169 \mathrm{~h}$ \\
\hline Cenário 4 - Histórico Pessimista & $5479,876 \mathrm{~h}$ \\
\hline
\end{tabular}

Fonte: Autor

Analogamente ao estudo da função confiabilidade, detalhado na seção 5.2.1, os instantes de tempo dos eventos de falha relacionados na Tabela 22 representam as abscissas dos pontos dos gráficos da Figura 50 a partir dos quais a taxa de decaimento da função segurança crítica (safety) de cada um dos respectivos cenários acentua-se devido ao aumento da taxa de falhas do sistema. A evolução temporal da taxa de falhas ao longo das primeiras 20.000 horas de estudo do sistema simples nos quatro cenários considerados é apresentada na Figura 51. Para todos os instantes de tempo posteriores a tal período inicial, a taxa de falhas do sistema manteve-se no mesmo patamar constatado ao final das primeiras 20.000 horas de avaliação. 
Figura 51 - Gráficos da Função Taxa de Falhas do Sistema Simples nos Quatro Cenários de Estudo da Função Confiabilidade

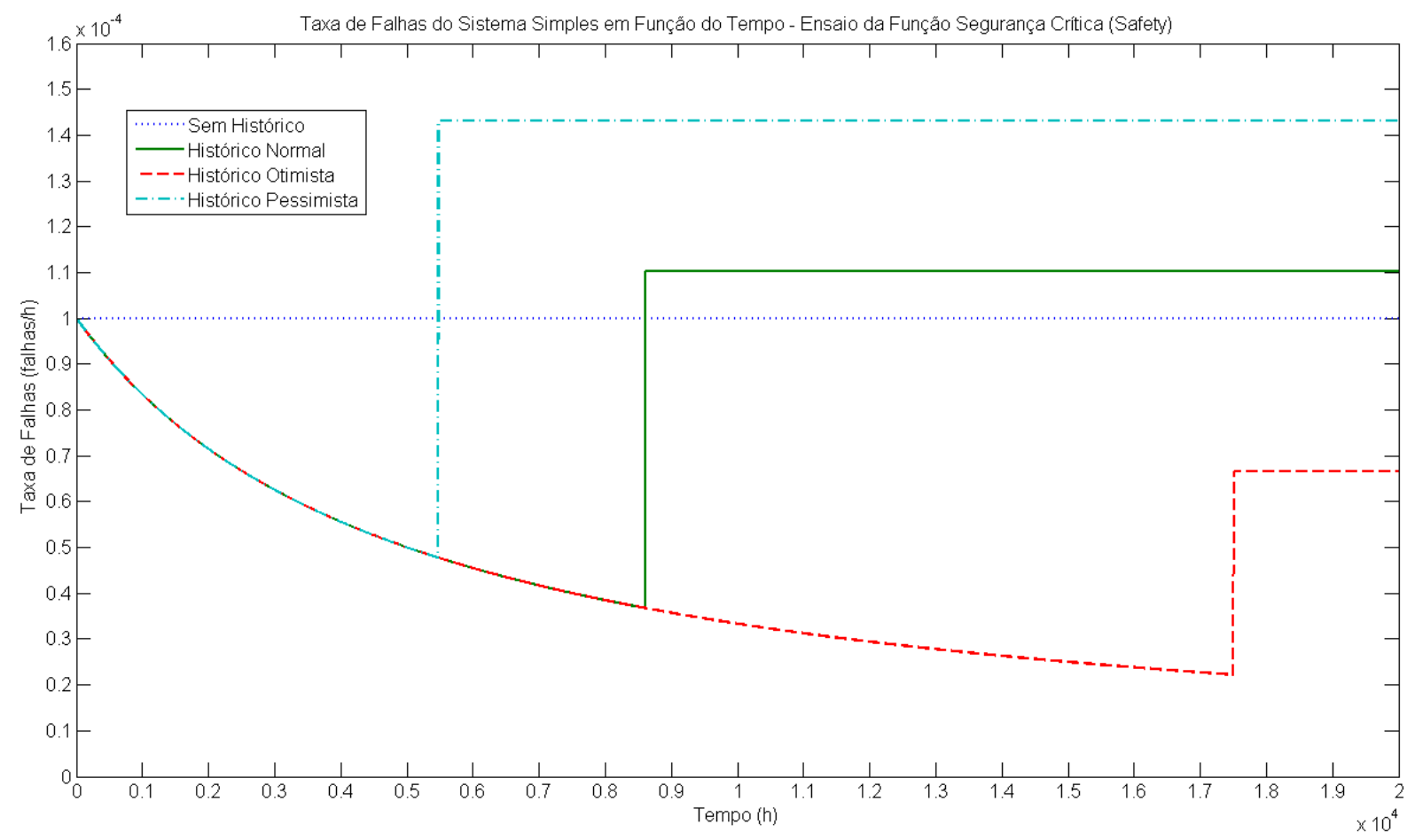

Fonte: Autor

Sob o ponto de vista qualitativo, é possível notar que as taxas de falhas obtidas nos quatro cenários considerados para o estudo da função segurança crítica (safety) respeitam a mesma ordenação crescente de magnitude já observada nos ensaios relacionados à função confiabilidade. Ao se comparar a Figura 48 e a Figura 51, a seguinte tendência pode ser constatada:

a) A menor taxa de falhas do sistema simples é obtida no cenário em que se utiliza um histórico otimista;

b) A segunda menor taxa de falhas do sistema simples é obtida no cenário em que não são empregados dados de histórico;

c) A segunda maior taxa de falhas do sistema é obtida no cenário em que se utiliza um histórico normal;

d) A maior taxa de falhas do sistema é obtida no cenário em que se utiliza um histórico pessimista. 
Considerando-se tal característica qualitativa, as mesmas justificativas utilizadas na seção 5.2.1 para o estudo da função confiabilidade podem ser estendidas à avaliação dos resultados relativos à função segurança crítica (safety):

a) Como a taxa de falhas do ensaio baseado no uso de um histórico otimista é a menor entre todas as simulações, a segurança crítica (safety) nessa simulação decai mais lentamente do que nas demais. Considerando-se o gráfico representado na Figura 50, observa-se que o valor assintótico de 0,9999 para a segurança crítica (safety) do sistema simples é atingida aproximadamente após 100.000 horas de estudo;

b) Como a taxa de falhas do ensaio baseado no uso de um histórico pessimista é a maior entre todas as simulações, a segurança crítica (safety) nessa simulação decai mais rapidamente do que nas demais. Considerando-se o gráfico representado na Figura 50, observa-se que o valor assintótico de 0,9999 para segurança crítica (safety) do sistema simples é atingida aproximadamente após 45.000 horas de estudo;

c) Com relação ao cenário em que se faz uso de um histórico normal, é possível verificar, por intermédio da Figura 50, que o decaimento da função segurança crítica (safety) mais lento do que o observado no ensaio sem histórico até aproximadamente 9.000 horas de utilização do sistema, correspondente ao instante de tempo em que se manifesta o evento de falha apresentado na Tabela 22. A partir desse ponto, a taxa de falhas do sistema no cenário de uso de histórico normal passa a assumir um valor ligeiramente superior ao valor nominal $\lambda=10^{-4}$ falhas $/ h$ e, consequentemente, a função segurança crítica (safety) passa a decair mais rapidamente do que na abordagem sem dados de histórico. Em ambos os ensaios, a convergência da segurança crítica (safety) ao seu valor assintótico 0,9999 ocorre aproximadamente após 60.000 horas de estudo do sistema.

\subsubsection{Função Disponibilidade}

Considerando-se a aproximação matemática da equação (16) para linearizar as taxas exponenciais das transições entre estados, pode-se elaborar o modelo de 
Markov de disponibilidade do sistema simples de acordo com a versão apresentada na Figura $52^{9}$.

Figura 52 - Modelo de Markov da Disponibilidade do Sistema Simples

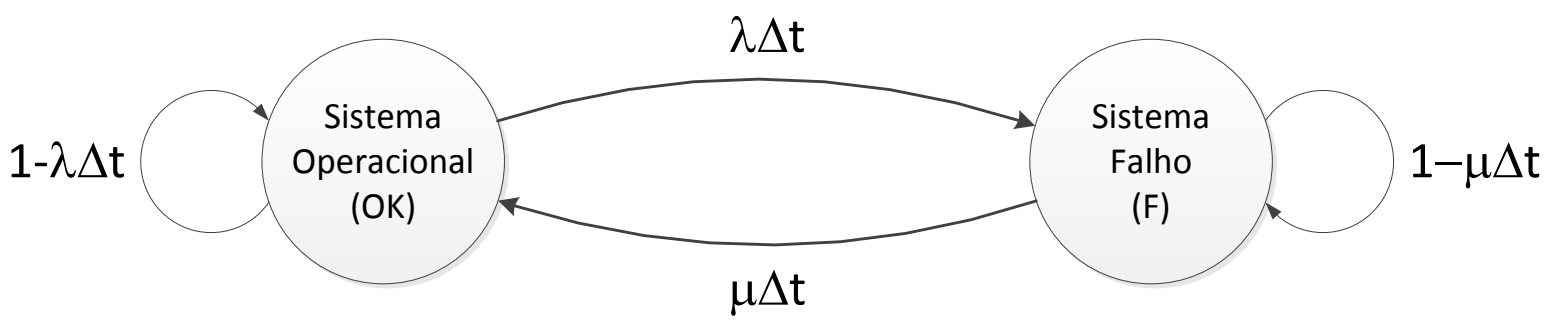

Fonte: Autor

Com base no modelo apresentado na Figura 52, a função disponibilidade do sistema simples é representada pela probabilidade de o sistema funcionar, em um dado instante de tempo, no estado "Sistema Operacional (OK)". Utilizando-se como parâmetros de simulação $\lambda=10^{-4}$ falhas $/ h, \mu=1$ reparo $/ h T_{\text {sim }}=10^{5}$ horas e $\Delta t_{\text {sim }}=0,5$ hora, a função disponibilidade do sistema simples nos quatro cenários de estudo relacionados na seção 5.2 (abordagens sem histórico, com histórico normal, com histórico otimista e com histórico pessimista) pode ser representada pelos gráficos expostos na Figura 53.

9 O modelo de Markov simplificado que representa a disponibilidade do sistema simples já havia sido apresentado anteriormente na Figura 16 (seção 2.4.1), mas preferiu-se repeti-lo na Figura 52 para melhorar 0 entendimento a respeito do Estudo de Caso. 
Figura 53 - Gráficos da Função Disponibilidade do Sistema Simples nos Quatro Cenários Estudados

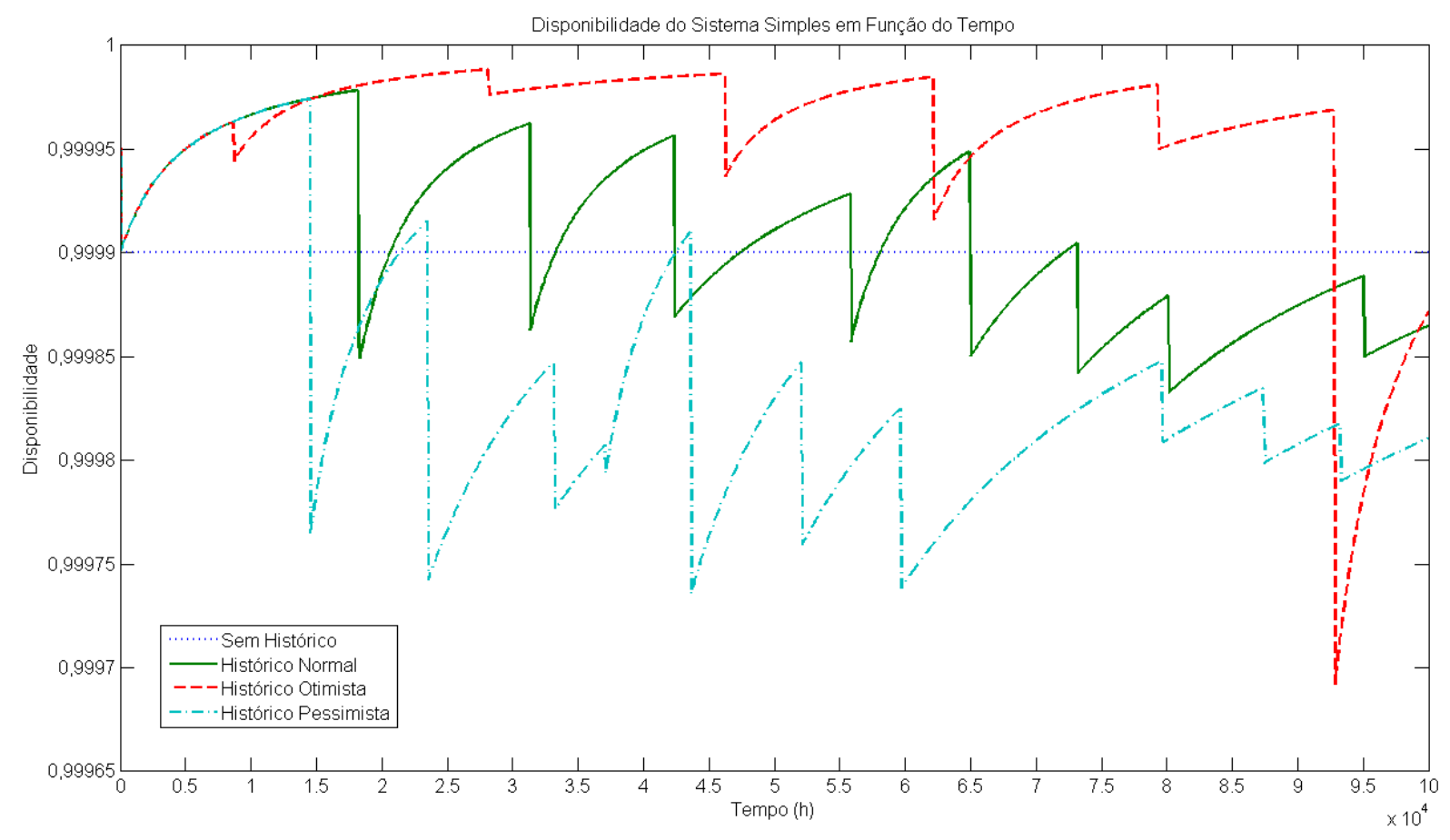

Fonte: Autor

Com auxílio da Figura 53, é possível observar que a disponibilidade do sistema simples determinada no cenário em que não se consideram dados de histórico de operação atingiu seu valor assintótico rapidamente, ainda nas primeiras iterações de cálculo que foram executadas. O valor numérico obtido para a disponibilidade assintótica no ensaio sem uso de dados de histórico é igual a 0,99990001, que coincide precisamente com a estimativa teórica obtida por meio da equação (5).

Já nos três cenários que preveem o uso de dados de histórico de operação, foram observadas oscilações no comportamento da função disponibilidade ao longo de todo o período de tempo $T_{\text {sim }}=10^{5}$ horas considerado no estudo. Mesmo com as flutuações verificadas, as seguintes tendências comportamentais da função disponibilidade podem ser extraídas dos gráficos da Figura 53: 
a) Na maior parte do intervalo de tempo $T_{\text {sim }}=10^{5}$ horas, a disponibilidade do sistema simples no cenário baseado no uso de um histórico otimista foi superior à constatada em todos os demais ensaios realizados;

b) Analogamente, a disponibilidade do sistema simples no cenário em que se empregou um histórico pessimista foi inferior à verificada em todos os demais ensaios realizados na maior parte do período de tempo $T_{\text {sim }}=10^{5}$ horas;

c) Com relação ao ensaio baseado na utilização de um histórico normal, é possível constatar que, na primeira metade do intervalo de tempo $T_{\text {sim }}=$ $10^{5}$ horas, a disponibilidade do sistema foi maior do que o valor assintótico obtido no cenário em que não se fez uso de dados de histórico. Na segunda metade do intervalo de tempo $T_{\text {sim }}=10^{5}$ horas, a tendência constatada na primeira metade inverteu-se e, consequentemente, a disponibilidade do sistema no ensaio em que se empregou um histórico normal passou a ser inferior ao valor assintótico determinado no cenário que desconsidera o uso de dados de histórico. Quando os gráficos da taxa de falhas do sistema nos quatro ensaios forem apresentados posteriormente, ficará evidente que essa inversão de comportamento decorre da maior frequência dos eventos de falha do sistema na segunda metade do ensaio, que ocorreram, em média, em intervalos de tempo inferiores ao seu MTTF nominal.

As flutuações observadas no gráfico da Figura 53 decorrem do tratamento dado aos eventos de falhas e manutenções registrados no histórico de operação do sistema pelo bloco "Cálculo das Taxas de Falhas e de Reparos condicionadas ao Histórico de Operação" ${ }^{\prime 10}$ do modelo proposto no trabalho, que promove alterações nos valores das taxas de falhas e de reparos do sistema simples a cada iteração de cálculo executada. A relação completa dos eventos de falhas e manutenções dos históricos operacionais gerados pelo módulo "Simulador de Dados de Entrada" do ambiente de desenvolvimento e ensaio nos cenários normal, otimista e pessimista é apresentada no Apêndice A.1.

As funções que descrevem a evolução temporal das taxas de falhas e de reparos do sistema simples nos quatro cenários estudados são graficamente

\footnotetext{
${ }^{10}$ Para maiores informações acerca do bloco "Cálculo das Taxas de Falhas e de Reparos condicionadas ao Histórico de Operação”, consultar a seção 3.3.
} 
representadas na Figura 54 e na Figura 55. Um aspecto a ser ressaltado é o de que, a partir da Figura 54, é possível confirmar a informação prévia de que os eventos de falha do sistema simples na segunda metade do ensaio baseado no uso de um histórico normal não só foram mais frequentes do que os observados na primeira metade da simulação, mas também ocorreram, em média, em períodos de tempo inferiores ao MTTF nominal do sistema simples.

Figura 54 - Gráfico da Taxa de Falhas do Sistema Simples nos Quatro Cenários de Estudo da Função Disponibilidade

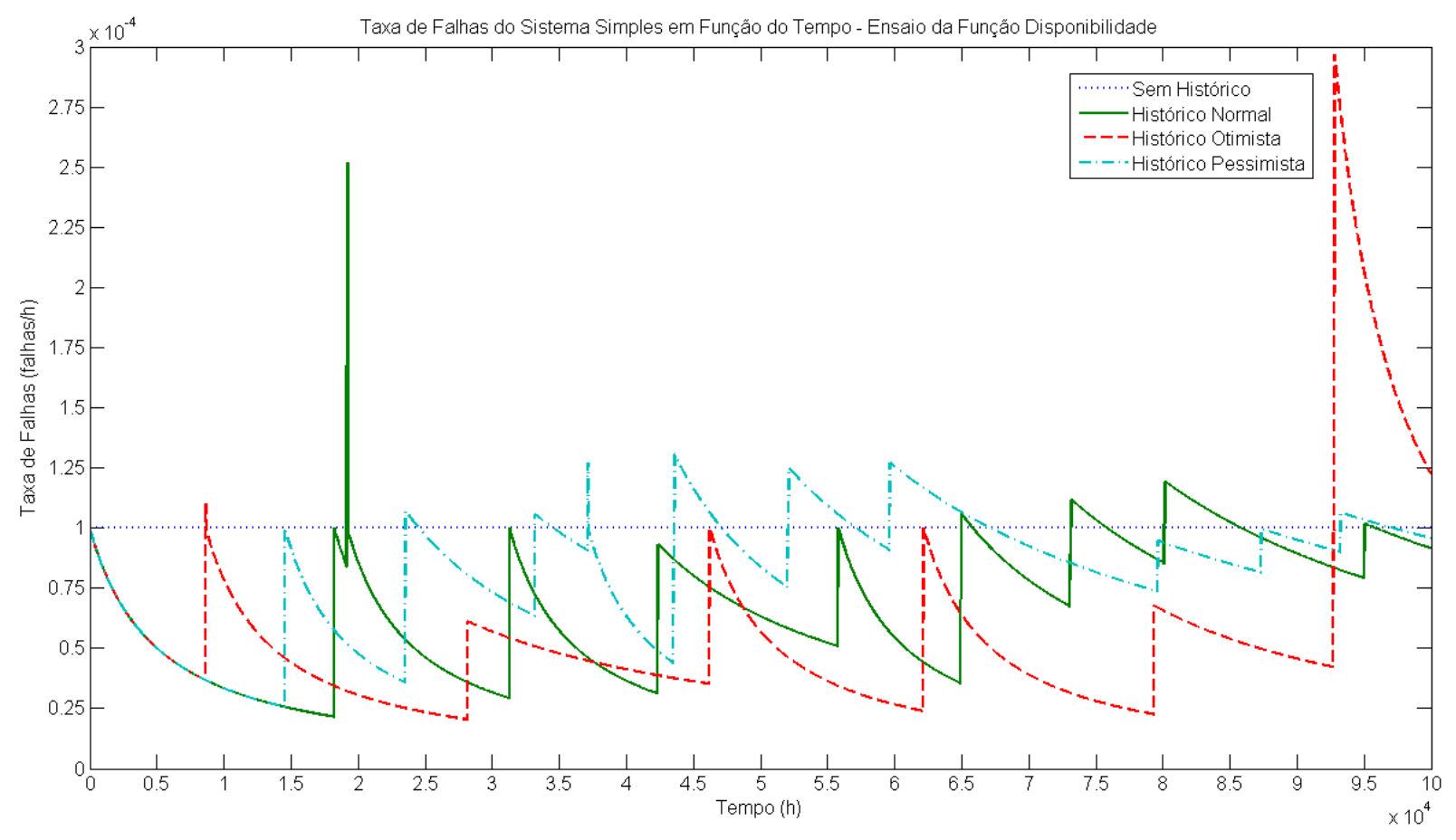

Fonte: Autor 
Figura 55 - Gráfico da Taxa de Reparos do Sistema Simples nos Quatro Cenários de Estudo da Função Disponibilidade

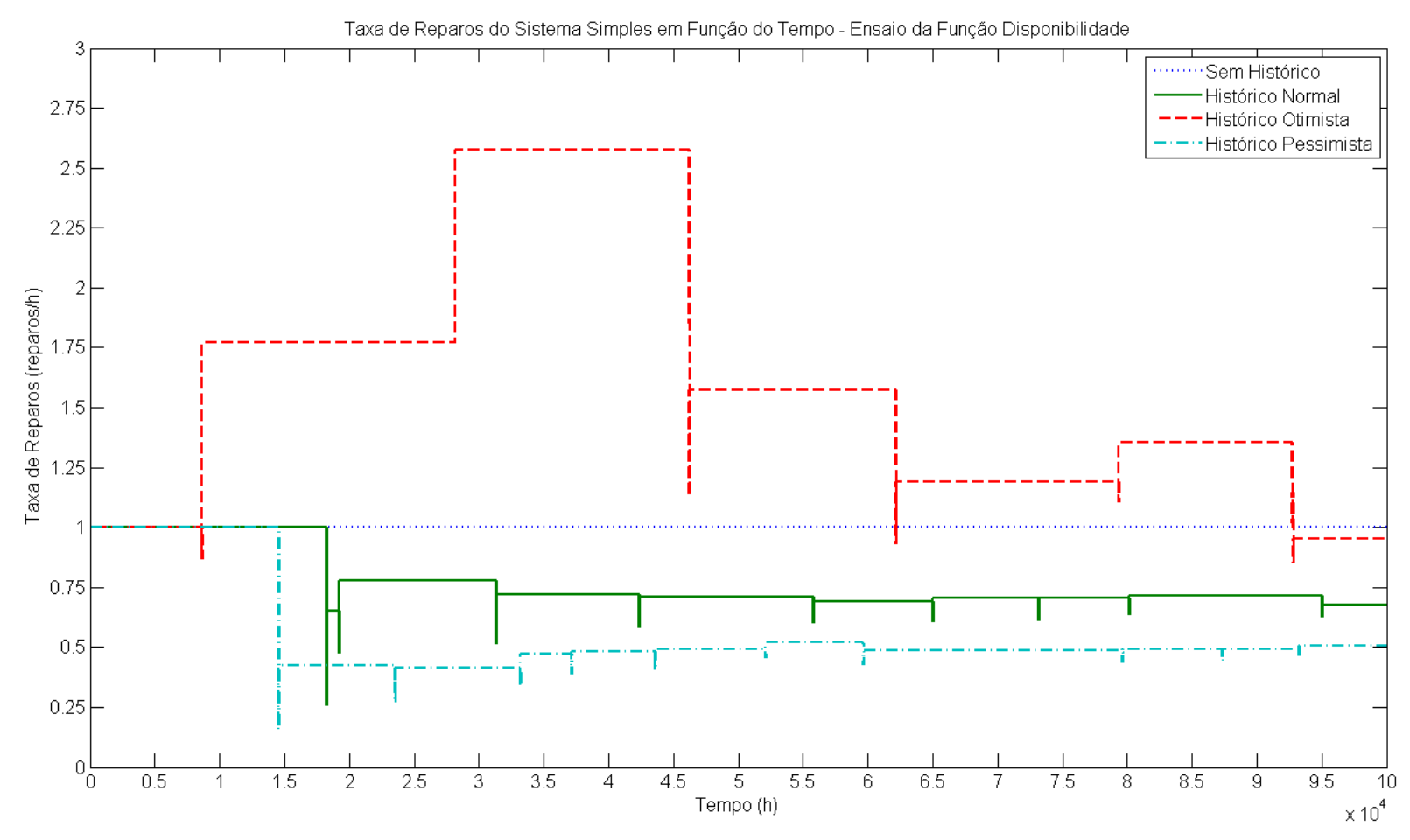

Fonte: Autor

Ao se interpretar de forma conjunta os gráficos apresentados na Figura 53, na Figura 54 e na Figura 55, é possível observar que, em todos os três cenários que envolvem a utilização de dados de histórico, elevações no índice de disponibilidade do sistema simples ocorrem nos períodos de tempo durante os quais a taxa de falhas do sistema assume comportamento decrescente. Sempre que ocorre um ponto de máximo local na função da taxa de falhas do sistema simples, a função disponibilidade experimenta uma queda, que é refletida em seus respectivos pontos de mínimo locais.

Embora os efeitos sejam menos significativos do que os determinados pela taxa de falhas, as oscilações na taxa de reparos também impactam sobre o perfil da disponibilidade do sistema simples. O comportamento que deve ser considerado é o de que a disponibilidade aumenta à medida que a taxa de reparos também aumenta, de tal modo a se refletir a tendência natural de que o sistema estará mais disponível com a diminuição do seu tempo de manutenção.

Outro comportamento relevante que deve ser ressaltado está relacionado à tendência assintótica de a taxa de reparos variar menos significativamente à medida 
que a simulação evolui. Esse comportamento deve-se ao algoritmo utilizado na implementação do módulo de "Cálculo das Taxas de Falhas e de Reparos condicionadas ao Histórico de Operação" do modelo proposto para determinar a evolução temporal dos parâmetros $a_{1}$ e $b_{1}^{\prime}$ da equação (41), que são cumulativos durante todo o período de tempo em que se avalia o comportamento do sistema. Com base na equação (41), é esperado que a taxa de reparos tenda ao quociente $a_{1} / b_{1}^{\prime}$ à medida que o parâmetro $a_{1}$ aumenta.

Um motivo análogo justifica o fato de a taxa de falhas, por sua vez, evoluir com variações mais significativas ao longo do tempo. Na implementação do módulo de "Cálculo das Taxas de Falhas e de Reparos condicionadas ao Histórico de Operação", o algoritmo utilizado para a atualização iterativa da taxa de falhas prevê que os parâmetros $a_{1}$ e $b_{1}^{\prime}$ da equação (38) sejam reiniciados sempre que ocorrer um evento de final de substituição do componente $\left(S F_{1}\right)$, o que, por sua vez, diminui a probabilidade de uma eventual convergência da taxa de falhas ao seu valor assintótico $\frac{a_{1}}{b_{1}^{\prime}}$.

Ao final do período de tempo $T_{\text {sim }}=10^{5}$ horas, as simulações executadas conduziram aos valores de disponibilidade relacionados na Tabela 23.

Tabela 23 - Disponibilidade do Sistema Simples após $T_{\text {sim }}=10^{5}$ horas

\begin{tabular}{|c|c|}
\hline Cenário Estudado & Disponibilidade do Sistema Simples \\
\hline Sem Histórico & 0,99990001 \\
\hline Histórico Normal & 0,99986503 \\
\hline Histórico Otimista & 0,99987156 \\
\hline Histórico Pessimista & 0,99981075 \\
\hline
\end{tabular}

Fonte: Autor

Além do levantamento da curva da função disponibilidade ao longo do período de tempo $T_{\text {sim }}=10^{5}$ horas, também foram produzidas, ao final dos três ensaios baseados no uso de dados de histórico, as estimativas dos instantes de tempo das cinco próximas falhas que deveriam ocorrer com o sistema simples no 
futuro. Tais valores, juntamente com os respectivos desvios padrão, são apresentados na Tabela 24.

Tabela 24 - Relação das Cinco Próximas Falhas do Sistema Simples após $T_{s i m}=10^{5}$ horas

\begin{tabular}{|c|c|c|c|c|c|c|}
\cline { 2 - 7 } \multicolumn{1}{c|}{} & \multicolumn{2}{c|}{ Histórico Normal } & \multicolumn{2}{c|}{ Histórico Otimista } & \multicolumn{2}{c|}{ Histórico Pessimista } \\
\cline { 2 - 7 } & $\begin{array}{c}\text { Tempo de } \\
\text { Ocorrência (h) }\end{array}$ & $\begin{array}{c}\text { Desvio } \\
\text { Padrão } \\
\text { (h) }\end{array}$ & $\begin{array}{c}\text { Tempo de } \\
\text { Ocorrência (h) }\end{array}$ & $\begin{array}{c}\text { Desvio } \\
\text { Padrão } \\
\text { (h) }\end{array}$ & $\begin{array}{c}\text { Tempo de } \\
\text { Ocorrência (h) }\end{array}$ & $\begin{array}{c}\text { Desvio } \\
\text { Padrão } \\
\text { (h) }\end{array}$ \\
\hline $\begin{array}{c}\text { Falha } \\
\mathbf{1}\end{array}$ & 107462,8 & 2900,8 & 97687,2 & 6808,8 & 103461,3 & 3587,0 \\
\hline $\begin{array}{c}\text { Falha } \\
\mathbf{2}\end{array}$ & 120207,8 & 2926,5 & 113392,9 & 6656,1 & 112231,5 & 3598,8 \\
\hline $\begin{array}{c}\text { Falha } \\
\mathbf{3}\end{array}$ & 134210,9 & 2954,7 & 128051,1 & 5847,9 & 120449,8 & 3586,9 \\
\hline $\begin{array}{c}\text { Falha } \\
\mathbf{4}\end{array}$ & 146059,8 & 2897,6 & 136959,5 & 5159,1 & 130096,8 & 3288,7 \\
\hline $\begin{array}{c}\text { Falha } \\
\mathbf{5}\end{array}$ & 156796,8 & 2693,5 & 148411,4 & 4452,7 & 138843,6 & 3152,6 \\
\hline
\end{tabular}

Fonte: Autor

Ao se avaliar os resultados relacionados na Tabela 24, é possível notar que há uma tendência de queda no valor do desvio padrão à medida que mais eventos de falhas futuras são previstos. Uma justificativa plausível para esse resultado é a propriedade dos Filtros de Kalman de minimização de erros estatísticos: como o bloco "Detector de Comportamento e Filtro de Kalman"11 considera, no cálculo da $i$ ésima falha futura, os instantes de todas as ( $i-1)$ falhas já previstas por ele, o erro estatístico associado a todas essas (i-1) falhas é minimizado pelo Filtro de Kalman quando o instante da $i$-ésima falha futura é calculado. No entanto, um aspecto a ser ressaltado é o de que, se um registro de falha futura muito distante do modelo de função afim utilizado pelo bloco "Detector de Comportamento e Filtro de Kalman" for empregado como referência para gerar da i-ésima falha futura do sistema, há a possibilidade de o desvio padrão associado a tal falha ser superior ao verificada para as falhas anteriores.

\footnotetext{
${ }^{11}$ Mais informações referentes ao módulo "Detector de Comportamento e Filtro de Kalman" do modelo proposto estão disponíveis na seção 3.5 .
} 
Outro aspecto a ser salientado é o de que os valores dos desvios padrão das falhas futuras do sistema simples no cenário em que se utiliza um histórico otimista são significativamente superiores aos verificados nos outros dois ensaios. Esse resultado pode ser sustentado por um ajuste ineficiente dos registros de falha do histórico à função afim prevista pela regressão linear executada pelo bloco "Detector de Comportamento e Filtro de Kalman" do modelo proposto, uma vez que, nessas condições, é esperado que as variâncias associadas aos coeficientes angular e linear da função produzida pela regressão linear sejam mais elevados.

A dificuldade de ajuste dos instantes de ocorrência de falhas por meio da regressão linear prevista no bloco "Detector de Comportamento e Filtro de Kalman" se deve à ocorrência de duas falhas consecutivas do sistema entre 92.700 e 92.800 horas de estudo do sistema, tal como se pode constatar inspecionando-se o histórico operacional apresentado na Tabela 53 do Apêndice A.1. Embora esses dois pontos não possam ser visualizados com precisão nos gráficos da Figura 53 e da Figura 54, é possível notar que tais falhas provocaram, aproximadamente na metade do intervalo entre 90.000 e 95.000 horas de simulação, um aumento significativo da taxa de falhas do sistema e, consequentemente, uma redução brusca de sua disponibilidade.

Outro resultado influenciado pela dificuldade de se ajustar os eventos de falha à função afim definida no modelo proposto é o instante de tempo da ocorrência da primeira falha futura do sistema no cenário em que se utiliza um histórico otimista. A partir da Tabela 24, é possível notar que o instante de tempo da primeira falha prevista para ocorrer com o sistema simples é inferior ao período $T_{\text {sim }}=10^{5}$ horas, sendo possível inferir, portanto, que a primeira falha futura determinada pelo modelo proposto situa-se, na verdade, no passado.

Comparando-se os instantes de tempo das predições realizadas nos três cenários, é possível notar que as falhas previstas no ensaio em que se utiliza um histórico pessimista tendem a ocorrer em intervalos de tempo inferiores aos determinados nos dois outros cenários. Esse comportamento evidencia que, pelo menos nos ensaios executados empregando-se históricos normal e pessimista, os algoritmos inerentes ao bloco "Detector de Comportamento e Filtro de Kalman" do modelo proposto conseguiram extrair a tendência comportamental dos intervalos de 
tempo entre eventos de falha do histórico operacional e utilizá-la como referência para determinar os instantes de ocorrência das falhas futuras.

Ainda com o propósito de permitir avaliar os algoritmos de predição de falhas utilizados pelo bloco "Detector de Comportamento e Filtro de Kalman" do modelo desenvolvido neste trabalho, foram executados experimentos complementares com o objetivo de que os três últimos eventos já presentes no histórico operacional do sistema simples fossem previstos considerando-se os instantes de ocorrência de todas as falhas anteriores a elas. Os resultados obtidos nesse estudo para os três cenários com uso de histórico operacional são exibidos na Tabela 25, na Tabela 26 e na Tabela $27^{12}$.

Tabela 25 - Comparação dos Instantes de Ocorrência das Três Últimas Falhas do Sistema Simples com as Previsões Produzidas pelo Modelo Proposto - Ensaio Baseado em Histórico Normal

\begin{tabular}{|c|c|c|c|}
\cline { 2 - 4 } \multicolumn{1}{c|}{} & Falha 1 & Falha 2 & Falha 3 \\
\hline Instante Real de Ocorrência (h) $-t_{\text {real }}$ & 73170,1 & 80144,8 & 95045,4 \\
\hline Instante Previsto (h) $-t_{\text {prev }}$ & 83541,9 & 90524,0 & 97485,1 \\
\hline Variância $\left.\mathbf{( h}^{\mathbf{2}}\right)-\sigma_{t_{\text {prev }}}$ & 18793572,6 & 19108213,2 & 17360649,8 \\
\hline Desvio Padrão (h) $-\sigma_{t_{\text {prev }}}$ & 4335,2 & 4371,3 & 4166,6 \\
\hline Erro Relativo entre Real e (Previsto - Desvio) & 0,0825 & 0,0750 & $-0,0182$ \\
\hline Erro Relativo entre Real e Previsto & 0,1417 & 0,1295 & 0,0257 \\
\hline Erro Relativo entre Real e (Previsto + Desvio) & 0,2010 & 0,1840 & 0,0695 \\
\hline
\end{tabular}

Fonte: Autor

12 Os valores registrados nas células das linhas "Instante Real de Ocorrência ( $h$ )" das tabelas correspondem aos instantes de tempo dos três últimos eventos "F1" registrados nas respectivas tabelas do Apêndice A.1. 
Tabela 26 - Comparação dos Instantes de Ocorrência das Três Últimas Falhas do Sistema Simples com as Previsões Produzidas pelo Modelo Proposto - Ensaio Baseado em Histórico Otimista

\begin{tabular}{|c|c|c|c|}
\cline { 2 - 4 } \multicolumn{1}{c|}{} & Falha 1 & Falha 2 & Falha 3 \\
\hline Instante Real de Ocorrência (h) $-t_{\text {real }}$ & 79305,2 & 92732,7 & 92788,1 \\
\hline Instante Previsto (h) $-t_{\text {prev }}$ & 81118,8 & 98354,6 & 110086,9 \\
\hline Variância $\left.\mathbf{( h}^{\mathbf{2}}\right)-\sigma_{t_{\text {prev }}}$ & 4466252,7 & 4614274,0 & 4253431,4 \\
\hline Desvio Padrão (h) $-\sigma_{t_{\text {prev }}}$ & 2113,4 & 2148,1 & 2062,4 \\
\hline Erro Relativo entre Real e (Previsto - Desvio) & $-0,0038$ & 0,0375 & 0,1642 \\
\hline Erro Relativo entre Real e Previsto & 0,0229 & 0,0606 & 0,1864 \\
\hline Erro Relativo entre Real e (Previsto + Desvio) & 0,0495 & 0,0838 & 0,2087 \\
\hline
\end{tabular}

Fonte: Autor

Tabela 27 - Comparação dos Instantes de Ocorrência das Três Últimas Falhas do Sistema Simples com as Previsões Produzidas pelo Modelo Proposto - Ensaio Baseado em Histórico Pessimista

\begin{tabular}{|c|c|c|c|}
\cline { 2 - 4 } \multicolumn{1}{c|}{} & Falha 1 & Falha 2 & Falha 3 \\
\hline Instante Real de Ocorrência (h) $-t_{\text {real }}$ & 79646,9 & 87362,0 & 93263,4 \\
\hline Instante Previsto (h) $-t_{\text {prev }}$ & 68011,6 & 74421,2 & 81304,3 \\
\hline Variância (h'⿳) $-\sigma_{t_{\text {prev }}}{ }^{2}$ & 2907767,3 & 3075772,5 & 3023162,0 \\
\hline Desvio Padrão (h) $-\sigma_{t_{\text {prev }}}$ & 1705,2 & 1753,8 & 1738,7 \\
\hline Erro Relativo entre Real e (Previsto - Desvio) & $-0,1675$ & $-0,1682$ & $-0,1469$ \\
\hline Erro Relativo entre Real e Previsto & $-0,1461$ & $-0,1481$ & $-0,1282$ \\
\hline Erro Relativo entre Real e (Previsto + Desvio) & $-0,1247$ & $-0,1281$ & $-0,1096$ \\
\hline
\end{tabular}

Fonte: Autor

As seguintes observações podem ser feitas em vista dos resultados relacionados na Tabela 25 , na Tabela 26 e na Tabela 27 :

a) No cenário em que se fez uso de um histórico operacional normal, os instantes de tempo dos três eventos de falha previstos mediante utilização do modelo proposto neste trabalho $\left(t_{\text {prev }}\right)$ foram superiores aos efetivamente registrados no histórico do sistema simples $\left(t_{\text {real }}\right)$. Considerando-se aceitável que $t_{\text {real }}$ pertença ao intervalo $\left[t_{\text {prev }}-\sigma_{t_{\text {prev }}} ; t_{\text {prev }}+\sigma_{t_{\text {prev }}}\right]$, é possível considerar que apenas o terceiro evento de falha pôde ser previsto com sucesso. Dessa forma, o modelo proposto comportou-se de forma otimista ao prever, nas condições do estudo, que os dois primeiros eventos de falha ocorreriam de forma mais tardia do que o real. 
A justificativa mais plausível para o otimismo das duas primeiras previsões é a de que a função afim gerada por meio da regressão linear prevista no modelo proposto não se ajustou adequadamente aos registros de falha do histórico operacional do sistema. Uma evidência dessa hipótese é a de que os valores de desvio padrão relacionados na Tabela 25 são significativamente maiores do que os expostos para o ensaio com histórico normal na Tabela 24, que foram estimados considerando-se a inclusão das três últimas falhas do histórico operacional às previsões de falhas futuras.

b) No ensaio em que foram utilizados dados de histórico otimistas, o instante de tempo previsto para o primeiro evento de falha $\left(t_{\text {prev }}\right)$ foi ligeiramente inferior ao valor presente no histórico real de utilização do sistema $\left(t_{\text {real }}\right)$; no entanto, considerando-se aceitável que $t_{\text {real }}$ pertença ao intervalo $\left[t_{\text {prev }}-\sigma_{t_{\text {prev }}} ; t_{\text {prev }}+\sigma_{t_{\text {prev }}}\right]$, é possível afirmar que a primeira falha prevista para o sistema simples nessas condições foi calculada com sucesso.

Com relação às duas falhas seguintes, é possível inferir a partir da Tabela 26 que, mesmo considerando-se como critério de aceitação a pertinência de $t_{\text {real }}$ ao intervalo $\left[t_{\text {prev }}-\sigma_{t_{\text {prev }}} ; t_{\text {prev }}+\sigma_{t_{\text {prev }}}\right]$, as previsões $t_{\text {prev }}$ superaram os instantes de tempo $t_{\text {real }}$ efetivamente presentes no histórico de operação do sistema. No caso específico do terceiro evento de falha, o desvio entre $t_{\text {real }} \mathrm{e}$ $t_{\text {prev }}$ foi mais acentuado (de $16,8 \%$ a $20,9 \%$, considerando-se a variabilidade do desvio padrão de $t_{\text {prev }}$ ) porque as duas últimas falhas ocorreram em instantes de tempo muito próximos entre si e, consequentemente, o valor $t_{\text {real }}$ do terceiro evento de falha distancia-se da tendência extraída a partir de todos os demais eventos de falha registrados no histórico operacional do sistema ${ }^{13}$.

c) Por fim, no cenário em que foi empregado um histórico pessimista, os instantes de tempo previstos para os três eventos de falha $\left(t_{\text {prev }}\right)$ foram inferiores aos valores efetivamente registrados no histórico real de utilização

${ }^{13}$ A relação completa de todos os eventos do histórico operacional otimista do sistema simples está registrada na Tabela 53 do Apêndice A.1. 
do sistema $\left(t_{\text {real }}\right)$. A principal justificativa para esse resultado decorre da análise do histórico operacional registrado na Tabela 54 do Apêndice A.1, a partir do qual se pode constatar que 0 evento de falha ocorrente em 79.646,9h (correspondente ao evento da primeira falha da Tabela 27) se manifestou após o transcurso de um intervalo de tempo de aproximadamente 20.000h depois da falha anterior (registrada em 59.669,4h), e esse período de tempo, por sua vez, é significativamente superior ao verificado entre todos os pares de eventos de falha consecutivos anteriores à falha de 79.646,9h.

Como o algoritmo que descreve a lógica do bloco "Detector de Comportamento e Filtro de Kalman" do modelo proposto baseia-se na tendência comportamental de todas as falhas extraídas do histórico operacional que Ihe são fornecidas como entrada, os três eventos de falhas futuras registrados na Tabela 27 foram calculados a partir da tendência observada até o evento da falha ocorrente em 59.669,4h. Uma vez que os intervalos de tempo entre todas as falhas consecutivas registradas no histórico operacional do sistema simples entre $0 \mathrm{~h}$ e 59.669,4h foram inferiores ao período de tempo de praticamente $20.000 \mathrm{~h}$ transcorrido até a ocorrência da falha de $79.646,9 \mathrm{~h}$, os resultados produzidos pelo modelo desenvolvido neste estudo foram mais pessimistas do que o esperado.

\subsection{Avaliação de UM Sistema SÉRIE COM DOIS COMPONENTES}

A presente seção do texto contempla a avaliação dos índices de confiabilidade, disponibilidade e segurança crítica (safety) de um sistema composto por dois componentes conectados em série em quatro cenários distintos, que serão apresentados e comparados:

- Cenário 1: Resultados gerados considerando-se a abordagem clássica de tratamento de processos de Markov (sem dependência de dados de histórico de operação);

- Cenário 2: Resultados gerados aplicando-se a técnica proposta neste estudo e utilizando-se dados de histórico simulados com base em um cenário operacional normal; 
- Cenário 3: Resultados gerados aplicando-se a técnica proposta neste estudo e utilizando-se dados de histórico simulados com base em um cenário operacional otimista;

- Cenário 4: Resultados gerados aplicando-se a técnica proposta neste estudo e utilizando-se dados de histórico simulados com base em um cenário operacional pessimista.

O sistema considerado no estudo pode ser representado pelo diagrama de blocos da Figura 56, que permite inferir que as saídas produzidas pelo sistema a partir de suas entradas dependem do funcionamento apropriado tanto do componente $\mathrm{C} 1$ quanto do componente $\mathrm{C} 2$.

Figura 56 - Diagrama de Blocos do Sistema Série com Dois Componentes

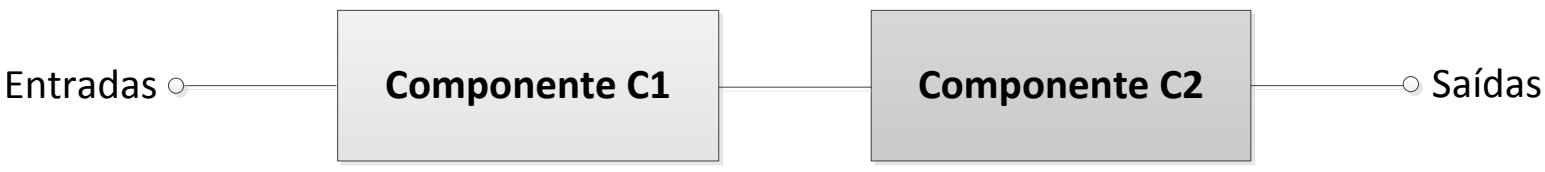

Fonte: Autor

\subsubsection{Função Confiabilidade}

Considerando-se a aproximação matemática da equação (16) para linearizar as taxas exponenciais das transições entre estados, é possível utilizar o modelo de Markov da Figura 57 para se determinar a confiabilidade do sistema série com dois componentes. 
Figura 57 - Modelo de Markov da Confiabilidade do Sistema Série com Dois Componentes

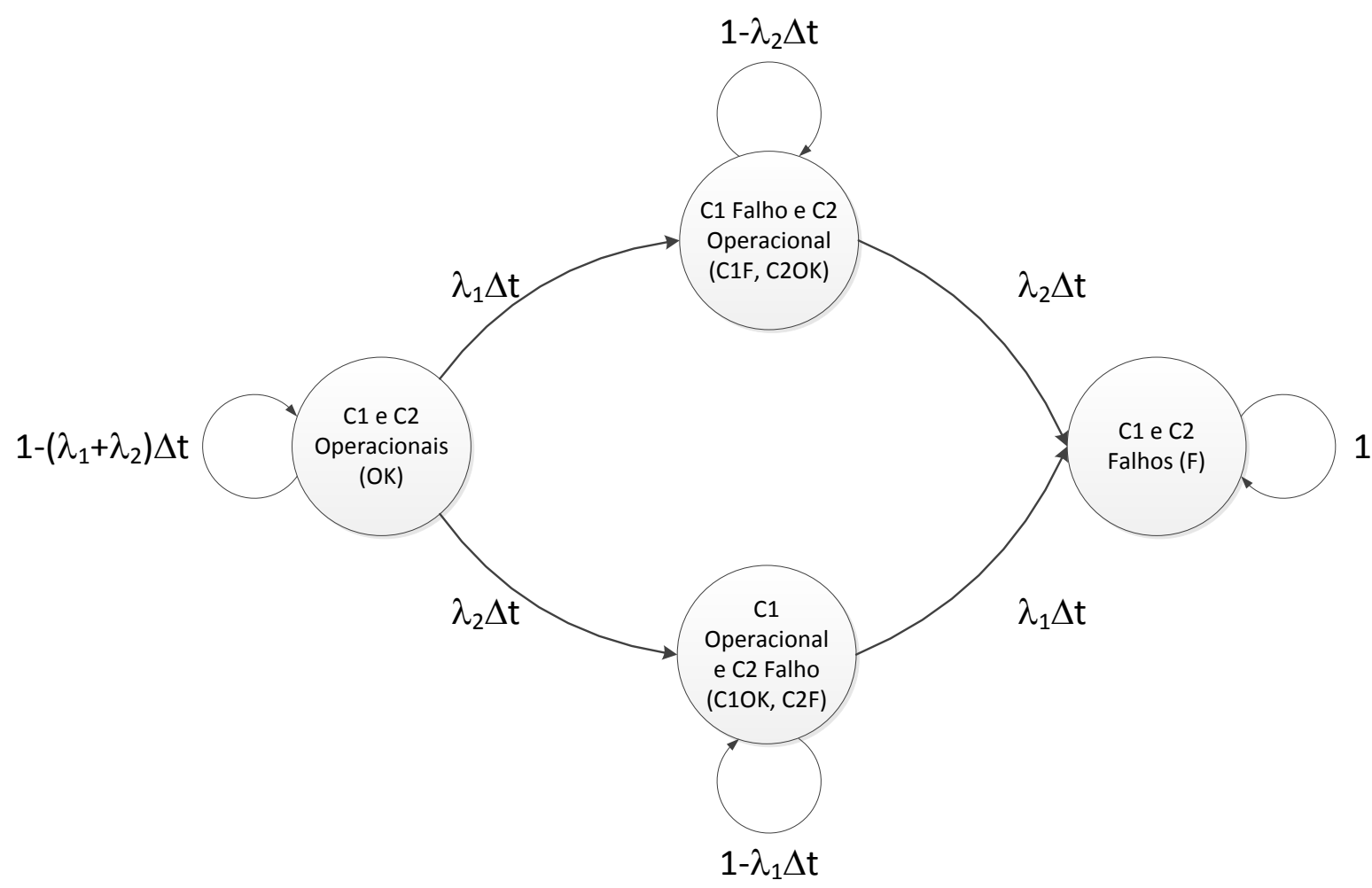

Fonte: Autor

Como o correto funcionamento do sistema série com dois componentes é atingido apenas quando ambos os componentes $\mathrm{C} 1$ e C2 não estão falhos, a função confiabilidade do sistema é representada pela probabilidade de ele funcionar, ao longo do tempo, no estado "C1 e C2 Operacionais (OK)". Considerando-se que as taxas de falhas dos componentes $\mathrm{C} 1$ e $\mathrm{C} 2$ sejam respectivamente iguais a $\lambda_{1}$ e $\lambda_{2}$, a confiabilidade da combinação serial de $\mathrm{C} 1$ e $\mathrm{C} 2$ decairá exponencialmente com uma taxa igual à soma de $\lambda_{1}$ e $\lambda_{2}$, tal como se define na equação (68) (JOHNSON, 1989) ${ }^{14}$.

$$
R(t)=e^{-\left(\lambda_{1}+\lambda_{2}\right) t}
$$

Utilizando-se como parâmetros de simulação $\lambda_{1}=10^{-4}$ falhas $/ h, \quad \lambda_{2}=$ $5.10^{-5}$ falhas $/ h, T_{\text {sim }}=10^{5}$ horas e $\Delta t_{\text {sim }}=1$ hora, a função confiabilidade do sistema série com dois componentes nos quatro cenários de estudo relacionados na

\footnotetext{
${ }^{14}$ A demonstração matemática utilizada para se obter a equação (68) não pertence ao escopo desta Dissertação de Mestrado. Para conhecê-la, recomenda-se consultar Johnson (1989).
} 
seção 5.3 (abordagens sem histórico, com histórico normal, com histórico otimista e com histórico pessimista) pode ser representada pelos gráficos expostos na Figura 58. Com o propósito de melhorar a legibilidade dos resultados obtidos, os gráficos da Figura 58 foram plotados restringindo-se o domínio do eixo do tempo às primeiras 60.000 horas de estudo do sistema, uma vez que se constatou que, após esse intervalo de tempo inicial, os resultados obtidos alteram-se de forma pouco significativa.

Figura 58 - Gráficos da Função Confiabilidade do Sistema Série com Dois Componentes nos Quatro Cenários Estudados

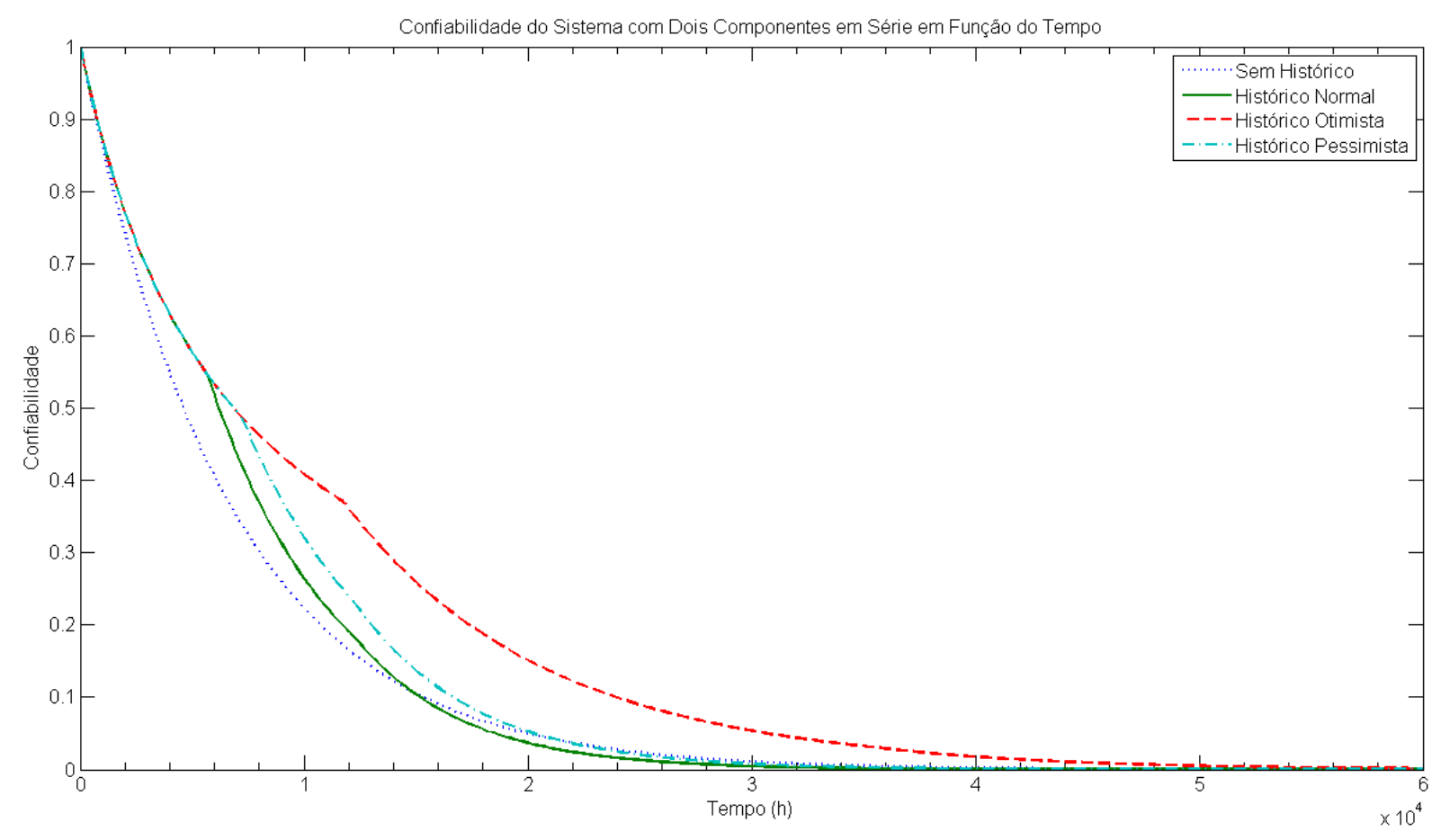

Fonte: Autor

Com base nos gráficos representados na Figura 58, verifica-se que 0 comportamento do sistema no cenário em que dados de histórico não são considerados segue a lei exponencial da equação (68), uma vez que as taxas de falhas $\lambda_{1}$ e $\lambda_{2}$ de seus componentes não se alteram com o tempo. Nos três ensaios em que dados de histórico foram incorporados ao cálculo da função confiabilidade, os valores das taxas de falhas $\lambda_{1}$ e $\lambda_{2}$ são continuamente atualizados ao longo do período de tempo $T_{\text {sim }}=10^{5}$ horas dependendo dos eventos de falha ocorrentes com os componentes $\mathrm{C} 1$ e C2. A relação completa dos eventos de falha gerados 
pelo módulo "Simulador de Dados de Entrada" nos três ensaios que envolvem a incorporação de dados de histórico é apresentada na Tabela 28.

Tabela 28 - Eventos de Falha Gerados nos Cenários de Estudo da Confiabilidade do Sistema Série com Dois Componentes e com Histórico de Operação

\begin{tabular}{|c|c|c|}
\hline Ensaio Executado & $\begin{array}{c}\text { Instante de Ocorrência do } \\
\text { Evento de Falha do } \\
\text { Componente C1 }\end{array}$ & $\begin{array}{c}\text { Instante de Ocorrência do } \\
\text { Evento de Falha do } \\
\text { Componente C2 }\end{array}$ \\
\hline $\begin{array}{c}\text { Cenário 2 - Histórico } \\
\text { Normal }\end{array}$ & $5700,180 \mathrm{~h}$ & $12335,541 \mathrm{~h}$ \\
\hline $\begin{array}{c}\text { Cenário 3 - Histórico } \\
\text { Otimista }\end{array}$ & $11798,469 \mathrm{~h}$ & $34450,40 \mathrm{~h}$ \\
\hline $\begin{array}{c}\text { Cenário 4 - Histórico } \\
\text { Pessimista }\end{array}$ & $7220,578 \mathrm{~h}$ & $12207,501 \mathrm{~h}$ \\
\hline
\end{tabular}

Fonte: Autor

Como já explorado no estudo da função confiabilidade do sistema simples, detalhado na seção 5.3.1, os instantes de tempo relacionados na Tabela 28 promovem um aumento das taxas de falhas dos componentes C1 e C2 e, consequentemente, um decaimento mais rápido da confiabilidade do sistema. Os gráficos da Figura 59 e da Figura 60 representam, respectivamente, a evolução temporal da taxa de falhas do componente $\mathrm{C} 1$ nas primeiras $15.000 \mathrm{~h}$ do intervalo $T_{\text {sim }}$ e a evolução temporal da taxa de falhas do componente C2 nas primeiras $40.000 \mathrm{~h}$ do intervalo $T_{\text {sim. }}$. Para todos os instantes de tempo posteriores aos intervalos iniciais definidos anteriormente, as taxas de falhas de C1 e C2 mantiveram-se nos mesmos patamares constatados ao final dos períodos preliminares. 
Figura 59 - Gráficos da Função Taxa de Falhas do Componente C1 do Sistema Série com Dois Componentes nos Quatro Cenários de Estudo da Função Confiabilidade

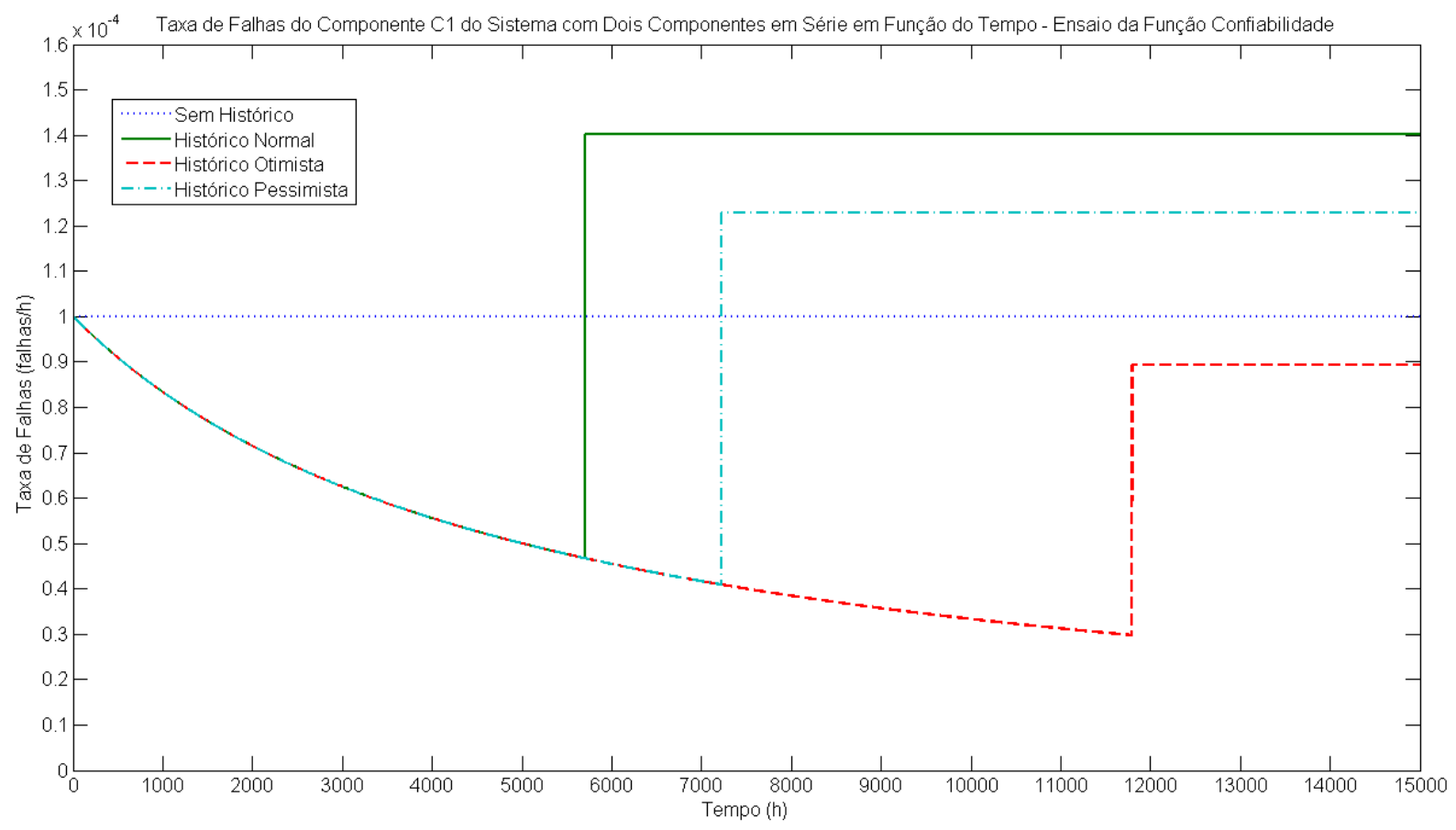

Fonte: Autor

Figura 60 - Gráficos da Função Taxa de Falhas do Componente C2 do Sistema Série com Dois Componentes nos Quatro Cenários de Estudo da Função Confiabilidade

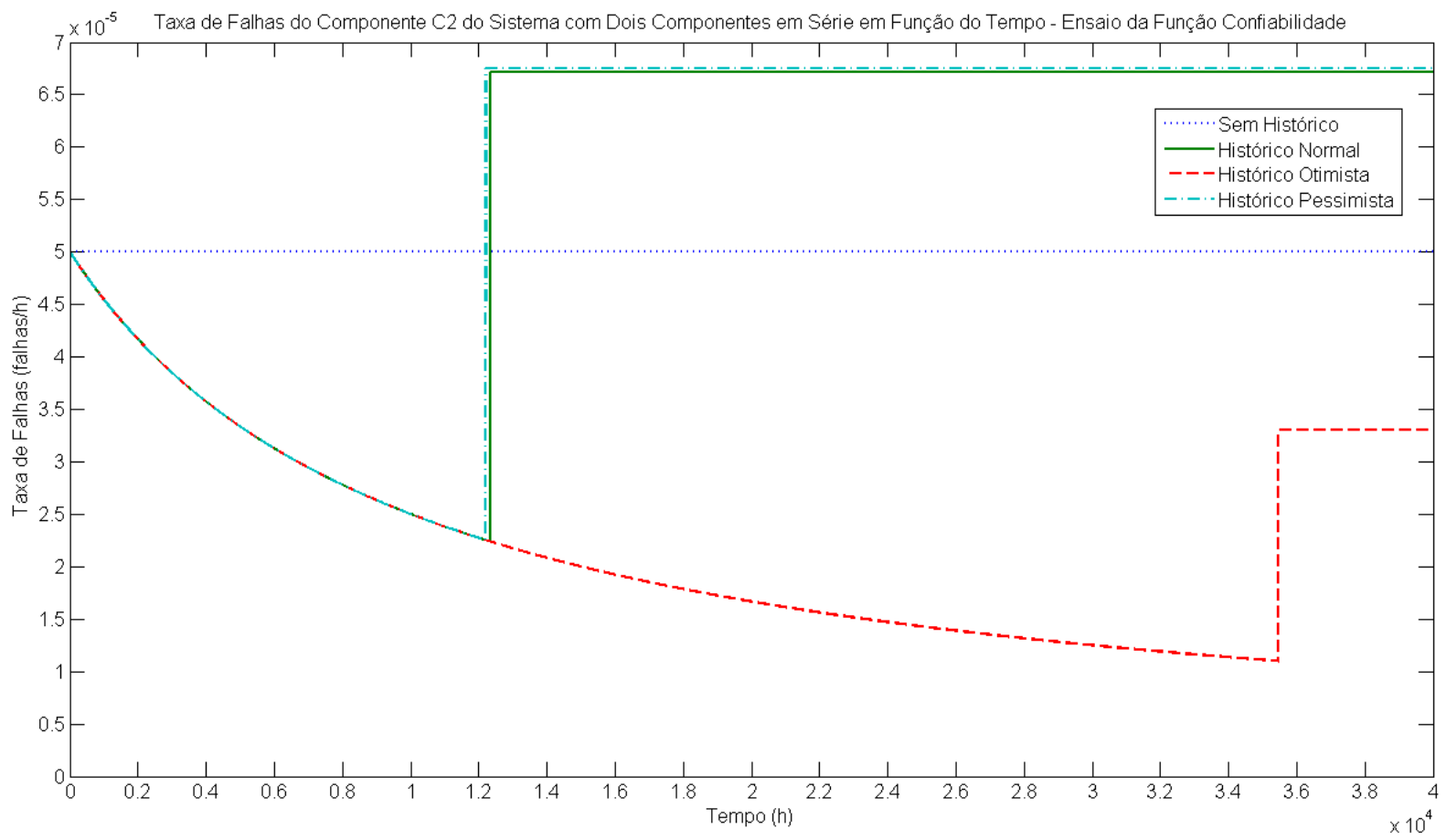

Fonte: Autor 
Ao longo do período de tempo $T_{\text {sim }}=10^{5}$ horas utilizado nas simulações executadas, é possível inferir, a partir da Figura 58, que a confiabilidade do sistema no cenário em que se empregou um histórico operacional otimista foi superior à verificada em todos os demais cenários. Esse resultado pode ser sustentado pelo fato de as taxas de falhas dos componentes $\mathrm{C} 1$ e $\mathrm{C} 2$ terem se mantido iguais ou inferiores às respectivas taxas de falhas de todos os outros ensaios ao longo de todo o período de tempo $T_{\text {sim }}$, tal como se observa nos gráficos da Figura 59 e da Figura 60. Na comparação direta entre os três cenários em que se considerou o uso de dados de histórico, a justificativa para a inferioridade de $\lambda_{1}$ e $\lambda_{2}$ no ensaio otimista é a ocorrência mais tardia dos eventos de falha dos componentes $\mathrm{C} 1$ e $\mathrm{C} 2$, que pode ser constatada a partir dos dados registrados na Tabela 28.

Outro resultado a ser destacado é o de que, neste ensaio específico, a confiabilidade do sistema no cenário em que se utilizou um histórico normal foi inferior à observada no ensaio baseado em um histórico pessimista. Com base nos dados representados na Tabela 28, essa constatação decorre do fato de o evento de falha do componente $\mathrm{C} 1$ ter ocorrido cerca de 1.500h mais cedo no cenário de histórico normal do que no cenário de histórico pessimista. Como a falha do componente $\mathrm{C} 1$ foi antecipada no ensaio baseado em um histórico normal, a Figura 59 permite verificar que a taxa de falhas associada a $\mathrm{C} 1$ nesse contexto estabilizouse em aproximadamente $1,40.10^{-4}$ falhas/ $h$, que é aproximadamente $15 \%$ superior ao observado no cenário de histórico pessimista $\left(1,22.10^{-4}\right.$ falhas $\left./ h\right)$.

Um aspecto a ser salientado com relação à inferioridade da confiabilidade do sistema no contexto em que se utilizou um histórico normal frente aos valores determinados no ensaio baseado em um histórico pessimista é o de que a taxa de falhas do componente $\mathrm{C} 2$ exerceu pouca influência nos resultados obtidos. Tal efeito reduzido decorre da proximidade temporal entre os eventos de falha de $\mathrm{C} 2$ nos dois ensaios (a partir da Tabela 28, é possível verificar que a falha de C2 ocorreu pouco menos de $130 \mathrm{~h}$ mais cedo no cenário pessimista), a qual, por sua vez, se traduziu em taxas de falhas similares em ambos os contextos. Por meio da Figura 60 , constata-se que os gráficos de $\lambda_{2}$ nos cenários baseados no uso de históricos normal e otimista são praticamente coincidentes entre si e convergem para valores similares, próximos de $6,75 \cdot 10^{-5}$ falhas $/ h$. 
Outra tendência observada nos três cenários em que se fez uso de dados de histórico operacionais é a de que os eventos de falha do componente C2 influenciaram menos significativamente a evolução temporal da confiabilidade do sistema do que os eventos de falha do componente $\mathrm{C} 1$. Tal influência reduzida deve-se principalmente ao fato de que, como a função confiabilidade decai com uma taxa igual à soma das taxas de falhas $\lambda_{1}$ e $\lambda_{2}$, e a taxa de falhas $\lambda_{2}$ é inferior à taxa de falhas $\lambda_{1}$, eventuais flutuações da taxa de falhas $\lambda_{2}$ afetam menos significativamente a função confiabilidade do que alterações na taxa de falhas $\lambda_{1}$.

Ao final do período de tempo $T_{\text {sim }}=10^{5}$ horas, as simulações executadas conduziram aos valores de confiabilidade relacionados na Tabela 53, que também sustentam a tendência comportamental explorada previamente.

Tabela 29 - Confiabilidade do Sistema Série com Dois Componentes após $T_{\text {sim }}=10^{5}$ horas

\begin{tabular}{|c|c|}
\hline Cenário Estudado & Confiabilidade do Sistema Série com Dois Componentes \\
\hline Sem Histórico & $3,055 \cdot 10^{-7}$ \\
\hline Histórico Normal & $2,299 \cdot 10^{-9}$ \\
\hline Histórico Otimista & $1,154 \cdot 10^{-5}$ \\
\hline Histórico Pessimista & $1,291 \cdot 10^{-8}$ \\
\hline
\end{tabular}

Fonte: Autor

\subsubsection{Função Segurança Crítica (Safety)}

A segurança crítica (safety) do sistema série com dois componentes pode ser representada pelo modelo de Markov da Figura 61, que já foi construído considerando-se a aproximação matemática da equação (16) para linearizar as taxas exponenciais das transições entre estados. No modelo de Markov da Figura 61, $\lambda_{i}$ e $C_{i}$ representam, respectivamente, a taxa de falhas e o percentual de falhas seguras do i-ésimo componente do sistema (com $i \in\{1 ; 2\}$ ).

Com o propósito de melhorar a legibilidade do diagrama de transição de estados do modelo de Markov da Figura 61, linhas com cores e aspectos de continuidade diferentes foram utilizadas para representar as transições que se originam nos estados "C1 Falha Segura e C2 Operacional (C1FS, C2OK)", "C1 Falha 
Insegura e C2 Operacional (C1Fl, C2OK)", "C1 Operacional e C2 Falha Segura (C1OK, C2FS)" e "C1 Operacional e C2 Falha Insegura (C1OK, C2FI)" e se destinam a outros estados do modelo.

Figura 61 - Modelo de Markov da Segurança Crítica (Safety) do Sistema Série com Dois
Componentes

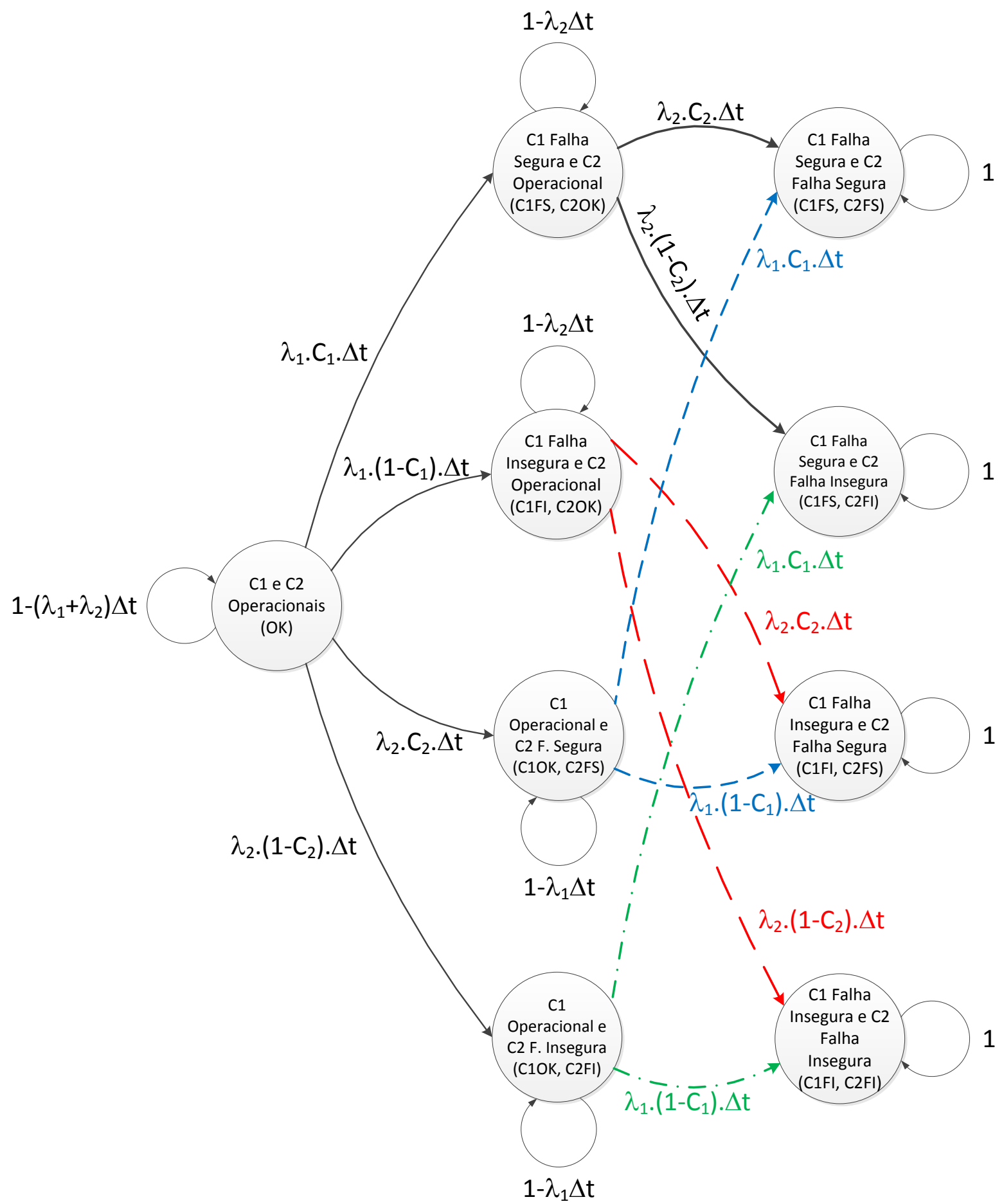


Com base no modelo apresentado na Figura 61, a função segurança crítica (safety) do sistema simples é representada pela soma das probabilidades de o sistema funcionar, ao longo do tempo, nos estados "C1 e C2 Operacionais (OK)", "C1 Falha Segura e C2 Operacional (C1FS, C2OK)", "C1 Operacional e C2 Falha Segura (C1OK, C2FS)" e "C1 Falha Segura e C2 Falha Segura (C1FS, C2FS)". Utilizando-se como parâmetros de simulação $\lambda_{1}=10^{-4}$ falhas $/ h$, $\lambda_{2}=5.10^{-5}$ falhas $/ h, \quad C_{1}=C_{2}=0,9999, \quad T_{\text {sim }}=10^{6}$ horas e $\Delta t_{\text {sim }}=2$ horas, a função segurança crítica (safety) do sistema série com dois componentes nos quatro cenários de estudo relacionados na seção 5.3 (abordagens sem histórico, com histórico normal, com histórico otimista e com histórico pessimista) pode ser representada pelos gráficos expostos na Figura 62. Com o propósito de melhorar a legibilidade dos resultados obtidos, os gráficos da Figura 62 foram plotados restringindo-se o domínio do eixo do tempo às primeiras 250.000 horas de estudo do sistema, uma vez que se constatou que, após esse intervalo de tempo inicial, os resultados obtidos alteram-se de forma pouco significativa.

Figura 62 - Gráficos da Função Segurança Crítica (Safety) do Sistema Série com Dois Componentes nos Quatro Cenários Estudados

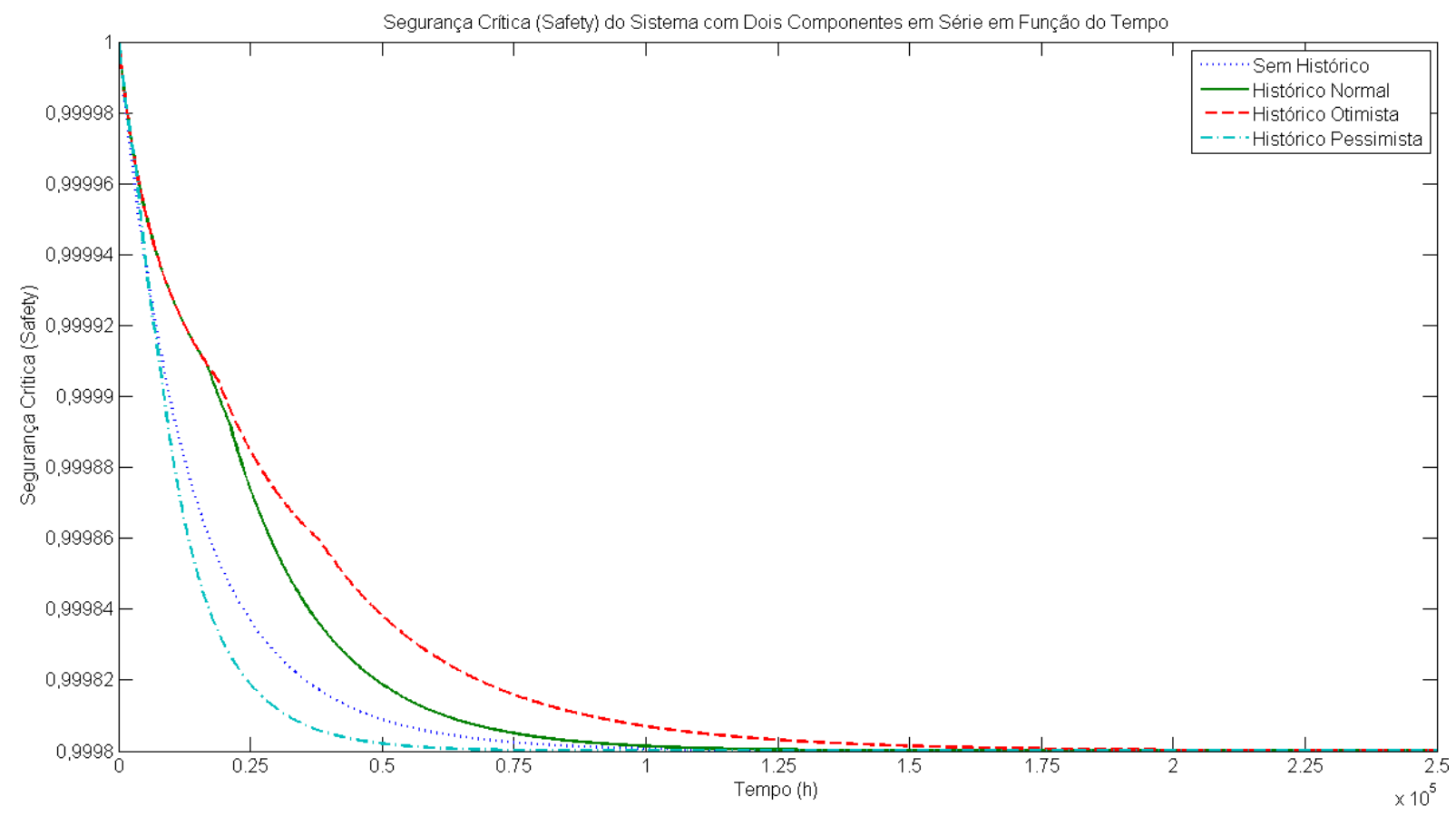

Fonte: Autor

A partir dos gráficos da Figura 62, é possível notar que, em todos os ensaios executados, a segurança crítica (safety) do sistema tende a um valor assintótico 
próximo de 0,9998 , que corresponde ao produto dos percentuais de falhas seguras $C_{1}$ e $C_{2}$. Como nenhum procedimento de manutenção foi considerado no modelo de Markov da Figura 61, a probabilidade de qualquer um dos componentes C1 e C2 funcionar sem nenhuma falha após um período de tempo suficientemente longo (por exemplo, as 250.000 horas utilizadas na abscissa do plano cartesiano da Figura 62) é muito baixa, e, dessa forma, a segurança crítica (safety) do sistema passa a ser dominada pela probabilidade de manifestação do estado "C1 Falha Segura e C2 Falha Segura (C1FS, C2FS)", no qual ambos os componentes C1 e C2 estão falhos de forma segura. Após um intervalo suficientemente grande de tempo, a probabilidade de o sistema operar nesse estado tende ao produto de $C_{1}$ e $C_{2}$, que representa $O$ percentual de ocorrência simultânea de falhas seguras nos componentes $\mathrm{C} 1$ e $\mathrm{C} 2$ dentro do universo de todas as falhas que podem acometer $\mathrm{O}$ sistema.

Ao final do tempo de simulação $T_{\text {sim }}=10^{6}$ horas, a variação relativa máxima do valor assumido pela função segurança crítica (safety) entre os quatro cenários estudados foi de $3,9 \cdot 10^{-13}$, índice que pode ser considerado pouco expressivo frente ao valor absoluto 0,9998 da função segurança crítica (safety) no mesmo intervalo de tempo. Esse resultado reforça a tendência já observada no estudo do sistema simples, relatado na seção 5.2.2, de que dados de histórico afetam pouco expressivamente a evolução temporal da segurança crítica (safety) de um sistema quando procedimentos de manutenção não são considerados no estudo.

As diferenças nas taxas de decaimento da função segurança crítica (safety) nos três ensaios baseados no uso de dados de histórico são consequência dos instantes de ocorrência das falhas dos componentes $\mathrm{C} 1$ e C2. A relação completa dos eventos de falha gerados pelo módulo "Simulador de Dados de Entrada" nos três cenários estudados consta na Tabela 30. 
Tabela 30 - Eventos de Falha Gerados nos Cenários de Estudo da Segurança Crítica (Safety) do Sistema Série com Dois Componentes e com Histórico de Operação

\begin{tabular}{|c|c|c|}
\hline Ensaio Executado & $\begin{array}{c}\text { Instante de Ocorrência do } \\
\text { Evento de Falha do } \\
\text { Componente C1 }\end{array}$ & $\begin{array}{c}\text { Instante de Ocorrência do } \\
\text { Evento de Falha do } \\
\text { Componente C2 }\end{array}$ \\
\hline $\begin{array}{c}\text { Cenário 2 - Histórico } \\
\text { Normal }\end{array}$ & $16875,398 \mathrm{~h}$ & $20874,385 \mathrm{~h}$ \\
\hline $\begin{array}{c}\text { Cenário 3 - Histórico } \\
\text { Otimista }\end{array}$ & $18947,244 \mathrm{~h}$ & $38279,748 \mathrm{~h}$ \\
\hline $\begin{array}{c}\text { Cenário 4 - Histórico } \\
\text { Pessimista }\end{array}$ & $3358,668 \mathrm{~h}$ & $7644,000 \mathrm{~h}$ \\
\hline
\end{tabular}

Fonte: Autor

Tal como já detalhado no estudo da função segurança crítica (safety) do sistema simples, explorado na seção 5.2.2, os eventos de falha registrados na Tabela 30 promovem uma elevação nas taxas de falhas dos componentes $\mathrm{C} 1$ e $\mathrm{C} 2 \mathrm{a}$ partir do instante em que eles se manifestam. Em decorrência desses aumentos das taxas de falhas, evidenciados nos gráficos representados na Figura 63 e na Figura $64^{15}$, a segurança crítica (safety) do sistema passa, nos três ensaios baseados no uso de dados de histórico, a decair mais rapidamente a partir dos instantes de tempo em que as falhas ocorrem.

${ }^{15}$ Por questões de legibilidade, os domínios temporais do eixo horizontal dos planos cartesianos da Figura 63 e da Figura 64 foram respectivamente restringidos aos intervalos de tempo de $20.000 \mathrm{~h}$ e $40.000 \mathrm{~h}$. Após esses períodos iniciais, as taxas de falhas dos componentes $\mathrm{C} 1$ e $\mathrm{C} 2$ foram mantidas nos mesmos patamares assumidos ao final do intervalo preliminar. 
Figura 63 - Gráficos da Função Taxa de Falhas do Componente C1 do Sistema Série com Dois Componentes nos Quatro Cenários de Estudo da Função Segurança Crítica (Safety)

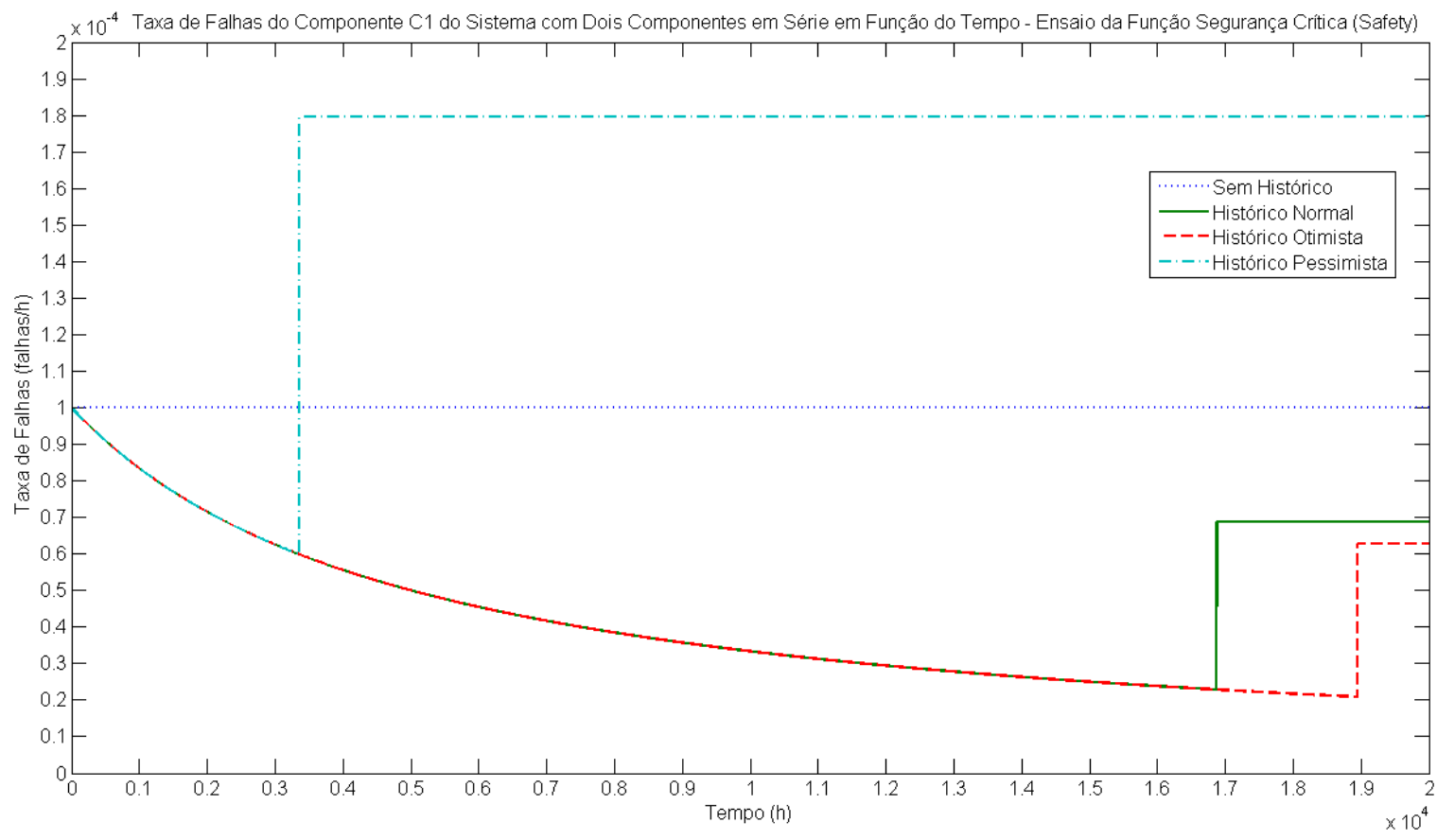

Fonte: Autor

Figura 64 - Gráficos da Função Taxa de Falhas do Componente C2 do Sistema Série com Dois Componentes nos Quatro Cenários de Estudo da Função Segurança Crítica (Safety)

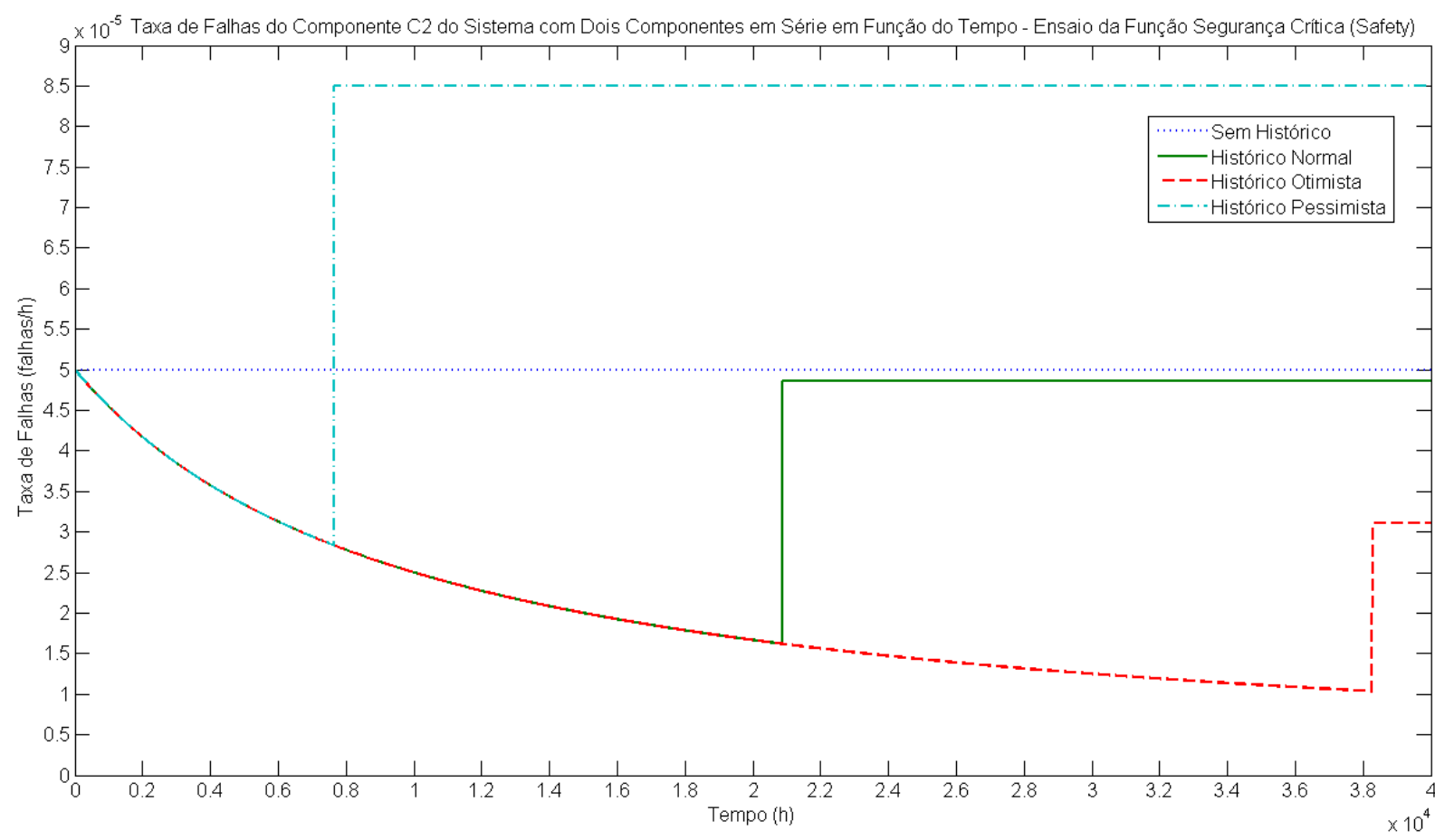

Fonte: Autor 
A partir dos gráficos representados na Figura 63 e na Figura 64, é possível constatar que as taxas de falhas de ambos os componentes $\mathrm{C} 1$ e C2 no cenário em que se utilizou um histórico pessimista foram superiores às observadas em todos os demais ensaios. Tal como já explorado no estudo da função confiabilidade do sistema simples, detalhado na seção 5.2.1, esse resultado decorre do fato de os eventos de falha de ambos os componentes terem ocorrido em instantes de tempo inferiores aos verificados em todas as demais configurações de histórico, como se pode detectar a partir da Tabela 30.

O mesmo argumento também pode ser utilizado para justificar que as menores taxas de falhas dos componentes C1 e C2 foram obtidas no ensaio com histórico otimista e que as taxas determinadas no cenário em que se emprega um histórico normal situam-se em um valor intermediário entre as situações otimista e pessimista. Na comparação direta entre os ensaios com histórico normal e sem histórico, as taxas de falhas obtidas no primeiro contexto foram inferiores às do segundo porque, tal como já explorado com mais detalhes no estudo documentado na seção 5.2.1, os eventos de falha dos componentes C1 e C2 ocorreram após o transcurso de um intervalo de tempo superior aos seus respectivos MTTFs nominais.

As ressalvas prévias a respeito dos perfis das taxas de falhas dos componentes $\mathrm{C} 1$ e $\mathrm{C} 2$ podem ser utilizadas para justificar os perfis dos gráficos da função segurança crítica ( safety) obtidos nos quatro cenários avaliados:

a) Como as taxas de falhas dos componentes $\mathrm{C} 1$ e $\mathrm{C} 2$ obtidas no ensaio com histórico pessimista foram as maiores entre todas as simulações, o valor assintótico 0,9998 da segurança crítica (safety) do sistema é atingido mais rapidamente. Por meio da Figura 62, nota-se que a convergência ao valor assintótico ocorreu após aproximadamente 75.000 horas de estudo do sistema no cenário com histórico pessimista;

b) Analogamente, como as taxas de falhas dos componentes $\mathrm{C} 1$ e $\mathrm{C} 2$ obtidas no ensaio com histórico otimista foram as menores entre todas as simulações, 0 valor assintótico 0,9998 da segurança crítica (safety) do sistema é atingido mais lentamente. A partir da Figura 62, nota-se que a convergência ao valor assintótico ocorreu apenas após aproximadamente 200.000 horas de estudo do sistema no cenário com histórico otimista; 
c) Como as taxas de falhas dos componentes $\mathrm{C} 1$ e C2 obtidas no ensaio com histórico normal são ligeiramente inferiores aos seus valores nominais, a convergência da função segurança crítica (safety) nesse ensaio ocorre um pouco mais lentamente do que no cenário sem dados de histórico. Com base na Figura 62, é possível notar que a convergência da função segurança crítica (safety) ao seu valor assintótico ocorreu após aproximadamente 100.000 horas de estudo do sistema tanto no ensaio com histórico normal quanto no estudo sem dados de histórico.

\subsubsection{Função Disponibilidade}

A disponibilidade do sistema série com dois componentes pode ser determinada a partir do modelo de Markov da Figura 65, que já foi construído considerando-se a aproximação matemática da equação (16) para linearizar as taxas exponenciais das transições entre estados. No modelo de Markov da Figura 65, $\lambda_{i}$ e $\mu_{i}$ simbolizam, respectivamente, a taxa de falhas e a taxa de reparos do $i$ ésimo componente do sistema (com $i \in\{1 ; 2\})$.

Figura 65 - Modelo de Markov da Disponibilidade do Sistema Série com Dois Componentes

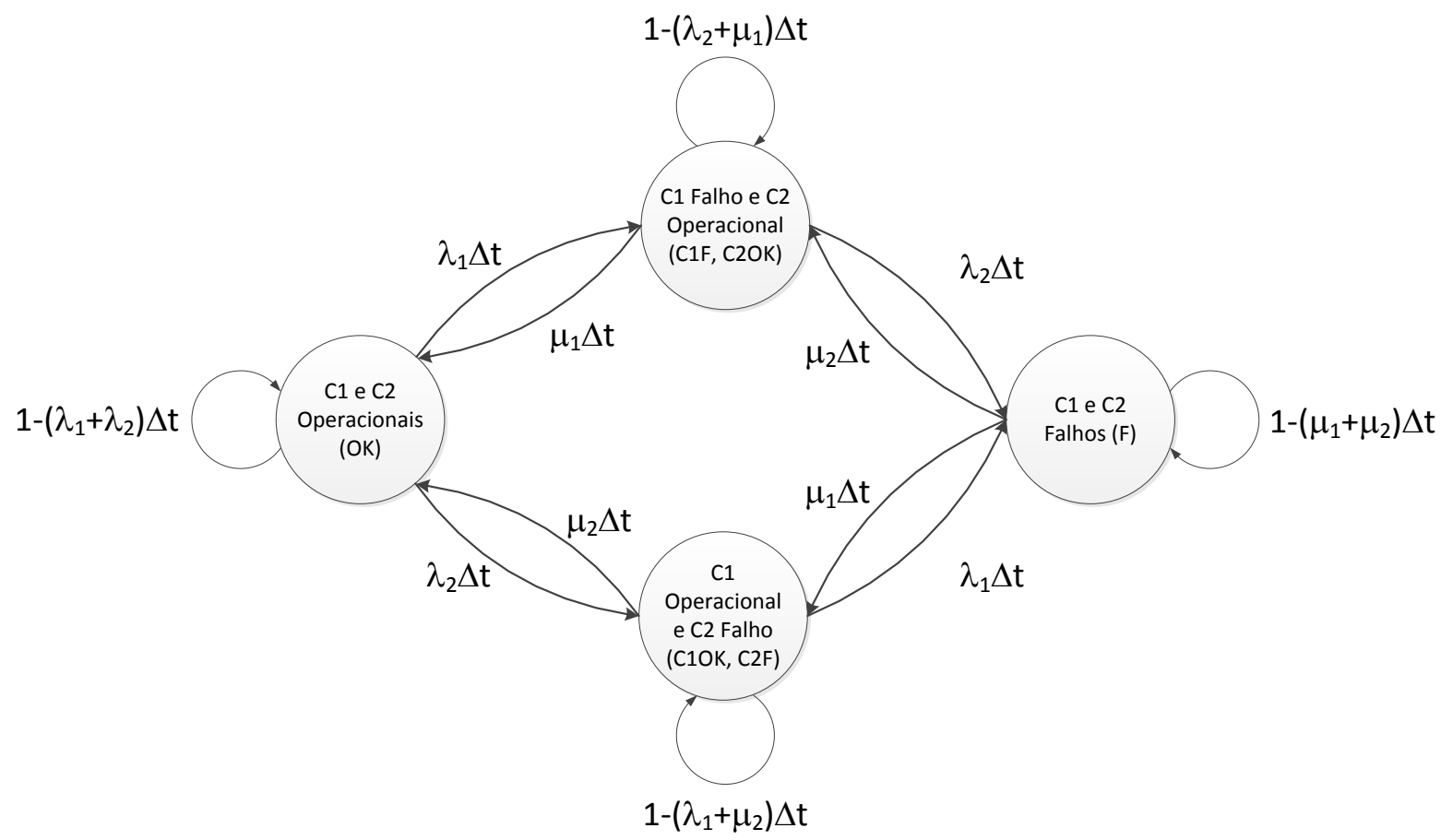

Fonte: Autor 
Com base no modelo apresentado na Figura 65, a função disponibilidade do sistema simples é representada pela probabilidade de o sistema funcionar, em um dado instante de tempo, no estado "C1 e C2 Operacionais (OK)". Utilizando-se como parâmetros de simulação $\lambda_{1}=10^{-4}$ falhas $/ h, \quad \lambda_{2}=5.10^{-5}$ falhas $/ h$, $\mu_{1}=1$ reparo $/ h, \mu_{2}=0,5$ reparo $/ h, T_{\text {sim }}=10^{5}$ horas e $\Delta t_{\text {sim }}=0,5$ hora, a função disponibilidade do sistema série com dois componentes nos quatro cenários de estudo relacionados na seção 5.3 (abordagens sem histórico, com histórico normal, com histórico otimista e com histórico pessimista) pode ser representada pelos gráficos expostos na Figura 66.

Figura 66 - Gráficos da Função Disponibilidade do Sistema Série com Dois Componentes nos Quatro Cenários Estudados

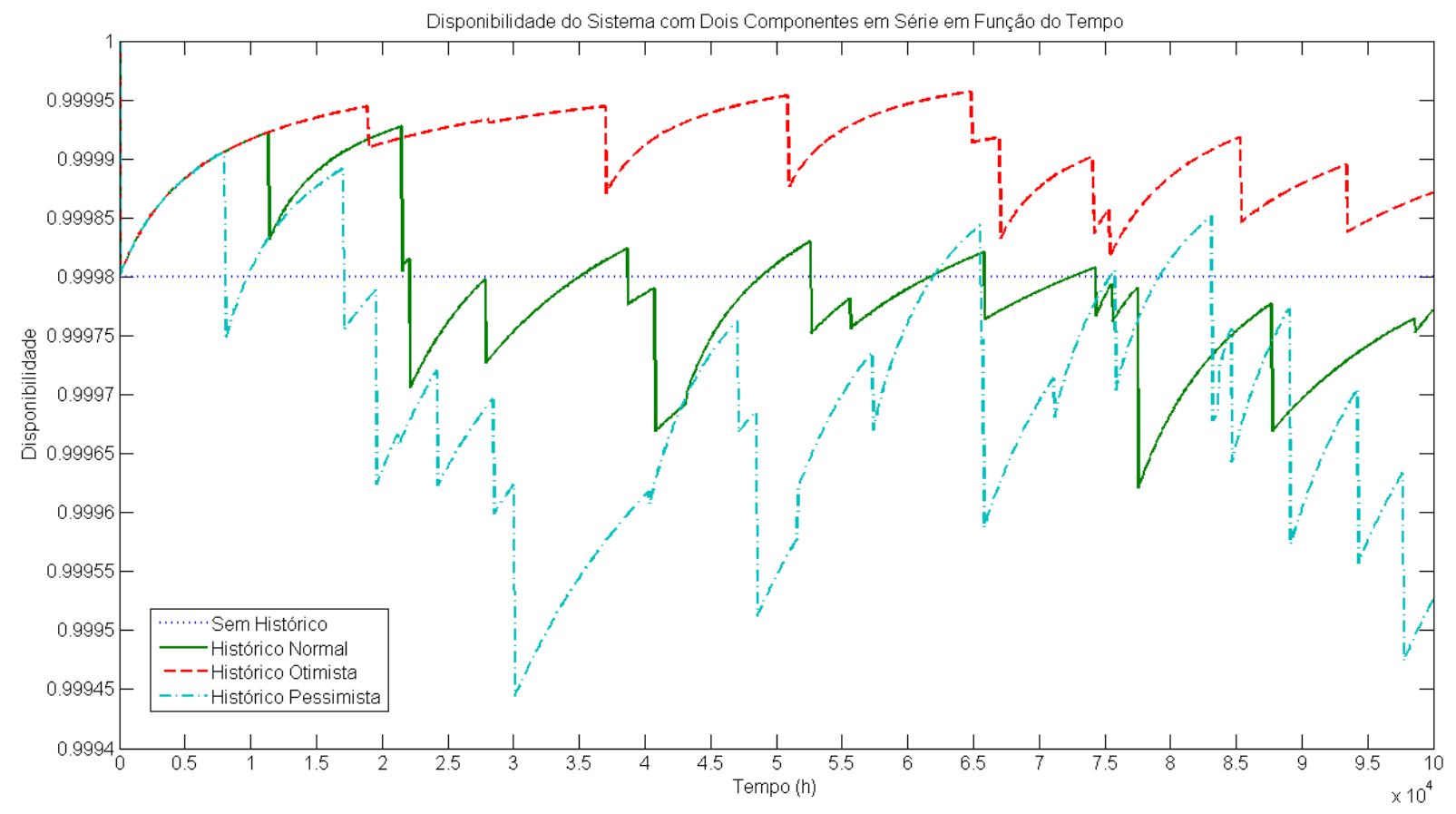

\section{Fonte: Autor}

Tal como constatado no ensaio da função disponibilidade do sistema simples, detalhado na seção 5.3.3, a disponibilidade do sistema série com dois componentes tende rapidamente a um valor assintótico no cenário em que se desconsideram dados de histórico. O valor absoluto da disponibilidade assintótica obtido nessa situação é igual a 0,99980003.

Nos três outros cenários considerados no estudo, a disponibilidade do sistema série com dois componentes oscila de acordo com as variações das taxas 
de falhas e de reparos dos componentes $\mathrm{C} 1$ e $\mathrm{C} 2$, cujos comportamentos ao longo do período de tempo $T_{\text {sim }}=10^{5}$ horas estão representados nos gráficos da Figura 67 até a Figura 70.

Figura 67 - Gráficos da Função Taxa de Falhas do Componente C1 do Sistema Série com Dois Componentes nos Quatro Cenários de Estudo da Função Disponibilidade

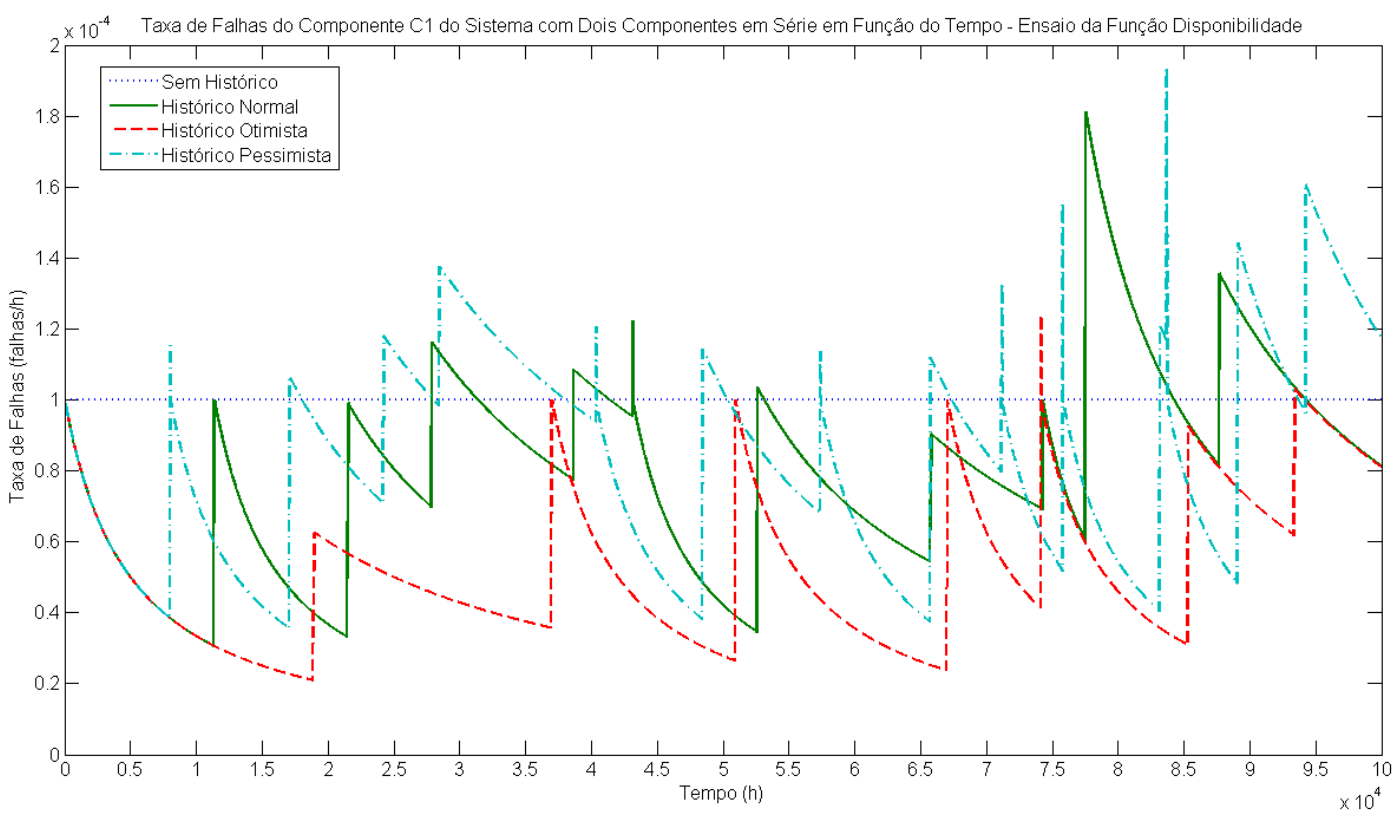

\section{Fonte: Autor}

Figura 68 - Gráficos da Função Taxa de Falhas do Componente C2 do Sistema Série com Dois Componentes nos Quatro Cenários de Estudo da Função Disponibilidade

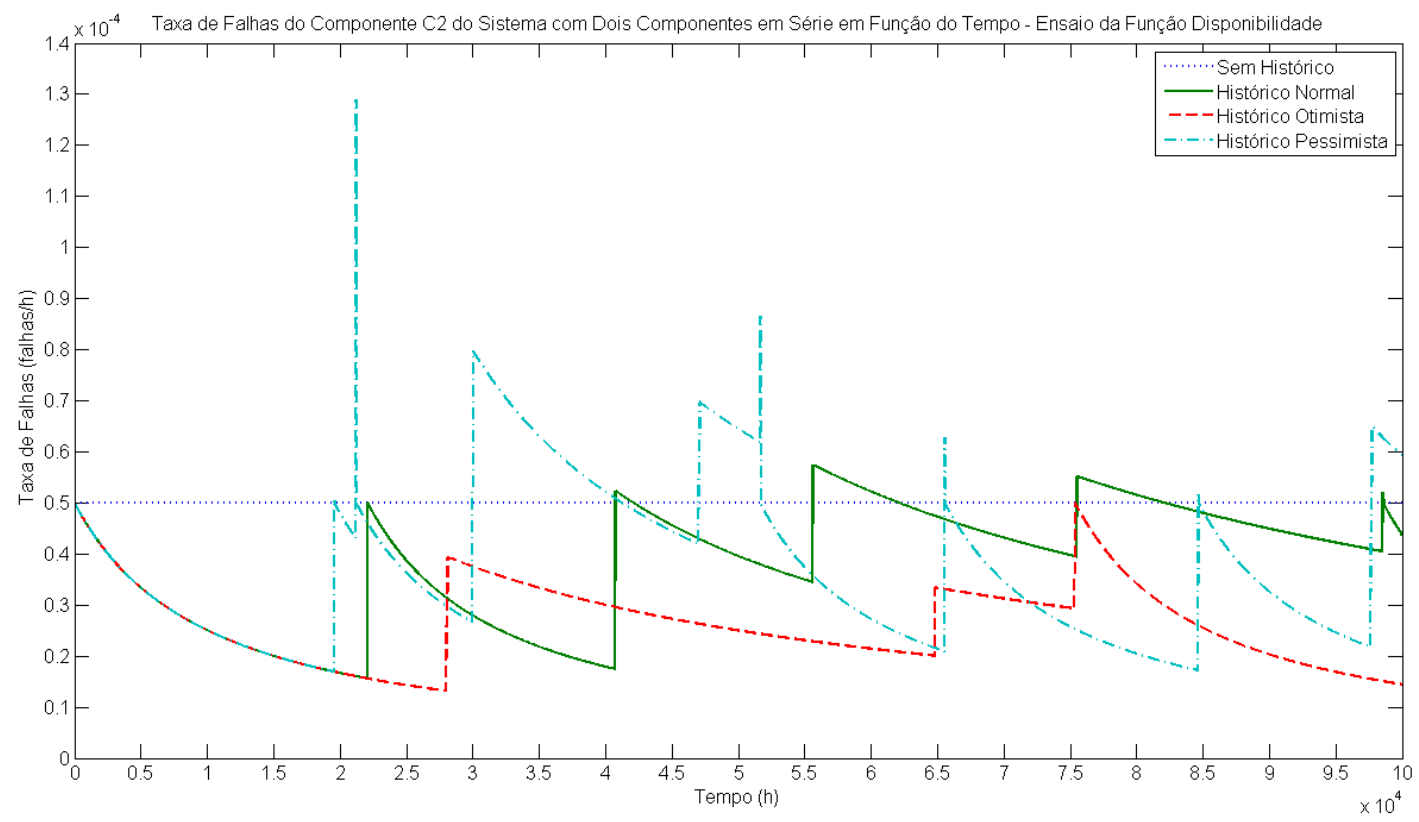


Figura 69 - Gráficos da Função Taxa de Reparos do Componente C1 do Sistema Série com Dois Componentes nos Quatro Cenários de Estudo da Função Disponibilidade

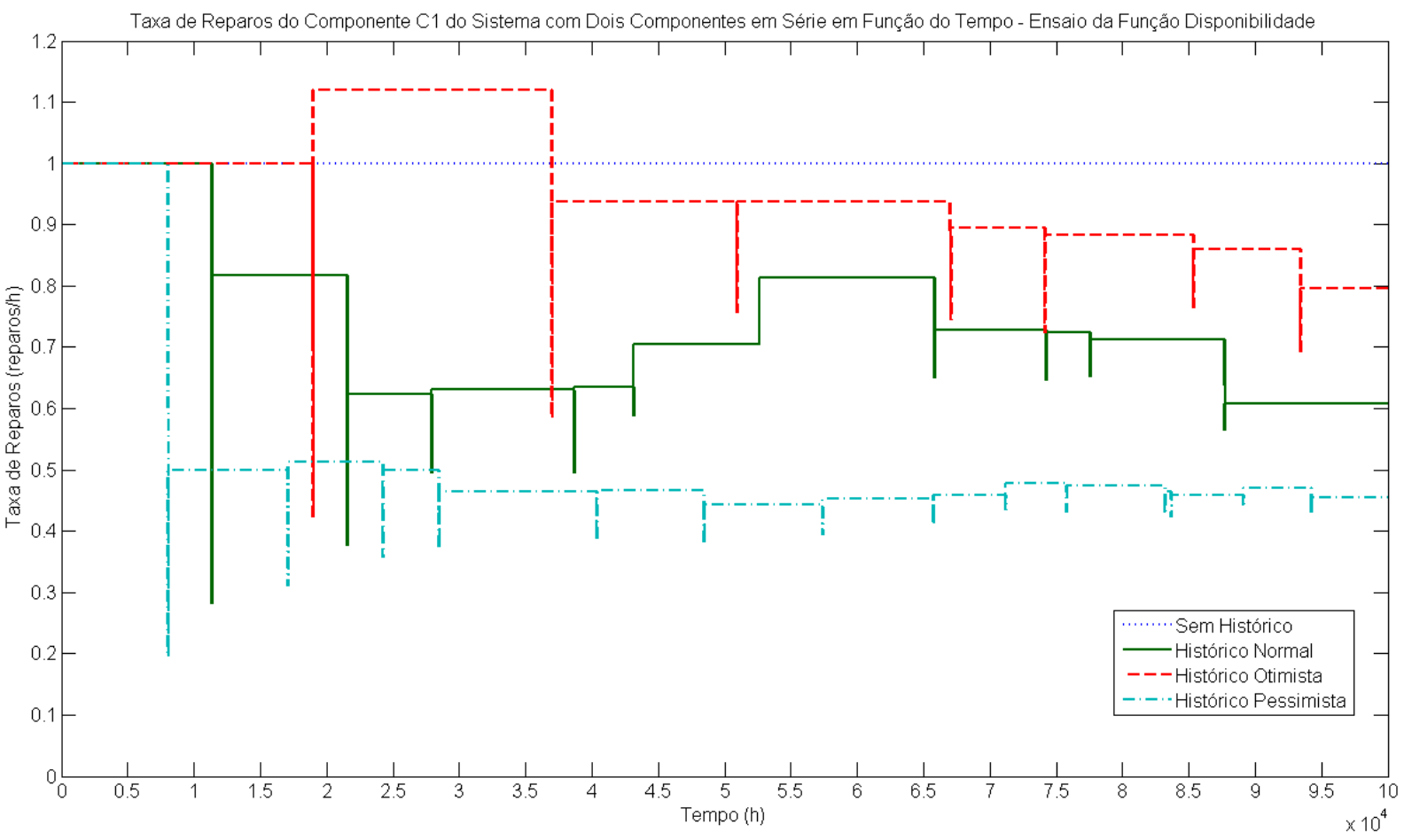

Fonte: Autor

Figura 70 - Gráficos da Função Taxa de Reparos do Componente C2 do Sistema Série com Dois Componentes nos Quatro Cenários de Estudo da Função Disponibilidade

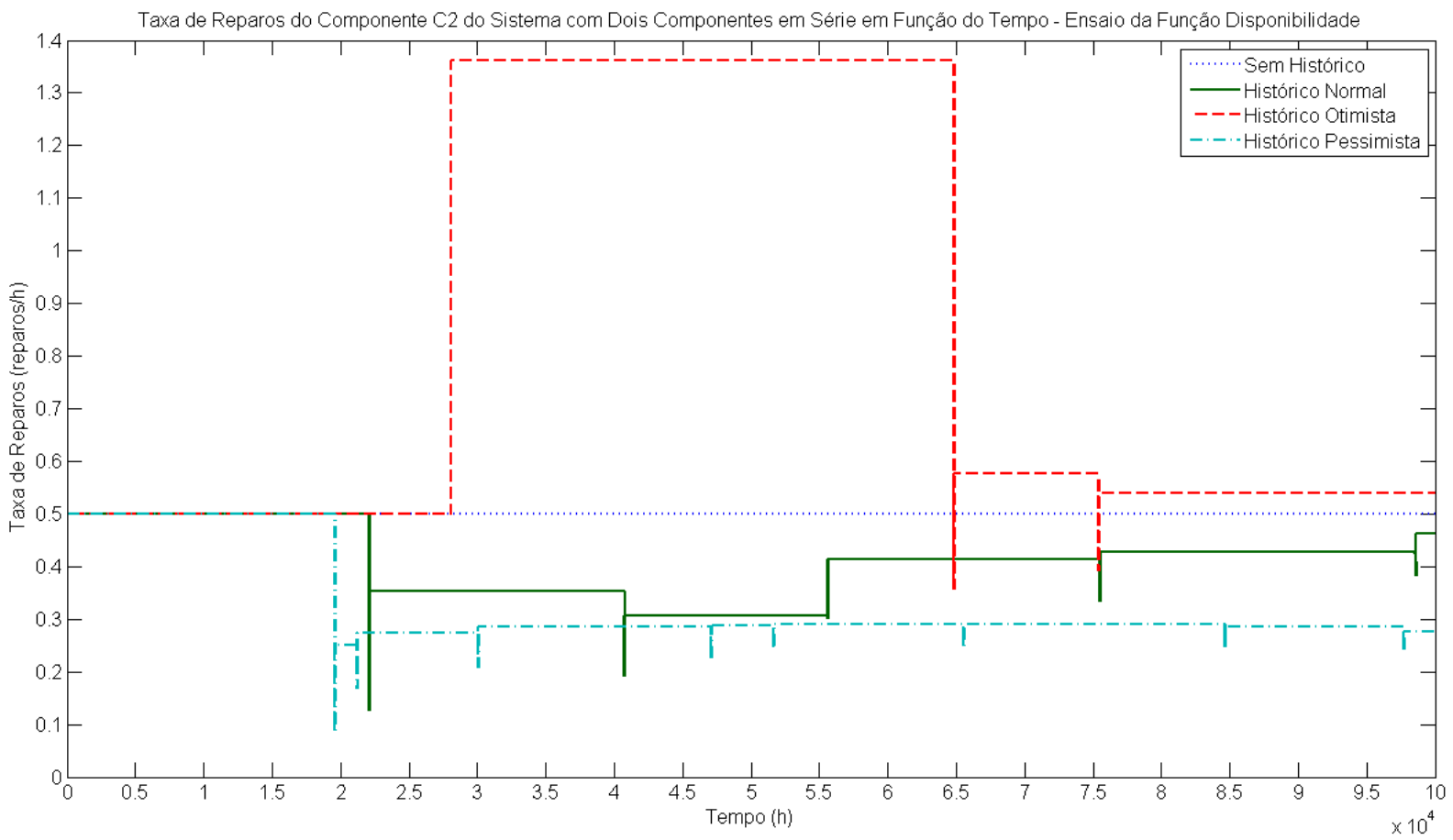

Fonte: Autor 
Tal como já explorado com mais detalhes no estudo da função disponibilidade do sistema simples, apresentado na seção 5.2.3, as variações das taxas de falhas e de reparos de $\mathrm{C} 1$ e $\mathrm{C} 2$ decorrem do tratamento matemático dado pelo módulo "Cálculo das Taxas de Falhas e de Reparos condicionadas ao Histórico de Operação"16 do modelo proposto no trabalho aos eventos de falhas e manutenções que constam nos históricos operacionais empregados nos ensaios. A relação completa dos históricos operacionais gerados pelo módulo "Simulador de Dados de Entrada" do ambiente de desenvolvimento e ensaio utilizados nas simulações dos cenários de históricos normal, otimista e pessimista é apresentada no Apêndice A.2.

Ao se interpretar conjuntamente os gráficos representados da Figura 66 até a Figura 70 , é possível atingir conclusões similares às já exploradas nos ensaios referentes ao sistema simples, detalhadas na seção 5.2.3:

a) Ao longo da maioria do intervalo de tempo $T_{\text {sim }}=10^{5}$ horas, a Figura 66 permite constatar que a disponibilidade do sistema no cenário em que se utilizou um histórico pessimista foi inferior à verificada nos demais ensaios. As principais justificativas relacionadas a esse resultado são as seguintes:

i. Considerando-se a Figura 67 e a Figura 68, nota-se que a função taxa de falhas dos componentes $\mathrm{C} 1$ e $\mathrm{C} 2$ possuem mais pontos de máximo locais no ensaio pessimista do que nos outros estudos com histórico e que, em decorrência dessa frequência maior, tais picos atingiram, em média, patamares superiores tanto ao valor nominal das taxas de falhas de C1 e C2 (utilizados no ensaio sem histórico) quanto aos produzidos nos cenários baseados no uso de históricos normal e otimista. Como, em decorrência desse comportamento, as taxas de falhas observadas para os componentes $\mathrm{C} 1$ e $\mathrm{C} 2$ mantiveram-se em patamares médios mais elevados ao longo do período de tempo $T_{\text {sim }}=10^{5}$ horas do ensaio pessimista, é esperado que a

\footnotetext{
${ }^{16}$ Para maiores informações acerca do bloco "Cálculo das Taxas de Falhas e de Reparos condicionadas ao
} Histórico de Operação”, consultar a seção 3.3. 
disponibilidade do sistema nessa situação seja inferior à observada nos demais cenários;

ii. A partir da Figura 69 e da Figura 70, é possível notar que os valores assintóticos atingidos pelas taxas de reparos dos componentes $\mathrm{C} 1 \mathrm{e}$ C2 ao final do intervalo de tempo $T_{\text {sim }}=10^{5}$ horas no estudo com histórico pessimista foram inferiores aos obtidos em todos os demais ensaios executados. Por conseguinte, a disponibilidade no cenário pessimista também é negativamente impactada em comparação às demais situações estudadas.

b) Analogamente, também se pode constatar a partir da Figura 66 que, na maioria do período $T_{\text {sim }}=10^{5}$ horas, a disponibilidade do sistema no cenário com histórico otimista foi superior à observada nos demais ensaios. Considerando-se o comportamento predominante das taxas de falhas e de reparos dos componentes $\mathrm{C} 1$ e $\mathrm{C} 2$ representadas nos gráficos da Figura 67 à Figura 70, a superioridade da disponibilidade do sistema série no ensaio otimista decorre tanto das taxas de falhas dos componentes C1 e C2, que se mantiveram, em média, em níveis inferiores aos de todos os outros ensaios, quanto de suas taxas de reparos, que se aproximaram de valores assintóticos maiores do que os obtidos nos outros cenários estudados.

c) Na comparação direta entre os ensaios com histórico normal e sem histórico, é possível verificar, por intermédio da Figura 66, que a disponibilidade do sistema série no primeiro cenário manteve-se predominantemente superior à verificada no último apenas nas primeiras $22.000 \mathrm{~h}$ do ensaio, durante as quais é possível constatar que as taxas de falhas dos componentes $\mathrm{C} 1$ e $\mathrm{C} 2$ mantiveram-se em níveis inferiores aos seus respectivos valores nominais, utilizados no estudo sem histórico.

No intervalo de tempo compreendido entre o término do período inicial de $22.000 \mathrm{~h}$ - que coincide com a primeira falha do componente $\mathrm{C} 2^{17}$ - e aproximadamente $77.000 \mathrm{~h}$, a disponibilidade do sistema série no cenário com histórico normal é ligeiramente inferior ao índice nominal determinado no

\footnotetext{
17 Inspecionando-se a Tabela 56 do Apêndice A.2, que contém o histórico utilizado no ensaio sem histórico, é possível notar que a primeira falha do componente C2 ocorre após aproximadamente 22.070h de estudo do sistema.
} 
ensaio sem histórico até aproximadamente $77.000 \mathrm{~h}$ de estudo do sistema. $\mathrm{O}$ comportamento ao longo desse intervalo intermediário decorre do fato de não terem sido observadas variações das taxas de falhas e de reparos dos componentes $\mathrm{C} 1$ e $\mathrm{C} 2$ que as levem a assumir valores muito distintos dos seus respectivos índices nominais, e, em decorrência dessas variações mais sensíveis, a disponibilidade do sistema oscila em torno de índices razoavelmente próximos ao valor assintótico do ensaio sem histórico.

Já na etapa final dos ensaios, entre $77.000 \mathrm{~h}$ e $100.000 \mathrm{~h}$, é possível notar que a disponibilidade do sistema série no cenário com histórico normal passa a ser exclusivamente inferior ao índice assintótico observado na situação em que nenhum dado operacional de histórico é empregado. A principal justificativa associada a esse resultado é o aumento significativo da taxa de falhas do componente $\mathrm{C} 1$ no início do período final da simulação, que passa de aproximadamente $6 \cdot 10^{-5}$ falhas $/ \mathrm{h}$ para $1,8 \cdot 10^{-4}$ falhas $/ \mathrm{h}$. Essa elevação significativa da taxa de falhas de $\mathrm{C} 1$ decorre da ocorrência de duas falhas consecutivas do componente $\mathrm{C} 1 \mathrm{em}$ um intervalo de tempo de aproximadamente $3.000 \mathrm{~h}$ de funcionamento do sistema (entre $74.200 \mathrm{~h}$ e 77.600h), tal como se pode constatar a partir da Tabela 56 do Apêndice A.2. Como o período de tempo de aproximadamente $3.000 \mathrm{~h}$ é significativamente inferior ao MTTF do componente $\mathrm{C} 1$, os cálculos executados pelo módulo "Cálculo das Taxas de Falhas e de Reparos condicionadas ao Histórico de Operação"18 do modelo proposto no trabalho promove uma elevação da taxa de falhas de $\mathrm{C} 1$.

Ao final do período de tempo $T_{\text {sim }}=10^{5}$ horas, as simulações executadas conduziram aos valores de disponibilidade relacionados na Tabela 31.

Tabela 31 - Disponibilidade do Sistema Série com Dois Componentes após $T_{\text {sim }}=10^{5}$ horas

\begin{tabular}{|c|c|}
\hline Cenário Estudado & Disponibilidade do Sistema Série com Dois Componentes \\
\hline Sem Histórico & 0,99980003 \\
\hline Histórico Normal & 0,99977162 \\
\hline
\end{tabular}

${ }^{18}$ Para maiores informações acerca do bloco "Cálculo das Taxas de Falhas e de Reparos condicionadas ao Histórico de Operação”, consultar a seção 3.3. 


\begin{tabular}{|c|c|}
\hline Cenário Estudado & Disponibilidade do Sistema Série com Dois Componentes \\
\hline Histórico Otimista & 0,99987160 \\
\hline Histórico Pessimista & 0,99952654 \\
\hline
\end{tabular}

Fonte: Autor

Além do estudo da função disponibilidade ao longo do período de tempo $T_{\text {sim }}=10^{5}$ horas, também foram produzidas, ao final dos três ensaios baseados no uso de dados de histórico, as estimativas dos instantes de tempo das cinco próximas falhas que deveriam ocorrer com os componentes C1 e C2 do sistema série. Os resultados obtidos estão registrados na Tabela 32 e na Tabela 33.

Tabela 32 - Relação das Cinco Próximas Falhas do Componente C1 do Sistema Série após $T_{\text {sim }}=10^{5}$ horas

\begin{tabular}{|c|c|c|c|c|c|c|}
\cline { 2 - 7 } \multicolumn{1}{c|}{} & \multicolumn{2}{c|}{ Histórico Normal } & \multicolumn{2}{c|}{ Histórico Otimista } & \multicolumn{2}{c|}{ Histórico Pessimista } \\
\cline { 2 - 7 } & $\begin{array}{c}\text { Tempo de } \\
\text { Ocorrência (h) }\end{array}$ & $\begin{array}{c}\text { Desvio } \\
\text { Padrão } \\
\text { (h) }\end{array}$ & $\begin{array}{c}\text { Tempo de } \\
\text { Ocorrência (h) }\end{array}$ & $\begin{array}{c}\text { Desvio } \\
\text { Padrão } \\
\text { (h) }\end{array}$ & $\begin{array}{c}\text { Tempo de } \\
\text { Ocorrência (h) }\end{array}$ & $\begin{array}{c}\text { Desvio } \\
\text { Padrão } \\
\text { (h) }\end{array}$ \\
\hline $\begin{array}{c}\text { Falha } \\
\mathbf{1}\end{array}$ & 100861,2 & 1974,0 & 110036,1 & 4492,4 & 102830,5 & 2954,9 \\
\hline $\begin{array}{c}\text { Falha } \\
\mathbf{2}\end{array}$ & 109174,3 & 1925,0 & 117798,2 & 4498,5 & 111013,1 & 2974,2 \\
\hline $\begin{array}{c}\text { Falha } \\
\mathbf{3}\end{array}$ & 120130,2 & 1971,3 & 131504,9 & 4406,4 & 118943,3 & 2962,8 \\
\hline $\begin{array}{c}\text { Falha } \\
\mathbf{4}\end{array}$ & 131683,7 & 1941,1 & 146822,4 & 4139,1 & 125838,2 & 2962,2 \\
\hline $\begin{array}{c}\text { Falha } \\
\mathbf{5}\end{array}$ & 140427,0 & 1965,6 & 159122,6 & 3692,0 & 133243,4 & 2811,8 \\
\hline
\end{tabular}

Fonte: Autor

Tabela 33 - Relação das Cinco Próximas Falhas do Componente C2 do Sistema Série após $T_{\text {sim }}=10^{5}$ horas

\begin{tabular}{|c|c|c|c|c|c|c|}
\cline { 2 - 7 } \multicolumn{1}{c|}{} & \multicolumn{2}{c|}{ Histórico Normal } & \multicolumn{2}{c|}{ Histórico Otimista } & \multicolumn{2}{c|}{ Histórico Pessimista } \\
\cline { 2 - 7 } & $\begin{array}{c}\text { Tempo de } \\
\text { Ocorrência (h) }\end{array}$ & $\begin{array}{c}\text { Desvio } \\
\text { Padrão } \\
\text { (h) }\end{array}$ & $\begin{array}{c}\text { Tempo de } \\
\text { Ocorrência (h) }\end{array}$ & $\begin{array}{c}\text { Desvio } \\
\text { Padrão (h) }\end{array}$ & $\begin{array}{c}\text { Tempo de } \\
\text { Ocorrência (h) }\end{array}$ & $\begin{array}{c}\text { Desvio } \\
\text { Padrão } \\
\text { (h) }\end{array}$ \\
\hline $\begin{array}{c}\text { Falha } \\
\mathbf{1}\end{array}$ & 116048,0 & 3529,1 & 102981,9 & 20403,9 & 100903,9 & 5607,5 \\
\hline $\begin{array}{c}\text { Falha } \\
\mathbf{2}\end{array}$ & 134038,1 & 3588,2 & 137087,4 & 15091,5 & 107505,4 & 5649,8 \\
\hline $\begin{array}{c}\text { Falha } \\
\mathbf{3}\end{array}$ & 149769,3 & 3690,8 & 173345,2 & 10656,9 & 114532,4 & 5684,0 \\
\hline
\end{tabular}




\begin{tabular}{|c|c|c|c|c|c|c|}
\cline { 2 - 7 } \multicolumn{1}{c|}{} & \multicolumn{2}{c|}{ Histórico Normal } & \multicolumn{2}{c|}{ Histórico Otimista } & \multicolumn{2}{c|}{ Histórico Pessimista } \\
\cline { 2 - 7 } & $\begin{array}{c}\text { Tempo de } \\
\text { Ocorrência (h) }\end{array}$ & $\begin{array}{c}\text { Desvio } \\
\text { Padrão } \\
\text { (h) }\end{array}$ & $\begin{array}{c}\text { Tempo de } \\
\text { Ocorrência (h) }\end{array}$ & $\begin{array}{c}\text { Desvio } \\
\text { Padrão (h) }\end{array}$ & $\begin{array}{c}\text { Tempo de } \\
\text { Ocorrência (h) }\end{array}$ & $\begin{array}{c}\text { Desvio } \\
\text { Padrão } \\
\text { (h) }\end{array}$ \\
\hline $\begin{array}{c}\text { Falha } \\
\mathbf{4}\end{array}$ & 166133,8 & 3521,4 & 208345,0 & 8186,2 & 123223,3 & 5579,5 \\
\hline $\begin{array}{c}\text { Falha } \\
\mathbf{5}\end{array}$ & 186899,5 & 3503,5 & 230262,1 & 6409,5 & 136721,8 & 5218,0 \\
\hline
\end{tabular}

Fonte: Autor

Ao se avaliar os resultados relacionados na Tabela 32 e na Tabela 33, é possível notar a mesma tendência já observada e discutida no estudo da função disponibilidade do sistema simples, detalhado na seção 5.2.3: devido à propriedade de minimização de erros estatísticos desempenhada pelo Filtro de Kalman do bloco "Detector de Comportamento e Filtro de Kalman" do modelo proposto, o valor do desvio padrão das previsões calculadas tende a cair à medida que mais eventos de falhas futuras são determinados e desde que tais eventos de falhas futuras ajustemse adequadamente à representação de função afim utilizado na regressão linear inerente ao modelo proposto. A única situação em que não houve queda significativa do desvio padrão dos instantes de ocorrência das falhas futuras do sistema série à medida que mais previsões eram feitas ocorreu com o componente $C 1$ no cenário de histórico normal, contexto em que foram observadas oscilações pouco significativas do desvio padrão associado às falhas previstas, inferiores a $3 \%$.

Outro aspecto a ser salientado, também abordado com maior profundidade na seção 5.2.3, é o de que, para ambos os componentes $\mathrm{C} 1$ e $\mathrm{C} 2$, os desvios padrão de suas falhas futuras no cenário em que se utiliza um histórico otimista são significativamente superiores aos verificados nos outros dois ensaios. A justificativa para esse comportamento é a de que os registros de falha do histórico otimista não se adaptaram tão eficientemente à função afim utilizada no bloco "Detector de Comportamento e Filtro de Kalman" do modelo proposto com relação aos dados empregados nos ensaios normal e pessimista, consequentemente levando os coeficientes angular e linear da função gerada a serem mais elevados.

O exemplo mais representativo dessa situação é o relacionado às previsões das falhas futuras do componente $\mathrm{C} 2$ no cenário de histórico otimista, que 
apresentaram os maiores valores de desvio padrão entre todos os ensaios executados. Como se pode constatar inspecionando-se tanto o gráfico da Figura 68 quanto os registros de histórico da Tabela 56 do Apêndice A.2, há apenas três registros de falha do componente $\mathrm{C} 2$, e essa quantidade, por sua vez, corresponde ao número mínimo de pontos que podem ser utilizados em uma regressão linear para que as variâncias dos coeficientes angular e linear sejam finitas. Por esse motivo, eventuais imprecisões no ajuste dos instantes dos eventos de falha à função afim utilizada no bloco "Detector de Comportamento e Filtro de Kalman" do modelo proposto podem ser traduzidas em valores significativamente elevados das variâncias associadas aos coeficientes angular e linear.

Outro aspecto que também merece destaque relaciona-se ao fato de, para todas as três categorias de histórico (normal, otimista e pessimista), os desvios padrão obtidos nas previsões das falhas do componente C2 terem sido superiores aos associados às falhas futuras do componente $\mathrm{C} 1$. Há duas justificativas plausíveis para esse comportamento:

a) Os registros das falhas do componente $\mathrm{C} 1$ adequaram-se mais apropriadamente à função afim produzida pelo bloco "Detector de Comportamento e Filtro de Kalman" do modelo proposto do que os eventos de falha do componente C2;

b) A partir da equação (68), apresentada na seção 4.5 para definir uma etapa intermediária do cálculo da variância dos instantes das falhas futuras de um componente, é possível verificar que uma parcela da variância final de cada estimativa de falha futura será diretamente proporcional ao MTTF do componente. Como a taxa de falhas do componente $\mathrm{C} 2$ é inferior à taxa de falhas do componente C1, o MTTF de C2 é maior do que o MTTF de C1 e, consequentemente, os desvios padrão associados às previsões das falhas de C2 serão superiores aos relativos às falhas futuras de $\mathrm{C} 1$.

Com o propósito de permitir avaliar os algoritmos de predição de falhas utilizados pelo bloco "Detector de Comportamento e Filtro de Kalman" do modelo desenvolvido neste trabalho, também foram executados experimentos complementares com o objetivo de que os três últimos eventos de falha dos componentes $\mathrm{C} 1$ e $\mathrm{C} 2$ já presentes no histórico operacional do sistema série fossem 
previstos considerando-se os instantes de ocorrência de todas as falhas anteriores a elas. Os resultados obtidos nesse estudo para os três cenários com uso de histórico operacional são exibidos da Tabela 34 até a Tabela $38^{19}$.

Um aspecto a ser salientado é o de que, como os algoritmos utilizados pelo bloco "Detector de Comportamento e Filtro de Kalman" do modelo proposto requerem que pelo menos três eventos passados de falha estejam disponíveis para eles serem executados com sucesso, não foi possível estender este experimento de predição de falhas passadas ao estudo do componente $\mathrm{C} 2$ no cenário com histórico otimista. Como já apresentado anteriormente, é possível constatar, a partir dos registros de histórico da Tabela 56 do Apêndice A.2, que há apenas três eventos de falha do componente $\mathrm{C} 2$; dessa forma, como a quantidade total de registros de falha de $\mathrm{C} 2$ no histórico operacional do sistema é igual à quantidade mínima de eventos de falha necessários para que o bloco "Detector de Comportamento e Filtro de Kalman" do modelo desenvolvido neste estudo funcione apropriadamente, apenas falhas ocorrentes em instantes de tempo posteriores aos da última falha preexistente no histórico poderão ser calculados.

Uma justificativa análoga à anterior também pode ser utilizada para respaldar o fato de apenas os dois últimos eventos de falha do componente C2 terem sido experimentalmente considerados no estudo do cenário com histórico normal. A partir da Tabela 55 do Apêndice A.2, é possível notar que existem cinco falhas do componente C2 no histórico operacional do sistema; dessa maneira, se três falhas devem ser obrigatoriamente utilizadas como referência para o funcionamento adequado do bloco "Detector de Comportamento e Filtro de Kalman" do modelo proposto, os dois últimos eventos de falha no histórico de C2 já poderiam ser previstos com base nos outros três eventos anteriores.

\footnotetext{
${ }^{19}$ Os valores registrados nas células das linhas "Instante Real de Ocorrência ( $h$ )" das tabelas correspondem aos instantes de tempo dos últimos eventos " $F 1$ " e "F2" registrados nas respectivas tabelas do Apêndice A.2.
} 
Tabela 34 - Comparação dos Instantes de Ocorrência das Três Últimas Falhas do Componente C1 do Sistema Série com as Previsões Produzidas pelo Modelo Proposto - Ensaio Baseado em Histórico Normal

\begin{tabular}{|c|c|c|c|}
\cline { 2 - 4 } \multicolumn{1}{c|}{} & Falha 1 & Falha 2 & Falha 3 \\
\hline Instante Real de Ocorrência (h) $-t_{\text {real }}$ & 74250,2 & 77526,2 & 87681,0 \\
\hline Instante Previsto (h) $-t_{\text {prev }}$ & 75420,5 & 84982,1 & 95671,0 \\
\hline Variância $\left.\mathbf{( h}^{\mathbf{2}}\right)-\sigma_{t_{\text {prev }}}$ & 5316827,3 & 5447347,5 & 5347082,4 \\
\hline Desvio Padrão (h) $-\sigma_{t_{\text {prev }}}$ & 2305,8 & 2334,0 & 2312,4 \\
\hline Erro Relativo entre Real e (Previsto - Desvio) & $-0,0153$ & 0,0661 & 0,0648 \\
\hline Erro Relativo entre Real e Previsto & 0,0158 & 0,0962 & 0,0911 \\
\hline Erro Relativo entre Real e (Previsto + Desvio) & 0,0468 & 0,1263 & 0,1175 \\
\hline
\end{tabular}

Fonte: Autor

Tabela 35 - Comparação dos Instantes de Ocorrência das Três Últimas Falhas do Componente C1 do Sistema Série com as Previsões Produzidas pelo Modelo Proposto - Ensaio Baseado em Histórico Otimista

\begin{tabular}{|c|c|c|c|}
\cline { 2 - 4 } \multicolumn{1}{c|}{} & Falha 1 & Falha 2 & Falha 3 \\
\hline Instante Real de Ocorrência (h) $-t_{\text {real }}$ & 74120,8 & 85310,5 & 93392,7 \\
\hline Instante Previsto $(\mathbf{h})-t_{\text {prev }}$ & 77296,2 & 87989,6 & 101973,7 \\
\hline Variância $\left.\mathbf{( h}^{\mathbf{2}}\right)-\sigma_{t_{\text {prev }}}$ & 3668387,1 & 4016930,2 & 4183297,7 \\
\hline Desvio Padrão (h) $-\sigma_{t_{\text {prev }}}$ & 1915,3 & 2004,2 & 2045,3 \\
\hline Erro Relativo entre Real e (Previsto - Desvio) & 0,0170 & 0,0079 & 0,0700 \\
\hline Erro Relativo entre Real e Previsto & 0,0428 & 0,0314 & 0,0919 \\
\hline Erro Relativo entre Real e (Previsto + Desvio) & 0,0687 & 0,0549 & 0,1138 \\
\hline
\end{tabular}

Fonte: Autor

Tabela 36 - Comparação dos Instantes de Ocorrência das Três Últimas Falhas do Componente C1 do Sistema Série com as Previsões Produzidas pelo Modelo Proposto - Ensaio Baseado em Histórico Pessimista

\begin{tabular}{|c|c|c|c|}
\cline { 2 - 4 } \multicolumn{1}{c|}{} & Falha 1 & Falha 2 & Falha 3 \\
\hline Instante Real de Ocorrência (h) $-t_{\text {real }}$ & 83689,1 & 84644,2 & 94240,7 \\
\hline Instante Previsto (h) $-t_{\text {prev }}$ & 87591,0 & 94291,7 & 100146,7 \\
\hline Variância $\left.\mathbf{( h}^{\mathbf{2}}\right)-\sigma_{t_{\text {prev }}}$ & 3688471,8 & 3495213,4 & 3517584,2 \\
\hline Desvio Padrão (h) $-\sigma_{t_{\text {prev }}}$ & 1920,5 & 1869,5 & 1875,5 \\
\hline Erro Relativo entre Real e (Previsto - Desvio) & 0,0237 & 0,0919 & 0,0428 \\
\hline Erro Relativo entre Real e Previsto & 0,0466 & 0,1140 & 0,0627 \\
\hline Erro Relativo entre Real e (Previsto + Desvio) & 0,0696 & 0,1361 & 0,0826 \\
\hline
\end{tabular}

Fonte: Autor 
Tabela 37 - Comparação dos Instantes de Ocorrência das Duas Últimas Falhas do Componente C2 do Sistema Série com as Previsões Produzidas pelo Modelo Proposto Ensaio Baseado em Histórico Normal

\begin{tabular}{|c|c|c|}
\cline { 2 - 3 } \multicolumn{1}{c|}{} & Falha 1 & Falha 2 \\
\hline Instante Real de Ocorrência (h) $-t_{\text {real }}$ & 75525,0 & 98565,8 \\
\hline Instante Previsto (h) $-t_{\text {prev }}$ & 89981,2 & 115011,0 \\
\hline Variância $\left.\mathbf{( h}^{\mathbf{2}}\right)-\sigma_{t_{\text {prev }}}$ & 11670600,4 & 10794271,0 \\
\hline Desvio Padrão (h) $-\sigma_{t_{\text {prev }}}$ & 3416,2 & 3285,5 \\
\hline Erro Relativo entre Real e (Previsto - Desvio) & 0,1462 & 0,1335 \\
\hline Erro Relativo entre Real e Previsto & 0,1914 & 0,1668 \\
\hline Erro Relativo entre Real e (Previsto + Desvio) & 0,2366 & 0,2002 \\
\hline
\end{tabular}

Fonte: Autor

Tabela 38 - Comparação dos Instantes de Ocorrência das Três Últimas Falhas do Componente C2 do Sistema Série com as Previsões Produzidas pelo Modelo Proposto - Ensaio Baseado em Histórico Pessimista

\begin{tabular}{|c|c|c|c|}
\cline { 2 - 4 } \multicolumn{1}{c|}{} & Falha 1 & Falha 2 & Falha 3 \\
\hline Instante Real de Ocorrência (h) $-t_{\text {real }}$ & 65537,6 & 88523,8 & 97691,4 \\
\hline Instante Previsto (h) $-t_{\text {prev }}$ & 66732,6 & 84208,0 & 97745,0 \\
\hline Variância $\left.\mathbf{( h}^{\mathbf{2}}\right)-\sigma_{t_{\text {prev }}}$ & 34803717,0 & 36623402,9 & 35636251,8 \\
\hline Desvio Padrão (h) $-\sigma_{t_{\text {prev }}}$ & 5899,5 & 6051,7 & 5969,6 \\
\hline Erro Relativo entre Real e (Previsto - Desvio) & $-0,0718$ & $-0,1171$ & $-0,0606$ \\
\hline Erro Relativo entre Real e Previsto & 0,0182 & $-0,0488$ & 0,0005 \\
\hline Erro Relativo entre Real e (Previsto + Desvio) & 0,1083 & 0,0196 & 0,0617 \\
\hline
\end{tabular}

Fonte: Autor

À luz dos resultados expostos da Tabela 34 até a Tabela 38, é possível inferir que a maioria dos instantes previstos para a ocorrência das falhas dos componentes C1 e C2 por meio do modelo proposto neste trabalho $\left(t_{\text {prev }}\right)$ foi maior do que os respectivos valores esperados, presentes nos três cenários de histórico operacional do sistema série $\left(t_{\text {real }}\right)$. Considerando-se como critério de aceitação dos resultados obtidos que $t_{\text {real }}$ pertença ao intervalo $\left[t_{\text {prev }}-\sigma_{t_{\text {prev }}} ; t_{\text {prev }}+\sigma_{t_{\text {prev }}}\right]$, quatro dos quatorze eventos de falha estudados para ambos os componentes foram previstos com sucesso:

a) A previsão da primeira falha do componente $\mathrm{C} 1$ no ensaio com histórico normal (evento "Falha 1" da Tabela 34), que, de acordo com os resultados registrados na Tabela 34, apresenta um erro relativo de $-1,5 \%$ a $+4,7 \%$ com relação a seu instante real de ocorrência; 
b) A previsão da primeira falha do componente $\mathrm{C} 2$ no ensaio com histórico pessimista (evento "Falha 1" da Tabela 38), a qual, com base nos dados da Tabela 38, apresenta um erro relativo de $-7,2 \%$ a $+10,8 \%$ com relação a seu instante real de ocorrência;

c) A previsão da segunda falha do componente C2 no ensaio com histórico pessimista (evento "Falha 2" da Tabela 38), que, segundo a Tabela 38, apresenta um erro relativo de $-11,7 \%$ a $+2,0 \%$ com relação a seu instante real de ocorrência;

d) A previsão da terceira falha do componente C2 no ensaio com histórico pessimista (evento "Falha 3" da Tabela 38), que apresenta um erro relativo entre $-6,1 \%$ e $+6,1 \%$ com relação a seu instante real de ocorrência.

Embora os resultados obtidos para as três predições de falhas de C2 no cenário de histórico pessimista tenham sido satisfatórios, um aspecto a ser ressaltado é o de que os desvios padrão dos três valores obtidos são significativamente maiores do que os observados em todos os demais ensaios. Esse comportamento pode ser justificado pela dificuldade de se ajustar à função afim utilizada pelo bloco "Detector de Comportamento e Filtro de Kalman" do modelo proposto os pontos associados às falhas de C2 que ocorreram após 22.070 e 55.633 horas do início do estudo do sistema série.

Como se pode constatar considerando-se tanto o gráfico da taxa de falhas do componente $\mathrm{C} 2$ no cenário pessimista, ilustrado na Figura 68, e a Tabela 57 do Apêndice A.2, os intervalos de tempo entre cada um desses eventos de falha e a falha imediatamente anterior a eles foram muito menores do que os períodos entre todos os outros pares de falhas consecutivas. Em consequência dessas discrepâncias, as incertezas dos coeficientes angular e linear da função afim representativa do modelo matemático de predição de falhas de $\mathrm{C} 2$ tornam-se maiores e, por fim, o desvio padrão das falhas futuras também cresce ${ }^{20}$.

Com relação à magnitude dos erros relativos entre $t_{\text {prev }}$ e $t_{\text {real }}$, é possível extrair dos dados apresentados da Tabela 34 até a Tabela 38 que as previsões de

\footnotetext{
20 A dependência entre a variância das falhas previstas e as variâncias dos coeficientes angular e linear da função afim utilizada para calcular as predições de falhas segue a formulação matemática da equação (59), apresentada na seção 3.5 .
} 
falhas cujos instantes de ocorrência mais se desviaram dos seus respectivos valores nominais foram as seguintes:

a) Segundo evento de falha do componente $C 1$ no cenário de histórico normal (coluna "Falha 2" da Tabela 34): $\mathrm{O}$ erro relativo entre $t_{\text {prev }}$ e $t_{\text {real }}$, situado entre $+6,6 \%$ e $+12,6 \%$ do valor de $t_{\text {real }}$ neste caso, pode ser justificado pelo desvio significativo de $t_{\text {real }}$ do modelo de função afim gerado por regressão linear pelo bloco "Detector de Comportamento e Filtro de Kalman" do modelo proposto. Esse desvio ocorre porque o intervalo de tempo efetivamente transcorrido entre a falha imediatamente anterior de C1 (ocorrente em aproximadamente $74.250 \mathrm{~h}$ de ensaio do sistema) e a falha em estudo (manifestada após $77.500 \mathrm{~h}$ de estudo do sistema) é significativamente inferior aos intervalos de tempo entre todos os pares de falhas consecutivas anteriores, que foram utilizados pelo bloco "Detector de Comportamento e Filtro de Kalman" para construir o modelo de função afim utilizado na predição das falhas futuras do componente $\mathrm{C} 1$;

b) Terceiro evento de falha do componente $\mathrm{C1}$ no cenário de histórico normal (coluna "Falha 3" da Tabela 34): $O$ erro relativo entre $t_{\text {prev }}$ e $t_{\text {real }}$, compreendido de $+6,5 \%$ a $+11,8 \%$ do valor de $t_{\text {real }}$ neste caso, decorre, essencialmente, do desvio herdado da previsão anterior, explorada no item a). Um aspecto a se ressaltar é o de que o intervalo de tempo transcorrido desde a falha anterior até a falha em estudo pôde ser previsto com razoável precisão, uma vez que 0 desvio entre 0 resultado das expressões " $t_{\text {real }}$ Falha $3_{3}-t_{\text {real }}$ Falha $2_{2} \cong 10.100 h$ " e " $t_{\text {prev }_{\text {Falha } 3}}-t_{\text {prev }_{\text {Falha } 2}} \cong 10.700 h$ " foi de apenas 600 horas (erro relativo de aproximadamente $6 \%$ );

c) Terceiro evento de falha do componente C1 no cenário de histórico otimista (coluna "Falha 3" da Tabela 35): O erro relativo entre $t_{\text {prev }}$ e $t_{\text {real }}$, situado entre $+7,0 \%$ e $+11,4 \%$ do valor de $t_{\text {real }}$ neste caso, resulta do fato de os instantes reais de ocorrência dos três eventos de falhas a serem previstos não se aproximarem idealmente do modelo de função afim inicialmente produzido pelo bloco "Detector de Comportamento e Filtro de Kalman" a partir de todos os registros de falhas do componente $\mathrm{C} 1$ ocorrentes antes dos três eventos previstos. 
Considerando-se tanto o gráfico da função taxa de falhas do componente $\mathrm{C} 1$ no cenário otimista, representado na Figura 67, quanto o histórico operacional exposto na Tabela 56 do Apêndice A.2, é possível constatar que as três últimas falhas de $\mathrm{C} 1$ demoraram, com relação a todas as falhas prévias utilizadas pelo bloco "Detector de Comportamento e Filtro de Kalman" para construir a função afim utilizada nas predições de falhas futuras, menos tempo para ocorrer desde o evento de manutenção imediatamente anterior a cada um dos respectivos eventos de falha. Devido a essa diferença comportamental entre o grupo das três últimas falhas do componente $\mathrm{C} 1$ e o conjunto de todas as falhas anteriores às três últimas, o modelo matemático utilizado pelo bloco "Detector de Comportamento e Filtro de Kalman" passaria a ter comportamento predominantemente mais otimista do que o real funcionamento do sistema.

d) Primeiro e segundo eventos de falha do componente C2 no cenário de histórico normal (Tabela 37): Em ambos os casos, os elevados valores obtidos para os erros relativos entre $t_{\text {prev }}$ e $t_{\text {real }}$ (oscilantes de $+13,4 \%$ a $+23,7 \%$ de $t_{\text {real }}$, como é possível constatar a partir da Tabela 37) decorrem do fato de o modelo matemático de função afim utilizado pelo bloco "Detector de Comportamento e Filtro de Kalman" ter sido construído com a quantidade mínima de três eventos de falha de $\mathrm{C} 2$, tal como já explicado anteriormente. Em decorrência do reduzido número de entradas utilizadas na construção do modelo de predição das falhas de $\mathrm{C} 2$ nesse cenário, a probabilidade de ele se desviar do fenômeno estudado pode ser elevada se as amostras utilizadas na construção do modelo não forem suficientemente representativas.

\subsection{Avaliação de um Sistema Paralelo com Dois Componentes Redundantes}

A presente seção do texto contempla a avaliação dos índices de confiabilidade, disponibilidade e segurança crítica (safety) de um sistema composto por dois componentes redundantes conectados em paralelo nos quatro mesmos cenários já considerados nas seções 5.2 e 5.3 : 
- Cenário 1: Resultados gerados considerando-se a abordagem clássica de tratamento de processos de Markov (sem dependência de dados de histórico de operação);

- Cenário 2: Resultados gerados aplicando-se a técnica proposta neste estudo e utilizando-se dados de histórico simulados com base em um cenário operacional normal;

- Cenário 3: Resultados gerados aplicando-se a técnica proposta neste estudo e utilizando-se dados de histórico simulados com base em um cenário operacional otimista;

- Cenário 4: Resultados gerados aplicando-se a técnica proposta neste estudo e utilizando-se dados de histórico simulados com base em um cenário operacional pessimista.

O sistema considerado no estudo pode ser representado pelo diagrama de blocos da Figura 71, que permite inferir que as saídas produzidas pelo sistema a partir de suas entradas dependem do funcionamento apropriado de pelo menos um dos componentes $\mathrm{C} 1$ e $\mathrm{C} 2$.

Figura 71 - Diagrama de Blocos do Sistema Paralelo com Dois Componentes Redundantes

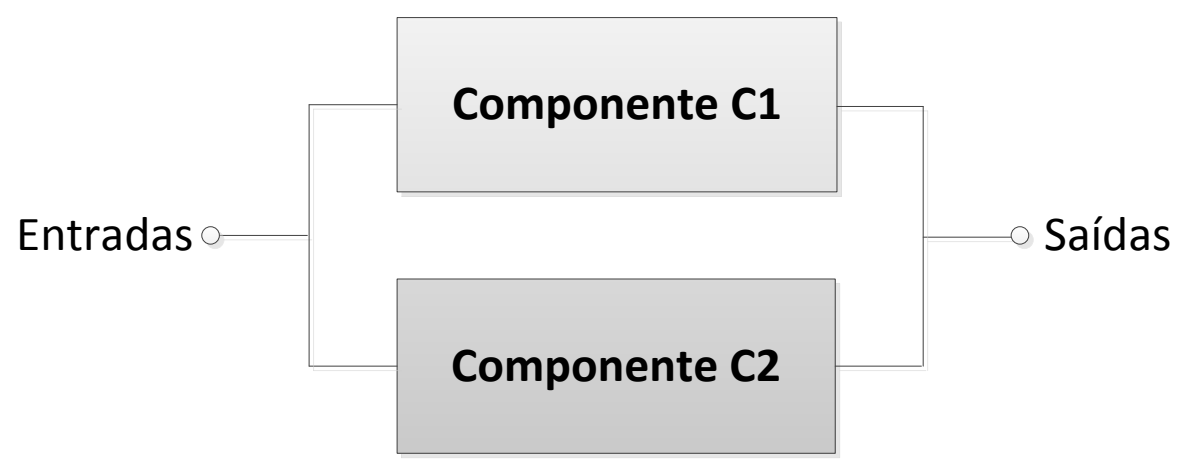

Fonte: Autor

\subsubsection{Função Confiabilidade}

A função confiabilidade do sistema paralelo com dois componentes redundantes pode ser determinada utilizando-se o mesmo modelo de Markov da 
Figura $57^{21}$, já empregado na seção 5.3.1 para se extrair a confiabilidade do sistema série com dois componentes. No entanto, como se requer que apenas um dos componentes $\mathrm{C} 1$ e $\mathrm{C} 2$ opere adequadamente para que o sistema paralelo funcione, sua confiabilidade equivale à soma das probabilidades de permanência nos estados "C1 e C2 Operacionais (OK)", "C1 Falho e C2 Operacional (C1F, C2OK)" e "C1 Operacional e C2 Falho (C1OK, C2F)".

Ao se desconsiderar o uso de dados de histórico no cálculo da função confiabilidade do sistema paralelo e definindo-se que as taxas de falhas dos componentes $\mathrm{C} 1$ e $\mathrm{C} 2$ sejam respectivamente iguais a $\lambda_{1}$ e $\lambda_{2}$, a confiabilidade da combinação paralela de C1 e C2 nesse cenário obedecerá a lei matemática definida na equação (69) (JOHNSON, 1989).

$$
R(t)=e^{-\lambda_{1} t}+e^{-\lambda_{2} t}-e^{-\left(\lambda_{1}+\lambda_{2}\right) t}
$$

Utilizando-se como parâmetros de simulação $\lambda_{1}=10^{-4}$ falhas $/ h, \lambda_{2}=$ $5.10^{-5}$ falhas $/ h, T_{\text {sim }}=10^{5}$ horas e $\Delta t_{\text {sim }}=1$ hora, a função confiabilidade do sistema série com dois componentes nos quatro cenários de estudo relacionados na seção 5.4 (abordagens sem histórico, com histórico normal, com histórico otimista e com histórico pessimista) pode ser representada pelos gráficos expostos na Figura 72.

\footnotetext{
${ }^{21}$ A Figura 57 está presente na página 209 da seção 5.3.1.
} 
Figura 72 - Gráficos da Função Confiabilidade do Sistema Paralelo com Dois Componentes Redundantes nos Quatro Cenários Estudados

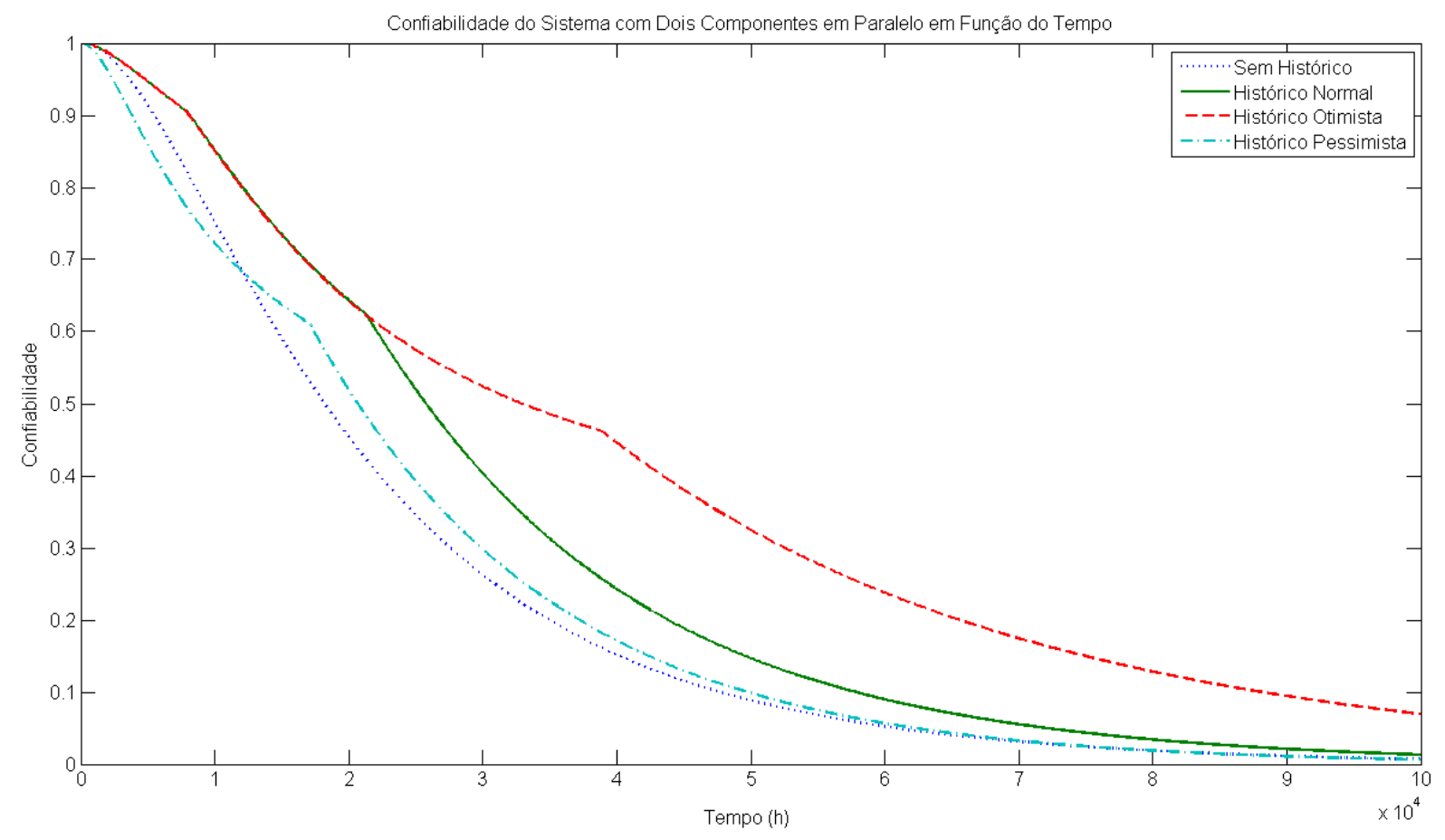

Fonte: Autor

Para que os gráficos da Figura 72 possam ser apropriadamente interpretados, é necessário considerar, conjuntamente a eles, a evolução temporal das taxas de falhas $\lambda_{1}$ e $\lambda_{2}$ ao longo de cada um dos ensaios. Os gráficos que descrevem 0 comportamento de $\lambda_{1}$ nas primeiras $10.000 \mathrm{~h}$ do intervalo $T_{\text {sim }}$ e a evolução de $\lambda_{2}$ nas primeiras $40.000 \mathrm{~h}$ do intervalo $T_{\text {sim }}$ estão presentes na Figura 73 e na Figura 74 . Para todos os instantes de tempo posteriores aos intervalos iniciais definidos anteriormente, as taxas de falhas de C1 e C2 mantiveram-se nos mesmos patamares constatados ao final dos períodos preliminares. 
Figura 73 - Gráficos da Função Taxa de Falhas do Componente C1 do Sistema Paralelo com Dois Componentes Redundantes nos Quatro Cenários de Estudo da Função Confiabilidade

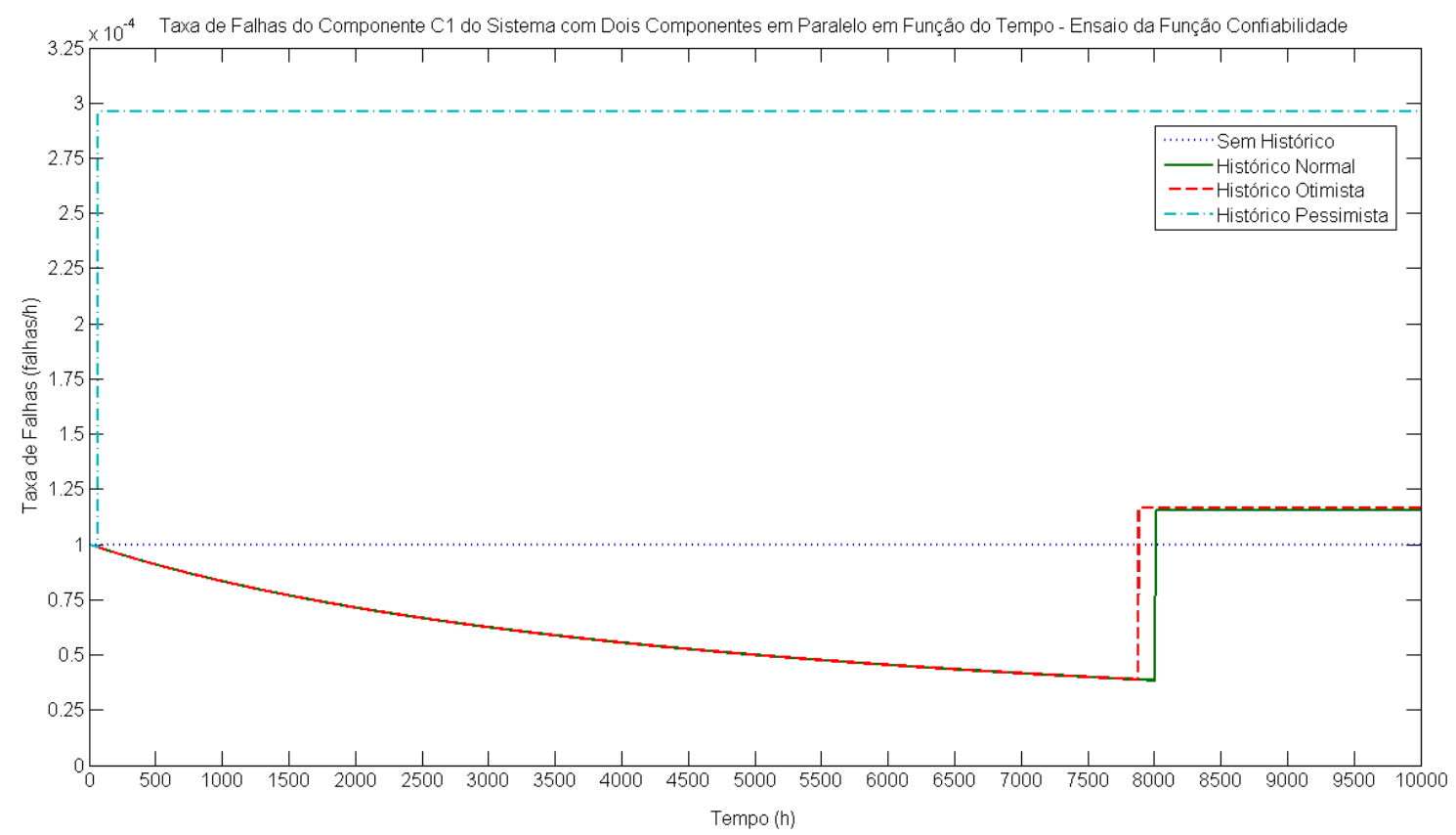

Fonte: Autor

Figura 74 - Gráficos da Função Taxa de Falhas do Componente C2 do Sistema Paralelo com Dois Componentes Redundantes nos Quatro Cenários de Estudo da Função Confiabilidade

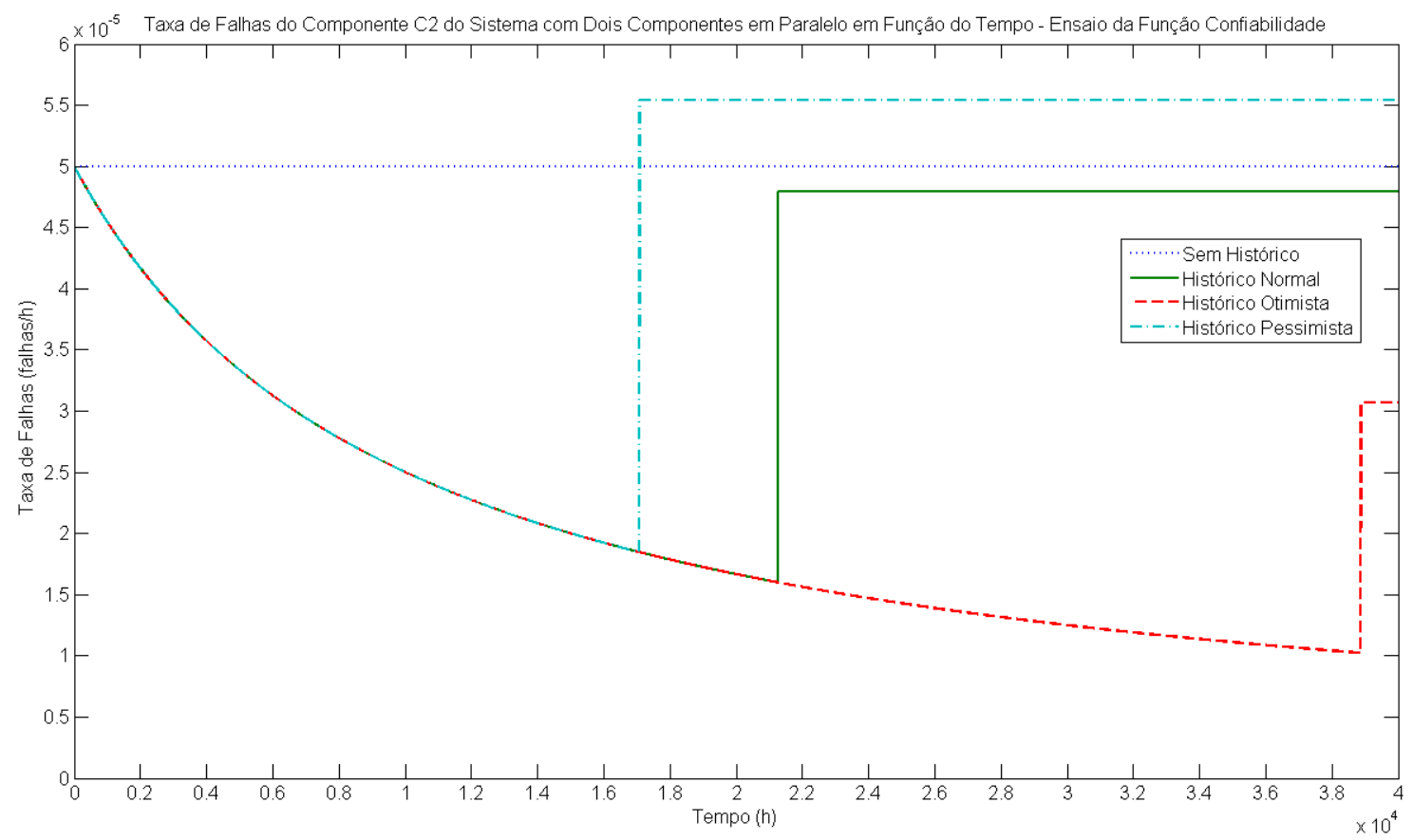

Fonte: Autor

Como já explorado nos estudos realizados nas seções 5.2.1 e 5.3.1, os instantes de tempo dos gráficos da Figura 73 e da Figura 74 nos quais as taxas de 
falhas dos componentes $\mathrm{C} 1$ e $\mathrm{C} 2$ aumentam bruscamente e atingem o valor assintótico mantido até o final dos cenários avaliados correspondem aos respectivos momentos em que existem registros de falhas de $\mathrm{C} 1$ e $\mathrm{C} 2$ no histórico operacional do sistema paralelo. A relação completa dos instantes das falhas de C1 e C2 utilizadas nos três ensaios com histórico está presente na Tabela 39.

Tabela 39 - Eventos de Falha Gerados nos Cenários de Estudo da Confiabilidade do Sistema Paralelo com Dois Componentes Redundantes e com Histórico de Operação

\begin{tabular}{|c|c|c|}
\hline Ensaio Executado & $\begin{array}{c}\text { Instante de Ocorrência do } \\
\text { Evento de Falha do } \\
\text { Componente C1 }\end{array}$ & $\begin{array}{c}\text { Instante de Ocorrência do } \\
\text { Evento de Falha do } \\
\text { Componente C2 }\end{array}$ \\
\hline $\begin{array}{c}\text { Cenário 2 - Histórico } \\
\text { Normal }\end{array}$ & $8010,714 \mathrm{~h}$ & $21270,523 \mathrm{~h}$ \\
\hline $\begin{array}{c}\text { Cenário 3 - Histórico } \\
\text { Otimista }\end{array}$ & $7881,717 \mathrm{~h}$ & $38876,993 \mathrm{~h}$ \\
\hline $\begin{array}{c}\text { Cenário 4 - Histórico } \\
\text { Pessimista }\end{array}$ & $66,083 \mathrm{~h}$ & $17092,024 \mathrm{~h}$ \\
\hline
\end{tabular}

Fonte: Autor

Com base na Figura 72, é possível verificar que a confiabilidade do sistema paralelo nos cenários em que se empregaram históricos operacionais otimista e normal foi maior do que a observada nos ensaios com histórico pessimista e sem histórico praticamente desde o início das simulações. A justificativa para os valores mais elevados da confiabilidade nos cenários otimista e normal decorre do fato de as taxas de falhas dos componentes $\mathrm{C} 1$ e $\mathrm{C} 2$ terem se mantido iguais ou inferiores às respectivas taxas de falhas dos outros dois ensaios ao longo de todo o período de tempo $T_{\text {sim }}$, tal como se pode constatar a partir da Figura 73 e da Figura 74.

Já na comparação entre os cenários com históricos otimista e normal, notase, a partir dos gráficos da Figura 72, que a confiabilidade do sistema paralelo manteve-se praticamente igual nas duas situações ao longo das primeiras 21.000 horas de avaliação do sistema. A similaridade entre os dois ensaios durante esse intervalo de tempo inicial deve-se ao fato de os eventos de falha do componente $\mathrm{C} 1$ terem ocorrido em instantes bastante próximos em ambos os cenários (aproximadamente 7.900 horas no cenário otimista e 8.000h no cenário normal, tal 
como se verifica a partir da Tabela 39), o que resultou em comportamentos temporais da taxa de falhas $\lambda_{1}$ parecidos nas duas situações.

Após tal período de tempo inicial, o cenário com histórico otimista passou a ter índices de confiabilidade superiores ao do ensaio com histórico normal devido ao fato de o evento de falha do componente C2 na situação otimista ter ocorrido cerca de 17.500 horas mais tarde do que no cenário normal - tal como se pode inferir a partir dos dados registrados na Tabela 39. Devido a esse comportamento, a taxa de falhas do componente C2 no ensaio otimista passou a ser menor do que a observada no cenário normal (tendência essa verificável a partir dos gráficos da Figura 74) e, consequentemente, a confiabilidade do sistema paralelo decaiu mais lentamente na situação otimista.

Ao se confrontar os resultados obtidos nos cenários sem histórico e com histórico pessimista, as seguintes ressalvas podem ser feitas:

a) Em decorrência da falha antecipada do componente $\mathrm{C} 1$ no cenário pessimista (manifestada aproximadamente 66 horas após o início do estudo do sistema paralelo, tal como se verifica a partir da Tabela 39), a taxa de falhas $\lambda_{1}$ aumenta e atinge, de acordo com o respectivo gráfico da Figura 73, um valor constante próximo de $3.10^{-4}$ falhas $/ h$, aproximadamente três vezes maior do que o seu índice nominal. Em decorrência desse aumento de $\lambda_{1}$, a taxa de decaimento da confiabilidade do sistema no cenário com histórico pessimista aumenta e, consequentemente, a confiabilidade do sistema atinge patamares menores do que os observados na situação em que não são utilizados dados de histórico praticamente desde o início do estudo.

Esse comportamento pode ser observado considerando-se os gráficos da Figura 72 até aproximadamente 12.000 horas de avaliação do sistema paralelo, quando o efeito do fenômeno descrito no item "b)" (a seguir) torna-se predominante e inverte a ordem de precedência da confiabilidade do sistema.

b) À medida que o tempo de estudo do sistema aumenta, é possível verificar, a partir da Figura 74, que a taxa de falhas do componente C2 no ensaio com histórico pessimista segue em tendência de queda até cerca de 17.000 horas 
de avaliação do sistema (instante em que, segundo a Tabela 39, C2 falha). Como a taxa de falhas do componente C1 está fixada em um patamar constante, é esperado que o decaimento da função confiabilidade no cenário com histórico pessimista reduza à medida que $\lambda_{2}$ diminui.

Com base nos gráficos representados na Figura 72, é possível verificar que essa tendência comportamental torna-se significativa a partir de aproximadamente 8.000 horas de estudo do sistema, instante em que a diferença entre os valores da função confiabilidade nos cenários com histórico pessimista e sem histórico diminui. Após cerca de 12.000 horas desde o início dos ensaios, os gráficos da função confiabilidade nas duas situações se cruzam e a confiabilidade no cenário sem histórico passa a ser maior do que a vigente no estudo com histórico pessimista.

c) Com a ocorrência da falha do componente C2 em aproximadamente 17.000 horas desde o início do estudo do sistema no cenário com histórico pessimista, é possível notar, por intermédio da Figura 74, que a taxa de falhas $\lambda_{2}$ também atinge um valor superior ao seu índice nominal a partir do momento em que o evento de falha de C2 ocorre. Como $\lambda_{1}$ também apresenta valor superior ao nominal nessas condições, a taxa de decaimento da função confiabilidade no cenário pessimista passa a ser maior do que a verificada no cenário sem histórico.

Após aproximadamente 80.200 horas de avaliação do sistema, a confiabilidade do sistema no cenário sem histórico passa a ser novamente superior à determinada no ensaio com histórico pessimista. $O$ fragmento da Figura 72 em que se enfatiza o cruzamento dos gráficos de ambos os cenários é representado na Figura 75. 
Figura 75 - Gráficos da Função Confiabilidade do Sistema Paralelo com Dois Componentes Redundantes nos Cenários Sem Histórico e com Histórico Pessimista entre 77.500h e 83.000h

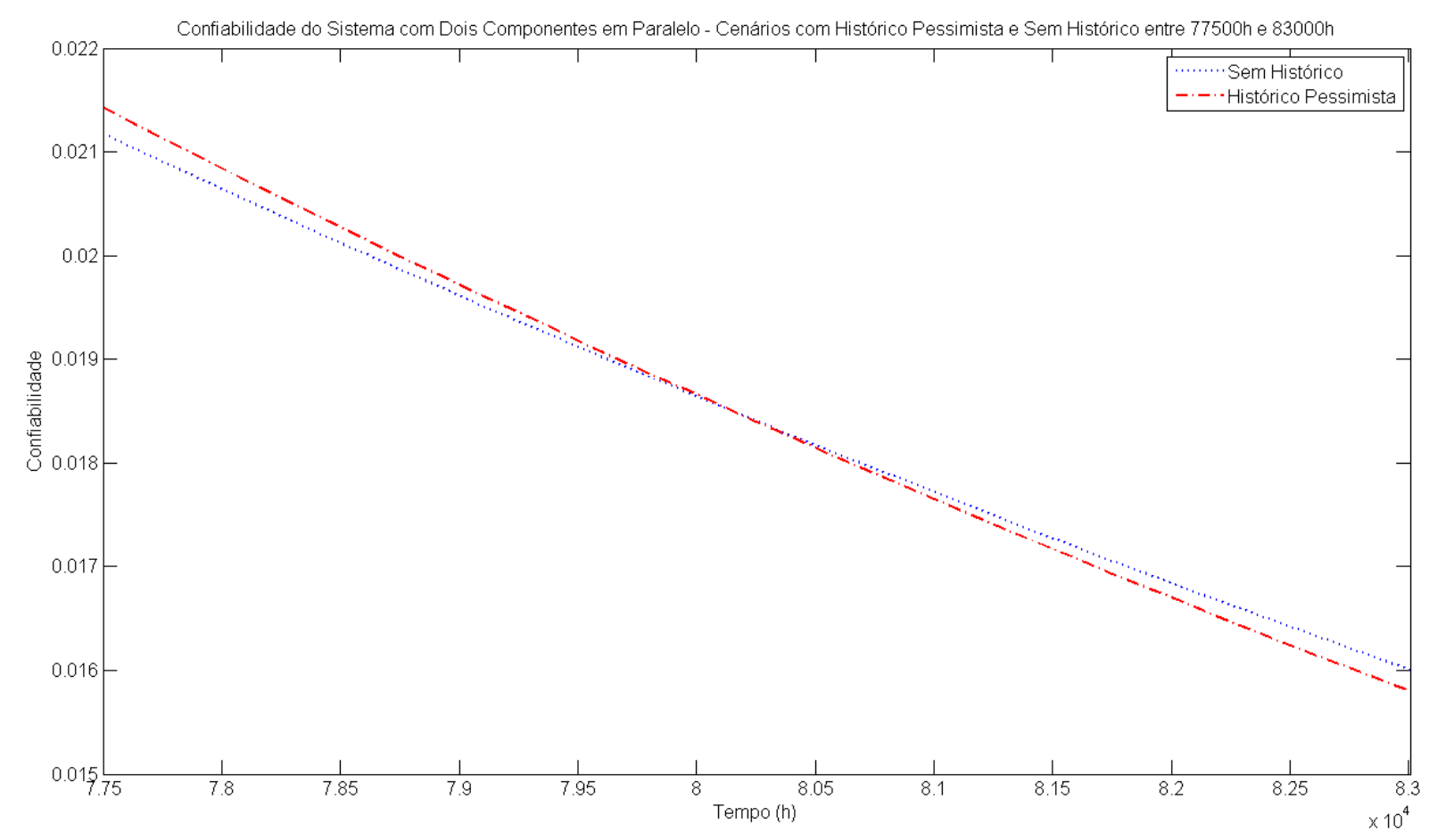

Fonte: Autor

Ao final do período de tempo $T_{\text {sim }}=10^{5}$ horas, as simulações executadas conduziram aos valores de confiabilidade relacionados na Tabela 40, que reforçam a validade do comportamento descrito previamente nos quatro ensaios realizados.

Tabela 40 - Confiabilidade do Sistema Paralelo com Dois Componentes após $T_{\text {sim }}=10^{5}$ horas

\begin{tabular}{|c|c|}
\hline Cenário Estudado & Confiabilidade do Sistema Paralelo com Dois Componentes \\
\hline Sem Histórico & $6,781 \cdot 10^{-3}$ \\
\hline Histórico Normal & $1,296 \cdot 10^{-2}$ \\
\hline Histórico Otimista & $6,932 \cdot 10^{-2}$ \\
\hline Histórico Pessimista & $6,165 \cdot 10^{-3}$ \\
\hline
\end{tabular}

Fonte: Autor

\subsubsection{Função Segurança Crítica (Safety)}

A função segurança crítica (safety) do sistema paralelo com dois componentes redundantes pode ser determinada utilizando-se o mesmo modelo de 
Markov da Figura $61^{22}$, já empregado na seção 5.3.2 para se extrair a segurança crítica (safety) do sistema série com dois componentes. No entanto, como um evento de falha insegura do sistema irá se manifestar apenas se ambos os componentes $\mathrm{C} 1$ e C2 falharem inseguramente, a segurança crítica (safety) do sistema paralelo equivale à soma das probabilidades de permanência em todos os estados da Figura 61 exceto "C1 Falha Insegura e C2 Falha Insegura (C1 FI, C2FI)".

Utilizando-se como parâmetros de simulação $\lambda_{1}=10^{-4}$ falhas $/ h, \quad \lambda_{2}=$ $5.10^{-5}$ falhas $/ h, C_{1}=C_{2}=0,9999, T_{\text {sim }}=10^{6}$ horas e $\Delta t_{\text {sim }}=2$ horas, a função segurança crítica (safety) do sistema paralelo com dois componentes redundantes nos quatro cenários de estudo relacionados na seção 5.4 (abordagens sem histórico, com histórico normal, com histórico otimista e com histórico pessimista) pode ser representada pelos gráficos ilustrados na Figura 76. Com o propósito de melhorar a legibilidade dos resultados obtidos, os gráficos da Figura 76 foram plotados restringindo-se o domínio do eixo do tempo às primeiras 250.000 horas de estudo do sistema, uma vez que se constatou que, após esse intervalo de tempo inicial, os resultados obtidos alteram-se de forma pouco significativa.

${ }^{22}$ A Figura 61 está presente na página 216 da seção 5.3.2. 
Figura 76 - Gráficos da Função Segurança Crítica (Safety) do Sistema Paralelo com Dois Componentes Redundantes nos Quatro Cenários Estudados

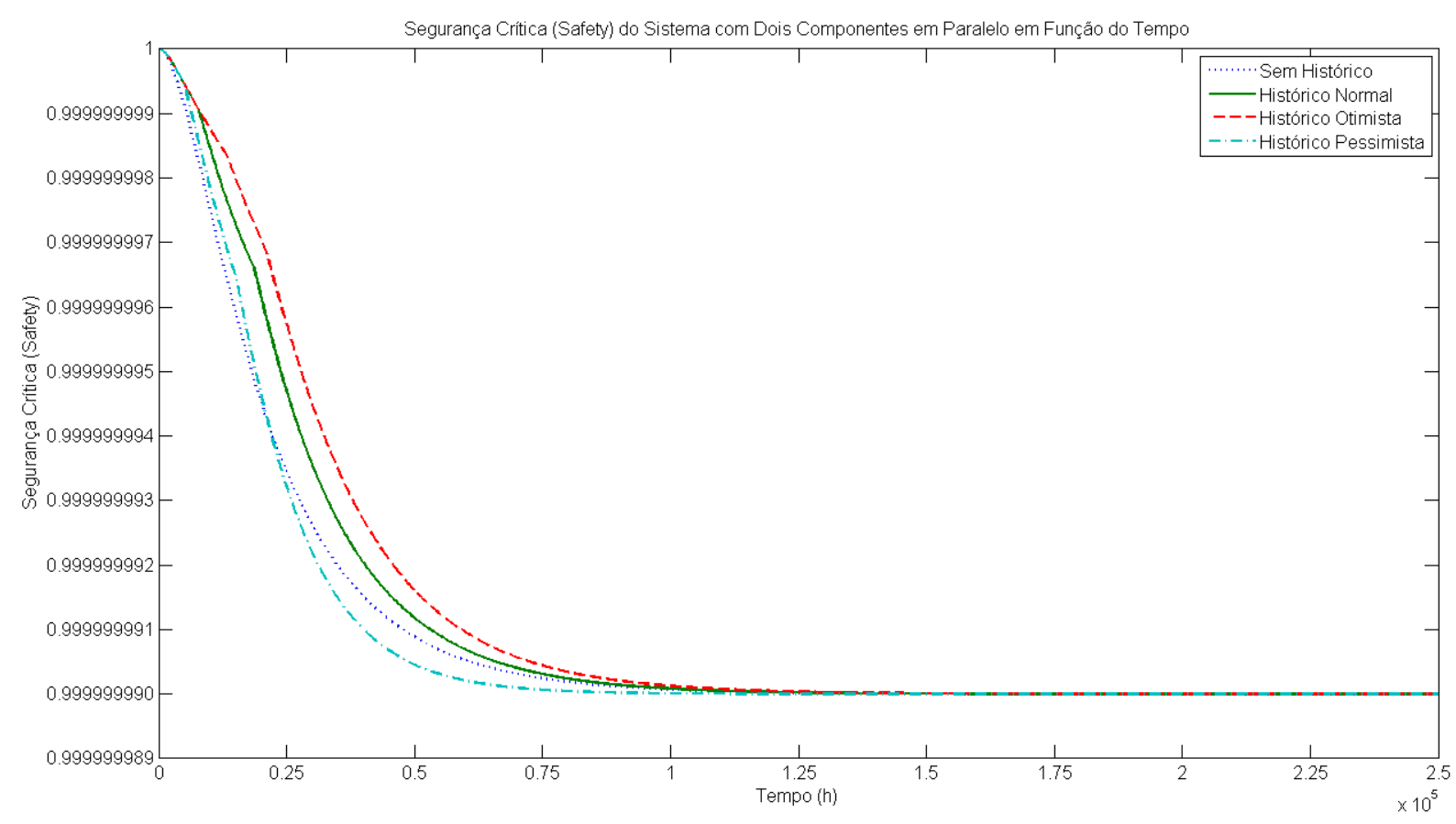

Fonte: Autor

Com base nos gráficos da Figura 76, é possível observar que a segurança crítica (safety) do sistema paralelo com dois componentes tende, nos quatro cenários estudados, a um valor assintótico próximo de $0,9_{8}{ }^{23}$, que pode ser deduzido a partir do seguinte raciocínio:

a) Considerando-se que $C_{1}$ e $C_{2}$ representam o percentual de falhas seguras dos componentes $\mathrm{C}_{1}$ e $\mathrm{C} 2$, é possível inferir que os valores complementares $\left(1-C_{1}\right)$ e $\left(1-C_{2}\right)$ simbolizam as razões entre as falhas inseguras e 0 universo de falhas que afetam, respectivamente, os componentes $\mathrm{C} 1$ e C2;

b) Desconsiderando-se procedimentos de manutenção do sistema, é esperado que, após um período de tempo suficientemente longo, ambos os componentes $\mathrm{C} 1$ e $\mathrm{C} 2$ estejam falhos;

c) A partir das definições apresentadas no item "a)", é possível inferir que, nas condições do item "b)", a presença simultânea de falhas inseguras nos componentes $\mathrm{C} 1$ e $\mathrm{C} 2$ seja expressa pelo produto $\left(1-C_{1}\right) \cdot\left(1-C_{2}\right)$. Dessa

${ }^{23}$ A notação 0,98 representa o número decimal 0,99999999 (com oito noves depois da vírgula) e será utilizada no texto para evitar a repetição exaustiva do número 0,99999999 por extenso. 
forma, a não existência de falhas inseguras concomitantes nos componentes C1 e C2 - que representa o valor assintótico da segurança crítica (safety) do sistema paralelo com dois componentes - pode ser representada pela expressão (70).

$$
\lim _{t \rightarrow \infty} S(t)=1-\left[\left(1-C_{1}\right) \cdot\left(1-C_{2}\right)\right]=C_{1}+C_{2}-C_{1} \cdot C_{2}
$$

Substituindo-se, em (70), os valores $C_{1}=C_{2}=0,9999$ utilizados nos quatro ensaios, obtém-se que a segurança crítica (safety) do sistema paralelo tende ao valor assintótico $0,9_{8}$.

Tal como já explorado nos estudos dos sistemas simples e série, respectivamente aprofundados nas seções 5.2.2 e 5.3.2, a variação relativa máxima do valor assumido, ao final do tempo de simulação $T_{\text {sim }}=10^{6}$ horas, pela função segurança crítica (safety) entre os quatro cenários avaliados foi pouco significativa frente ao valor absoluto da função segurança crítica (safety) no mesmo intervalo de

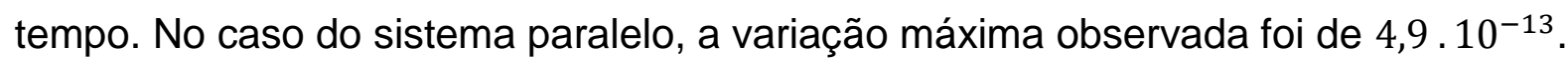

Também por analogia aos ensaios sobre os sistemas simples e série, as diferenças das taxas de decaimento da função segurança crítica (safety) nos três cenários em que dados de histórico foram utilizados dependem diretamente dos instantes de tempo em que as falhas dos componentes C1 e C2 manifestaram-se. A relação completa dos eventos de falha gerados pelo módulo "Simulador de Dados de Entrada" nas três situações consideradas consta na Tabela 41. 
Tabela 41 - Eventos de Falha Gerados nos Cenários de Estudo da Segurança Crítica (Safety) do Sistema Paralelo com Dois Componentes Redundantes e com Histórico de Operação

\begin{tabular}{|c|c|c|}
\hline Ensaio Executado & $\begin{array}{c}\text { Instante de Ocorrência do } \\
\text { Evento de Falha do } \\
\text { Componente C1 }\end{array}$ & $\begin{array}{c}\text { Instante de Ocorrência do } \\
\text { Evento de Falha do } \\
\text { Componente C2 }\end{array}$ \\
\hline $\begin{array}{c}\text { Cenário 2 - Histórico } \\
\text { Normal }\end{array}$ & $7667,870 \mathrm{~h}$ & $18609,481 \mathrm{~h}$ \\
\hline $\begin{array}{c}\text { Cenário 3 - Histórico } \\
\text { Otimista }\end{array}$ & $13355,423 \mathrm{~h}$ & $20839,831 \mathrm{~h}$ \\
\hline $\begin{array}{c}\text { Cenário 4 - Histórico } \\
\text { Pessimista }\end{array}$ & $15098,273 \mathrm{~h}$ & $4942,715 \mathrm{~h}$ \\
\hline
\end{tabular}

Fonte: Autor

De forma análoga aos estudos detalhados nas seções 5.2 .2 e 5.3.2, as taxas de falhas dos componentes $\mathrm{C} 1$ e $\mathrm{C} 2$ aumentam rapidamente nos instantes de tempo dos eventos de falha registrados na Tabela 41 e atingem seus valores assintóticos, que serão mantidos ao longo de todo o período de tempo $T_{\text {sim }}=10^{6}$ horas. Os gráficos da Figura 77 e da Figura 78 descrevem, respectivamente, o comportamento da taxa de falhas do componente $\mathrm{C} 1$ nas primeiras $20.000 \mathrm{~h}$ do intervalo $T_{\text {sim }}$ e a evolução da taxa de falhas do componente $\mathrm{C} 2$ nas primeiras $22.000 \mathrm{~h}$ do intervalo $T_{\text {sim }}$. 
Figura 77 - Gráficos da Função Taxa de Falhas do Componente C1 do Sistema Paralelo com Dois Componentes Redundantes nos Quatro Cenários de Estudo da Função Segurança Crítica (Safety)

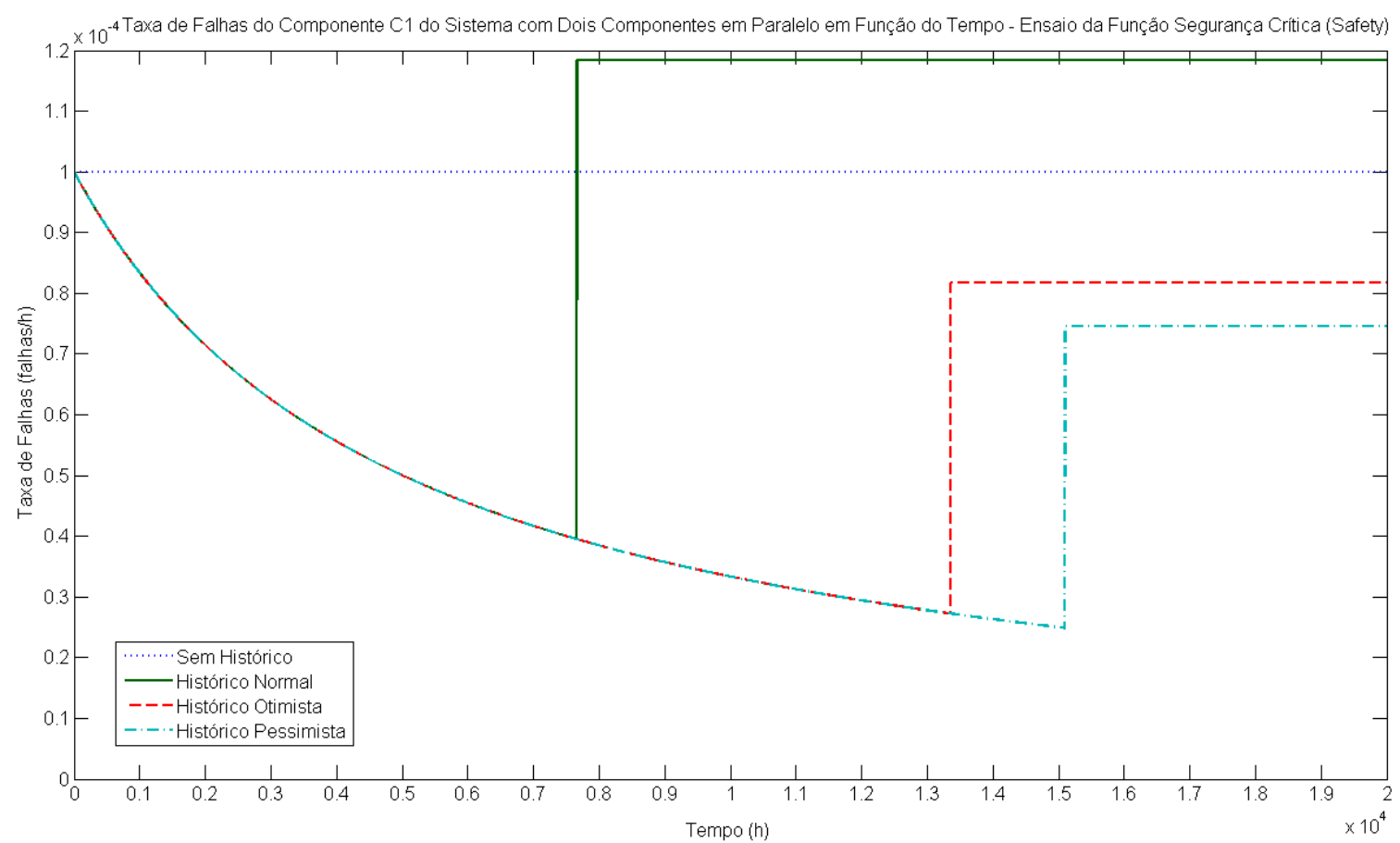

Fonte: Autor

Figura 78 - Gráficos da Função Taxa de Falhas do Componente C2 do Sistema Paralelo com Dois Componentes Redundantes nos Quatro Cenários de Estudo da Função Segurança Crítica (Safety)

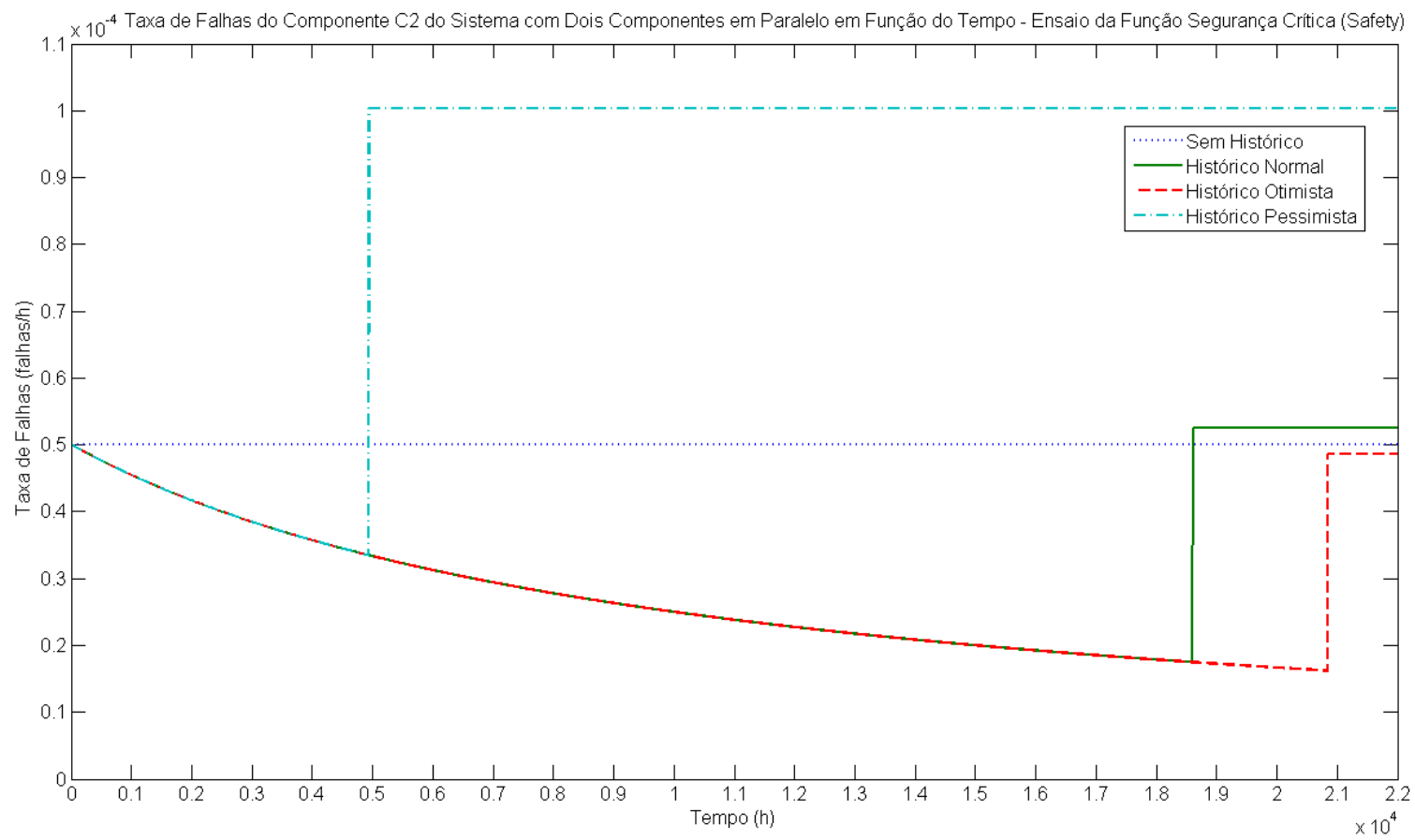

Fonte: Autor 
A partir da Tabela 41, é possível notar que o instante de ocorrência da falha do componente $\mathrm{C} 2$ no cenário em que se utiliza um histórico operacional pessimista é inferior não só aos momentos verificados nos dois outros ensaios com histórico, mas também ao próprio MTTF nominal de C2. Com base nas leis matemáticas que regem o funcionamento do bloco "Cálculo das Taxas de Falhas e de Reparos Condicionadas ao Histórico de Operação" do modelo proposto ${ }^{24}$, a falha antecipada do componente $\mathrm{C} 2$ no cenário com histórico pessimista leva a taxa de falhas $\lambda_{2}$ a atingir rapidamente um valor assintótico de aproximadamente $10^{-4}$ falhas $/ h$, cerca de duas vezes superior ao verificado nos três outros cenários. Esse comportamento é evidenciado na Figura 78.

Como, nos cenários sem histórico e com históricos normal e otimista, a taxa de falhas $\lambda_{2}$ mantém-se em patamares menores ao valor assintótico do ensaio com histórico pessimista, o decaimento da segurança crítica (safety) nesse caso passa a ocorrer mais rapidamente do que nos demais. Essa tendência pode ser observada a partir dos gráficos representados na Figura 79, em que foi destacado o fragmento da Figura 76 que descreve a evolução temporal da segurança crítica (safety) do sistema paralelo com dois componentes nas primeiras 25.000 horas de estudo.

24 Para maiores informações sobre o bloco "Cálculo das Taxas de Falhas e de Reparos Condicionadas ao Histórico de Operação", consultar a seção 3.3. 
Figura 79 - Gráficos da Função Segurança Crítica (Safety) do Sistema Paralelo com Dois Componentes Redundantes nas Primeiras 25.000 Horas de Estudo

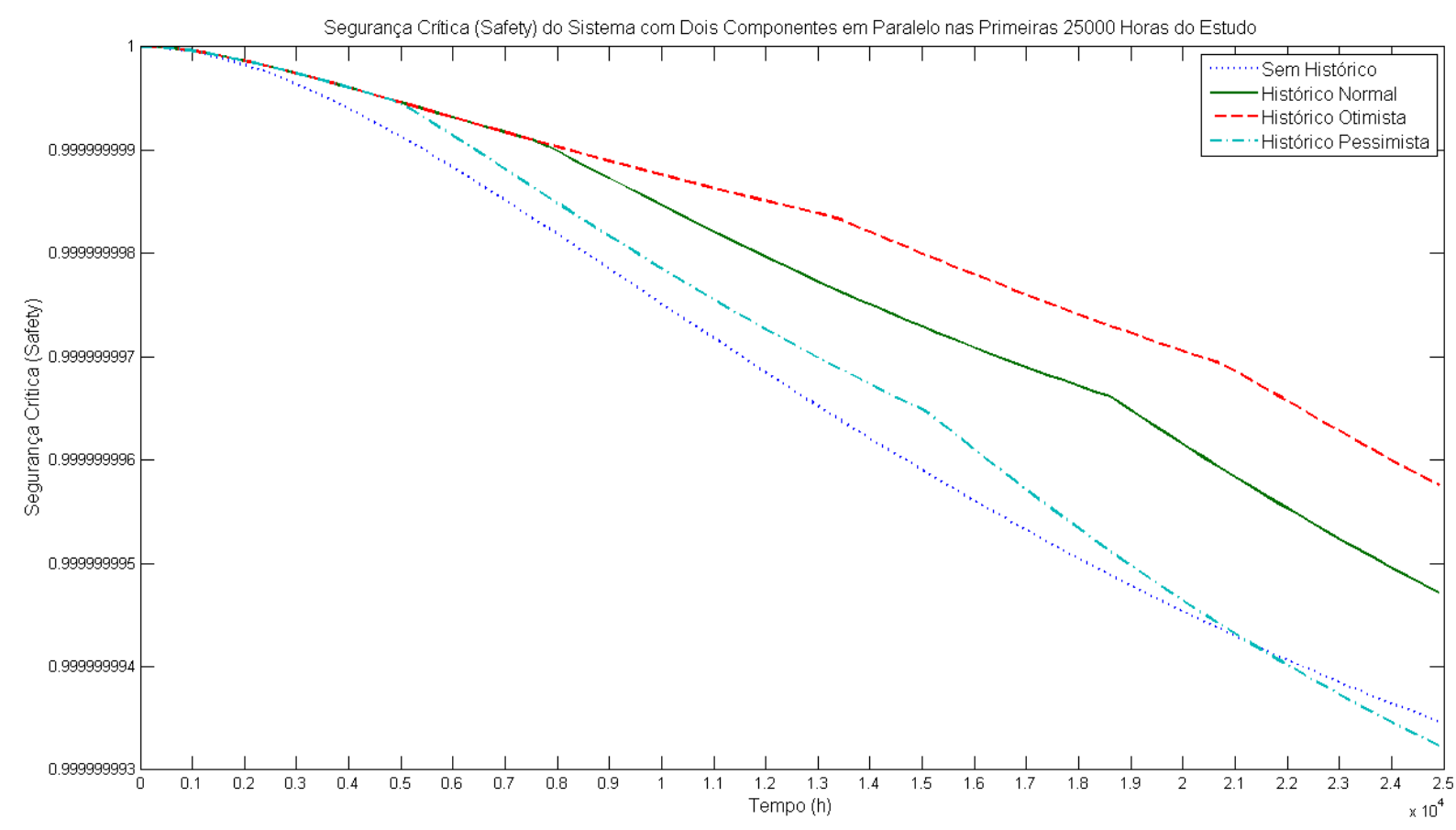

Fonte: Autor

A partir dos gráficos representados na Figura 79, um aspecto que vale ser ressaltado é o de que, mesmo com a assunção de um valor próximo do dobro do nominal pela taxa de falhas $\lambda_{2}$ no cenário com histórico pessimista, é possível notar que a segurança crítica ( safety) do sistema nessas condições tornou-se inferior à do sistema simples apenas após cerca de 21.500 horas de estudo do sistema. Tal comportamento está relacionado ao fato de a taxa de falhas do componente C1 no cenário pessimista ter mantido uma tendência contínua de queda até aproximadamente 15.000 horas de operação do sistema, instante a partir do qual a taxa de falhas $\lambda_{1}$ passou a assumir, de acordo com a Figura 77, valor aproximado de 8. $10^{-5}$ falhas $/ h$, ou seja, $20 \%$ inferior ao valor nominal de $\lambda_{1}$.

A partir do momento em que o valor assintótico de $\lambda_{1}$ no ensaio com histórico pessimista foi atingido, a taxa de decaimento da função segurança crítica (safety) nesse cenário passou a ser maior do que a observada na situação sem histórico. Devido a essa tendência, os gráficos da função segurança crítica (safety) em ambos os cenários cruzaram-se em aproximadamente 21.500 horas de estudo, instante a partir do qual a segurança crítica (safety) na situação sem histórico passa a ser estritamente maior do que a observada no estudo com histórico pessimista. 
Outro aspecto a ser salientado a partir dos gráficos da Figura 79 é o de que o elevado valor assumido pela taxa de falhas $\lambda_{2}$ ainda nas primeiras 5.000 horas de estudo do sistema foi responsável por manter a segurança crítica (safety) no ensaio pessimista inferior à observada nos cenários com históricos normal e otimista. Em ambas essas situações, é possível constatar, a partir da Tabela 41, que os eventos de falha do componente C1 ocorreram em instantes de tempo inferiores ao do ensaio pessimista; no entanto, tais falhas de $\mathrm{C} 1$ não foram suficientes para promover alterações significativas no decaimento da função segurança crítica (safety) nos cenários com históricos normal e otimista a ponto de alterar a ordem de precedência dos valores obtidos nos três ensaios.

Na comparação direta entre as situações com históricos normal e otimista, é possível notar, a partir da Figura 77 e da Figura 78, que as taxas de falhas dos componentes $\mathrm{C} 1$ e $\mathrm{C} 2$ no ensaio otimista mantiveram-se em níveis menores ou iguais aos observados no cenário com histórico normal ao longo de todo o período $T_{\text {sim }}=10^{6}$ horas. Esse argumento justifica o decaimento mais lento da segurança crítica (safety) do sistema paralelo no cenário otimista, evidente na Figura 76 e na Figura 79.

\subsubsection{Função Disponibilidade}

A função disponibilidade do sistema paralelo com dois componentes redundantes pode ser estimada mediante uso do mesmo modelo de Markov da Figura $65^{25}$, já empregado na seção 5.3 .3 para se determinar a disponibilidade do sistema série com dois componentes. No entanto, como o sistema paralelo ficará indisponível apenas se ambos os componentes C1 e C2 estiverem simultaneamente falhos, sua disponibilidade é expressa pela soma das probabilidades de permanência nos estados "C1 e C2 Operacionais (OK)", "C1 Falho e C2 Operacional (C1F, C2OK)" e "C1 Operacional e C2 Falho (C1OK, C2F)" da Figura 65.

\footnotetext{
Utilizando-se como parâmetros de simulação $\lambda_{1}=10^{-4}$ falhas $/ h$, $\lambda_{2}=5.10^{-5}$ falhas $/ h, \quad \mu_{1}=1$ reparo $/ h, \quad \mu_{2}=0,5$ reparo $/ h, \quad T_{\text {sim }}=10^{5}$ horas $\mathrm{e}$ $\Delta t_{\text {sim }}=0,5$ hora, a função disponibilidade do sistema paralelo com dois

${ }^{25}$ A Figura 65 está presente na página 222 da seção 5.3.3.
} 
componentes redundantes nos quatro cenários de estudo relacionados na seção 5.4 (abordagens sem histórico, com histórico normal, com histórico otimista e com histórico pessimista) pode ser representada pelos gráficos expostos na Figura 80. Figura 80 - Gráficos da Função Disponibilidade do Sistema Paralelo com Dois Componentes
Redundantes nos Quatro Cenários Estudados

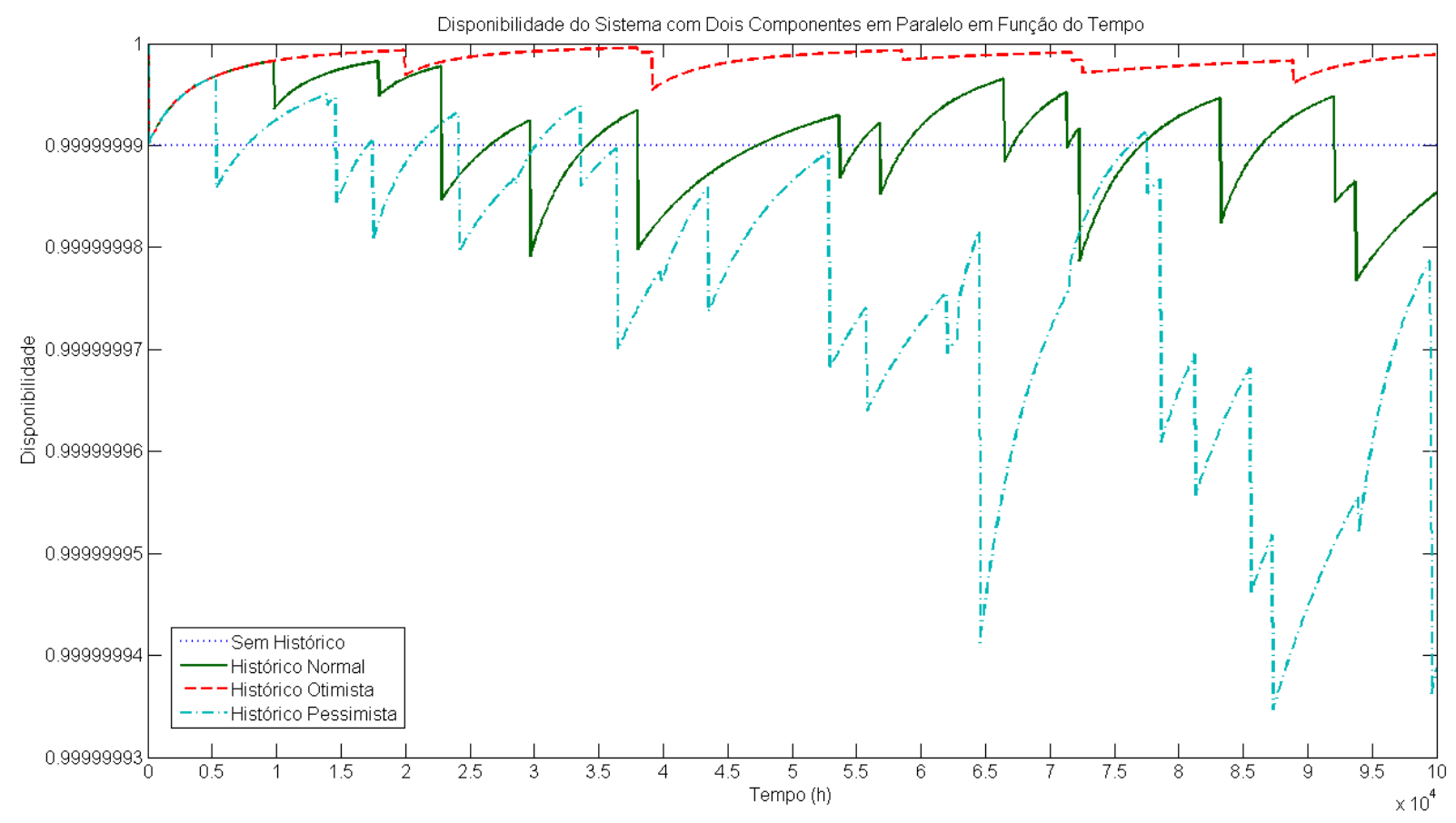

Fonte: Autor

Da mesma forma que nos estudos da função disponibilidade dos sistemas simples e série, respectivamente detalhados nas seções 5.2 .3 e 5.3.3, a convergência da disponibilidade no ensaio sem histórico ao seu valor assintótico ocorreu rapidamente, ainda nas primeiras iterações dos cálculos executados. $O$ valor absoluto da disponibilidade assintótica obtido nessa situação é igual a $0,9_{8}$.

Nos três cenários em que dados de histórico são incorporados ao estudo, as oscilações da disponibilidade do sistema paralelo com dois componentes redundantes decorrem das variações das taxas de falhas e de reparos dos componentes C1 e C2 ao longo do intervalo de tempo $T_{\text {sim }}=10^{5}$ horas. Os gráficos das taxas de falhas e de reparos dos componentes C1 e C2 são representados da Figura 81 até a Figura 84 . 
Figura 81 - Gráficos da Função Taxa de Falhas do Componente C1 do Sistema Paralelo com Dois Componentes Redundantes nos Quatro Cenários de Estudo da Função Disponibilidade

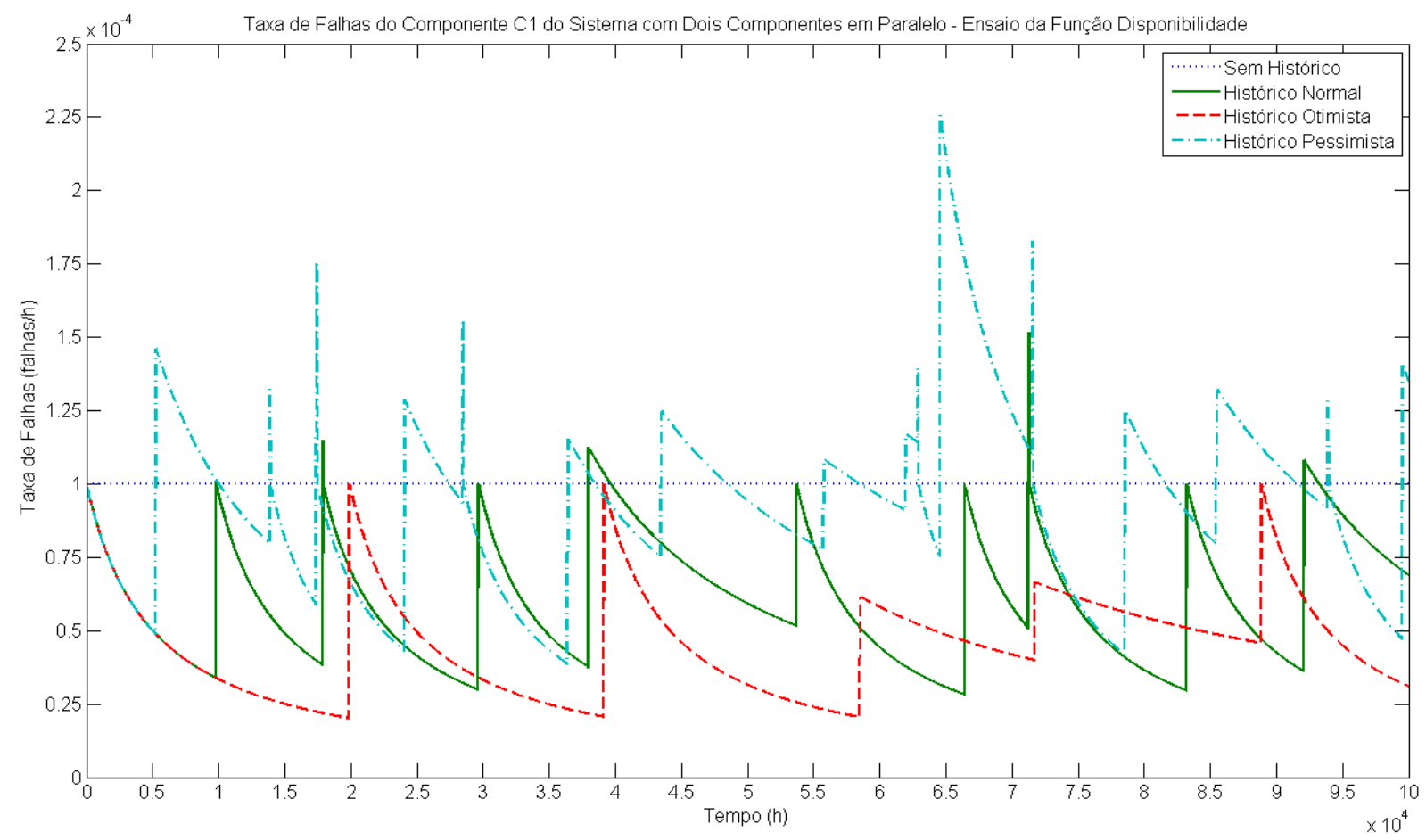

Fonte: Autor

Figura 82 - Gráficos da Função Taxa de Falhas do Componente C2 do Sistema Paralelo com Dois Componentes Redundantes nos Quatro Cenários de Estudo da Função Disponibilidade

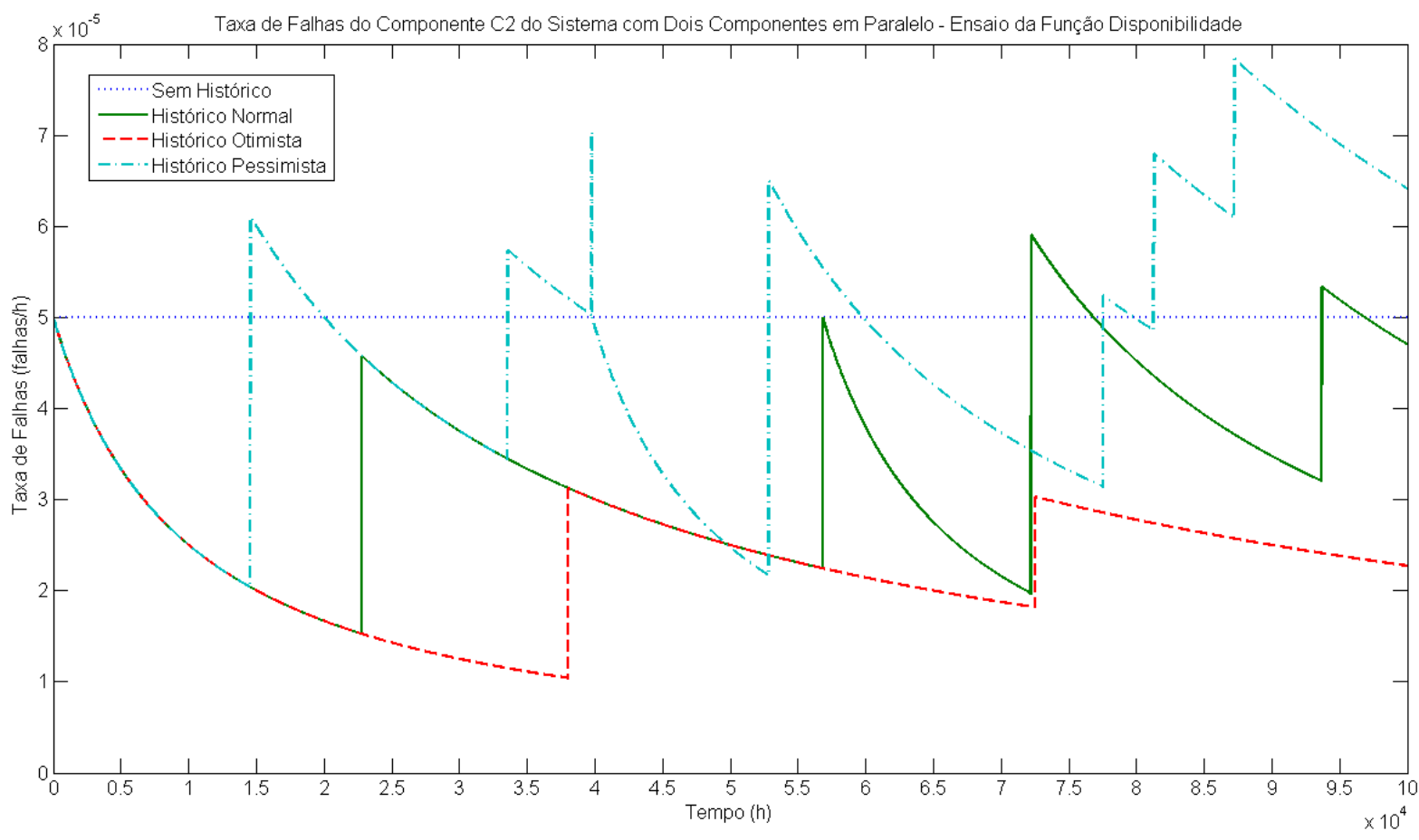

Fonte: Autor 
Figura 83 - Gráficos da Função Taxa de Reparos do Componente C1 do Sistema Paralelo com Dois Componentes Redundantes nos Quatro Cenários de Estudo da Função Disponibilidade

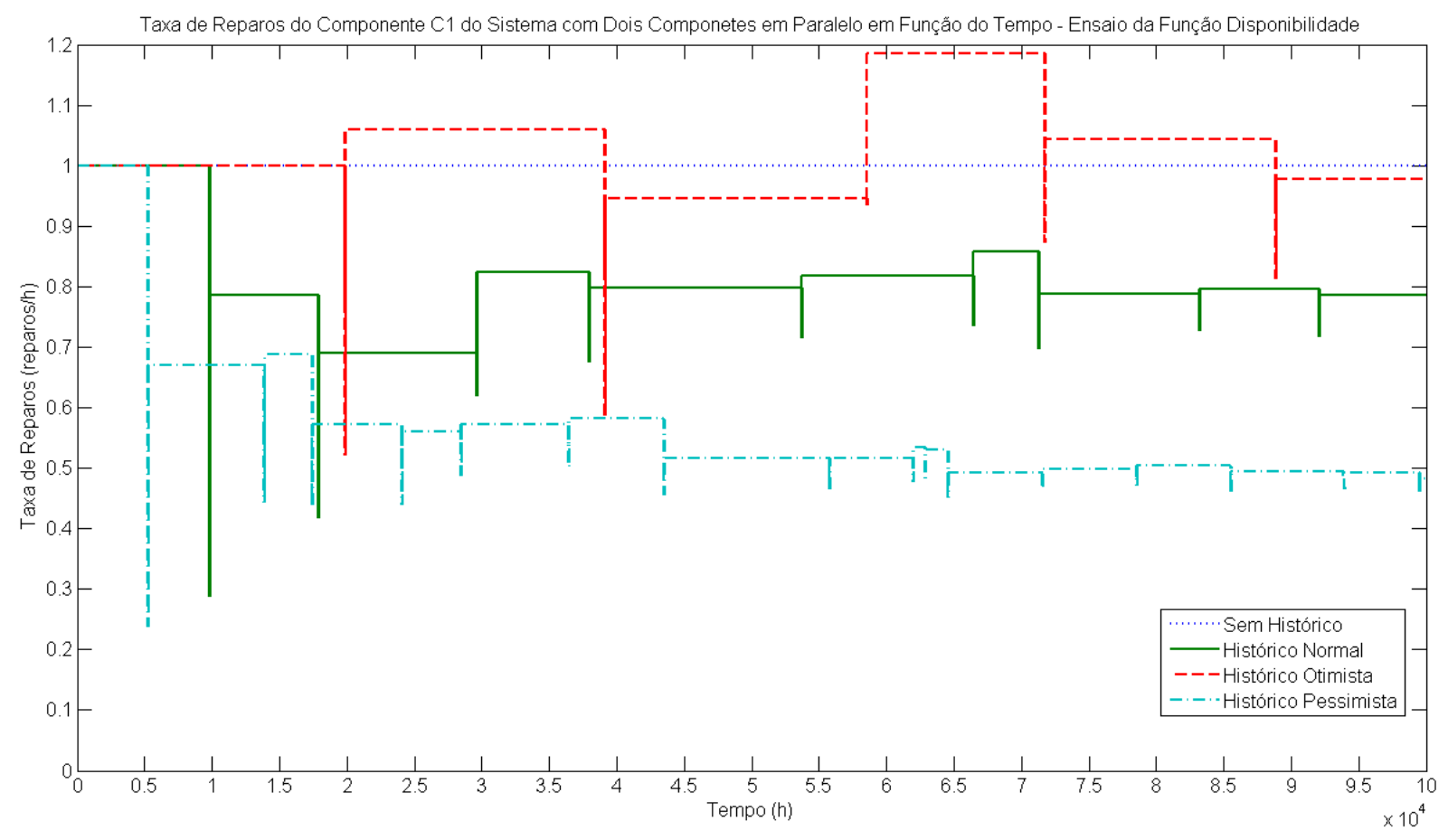

Fonte: Autor

Figura 84 - Gráficos da Função Taxa de Reparos do Componente C2 do Sistema Paralelo com Dois Componentes Redundantes nos Quatro Cenários de Estudo da Função Disponibilidade

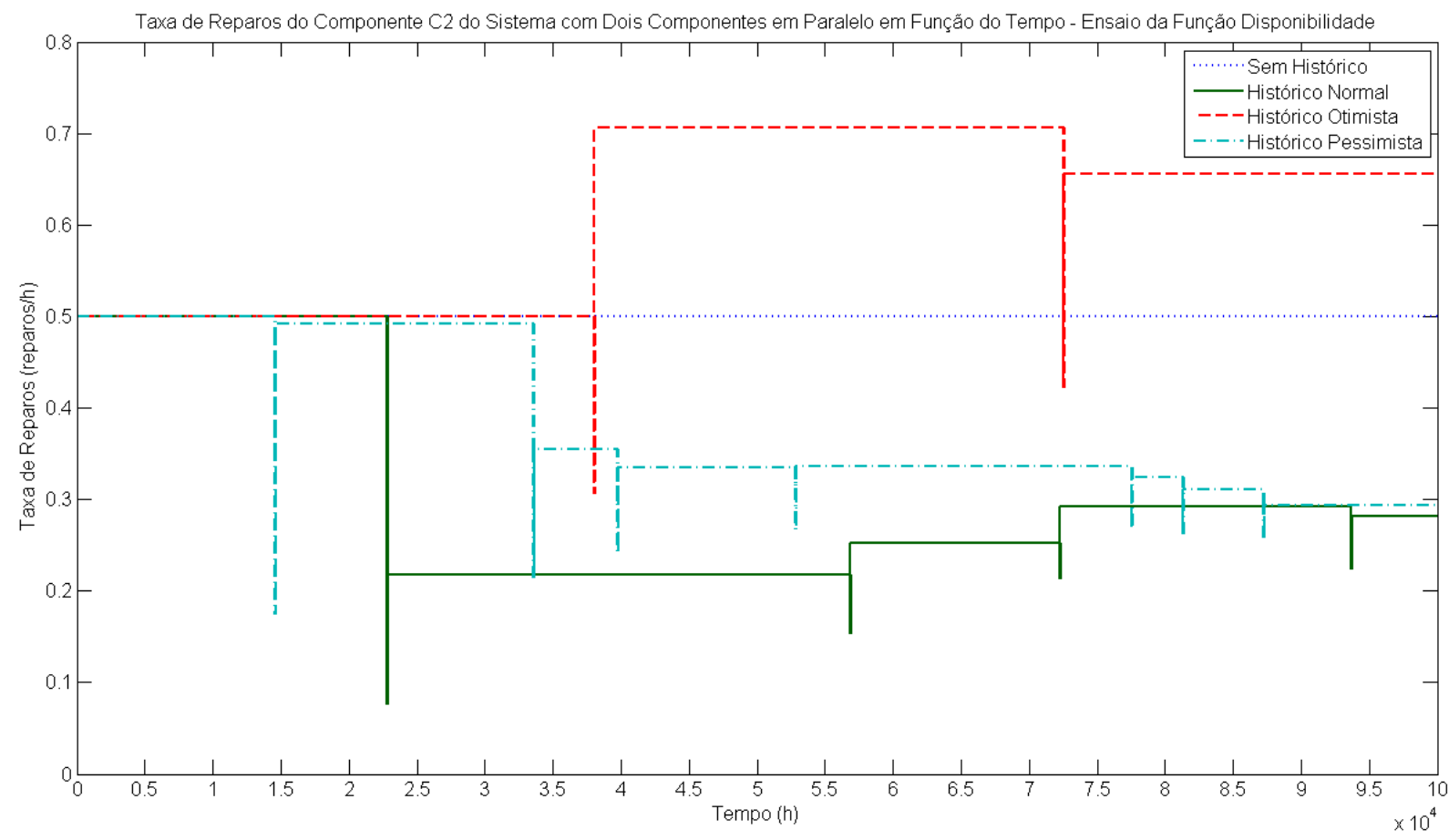

Fonte: Autor 
Analogamente às situações já abordadas nos estudos da função disponibilidade dos sistemas simples e série, presentes nas seções 5.2 .3 e 5.3.3, as variações temporais das taxas de falhas e de reparos dos componentes C1 e C2 resultam do tratamento dado pelo modelo proposto aos eventos do histórico operacional do sistema paralelo. A relação completa dos dados utilizados nos três ensaios em que registros de histórico foram incorporados ao cálculo da disponibilidade do sistema paralelo situa-se no Apêndice A.3 desta dissertação.

Justificativas similares às expostas no estudo da função disponibilidade do sistema série podem ser utilizadas para descrever o comportamento dos gráficos da Figura 80:

a) Com base na Figura 80, é possível verificar que a disponibilidade do sistema paralelo no cenário em que se utilizou um histórico pessimista manteve-se, em média, em patamares menores do que os dos demais ensaios. Tal como já explorado com mais detalhes no estudo do sistema série (seção 5.3.3), as principais justificativas relacionadas a esse resultado são as seguintes:

i. A partir da Figura 81 e da Figura 82, é possível verificar que os pontos de máximo das taxas de falhas dos componentes $\mathrm{C} 1$ e $\mathrm{C} 2$ no cenário pessimista atingiram patamares mais altos do que os dos demais cenários. Por conseguinte, $\lambda_{1}$ e $\lambda_{2}$ permaneceram, em média, em níveis superiores aos dos cenários sem histórico e com históricos normal e otimista, o que corroborou para que a disponibilidade do sistema paralelo no ensaio com histórico pessimista fosse inferior à observada nas demais situações;

ii. Considerando-se a Figura 83 e a Figura 84, é possível notar que as taxas de reparos dos componentes $\mathrm{C} 1$ e $\mathrm{C} 2$ no cenário com histórico pessimista foram mantidas em patamares inferiores aos de todos os demais ensaios. Esse fator também contribui para que a disponibilidade no cenário pessimista seja menor do que a observada nas demais situações.

b) Por motivos similares aos apresentados no item “a)", também é possível justificar o fato de a disponibilidade do sistema paralelo no cenário otimista ter sido predominantemente maior do que a dos outros ensaios realizados ao 
longo do período $T_{\text {sim }}=10^{5}$ horas, tal como se pode notar na Figura 80 . Considerando-se os gráficos da Figura 81 à Figura 84, esse resultado decorre tanto do fato de as taxas de falhas de ambos os componentes do sistema terem se mantido, no cenário otimista, em níveis médios menores do que os das demais situações, quanto do fato de as respectivas taxas de reparos terem permanecido, em média, em patamares superiores aos dos três outros cenários.

c) Ao se confrontar diretamente os ensaios com histórico normal e sem histórico, a Figura 80 permite verificar que a disponibilidade do sistema paralelo no cenário com histórico normal manteve-se predominantemente superior à do ensaio sem histórico até aproximadamente 23.000 horas desde o início do estudo. Como se pode inferir a partir da Figura 81 e da Figura 82, esse comportamento é consequência de as taxas de falhas dos componentes $\mathrm{C} 1 \mathrm{e}$ $\mathrm{C} 2$ terem assumido, em praticamente todo o período inicial, valores menores do que os seus índices nominais, utilizados no estudo sem histórico.

Após as primeiras 23.000 horas, a disponibilidade do sistema paralelo no cenário com histórico normal oscilou em torno do valor assintótico obtido no ensaio sem histórico, assumindo tanto valores superiores quanto inferiores a ele. O comportamento ao longo desse intervalo intermediário decorre do fato de não terem sido observadas variações das taxas de falhas e de reparos dos componentes $\mathrm{C} 1$ e $\mathrm{C} 2$ que as levem a assumir valores muito distintos de seus valores nominais, e, em decorrência dessas variações mais sensíveis.

Após aproximadamente 93.000 horas de estudo do sistema, é possível notar, a partir da Figura 80, que a disponibilidade no cenário com histórico normal atinge seu valor mínimo ao longo de todo o período de tempo $T_{\text {sim }}=10^{5}$ horas. Esse resultado é consequência do aumento das taxas de falhas dos componentes $\mathrm{C} 1$ e $\mathrm{C} 2$ devido a duas falhas manifestadas no sistema em um intervalo de tempo de apenas 1.700 horas: uma falha no 
componente $\mathrm{C} 1 \mathrm{em}$ aproximadamente 92.000 horas e uma falha no componente $\mathrm{C} 2$ em aproximadamente 93.700 horas $^{26}$.

Ao final do período de tempo $T_{\text {sim }}=10^{5}$ horas, as simulações executadas conduziram aos valores de disponibilidade relacionados na Tabela 42.

Tabela 42 - Disponibilidade do Sistema Paralelo com Dois Componentes Redundantes após $T_{\text {sim }}=10^{5}$ horas

\begin{tabular}{|c|c|}
\hline Cenário Estudado & Disponibilidade do Sistema Paralelo com Dois Componentes \\
\hline Sem Histórico & 0,999999990002 \\
\hline Histórico Normal & 0,999999985351 \\
\hline Histórico Otimista & 0,999999998901 \\
\hline Histórico Pessimista & 0,999999938734 \\
\hline
\end{tabular}

Fonte: Autor

Além do estudo da função disponibilidade ao longo do período de tempo $T_{\text {sim }}=10^{5}$ horas, também foram produzidas, ao final dos três ensaios baseados no uso de dados de histórico, as estimativas dos instantes de tempo das cinco próximas falhas que deveriam ocorrer com os componentes $\mathrm{C} 1$ e $\mathrm{C} 2$ do sistema paralelo. Os resultados obtidos estão registrados na Tabela 43 e na Tabela 44.

Um aspecto a ser ressaltado é o de que, devido à existência de apenas dois eventos de falha do componente $\mathrm{C} 2$ no histórico operacional do cenário otimista (vide Tabela 59 do Apêndice A.3), o algoritmo de predição de falhas inerente ao bloco "Detector de Comportamento e Filtro de Kalman" do modelo proposto não pôde produzir estimativas das falhas futuras de C2. Essa característica do modelo é explorada com mais profundidade na seção 3.5 .

${ }^{26}$ Os instantes de tempo das duas falhas abordadas foram extraídos da Tabela 58 do Apêndice A.3, na qual é possível verificar que houve uma falha do componente $\mathrm{C} 1 \mathrm{em} 92.088,3 \mathrm{~h}$ e uma falha do componente C2 em $93.715,4 \mathrm{~h}$. 
Tabela 43 - Relação das Cinco Próximas Falhas do Componente C1 do Sistema Paralelo após $T_{\text {sim }}=10^{5}$ horas

\begin{tabular}{|c|c|c|c|c|c|c|}
\cline { 2 - 7 } \multicolumn{1}{c|}{} & \multicolumn{2}{c|}{ Histórico Normal } & \multicolumn{2}{c|}{ Histórico Otimista } & \multicolumn{2}{c|}{ Histórico Pessimista } \\
\cline { 2 - 7 } & $\begin{array}{c}\text { Tempo de } \\
\text { Ocorrência (h) }\end{array}$ & $\begin{array}{c}\text { Desvio } \\
\text { Padrão } \\
\text { (h) }\end{array}$ & $\begin{array}{c}\text { Tempo de } \\
\text { Ocorrência (h) }\end{array}$ & $\begin{array}{c}\text { Desvio } \\
\text { Padrão } \\
\text { (h) }\end{array}$ & $\begin{array}{c}\text { Tempo de } \\
\text { Ocorrência (h) }\end{array}$ & $\begin{array}{c}\text { Desvio } \\
\text { Padrão } \\
\text { (h) }\end{array}$ \\
\hline $\begin{array}{c}\text { Falha } \\
\mathbf{1}\end{array}$ & 101905,3 & 2240,6 & 101095,7 & 2781,7 & 109233,3 & 1940,5 \\
\hline $\begin{array}{c}\text { Falha } \\
\mathbf{2}\end{array}$ & 113378,1 & 2293,2 & 117785,5 & 2888,2 & 115671,9 & 1958,5 \\
\hline $\begin{array}{c}\text { Falha } \\
\mathbf{3}\end{array}$ & 125486,1 & 2314,3 & 129846,2 & 2664,2 & 122190,0 & 1976,5 \\
\hline $\begin{array}{c}\text { Falha } \\
\mathbf{4}\end{array}$ & 138426,9 & 2321,7 & 145508,4 & 2635,4 & 129757,9 & 1959,0 \\
\hline $\begin{array}{c}\text { Falha } \\
\mathbf{5}\end{array}$ & 152485,6 & 2262,1 & 161755,4 & 2508,8 & 136515,9 & 1971,3 \\
\hline
\end{tabular}

Fonte: Autor

Tabela 44 - Relação das Cinco Próximas Falhas do Componente C2 do Sistema Paralelo após $T_{\text {sim }}=10^{5}$ horas

\begin{tabular}{|l|c|c|c|c|}
\cline { 2 - 5 } \multicolumn{1}{c|}{} & \multicolumn{2}{c|}{ Histórico Normal } & \multicolumn{2}{c|}{ Histórico Pessimista } \\
\cline { 2 - 5 } \multicolumn{1}{c|}{} & $\begin{array}{c}\text { Tempo de } \\
\text { Ocorrência (h) }\end{array}$ & Desvio Padrão (h) & $\begin{array}{c}\text { Tempo de } \\
\text { Ocorrência (h) }\end{array}$ & Desvio Padrão (h) \\
\hline Falha 1 & 118974,0 & 9136,7 & 99486,3 & 6159,8 \\
\hline Falha 2 & 141045,3 & 8675,1 & 109658,7 & 6236,5 \\
\hline Falha 3 & 156983,2 & 8277,6 & 122724,8 & 6028,4 \\
\hline Falha 4 & 170739,7 & 6307,6 & 135546,2 & 5961,4 \\
\hline Falha 5 & 185595,6 & 5265,6 & 148043,9 & 5702,1 \\
\hline
\end{tabular}

Fonte: Autor

A partir dos resultados presentes na Tabela 43 e na Tabela 44, é possível estender às previsões das falhas futuras do sistema paralelo duas tendências já exploradas nos estudos dos sistemas simples e série:

a) Nas previsões de falhas do componente $\mathrm{C} 1$ no cenário com histórico otimista e do componente $\mathrm{C} 2 \mathrm{em}$ ambos os ensaios explorados (históricos normal e pessimista), é possível notar que, em decorrência da minimização de erros estatísticos desempenhada pelo Filtro de Kalman do bloco "Detector de Comportamento e Filtro de Kalman" do modelo proposto, os desvios padrão associados aos resultados produzidos caem à medida que mais eventos de falhas futuras são gerados. 
Nas duas outras situações consideradas, o desvio padrão de todas as amostras geradas manteve-se praticamente estável, com variação inferior a 4\% entre todas as previsões de falhas do componente $C 1$ no cenário com histórico normal e inferior a $2 \%$ entre todas as previsões de falhas do componente $\mathrm{C} 1$ no ensaio com histórico pessimista;

b) Os desvios padrão das falhas futuras do componente C2 foram maiores do que os associados às previsões de falhas do componente $\mathrm{C} 1$ por dois motivos plausíveis: a proporcionalidade de parte do desvio padrão ao MTTF nominal do componente (vide equação (68) da seção 4.5) e uma eventual menor adequação dos registros das falhas do componente C2 à função afim utilizada pelo bloco "Detector de Comportamento e Filtro de Kalman" do modelo proposto.

Outro resultado que merece destaque é o instante de tempo associado à primeira falha futura do componente C2 no cenário com histórico pessimista. Como, a partir da Tabela 44, é possível notar que o instante de tempo desse evento de falha é menor do que o período de tempo $T_{\text {sim }}=10^{5}$ horas utilizado para construir o histórico operacional do sistema, é possível inferir que a primeira falha futura de C2 determinada pelo modelo proposto situa-se, na verdade, no passado.

Uma justificativa para esse resultado relaciona-se a um ajuste não suficientemente adequado dos instantes dos eventos de falha do componente C2 registrados no histórico operacional pessimista do sistema paralelo ao modelo de função afim utilizado pelo bloco "Detector de Comportamento e Filtro de Kalman". Considerando-se o histórico de funcionamento do sistema paralelo no cenário pessimista, disponível na Tabela 60 do Apêndice A.3, é possível considerar que a ineficiência do ajuste dos instantes das falhas do componente C2 por meio da regressão linear utilizada foi motivada por flutuações significativas dos intervalos de tempo entre alguns pares de falhas consecutivas registradas no histórico operacional do cenário pessimista. Com base nos dados da Tabela 60, tais intervalos entre falhas consecutivas variaram de aproximadamente 4.000 horas até 22.000 horas.

Com o propósito de permitir avaliar os algoritmos de predição de falhas utilizados pelo bloco "Detector de Comportamento e Filtro de Kalman" do modelo 
desenvolvido neste trabalho, também foram executados experimentos complementares com o objetivo de que os três últimos eventos de falha dos componentes C1 e C2 já presentes no histórico operacional do sistema paralelo fossem previstos considerando-se os instantes de ocorrência de todas as falhas anteriores a elas. Os resultados obtidos nesse estudo para os três cenários com uso de histórico operacional são exibidos da Tabela 45 até a Tabela $49^{27}$.

Devido à existência de apenas quatro eventos de falha do componente C2 no cenário em que o histórico operacional do sistema paralelo é normal e à necessidade de pelo menos três eventos de falha serem usados como referência para as previsões de falhas futuras, apenas o último dos quatro eventos de falha de C2 existentes na Tabela 58 do Apêndice A.3 pôde ser previsto nesta etapa do estudo. Essa justificativa também se estende ao fato de apenas dois eventos de falha do componente $\mathrm{C} 1$ terem sido considerados nas previsões realizadas no ensaio com histórico otimista: como pelo menos três falhas necessitam ser utilizadas na construção do modelo matemático utilizado nas previsões a serem feitas, apenas as duas últimas das cinco falhas de $\mathrm{C} 1$ registradas na Tabela 59 do Apêndice A.3 foram incorporadas ao estudo.

Tabela 45 - Comparação dos Instantes de Ocorrência das Três Últimas Falhas do Componente C1 do Sistema Paralelo com as Previsões Produzidas pelo Modelo Proposto - Ensaio Baseado em Histórico Normal

\begin{tabular}{|c|c|c|c|}
\cline { 2 - 4 } \multicolumn{1}{c|}{} & Falha 1 & Falha 2 & Falha 3 \\
\hline Instante Real de Ocorrência (h) $-t_{\text {real }}$ & 71285,8 & 83217,7 & 92088,3 \\
\hline Instante Previsto (h) $-t_{\text {prev }}$ & 78617,6 & 91762,6 & 101582,3 \\
\hline Variância $\left.\mathbf{( h}^{\mathbf{2}}\right)-\sigma_{t_{\text {prev }}}$ & 8427898,2 & 8874348,8 & 8549185,9 \\
\hline Desvio Padrão (h) $-\sigma_{t_{\text {prev }}}$ & 2903,1 & 2979,0 & 2923,9 \\
\hline Erro Relativo entre Real e (Previsto - Desvio) & 0,0621 & 0,0669 & 0,0713 \\
\hline Erro Relativo entre Real e Previsto & 0,1029 & 0,1027 & 0,1031 \\
\hline Erro Relativo entre Real e (Previsto + Desvio) & 0,1436 & 0,1385 & 0,1348 \\
\hline
\end{tabular}

Fonte: Autor

${ }^{27}$ Os valores registrados nas células das linhas "Instante Real de Ocorrência ( $h$ )" das tabelas correspondem aos instantes de tempo dos últimos eventos " $F 1$ " e " $F 2$ " registrados nas respectivas tabelas do Apêndice A.3. 
Tabela 46 - Comparação dos Instantes de Ocorrência das Duas Últimas Falhas do Componente C1 do Sistema Paralelo com as Previsões Produzidas pelo Modelo Proposto Ensaio Baseado em Histórico Otimista

\begin{tabular}{|c|c|c|}
\cline { 2 - 3 } \multicolumn{1}{c|}{} & Falha 1 & Falha 2 \\
\hline Instante Real de Ocorrência (h) $-t_{\text {real }}$ & 71694,4 & 88867,8 \\
\hline Instante Previsto (h) $-t_{\text {prev }}$ & 77719,0 & 95045,6 \\
\hline Variância (h') $\mathbf{2}-\sigma_{t_{\text {prev }}}$ & 60239,3 & 77518,9 \\
\hline Desvio Padrão (h) $-\sigma_{t_{\text {prev }}}$ & 245,4 & 278,4 \\
\hline Erro Relativo entre Real e (Previsto - Desvio) & 0,0806 & 0,0664 \\
\hline Erro Relativo entre Real e Previsto & 0,0840 & 0,0695 \\
\hline Erro Relativo entre Real e (Previsto + Desvio) & 0,0875 & 0,0726 \\
\hline
\end{tabular}

Fonte: Autor

Tabela 47 - Comparação dos Instantes de Ocorrência das Três Últimas Falhas do Componente C1 do Sistema Paralelo com as Previsões Produzidas pelo Modelo Proposto - Ensaio Baseado em Histórico Pessimista

\begin{tabular}{|c|c|c|c|}
\cline { 2 - 4 } \multicolumn{1}{c|}{} & Falha 1 & Falha 2 & Falha 3 \\
\hline Instante Real de Ocorrência (h) $-t_{\text {real }}$ & 85508,9 & 93905,8 & 99524,7 \\
\hline Instante Previsto (h) $-t_{\text {prev }}$ & 85233,5 & 88654,0 & 92900,1 \\
\hline Variância (h') $-\sigma_{t_{\text {prev }}}$ & 6010753,5 & 6056058,8 & 6084305,7 \\
\hline Desvio Padrão (h) $-\sigma_{t_{\text {prev }}}$ & 2451,7 & 2460,9 & 2466,6 \\
\hline Erro Relativo entre Real e (Previsto - Desvio) & $-0,0319$ & $-0,0821$ & $-0,0913$ \\
\hline Erro Relativo entre Real e Previsto & $-0,0032$ & $-0,0559$ & $-0,0666$ \\
\hline Erro Relativo entre Real e (Previsto + Desvio) & 0,0255 & $-0,0297$ & $-0,0418$ \\
\hline
\end{tabular}

Fonte: Autor

Tabela 48 - Comparação dos Instantes de Ocorrência da Última Falha do Componente C2 do Sistema Paralelo com as Previsões Produzidas pelo Modelo Proposto - Ensaio Baseado em Histórico Normal

\begin{tabular}{|c|c|}
\cline { 2 - 2 } \multicolumn{1}{c|}{} & Falha 1 \\
\hline Instante Real de Ocorrência (h) $-t_{\text {real }}$ & 93715,4 \\
\hline Instante Previsto $\mathbf{( h )}-t_{\text {prev }}$ & 93386,9 \\
\hline Variância $\left.\mathbf{( h}^{\mathbf{2}}\right)-\sigma_{t_{\text {prev }}}$ & 210872538,6 \\
\hline Desvio Padrão (h) $-\sigma_{t_{\text {prev }}}$ & 14521,5 \\
\hline Erro Relativo entre Real e (Previsto - Desvio) & $-0,1585$ \\
\hline Erro Relativo entre Real e Previsto & $-0,0035$ \\
\hline Erro Relativo entre Real e (Previsto + Desvio) & 0,1514 \\
\hline
\end{tabular}

Fonte: Autor 
Tabela 49 - Comparação dos Instantes de Ocorrência das Três Últimas Falhas do Componente C2 do Sistema Paralelo com as Previsões Produzidas pelo Modelo Proposto - Ensaio Baseado em Histórico Pessimista

\begin{tabular}{|c|c|c|c|}
\cline { 2 - 4 } \multicolumn{1}{c|}{} & Falha 1 & Falha 2 & Falha 3 \\
\hline Instante Real de Ocorrência (h) $-t_{\text {real }}$ & 77541,6 & 81278,6 & 87246,3 \\
\hline Instante Previsto (h) $-t_{\text {prev }}$ & 68110,8 & 84347,3 & 100391,8 \\
\hline Variância (h') $)-\sigma_{t_{\text {prev }}}$ & 33698826,5 & 33282217,7 & 28515993,7 \\
\hline Desvio Padrão (h) $-\sigma_{t_{\text {prev }}}$ & 5805,1 & 5769,1 & 5340,0 \\
\hline Erro Relativo entre Real e (Previsto - Desvio) & $-0,1965$ & $-0,0332$ & 0,0895 \\
\hline Erro Relativo entre Real e Previsto & $-0,1216$ & 0,0378 & 0,1507 \\
\hline Erro Relativo entre Real e (Previsto + Desvio) & $-0,0468$ & 0,1087 & 0,2119 \\
\hline
\end{tabular}

Fonte: Autor

Considerando-se como critério de aceitação das previsões relacionadas nas tabelas anteriores que os instantes de tempo das falhas efetivamente registradas nos históricos operacionais do sistema paralelo $\left(t_{\text {real }}\right)$ pertençam ao intervalo $\left[t_{\text {prev }}-\sigma_{t_{\text {prev }}} ; t_{\text {prev }}+\sigma_{t_{\text {prev }}}\right]$, três dos doze eventos de falha estudados para ambos os componentes foram previstos com sucesso:

a) A previsão da primeira falha do componente $C 1$ no ensaio com histórico pessimista (evento "Falha 1" da Tabela 34), que, de acordo com os resultados registrados na Tabela 47 , apresenta um erro relativo de $-3,2 \%$ a $+2,6 \%$ com relação a seu instante real de ocorrência;

b) A previsão da única falha do componente $\mathrm{C} 2$ no ensaio com histórico normal (evento "Falha 1" da Tabela 48), a qual, com base nos dados da Tabela 38, apresenta um erro relativo de $-15,8 \%$ a $+15,1 \%$ com relação a seu instante real de ocorrência.

c) A previsão da segunda falha do componente C2 no ensaio com histórico pessimista (evento "Falha 2" da Tabela 49), que apresenta um erro relativo entre $-3,3 \%$ e $+10,9 \%$ com relação a seu instante real de ocorrência.

Ao se analisar com detalhes os resultados das previsões dos três últimos eventos de falha do componente $\mathrm{C} 1$ no cenário com histórico normal e correlacionando-os ao conjunto de todas as falhas de $\mathrm{C} 1$ apresentadas na Tabela 58 do Apêndice A.3, é possível inferir que a primeira falha prevista (evento "Falha 1" da Tabela 45) não pôde ser determinada com sucesso porque o intervalo de tempo 
transcorrido desde a falha imediatamente anterior a ela (ocorrente após aproximadamente 66.400 horas desde o início da simulação, conforme a Tabela 58) foi significativamente menor do que o observado entre todos os pares prévios de falhas consecutivas do componente C1. Por esse motivo, a expectativa de que o modelo matemático construído pelo bloco "Detector de Comportamento e Filtro de Kalman" do modelo proposto para realizar a predição das falhas futuras do componente $\mathrm{C} 1$ comportar-se-ia de forma mais otimista que o real funcionamento de C1 nessas condições foi confirmada, uma vez que $t_{\text {prev }}$ foi superior a $t_{\text {real }}$ mesmo considerando-se o critério de aceitação de pertinência de $t_{\text {real }}$ ao intervalo $\left[t_{\text {prev }}-\sigma_{t_{\text {prev }}} ; t_{\text {prev }}+\sigma_{t_{\text {prev }}}\right]$.

Devido ao otimismo na previsão da primeira falha futura do componente $\mathrm{C} 1$, as duas falhas seguintes consideradas no estudo também se caracterizaram pela superioridade de $t_{\text {prev }}$ em relação a $t_{\text {real }}$. Um aspecto a ser ressaltado, no entanto, é o de que o erro relativo entre $t_{\text {prev }}$ e $t_{\text {real }}$ nos dois últimos eventos da Tabela 45 é majoritariamente resultante do deslocamento $t_{\text {desl }}$ Falha $1_{1}$ derivado do otimismo da última falha, e não de uma imprecisão do modelo proposto ao determinar o intervalo de tempo transcorrido entre a falha a ser prevista e o evento de falha imediatamente anterior. $O$ deslocamento $t_{\text {desl Falha } 1}$ é definido na equação (71):

$$
t_{\text {desl }_{\text {Falha } 1}}=t_{\text {prev }_{\text {Falha } 1}}-t_{\text {real }_{\text {Falha } 1}} \cong 7331,8 h
$$

Se os valores de $t_{\text {prev }}$ associados aos eventos "Falha 2" e "Falha 3" da Tabela 45 forem diminuídos em $t_{\text {desl }}$ Falha $1_{1}$ horas, os novos valores dos instantes de tempo das duas últimas falhas previstas para o componente $\mathrm{C} 1$ passam a ser $\overline{t_{\text {prev }_{\text {Falha } 2}}}=84430,8 \mathrm{~h}$ e $\overline{t_{\text {prev }_{\text {Falha } 3}}}=94250,5 \mathrm{~h}$. Nessas condições, os novos valores de erro relativo entre os pares de valores $\left(t_{\text {real Falha } 2_{2}} ; \overline{t_{\text {prev }} \text { Falha } 2}\right)$ e $\left(t_{\text {real }_{\text {Falha } 3}} ; \overline{t_{\text {prev Falha } 3_{3}}}\right)$ passam a ser, respectivamente, de $+1,46 \%$ e $+2,35 \%$. Como esses valores são significativamente inferiores aos verificados a partir dos dados da Tabela 45, a justificativa previamente apresentada, de que o erro relativo de $t_{\text {prev }}$ Falha $2_{2}$ e $t_{\text {prev }}$ Falha $3_{3}$ decorre majoritariamente do deslocamento $t_{\text {desl }}$ Falha $1_{\text {é }}$ confirmada. 
Uma argumentação análoga à apresentada na análise dos resultados da Tabela 45 também pode ser estendida aos valores relacionados na Tabela 46, em que se exploram as previsões das duas últimas falhas do componente $C 1$ no cenário em que se utilizam os dados do histórico otimista da Tabela 59 do Apêndice A.3. Nessa situação, o valor obtido para a previsão do instante $t_{\text {prev }}$ Falha $1_{1}$ de ocorrência da primeira falha do componente C1 (evento "Falha 1" da Tabela 46) também foi maior do que $t_{\text {real }}$ porque $o$ intervalo de tempo transcorrido desde a falha imediatamente anterior a ela (ocorrente após aproximadamente 58.500 horas desde o início da simulação, conforme a Tabela 59) foi significativamente menor do que o observado entre todos os três pares prévios de falhas consecutivas do componente C1. Em consequência do otimismo associado ao valor $t_{\text {prev }_{\text {Falha } 1} \text {, a previsão }}$ $t_{\text {prev }_{\text {Falha } 2}}$ também foi significativamente maior do que $t_{\text {real }}$ Falha $2_{2}$ devido, sobretudo, ao deslocamento $t_{\text {desl }_{\text {Falha } 1}}$ definido na equação (71). Se tal desvio for subtraído de $t_{\text {prev }_{\text {Falha } 2} \text {, }}$ a tendência de redução do erro relativo entre o novo valor de $t_{\text {prev }_{\text {Falha } 2}}$ e $t_{\text {real }}$ Falha $2_{2}$ explorada a partir dos dados da Tabela 45 também valerá neste caso.

Ainda com relação aos resultados da Tabela 46, outro aspecto a ser salientado é o de que os desvios padrão associados às duas previsões de falhas calculadas foram bastante inferiores aos obtidos em todos os outros ensaios realizados (considerando-se os resultados da Tabela 45, da Tabela 47, da Tabela 48 e da Tabela 49, os desvios padrão apresentados na Tabela 46 foram pelo menos dez vezes menores do que todos os demais). Ao se considerar os instantes de tempo dos três primeiros registros de falhas do componente $C 1$ na Tabela 59 do Apêndice A.3, utilizados para construir o modelo matemático empregado no cálculo das falhas futuras da Tabela 46, é possível notar que os intervalos de tempo transcorridos entre cada falha consecutiva se mantiveram praticamente constantes. Por esse motivo, considerando-se o modelo de função afim utilizado pelo bloco "Detector de Comportamento e Filtro de Kalman" do modelo proposto no estudo, os pontos formados pelos três eventos de falha utilizados como referência podem ser considerados praticamente colineares, condição em que as variâncias (e, consequentemente, os desvios padrão) dos coeficientes angular e linear da reta determinada são reduzidas (reduzidos). 
Já ao se analisar os resultados das previsões dos três últimos eventos de falha do componente $\mathrm{C} 1$ no cenário com histórico pessimista, é possível observar que os instantes de tempo $t_{\text {prev }}$ das duas últimas falhas estimadas (eventos "Falha 2 " e "Falha 3" da Tabela 47) foram inferiores aos respectivos valores de $t_{\text {real }}$. A justificativa para esse resultado decorre do fato de haver, no conjunto de registros de falhas de $\mathrm{C} 1$ presentes no histórico operacional da Tabela 60 do Apêndice A.3, eventos de falhas consecutivas que ocorreram em intervalos de tempo sensivelmente menores do que os períodos de tempo médios entre falhas observados ao longo de todo o ensaio pessimista do sistema paralelo. Devido aos intervalos reduzidos de tempo entre alguns pares de falhas consecutivas de $\mathrm{C} 1$, a função afim produzida pelo bloco "Detector de Comportamento e Filtro de Kalman" do modelo proposto tornou-se mais pessimista do que o comportamento real das falhas da Tabela 47, e, por esse motivo, essa tendência tornou-se evidente nas duas últimas predições realizadas.

Com relação à única falha estimada para o componente $\mathrm{C} 2$ no cenário em que se utilizou um histórico operacional normal para o sistema paralelo, registrada na Tabela 48, é possível notar que o desvio padrão associado à previsão realizada é bastante significativo. A explicação associada a esse resultado é a de que o modelo de função afim utilizado para descrever a tendência dos instantes de tempo em que as falhas do componente $\mathrm{C} 2$ ocorrem não se ajustou apropriadamente aos registros de falha do histórico operacional da Tabela 59 do Apêndice A.3 utilizados como referência. Tal dificuldade de ajuste foi potencializada porque a quantidade de eventos de falha utilizados para produzir a função afim descritora do comportamento das falhas do componente $\mathrm{C} 2$ corresponde ao mínimo de três registros, e, nessas condições, eventuais desvios entre esses pontos afetam de forma mais significativa - cálculo dos coeficientes angular e linear da função afim gerada e, consequentemente, os seus respectivos desvios padrão.

Por fim, os resultados das previsões das falhas futuras do componente $\mathrm{C} 2$ no cenário com histórico pessimista, registrados na Tabela 49, podem ser justificados da seguinte forma: 
a) No caso da primeira falha do componente C2 (evento "Falha 1" da Tabela 49), 0 valor do instante de tempo $t_{\text {prev }}$ foi superior a $t_{\text {real }}$ devido ao fato de 0 modelo de função afim utilizado para realizar a predição da falha ter sido mais pessimista do que o real comportamento do componente $\mathrm{C} 2$. O principal aspecto que influenciou o pessimismo dessa estimativa relaciona-se à existência, no histórico operacional da Tabela 60 do Apêndice A.3, de dois eventos consecutivos de falha do componente $\mathrm{C} 2$ em um intervalo de tempo de tempo de aproximadamente 6.000 horas $^{28}$, significativamente inferior às quase 25.000 horas do período compreendido entre o instante $t_{\text {real }}$ do evento "Falha 1" da Tabela 49 e o registro da falha imediatamente anterior a ele (ocorrente após aproximadamente 53.000 horas desde o início do estudo do sistema paralelo, como se pode observar na Tabela 60 do Apêndice A.3);

b) $O$ otimismo relacionado às duas outras falhas previstas na Tabela 49, por sua vez, deve-se exatamente ao motivo oposto ao apresentado no item "a)" para justificar o pessimismo do primeiro evento de falha da Tabela 49. Como os intervalos $\left[t_{\text {real }_{\text {Falha } 1}} ; t_{\text {real }_{\text {Falha }} 2}\right]$ e $\left[t_{\text {real }_{\text {Falha }} 2} ; t_{\text {real }_{\text {Falha }}}\right]$ compreendem períodos de tempo inferiores à média dos intervalos entre todos os pares de falhas consecutivas extraídas do histórico operacional da Tabela 60 do Apêndice A.3, é esperado que o modelo matemático da função afim utilizada para orientar as predições das falhas futuras do componente C2 seja mais otimista do que o real comportamento observado.

\subsection{SumÁRIO dos RESULtAdos ObTIDOS}

A partir das discussões realizadas nas seções 5.2, 5.3 e 5.4, é possível elaborar um sumário das principais tendências comportamentais observadas em todos os estudos de caso que foram considerados nesta pesquisa. Esse resumo é apresentado na Tabela 50.

${ }^{28}$ Os eventos de falha referenciados aqui ocorreram em aproximadamente $33.600 \mathrm{~h}$ e $39.800 \mathrm{~h}$, como se pode verificar na Tabela 60 do Apêndice A.3. 
Tabela 50 - Sumário dos Principais Resultados Obtidos nos Três Estudos de Caso

\begin{tabular}{|c|c|}
\hline \multicolumn{2}{|r|}{ Estudo do Sistema Simples (seção 5.2) } \\
\hline Confiabilidade & $\begin{array}{l}\text { - Cenário otimista com decaimento mais lento entre todos os ensaios; } \\
\text { - Cenário pessimista com decaimento mais rápido entre todos os ensaios a partir } \\
\text { do instante de ocorrência da falha do componente; } \\
\text { - Cenário normal com decaimento mais lento do que o do cenário sem histórico } \\
\text { até o instante de ocorrência da falha do sistema. A partir desse ponto, o } \\
\text { decaimento da confiabilidade do cenário normal passou a ser maior do que a do } \\
\text { cenário sem histórico. }\end{array}$ \\
\hline $\begin{array}{c}\text { Segurança } \\
\text { Crítica (Safety) }\end{array}$ & $\begin{array}{l}\text { - Em todos os cenários, houve convergência da segurança ao valor do percentual } \\
\text { de falhas seguras do sistema; } \\
\text { - A ordem de precedência do decaimento da segurança crítica (safety) foi a } \\
\text { mesma observada no ensaio da função confiabilidade. }\end{array}$ \\
\hline Disponibilidade & $\begin{array}{l}\text { - A disponibilidade variou inversamente com a taxa de falhas do sistema e } \\
\text { diretamente com a sua taxa de reparos. } \\
\text { - Ao longo da maioria da simulação, a maior disponibilidade foi detectada no } \\
\text { cenário com histórico otimista, ao passo que a menor disponibilidade foi obtida no } \\
\text { ensaio com histórico pessimista. } \\
\text { - No ensaio com histórico normal, a disponibilidade oscilou em torno da } \\
\text { disponibilidade assintótica do cenário sem histórico. Â medida que mais falhas } \\
\text { ocorreram com o sistema, a disponibilidade no cenário com histórico normal } \\
\text { passou a ser inferior à do ensaio sem histórico. } \\
\text { - Ao se tentar prever as três últimas falhas já existentes no histórico de operação } \\
\text { do sistema nos três cenários (normal, otimista e pessimista), as seguintes } \\
\text { tendências foram observadas: } \\
\rightarrow \text { Duas previsões foram feitas com sucesso (uma no cenário normal e uma no } \\
\text { cenário otimista); } \\
\rightarrow \text { Três previsões foram mais otimistas do que o real comportamento do sistema } \\
\text { (todas no cenário pessimista); } \\
\rightarrow \text { Quatro previsões foram mais pessimistas do que o real comportamento do } \\
\text { sistema (duas no cenário normal e duas no cenário otimista). }\end{array}$ \\
\hline \multicolumn{2}{|r|}{ Estudo do Sistema Série com Dois Componentes (seção 5.3) } \\
\hline Confiabilidade & $\begin{array}{l}\text { - Cenário otimista com decaimento mais lento entre todos os ensaios; } \\
\text { - Cenário normal apresentou decaimento mais rápido do que os cenários sem } \\
\text { histórico e com histórico pessimista devido à existência de um evento de falha do } \\
\text { componente C1 sorteado aleatoriamente para ocorrer de forma muito antecipada. }\end{array}$ \\
\hline $\begin{array}{c}\text { Segurança } \\
\text { Crítica (Safety) }\end{array}$ & $\begin{array}{l}\text { - Em todos os cenários, houve convergência da segurança ao valor do produto } \\
\text { dos percentuais de falhas seguras de ambos os componentes do sistema; } \\
\text { - A ordem de precedência do decaimento da segurança crítica (safety) foi a } \\
\text { mesma observada no ensaio da função segurança crítica (safety) no sistema } \\
\text { simples. }\end{array}$ \\
\hline
\end{tabular}




\begin{tabular}{|c|c|}
\hline Disponibilidade & $\begin{array}{l}\text { - As mesmas tendências apresentadas nos três primeiros itens do estudo da } \\
\text { disponibilidade do sistema simples também foram observadas no ensaio do } \\
\text { sistema série; } \\
\text { - Ao se tentar prever as três últimas falhas de cada componente do sistema já } \\
\text { existentes em seu histórico operacional nos três cenários considerados (normal, } \\
\text { otimista e pessimista), as seguintes tendências foram observadas: } \\
\rightarrow \text { Quatro previsões foram feitas com sucesso (uma no cenário normal e três no } \\
\text { cenário pessimista); } \\
\rightarrow \text { Dez previsões foram mais otimistas do que o real comportamento do sistema } \\
\text { (quatro no cenário normal, três no cenário otimista e três no cenário pessimista); } \\
\rightarrow \text { Nenhuma previsão foi mais pessimista do que o real comportamento do } \\
\text { sistema; } \\
\rightarrow \text { Devido à inexistência de registros de falha suficientes para que três } \\
\text { predições de falhas fossem realizadas, nenhuma falha do componente com } \\
\text { maior taxa de falhas foi realizada no cenário com histórico otimista e apenas } \\
\text { uma falha do componente com maior taxa de falhas pôde ser prevista no } \\
\text { cenário com histórico normal. }\end{array}$ \\
\hline \multicolumn{2}{|c|}{ Estudo do Sistema Paralelo com Dois Componentes Redundantes (seção 5.4) } \\
\hline Confiabilidade & $\begin{array}{l}\text { - Cenário otimista com decaimento mais lento entre todos os ensaios; } \\
\text { - Cenário pessimista com decaimento mais rápido entre todos os ensaios apenas } \\
\text { a partir do instante em que ambos os componentes do sistema falharam; } \\
\text { - Cenário normal com decaimento mais lento do que o do cenário sem histórico. }\end{array}$ \\
\hline $\begin{array}{c}\text { Segurança } \\
\text { Crítica (Safety) }\end{array}$ & $\begin{array}{l}\text { - Em todos os cenários, houve convergência da segurança ao complemento do } \\
\text { produto do percentual de falhas inseguras de ambos os componentes do sistema; } \\
\text { - A ordem de precedência do decaimento da segurança crítica (safety) foi a } \\
\text { mesma observada no ensaio da função confiabilidade (incluindo o decaimento } \\
\text { mais rápido no cenário pessimista apenas a partir do instante em que ambos os } \\
\text { componentes do sistema falharam). }\end{array}$ \\
\hline Disponibilidade & $\begin{array}{l}\text { - As mesmas tendências apresentadas nos três primeiros itens do estudo da } \\
\text { disponibilidade do sistema simples também foram observadas no ensaio do } \\
\text { sistema série. } \\
\text { - Ao se tentar prever as três últimas falhas de cada componente do sistema já } \\
\text { existentes em seu histórico operacional nos três cenários considerados (normal, } \\
\text { otimista e pessimista), as seguintes tendências foram observadas: } \\
\rightarrow \text { Três previsões foram feitas com sucesso (uma no cenário normal e duas no } \\
\text { cenário pessimista); } \\
\rightarrow \text { Seis previsões foram mais otimistas do que o real comportamento do sistema } \\
\text { (três no cenário normal, duas no cenário otimista e uma no cenário pessimista); } \\
\rightarrow \text { Três previsões foram mais pessimistas do que o real comportamento do } \\
\text { sistema (todas no cenário pessimista); } \\
\rightarrow \text { Devido à inexistência de registros de falha suficientes para que três } \\
\text { predições de falhas fossem realizadas, nenhuma falha do componente com } \\
\text { maior taxa de falhas foi realizada no cenário com histórico otimista, apenas uma } \\
\text { falha do componente com maior taxa de falhas pôde ser prevista no cenário } \\
\text { com histórico normal e apenas duas falhas do componente com menor taxa de } \\
\text { falhas puderam ser previstas no cenário com histórico otimista. }\end{array}$ \\
\hline
\end{tabular}

Fonte: Autor 


\subsection{CONSIDERAÇÕES FINAIS dO CAPÍTULO}

Apresentaram-se neste capítulo os Estudos de Caso utilizados para se avaliar o modelo proposto no presente estudo científico. Essa avaliação foi feita por meio da comparação dos resultados obtidos pelas abordagens clássicas de estimativa de índices de confiabilidade de sistemas elétricos, eletrônicos e programáveis com os gerados por meio do uso do ambiente de desenvolvimento e ensaio do modelo apresentado neste trabalho de pesquisa. Para tanto, três diferentes sistemas foram estudados: um sistema formado por um único componente, um sistema constituído por dois componentes conectados serialmente entre si e um sistema munido de dois componentes interligados em paralelo.

À luz dos resultados registrados a partir dos três estudos de caso, irão ser abordadas no próximo capítulo as considerações finais referentes ao presente estudo científico. O objetivo dessa próxima etapa é evidenciar as principais contribuições da pesquisa com a área de conhecimento que ela abrange e as eventuais melhorias e trabalhos correlatos que podem ser desenvolvidos futuramente. 


\section{CONSIDERAÇÕES FINAIS}

Este Capítulo apresenta as principais conclusões que podem ser obtidas depois da avaliação do modelo proposto no presente estudo científico. São abordadas as contribuições que este trabalho faz às áreas de conhecimento que ele envolve sugestões para futuras melhorias e trabalhos correlatos que podem ser desenvolvidos a partir deste estudo.

\subsection{Conclusões da Pesquisa do Mestrado}

Com base nos estudos de caso explorados no Capítulo 5, é possível considerar que o modelo proposto e desenvolvido neste trabalho pôde ser satisfatoriamente utilizado para que os dois principais objetivos definidos no Capítulo 1 fossem explorados:

a) A avaliação do impacto do uso de dados de histórico de operação sobre os índices de dependabilidade (confiabilidade, disponibilidade e segurança crítica - safety) de sistemas elétricos, eletrônicos e programáveis;

b) A possibilidade de se prever quando ocorrerão falhas futuras dos componentes de sistemas elétricos, eletrônicos e programáveis a partir dos registros de todos os seus respectivos eventos passados de falhas e manutenções.

Considerando-se os resultados apresentados e discutidos no Capítulo 5, foi possível observar que o modelo preconizado no padrão RIAC-HDBK-217Plus para se calcular a taxa de falhas de um componente elétrico, eletrônico ou programável a partir da contagem das falhas manifestadas por ele e da medição dos períodos de tempo em que ele se manteve operacional mostrou-se uma alternativa viável para permitir que as taxas de falhas dos componentes dos sistemas estudados fossem atualizadas de acordo com dados de histórico. Uma explicação análoga pode ser utilizada, também, para justificar a viabilidade de uso da extensão do arcabouço da norma RIAC-HDBK-217Plus proposta na seção 3.3 para que a variação temporal das taxas de reparos de componentes elétricos, eletrônicos e programáveis a partir de registros de manutenções já executadas previamente fosse estimada. 
Com relação à significância dos resultados obtidos para a evolução temporal das funções confiabilidade, disponibilidade e segurança crítica (safety), a tendência observada em praticamente todos os ensaios realizados foi a seguinte:

a) Os maiores níveis de confiabilidade, disponibilidade e segurança crítica (safety) são obtidos quando o histórico de operação do sistema em estudo apresenta características otimistas, tais como longos períodos de tempo entre falhas e curtos períodos de tempo para se desempenhar procedimentos de manutenção. Essas condições são usualmente observadas em situações nas quais um sistema está submetido a condições operacionais apropriadas (presentes, por exemplo, quando os componentes do sistema operam com margem significativa de seus limiares físicos de tensão e corrente) e quando as equipes de instalação, operação e manutenção do sistema desempenham suas tarefas rápida e apropriadamente;

b) Os menores níveis de confiabilidade, disponibilidade e segurança crítica (safety) são obtidos quando o histórico de operação do sistema em estudo apresenta características pessimistas, tais como curtos períodos de tempo entre falhas e longos períodos de tempo para se executar procedimentos de manutenção. Essas condições são típicas de cenários nos quais um sistema está submetido a condições operacionais adversas (resultantes, por exemplo, de situações em que um ou mais componentes do sistema operam perto ou acima dos seus limites físicos de tensão e corrente) e quando as equipes de instalação, operação e manutenção do sistema não desempenham suas tarefas de forma satisfatória, seja demorando mais tempo do que o necessário, seja executando reparos imperfeitos;

c) Na comparação entre os cenários com histórico normal e sem histórico, foi possível constatar que os índices de confiabilidade, disponibilidade e segurança crítica (safety) obtidos em ambos os cenários tendem a ser razoavelmente próximos entre si, com leve predominância de resultados mais otimistas nas situações em que dados de histórico são utilizados. A justificativa para a tendência de otimismo nos resultados produzidos nos ensaios com histórico decorre do decaimento imposto às taxas de falhas dos componentes do sistema pelo uso iterativo dos modelos matemáticos do padrão RIAC-HDBK-217Plus ao longo dos intervalos de tempo em que eles 
funcionam sem falhar: mesmo que todas as falhas de um componente ocorram rigorosamente em períodos de tempo iguais ao MTTF nominal do componente, a equação (12) manterá a taxa de falhas dele em patamares menores ou iguais ao seu respectivo valor nominal.

Em algumas situações isoladas abordadas nos estudos de caso do Capítulo 5 , foi mencionado que a justificativa para alguns comportamentos não esperados das funções confiabilidade, segurança crítica (safety) e disponibilidade é a de que alguns eventos discrepantes de falhas e manutenções dos componentes dos sistemas avaliados haviam sido gerados pseudoaleatoriamente pelo módulo "Simulador de Dados de Entrada" do ambiente de desenvolvimento e ensaio. O principal exemplo de comportamento inesperado foi observado no estudo da função confiabilidade do sistema série, em que se pôde verificar que a confibilidade no cenário com histórico normal foi menor do que a observada na situação com histórico pessimista devido ao sorteio de um evento de falha excessivamente antecipado no ensaio com histórico normal ${ }^{29}$.

Os resultados obtidos - incluindo as próprias situações cujo comportamento desviou-se da tendência esperada - evidenciam que o modelo proposto neste estudo tem potencial para fornecer estimativas dos índices de dependabilidade de sistemas elétricos, eletrônicos e programáveis mais próximas do real comportamento desses sistemas. Essa propriedade é esperada porque os cálculos desses índices são feitos considerando-se não só o valor nominal das taxas de falhas e de reparos dos componentes do sistema, mas também as informações que prescrevem as suas reais características de funcionamento em seus respectivos contextos de operação.

A tendência de obtenção de estimativas mais próximas do comportamento real dos sistemas elétricos, eletrônicos e programáveis é desejada para quaisquer levantamentos de confiabilidade, disponibilidade e segurança crítica (safety), visto que estimativas excessivamente otimistas podem levar a falsas interpretações sobre a probabilidade de ocorrência de determinados tipos de falhas indesejadas e que estimativas demasiadamente pessimistas podem demandar elevados custos nas etapas de projeto e de manutenção do sistema. A necessidade de estimativas

\footnotetext{
${ }^{29}$ Mais detalhes a respeito desse comportamento foram explorados na seção 5.3.1.
} 
precisas e fidedignas é importante, sobretudo, em sistemas críticos com relação à segurança (safety), nos quais a manifestação de falhas inseguras pode levar a situações catastróficas com danos à vida humana e ao meio ambiente.

Com relação aos algoritmos desenvolvidos para se realizar a predição das falhas futuras de um sistema elétrico, eletrônico e programável, o sumário de resultados apresentado na seção 5.5 permite inferir que a utilização combinada de regressão linear e filtragem Kalman produz, em geral, estimativas de falha mais otimistas do que o real comportamento esperado para o sistema. Além desse aspecto, outra característica a ser ressaltada é a de que os algoritmos desenvolvidos necessitam que pelo menos três registros de falhas passadas de cada componente do sistema estejam disponíveis para que os instantes de ocorrência de suas eventuais falhas futuras possam ser estimados.

Em situações nas quais a quantidade de registros de falhas presentes no histórico operacional de um sistema é reduzida, ou em cenários nos quais existem eventos de falha que se distanciam de uma tendência média - usualmente classificados como "outliers" - foi possível observar que o uso combinado das técnicas de regressão linear e filtragem Kalman leva à produção de estimativas de falhas com incertezas significativamente elevadas. Esse comportamento pode ser justificado, sobretudo, pela dificuldade de o modelo de função afim utilizado pela regressão linear se adaptar apropriadamente ao conjunto de pontos dos instantes de tempo de todas as falhas extraídas do histórico operacional e utilizadas como referência para as predições.

Nos cenários em que as estimativas de falhas futuras dos componentes de um sistema não são consideradas excessivamente otimistas ou pessimistas, os resultados produzidos pelo modelo devem ser utilizados de tal forma que a execução dos procedimentos de manutenção do sistema seja agendada para ocorrer nos instantes de tempo das predições determinadas pelo modelo. É nesse contexto em que a capacidade de presciência de falhas do modelo proposto insere-se como uma ferramenta de suporte à manutenção preditiva de sistemas elétricos, eletrônicos e programáveis. 
Outro aspecto que vale ser mencionado relaciona-se ao tempo de processamento utilizado para que todas as simulações matemáticas dos estudos de caso apresentados no Capítulo 5 pudessem ser executadas. Em um computador pessoal portátil (notebook) equipado com processador Inte ${ }^{\Theta}$ Core $^{T M}$ i5 de quatro núcleos operando com frequência de clock de 2,4GHz, 4GB de memória RAM DDR3, disco rígido de 500GB e 5400rpm e executando apenas processos inerentes ao sistema operacional Windows 7 Professional (com Service Pack 1) e ao software $M A T L A B^{\Theta}$, foram obtidos os tempos de execução aproximados relacionados na Tabela 51.

Tabela 51 - Relação dos Tempos de Execução das Simulações dos Estudos de Caso

\begin{tabular}{|c|c|c|c|c|}
\cline { 3 - 4 } \multicolumn{2}{c|}{} & \multicolumn{3}{c|}{ Tempos de Execução } \\
\cline { 3 - 5 } \multicolumn{2}{c|}{} & Confiabilidade & $\begin{array}{c}\text { Segurança } \\
\text { Crítica (Safety) }\end{array}$ & Disponibilidade \\
\hline \multirow{2}{*}{ Sistema Simples } & Sem Histórico & 5 segundos & 25 segundos & 10 segundos \\
\cline { 2 - 5 } & Com Histórico & 20 minutos & 2 horas & 40 minutos \\
\hline \multirow{2}{*}{$\begin{array}{c}\text { Sistemas Série e } \\
\text { Paralelo }\end{array}$} & Sem Histórico & 15 segundos & 2 minutos & 30 segundos \\
\cline { 2 - 5 } & Com Histórico & $\begin{array}{c}1 \text { hora e } 15 \\
\text { minutos }\end{array}$ & $\begin{array}{c}13 \text { horas e } 15 \\
\text { minutos }\end{array}$ & $\begin{array}{c}2 \text { horas e } 30 \\
\text { minutos }\end{array}$ \\
\hline
\end{tabular}

Fonte: Autor

O aumento significativo dos tempos de execução de todos os cenários em que dados de histórico são considerados relaciona-se à necessidade de se reavaliar, a cada iteração dos cálculos das funções confiabilidade, disponibilidade e segurança crítica (safety), os valores de todas as transições entre estados dos modelos de Markov, uma vez que os valores das taxas de falhas e de reparos dos componentes dos sistemas variam com o tempo. Como tal reavaliação é baseada em processamento literal (de texto) das expressões matemáticas das probabilidades das transições entre os estados dos modelos de Markov, e essa categoria de processamento de dados é computacionalmente custosa, o tempo total de execução dos algoritmos do modelo desenvolvido torna-se significativamente maior do que o associado aos cenários sem uso de dados de histórico, nos quais não há necessidade de se recalcular os valores das probabilidade das transições entre estados do modelo de Markov porque as taxas de falhas e de reparos dos componentes do sistema mantêm-se constantes ao longo de toda a simulação. 
Ainda com relação aos tempos de simulação obtidos, foi observado que o tempo de execução dos algoritmos utilizados para se realizar as predições das falhas futuras dos componentes dos três sistemas estudados aproximou-se de 1 segundo em todos os cenários avaliados (com históricos normal, otimista e pessimista). Esse resultado reforça a tendência já discutida anteriormente de que o tempo de execução dos algoritmos desenvolvidos neste trabalho de pesquisa é majoritariamente composto pelo tempo necessário para se processar as funções confiabilidade, disponibilidade e segurança crítica (safety) a partir do modelo Markoviano do sistema.

\subsection{Principals Contribuições À Área de MANUTEnÇÃo Preditiva}

Com base tanto nos objetivos e nas justificativas definidos no Capitulo 1 quanto nas conclusões apresentadas na seção 6.1, é possível destacar que a presente pesquisa provê as seguintes contribuições ao avanço científico da área de Manutenção Preditiva:

a) O estabelecimento de um modelo matemático de suporte à manutenção preditiva de sistemas elétricos, eletrônicos e programáveis baseado exclusivamente no monitoramento dos eventos de falhas e manutenções de seus componentes;

b) A definição de um modelo matemático estendido a partir do padrão internacional RIAC-HDBK-217Plus para permitir que as taxas de falhas e de reparos de componentes elétricos, eletrônicos e programáveis sejam continuamente atualizadas ao longo do tempo com base em eventos de falhas e manutenções. Por intermédio dessa abordagem, eventuais cálculos de dependabilidade (por exemplo, confiabilidade, disponibilidade e segurança crítica - safety) aplicáveis a sistemas elétricos, eletrônicos e programáveis podem ser numericamente executados com base em modelos SemiMarkovianos sem haver a necessidade de se definir expressões matemáticas literais para descrever a evolução das taxas de falhas e de reparos ao longo do tempo. 


\subsection{SUGESTÕES PARA TRABALHOS FUtUROS}

São apresentadas, na presente seção, propostas relacionadas a futuras melhorias do modelo proposto e a trabalhos em áreas correlatas, que podem ser desenvolvidos utilizando-se este trabalho como base de conhecimento. $O$ intuito não é esgotar as possibilidades existentes, mas apresentar alguns temas que surgiram como ideias durante a realização deste trabalho de pesquisa.

a) Como apenas sistemas conceituais foram utilizados nos estudos de caso apresentados nesta dissertação, um possível trabalho futuro consiste em se realizar estudos de sistemas de aplicação prática, tais como a avaliação dos índices de disponibilidade e das falhas futuras que podem ocorrer em um sistema de distribuição de energia elétrica após um determinado intervalo de tempo. Exemplos de sistemas de distribuição elétrica que podem ser utilizados em tais trabalhos futuros estão disponíveis, por exemplo, em Billinton e Li (1994) e em Santos et al. (2009), sendo a última referência, inclusive, passível de ser utilizada em um estudo comparativo entre o modelo apresentado nela e o modelo desenvolvido neste trabalho.

Como complemento à proposta prévia, eventuais análises de custo-benefício podem ser conduzidas se dados que quantifiquem os custos envolvidos no contexto proposto (por exemplo, salários das equipes de manutenção, custeio de estoque de peças de reposição) estiverem disponíveis.

b) Para que o modelo proposto no presente estudo possa ser estendido a sistemas não exclusivamente elétricos, eletrônicos e programáveis incluindo-se, até mesmo, os efeitos do empacotamento mecânico dos componentes do sistema sobre as eventuais falhas manifestadas por ele uma mesma estrutura de blocos análoga à apresentada na Figura 21 do Capítulo 3 pode ser utilizada, desde que outras categorias de processos estocásticos e de mecanismos de predição de falhas futuras, aplicáveis ao tipo de sistema a ser analisado, sejam consideradas. No caso de componentes eletromecânicos, por exemplo, o modelo a ser desenvolvido deve contemplar que a probabilidade de ocorrência de falhas segue, em lugar da distribuição exponencial utilizada neste trabalho, a distribuição de Weibull; 
c) Para que predições de falhas futuras realizadas pelo bloco "Detector de Comportamento e Filtro de Kalman" possam ser mais precisas e menos susceptíveis a perturbações provocadas por eventos isolados de falha que se distanciam de uma tendência considerada normal para a operação de um sistema ("outliers"), é sugerido que, em trabalhos futuros, seja investigada a eficácia e a capacidade de utilização de novos algoritmos de predição de falhas, baseados, por exemplo, algoritmos genéticos ou em redes neurais;

d) Para que dados práticos de histórico operacional possam ser utilizados para realizar predições das falhas futuras dos componentes de um sistema, é necessário incorporar ao bloco "Detector de Comportamento e Filtro de Kalman" do modelo desenvolvido uma funcionalidade adicional, que the permita avaliar de qual dos modelos de histórico conceituais (otimista, normal ou pessimista) os dados práticos se aproximam. Essa avaliação é necessária para que os valores pseudoaleatórios iterativamente produzidos para a entrada de dados $z(\beta+1)$ do filtro de Kalman sejam gerados apropriadamente;

e) Também com relação aos cenários em que dados práticos são considerados pelo modelo proposto, eventuais alterações nos algoritmos de aquisição de dados de histórico operacional podem ser efetuadas para que, se novos dados de histórico (posteriores aos já existentes até o instante de tempo máximo configurado na "Etapa 1 - Iniciação" da dinâmica do modelo ${ }^{30}$ ) estiverem disponíveis, eles já sejam processados com o intuito de otimizar a calibragem dos parâmetros internos do bloco "Detector de Comportamento e Filtro de Kalman" durante a execução do próprio algoritmo proposto;

f) Ainda com relação ao uso de dados práticos para se avaliar o modelo desenvolvido nesta pesquisa, um possível caso de teste que pode ser considerado prevê o uso de duas instâncias físicas de um mesmo sistema, projetadas e montadas de tal forma que todos os componentes utilizados em ambos os sistemas sejam de um mesmo lote (para evitar desvios significativos dos processos produtivos dos componentes) e que a mesma equipe de manutenção atue sobre ambos os sistemas em caso de falha.

30 Para mais detalhes sobre a dinâmica funcional do modelo proposto, vide Figura 22 (página 106, seção 3.1). 
Nesse caso, o cerne do processo de verificação e validação do modelo basear-se-ia em se executar manutenções preditivas conforme sugerido pelas previsões propostas mediante aplicação do modelo apenas em uma das instâncias do sistema, ao passo que não se interferiria na outra instância do sistema até que falhas efetivamente ocorram nela.

A ideia que permeia esse raciocínio reside no fato de que, como ambos os sistemas são similares e estão submetidos a condições de operação também análogas, é esperado que as falhas que irão acontecer sobre eles ocorram em instantes de tempo muito próximos entre si. Dessa forma, os instantes das predições de falhas realizadas sobre uma das instâncias do sistema deveriam ser próximos dos momentos efetivos em que as mesmas falhas manifestar-se-iam na outra instância do sistema;

g) Com o propósito de minimizar a frequência de produção de eventuais registros discrepantes (outliers) de falhas e manutençoes pelos métodos pseudoaleatórios do módulo "Simulador de Dados de Entrada" do ambiente de desenvolvimento e ensaio, uma possível extensão futura dos algoritmos desenvolvidos consiste em se determinar o instante de ocorrência de cada evento do histórico operacional de um sistema a partir da média dos resultados produzidos em múltiplas rodadas de execução das funções apresentados nas seções 4.3.1 a 4.3.5, e não a partir de apenas um único procedimento de sorteio;

h) Um estudo adicional que também pode ser realizado baseia-se em se verificar se os resultados apresentados e discutidos no Capítulo 5 também são válidos ao se substituir os processos Markovianos considerados no bloco "Cálculos Matemáticos do Modelo de Markov Estendido" do modelo desenvolvido por um modelo Semi-Markoviano, cujo embasamento teórico enquadra-se de forma mais satisfatória do que a base conceitual dos processos de Markov para representar processos estocásticos cujas transições entre estados variam com o tempo (como é o caso de todos os estudos de caso considerados nesta pesquisa).

Nessa investigação, também é possível avaliar o impacto do uso de modelos Semi-Markovianos sobre o tempo de execução das simulações matemáticas 
e quantificar se o benefício associado a uma eventual representação mais realista dos modelos Semi-Markov compensa um provável aumento no tempo de processamento dos cálculos executados.

i) Outra possível extensão do modelo desenvolvido no presente trabalho consiste em se permitir que dados utilizados em procedimentos de teste acelerado (executados, por exemplo, durante ensaios de triagem - ou screening, diretamente do Inglês) também sejam empregados como referência para se estimar os índices de dependabilidade e as falhas futuras de um sistema. Para tanto, as leis matemáticas do bloco "Cálculo das Taxas de Falhas e de Reparos condicionadas ao Histórico de Operação" do modelo desenvolvido necessitam ser alteradas de tal forma a incorporar o fator de aceleração $\left(A F_{i}\right)$ preconizado no padrão internacional RIAC-HDBK-217Plus e utilizado na equação (11) da seção 2.3.2;

j) Conforme apresentado na seção 2.5, uma das hipóteses assumidas para que os Filtros de Kalman minimizem a variância das predições realizadas por ele é a de que o ruído dos sensores utilizados para se coletar os dados empregados por ele possui uma distribuição probabilística Gaussiana. Dessa maneira, um eventual estudo futuro que pode ser desenvolvido consiste em se verificar se sensores usualmente adotados em aplicações reais para se coletar dados de falhas e manutenções dos componentes de um sistema apresentam, ou não, comportamento próximo ao esperado para a utilização do Filtro de Kalman proposto no presente trabalho;

k) Considerando-se que, em um cenário prático, a manutenção dos dados do histórico operacional de um sistema pode ser realizada por um subsistema de diagnóstico auxiliar, representado na Figura 24 da seção 3.2, um aspecto a ser ressaltado é o de que nem sempre é possível se garantir que tal subsistema estará livre de falhas. Uma maneira de se tentar detectar a presença de falhas no subsistema de diagnóstico consistiria em se verificar se o histórico de operação que é atualizado por ele é consistente, ou seja, se os perfis dos eventos de falhas e manutenções dos componentes do sistema monitorado por ele estão condizentes entre si. 
Uma forma de fazê-lo seria por intermédio da incorporação de técnicas de inteligência artificial ao módulo "Simulador de Dados de Entrada" do ambiente de desenvolvimento e ensaio do modelo proposto e do desenvolvimento da arquitetura representada na Figura 85. Para se avaliar a consistência do subsistema de diagnóstico, as seguintes etapas poderiam ser executadas:

i. Inicialmente, é extraída uma amostra do histórico de operação mantido por subsistema de diagnóstico que é composta por eventos de falhas e manutenções validados;

ii. Em seguida, a amostra coletada é encaminhada ao módulo "Simulador de Dados de Entrada" estendido com técnicas de inteligência artificial para que ele produza, a partir dela, um histórico hipotético até o final do período de tempo considerado no ensaio;

iii. Por fim, os registros do histórico mantido pelo subsistema de diagnóstico são comparados por um elemento externo, que decide se o histórico mantido pelo subsistema de diagnóstico é, ou não, plausível.

Figura 85 - Arquitetura da Proposta de Extensão do Simulador de Dados de Entrada

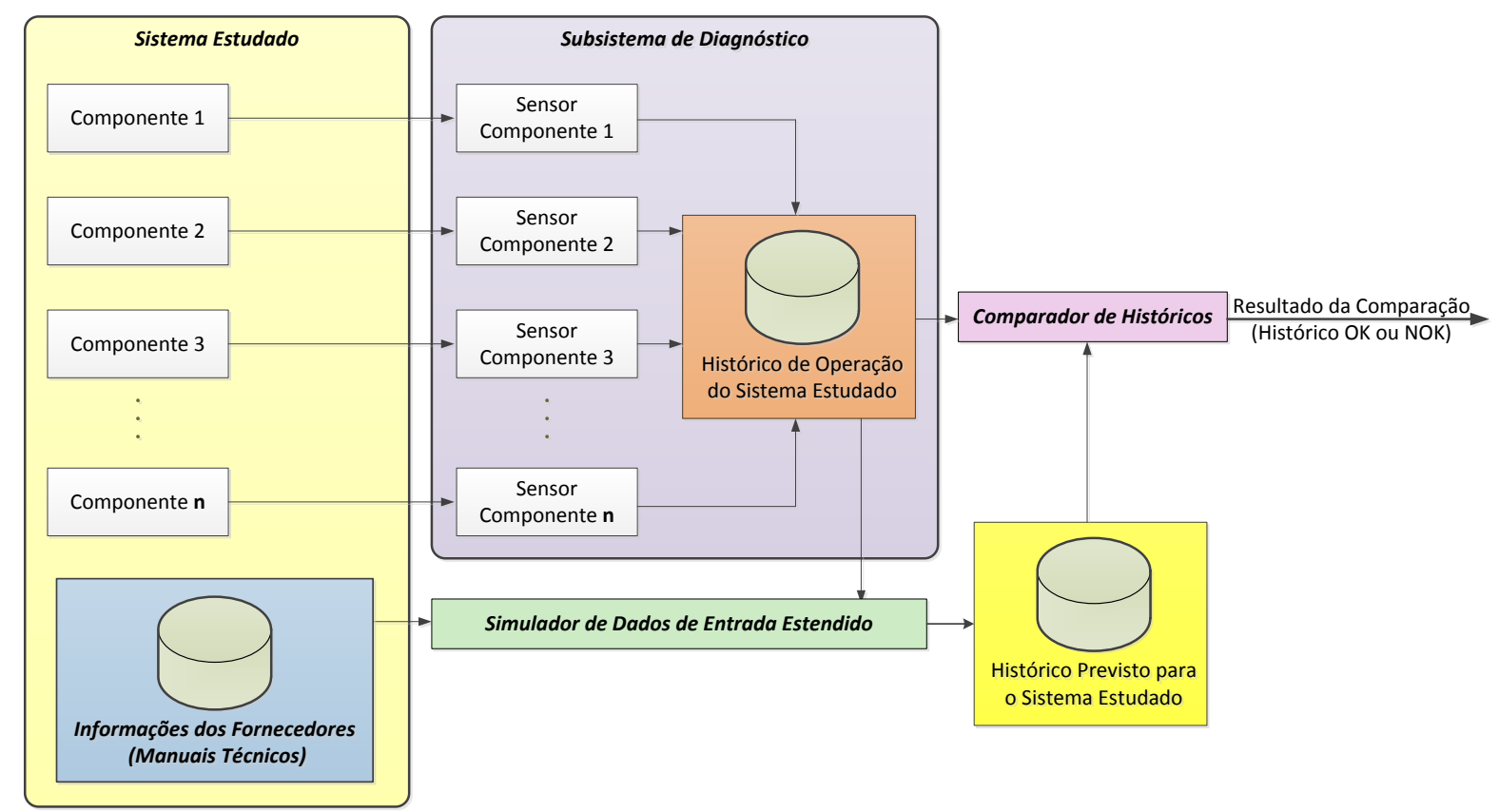

Fonte: Autor 


\subsection{CONSIDERAÇÃo FINAL}

Em vista das considerações expostas neste Capítulo, é possível considerar que a abordagem utilizada no modelo desenvolvido na presente pesquisa apresentase como uma alternativa promissora para permitir que um embrião de programa de manutenção preditiva de baixo custo possa ser instalado em situações práticas nas quais há disponibilidade imediata ou em curto prazo de dados de histórico dos eventos de falhas e manutenções dos componentes de um sistema - normalmente mantidos por departamentos de assistência técnica de empresas e instituições de engenharia. As limitações observadas, sobretudo as relacionadas à precisão e à validade das estimativas das falhas futuras dos componentes de um sistema, podem ser contornadas em alguns dos eventuais trabalhos futuros sugeridos neste Capítulo. 


\section{REFERÊNCIAS BIBLIOGRÁFICAS}

ABRAMAN. Mensagem do presidente - Abraman. Disponível em: <http://www.abraman.org.br/sidebar/documento-nacional/mensagem-do-presidente>. Acesso em: 24 jul. 2012.

. A situação da manutenção no Brasil. In: $26^{\circ}$ Congresso Brasileiro de Manutenção. Curitiba, 2011. Disponível em:

<http://www.abraman.org.br/Arquivos/7/7.pdf> Acesso em: 24 jul. 2012.

ALMEIDA, M. T. Manutenção preditiva: confiabilidade e qualidade. Itajubá (MG):

[s.n.]. Disponível em: <http://www.mtaev.com.br/download/mnt1.pdf>. Acesso em: 24 jul. 2012.

. Manutenção preditiva: benefícios e lucratividade. Itajubá (MG): [s.n.]. Disponível em: <http://www.mtaev.com.br/download/mnt2.pdf>. Acesso em: 24 jul. 2012.

ALMEIDA JR., J. R. Segurança em sistemas críticos e em sistemas de informação - um estudo comparativo. 2003, 191p. Tese (Livre Docência) Departamento de Engenharia de Computação e Sistemas Digitais. Escola Politécnica da Universidade de São Paulo, 2003.

ANEEL. Informações Técnicas - Qualidade do Serviço. Disponível em: <http://www.aneel.gov.br/area.cfm?idArea=79\&idPerfil=2>. Acesso em: 26 jul. 2012.

ARAIZA, M. L. A formal framework for predictive maintenance. In: AUTOTESTCON 2004. Proceedings... San Antonio (EUA): IEEE, 2004. Disponível em: $<$ http://ieeexplore.ieee.org/xpl/articleDetails.jsp?reload=true\&arnumber $=1436938 \& c 0$ ntent Type $=$ Conference+Publications $>$. Acesso em: 26 jul. 2012

BENDELL, A.; HUMBLE, S. Operating history and failure and degradation tendencies. IEEE Transactions on Reliability, v. R-27, n. 1, p. 75-76, abr. 1978.

BILLINTON, R.; LI, W. Reliability Assessment of Electric Power Systems Using Monte Carlo Methods. New York: Plenum Press, 1994.

BURKARDT, J. Linear algebra glossary. Disponível em: $<$ http://people.sc.fsu.edu/ jburkardt/html/linear_glossary.html>. Acesso em: 27 set. 2012.

CADINI, F.; ZIO, E.; AVRAM, D. Model-based Monte Carlo state estimation for condition-based component replacement. Reliability Engineering \& System Safety, v. 94, n. 3, p. 752-758, 2009.

CAMARGO JR., J. B. Metodologia de análise de risco em sistemas computacionais de aplicação crítica. 2002, 141 p. Tese (Livre Docência) Departamento de Engenharia de Computação e Sistemas Digitais. Escola Politécnica da Universidade de São Paulo, 2002. 
CENELEC. EN50129:2003 - railway applications - communication, signalling and processing systems - safety-related electronic systems for signalling. Bruxelas: CENELEC, 2003.

CHRISTER, A. H.; WANG, W.; SHARP, J. M. A state space condition monitoring model for furnace erosion prediction and replacement. European Journal of Operational Research, v. 101, n. 1, p. 1-14, 1997.

D'ERRICO, J. Polyfitn - file exchange - MATLAB central. Disponível em: <http://www.mathworks.com/matlabcentral/fileexchange/34765-polyfitn\#feedback>. Acesso em: 13 dez. 2013.

DOD. MIL-HDBK-217F - military handbook - reliability prediction of electronic equipment. Washington DC: DOD, 1991.

DOD. MIL-STD-338B - military handbook - electronic reliability design handbook. Washington DC: DOD, 1998.

FAN, $\mathrm{H}$. et al. Cooperative predictive maintenance of repairable systems with dependent failure modes and resource constraint. IEEE Transactions on Reliability, v. 60, n. 1, p. 144-157, mar. 2011.

FOLHA ONLINE. Acompanhe a cronologia de panes nos serviços prestados pela Telefônica. Disponível em:

<http://www1.folha.uol.com.br/folha/informatica/ult124u584620.shtml>. Acesso em: 26 jul. 2012.

GHADERI, A.; HAGHIFAM, M. R.; MOSTAFA ABEDI, S. Application of Monte Carlo simulation in Markov process for reliability analysis, 2010. In: IEEE 11th International Conference on Probabilistic Methods Applied to Power Systems. Anais...IEEE, jun. 2010. Disponível em:

$<$ http://ieeexplore.ieee.org/xpl/articleDetails.jsp?tp=\&arnumber=5528836\&contentTyp $\mathrm{e}=$ Conference+Publications\&searchField=Search_All\&queryText=monte+carlo+simul ation+in+markov+process $>$. Acesso em: 19 set. 2012

GRALL, A. et al. Continuous-time predictive-maintenance scheduling for a deteriorating system. IEEE Transactions on Reliability, v. 51, n. 2, p. 141-150, jun. 2002.

GROBA, C. et al. Architecture of a predictive maintenance framework, 2007. In: 6th International Conference on Computer Information Systems and Industrial Management Applications (CISIM'07). Anais...IEEE, jun. 2007. Disponível em: $<$ http://ieeexplore.ieee.org/xpl/articleDetails.jsp?tp=\&arnumber=4273496\&contentTyp $\mathrm{e}=$ Conference+Publications\&searchField=Search_All\&queryText=Architecture+of $+\mathrm{a}+$ Predictive+Maintenance+Framework>. Acesso em: 26 jul. 2012

HALL, A. Seven myths of formal methods. IEEE Software, v. 7, n. 5, p. 11-19, set. 1990. 
HASHEMIAN, H. M.; BEAN, W. C. State-of-the-art predictive maintenance techniques. IEEE Transactions on Instrumentation and Measurement, v. 60, n. 1, p. 226-236, jan. 2011.

HONG, H. P. et al. Optimal condition-based maintenance decisions for systems with dependent stochastic degradation of components. Reliability Engineering \& System Safety, 2013.

IBGE. De 2005 para 2008, acesso à Internet aumenta 75,3\%. Disponível em: $<$ http://www.ibge.gov.br/home/presidencia/noticias/noticia_visualiza.php?id_noticia=1 517>. Acesso em: 26 jul. 2012.

IEC. IEC61508:2010 - functional safety of electrical/electronic/programmable electronic safety-related systems (7 parts). Genebra: IEC, 2010.

JASPAN, C. et al. Software mythbusters explore formal methods. IEEE Software, v. 26, n. 6, p. 60-63, nov. 2009.

JENS, R. D. Modelo de monitoramento e avaliação da confiabilidade e disponibilidade de sistemas de distribuição de energia elétrica com base nas condições de uso de transformadores. 2006, 134p. Dissertação (Mestrado) Departamento de Engenharia de Computação e Sistemas Digitais. Escola Politécnica da Universidade de São Paulo, 2006.

JOHNSON, B. W. Design and analysis of fault-tolerant digital systems. Reading: Addison-Wesley, 1989. p. 602

KAISER, K. A.; GEBRAEEL, N. Z. Predictive maintenance management using sensor-based degradation models. IEEE Transactions on Systems, Man, and Cybernetics - Part A: Systems and Humans, v. 39, n. 4, p. 840-849, jul. 2009.

KALMAN, R. E. A new approach to linear filtering and prediction problems. Transactions of ASME - Journal of Basic Engineering, n. 82, p. 35-45, 1960.

KLEINBAUER, R. Kalman Filtering Implementation with MATLAB. Stuttgart. Disponível em <http://elib.uni-stuttgart.de/opus/volltexte/2005/2183/pdf/ kleinbauer.pdf>. Acesso em: 18 out. 2013.

KUMAR, P.; SRIVASTAVA, R. K. An expert system for predictive maintenance of mining excavators and its various forms in open cast mining, 2012. In:1st International Conference on Recent Advances in Information Technology (RAIT). Anais... IEEE, mar. 2012. Disponível em: $<\mathrm{http}$ ://ieeexplore.ieee.org/xpl/articleDetails.jsp?tp=\&arnumber=6194607\&contentTyp $\mathrm{e}=$ Conference+Publications\&searchField=Search_All\&queryText=An+Expert+Syste $\mathrm{m}+$ for+Predictive+Maintenance+of+Mining+Excavators+and+its+Various+Forms+in+ Open+Cast+Mining >. Acesso em: 26 jul. 2012

LI, Y.; CHUN, L.; CHING, A. N. Y. An agent-based platform for web-enabled equipment predictive maintenance. In: EEE/WIC/ACM International Conference on Intelligent Agent Technology. Anais...Compiègne (França): IEEE, 2005. Disponível 
em: <http://ieeexplore.ieee.org//pdocs/epic03/wrapper.htm?arnumber=1565523>. Acesso em: 26 jul. 2012

LIU, Y.; HUANG, H.-Z. Comment on "A framework to practical predictive maintenance modeling for multi-state systems" by Tan C.M. and Raghavan N. [Reliab Eng Syst Saf 2008; 93(8):1138-50]. Reliability Engineering \& System Safety, v. 94, n. 3, p. 776-780, mar. 2009.

LU, S.; TU, Y.-C.; LU, H. Predictive condition-based maintenance for continuously deteriorating systems. Quality and Reliability Engineering International, v. 23, n. 1, p. 71-81, fev. 2007.

MARQUES, A. et al. Os principais equipamentos utilizados nas empresas de beneficiamento de mármore e granito, suas funções e importância no processo. In: XIII SIMPEP - Simpósio de Engenharia de Produção. Anais...2006. Disponível em: <http://www.simpep.feb.unesp.br/anais/anais_13/artigos/604.pdf>

MAYBECK, P. S. Stochastic models, estimation and control. Nova lorque: Academic Press, 1979. v.1, p. 423

MICHAELIS. Definição de sistema. Disponível em: $<$ http://dic.busca.uol.com.br/result.html?group=0\&t=10\&q=sistema>. Acesso em: 17 ago. 2012.

MING TAN, C.; RAGHAVAN, N. A framework to practical predictive maintenance modeling for multi-state systems. Reliability Engineering \& System Safety, v. 93, n. 8 , p. $1138-1150$, ago. 2008.

. Reply to comments on "A framework to practical predictive maintenance modeling for multi-state systems."Reliability Engineering \& System Safety, v. 94, n. 3, p. 781-782, mar. 2009.

NOWLAN, F. S.; HEAP, H. F. Reliability-centered maintenance. Springfield, VA.: AD-A066-579, 1978.

PINTO, A. K.; XAVIER, J. DE A. N. Manutenção: função estratégica. $2^{a}$. ed. Rio de Janeiro: Qualitymark, 2007. p. 341

RIAC. Handbook of 217Plus(TM) reliability prediction models. Nova lorque: RIAC, 2006.

217Plus consulting. Disponível em:

<http://www.theriac.org/productsandservices/products/217plus/consulting.swn>. Acesso em: 20 set. 2012.

RIAC government sponsors. Disponível em:

<http://www.theriac.org/about/sponsors.html>. Acesso em: 2 jan. 2013.

SANTOS, R. C. et al. Análise de disponibilidade de subestações de alta tensão considerando seus principais equipamentos. In: The 8th Latin-American Congress on 
Electricity Generation and Transmission - CLAGTEE 2009. Anais...Ubatuba: CLAGTEE, 2009.

SHOOMAN, M. L. Probabilistic reliability: an engineering approach. 2. ed. Nova lorque: Krieger Publishing, 1990. p. 702

SILVA, P. R. N. et al. A new methodology of fault location for predictive maintenance of transmission lines. International Journal of Electrical Power \& Energy Systems, v. 42, n. 1, p. 568-574, nov. 2012.

SILVA NETO, A. V.; CUGNASCA, P. S. Utilização de Dados de Histórico na Manutenção Preditiva de Equipamentos Elétricos, Eletrônicos e Programáveis em Aplicações Metroferroviárias. 19ª Semana de Tecnologia Metroferroviária da AEAMESP. Anais... AEAMESP, 2013. Disponível em: <http://biblioteca.aeamesp.org.br/smns/19smtf130912T27rl.pdf>. Acesso em: 14 jul. 2014.

SIMON, D. Kalman filtering with state constraints: a survey of linear and nonlinear algorithms. IET Control Theory \& Applications, v. 4, n. 8, p. 1303-1318, 1 ago. 2010.

STOREY, N. Safety-critical computer systems. Reading: Addison-Wesley, 1996. p. 453

TRODD, G. Practical implementation of predictive maintenance. In: Conference Record of 1998. Annual Pulp and Paper Industry Technical Conference (Cat. No.98CH36219). Anais...IEEE, 1998. Disponível em: $<$ http://ieeexplore.ieee.org/xpl/articleDetails.jsp?tp=\&arnumber=685501\&contentType $=$ Conference + Publications\&searchField $=$ Search_All\&queryText=Practical+Implement ation+of+Predictive+Maintenance>. Acesso em: 26 jul. 2012

VISMARI, L. F. Vigilância dependente automática no controle de tráfego aéreo: avaliação de risco baseada em modelagem em redes de Petri fluidas e estocásticas. 2007, 272p. Dissertação (Mestrado) - Departamento de Engenharia de Computação e Sistemas Digitais. Escola Politécnica da Universidade de São Paulo, 2007.

WANG, K. S.; HSU, F. S.; LIU, P. P. Modeling the bathtub shape hazard rate function in terms of reliability. Reliability Engineering \& System Safety, v. 75, n. 3, p. 397406, mar. 2002.

WELSH, G.; BISHOP, G. An introduction to the Kalman filter. Chapel Hill, 2006. Disponível em: <http://www.cs.unc.edu/ tracker/media/pdf/SIGGRAPH2001 _CoursePack_08.pdf). Acesso em 18 out. 2013.

WU, S. Comments on "Reliability-centered predictive maintenance scheduling for a continuously monitored system subject to degradation" by X. Zhou, L. Xi and J. Lee [Reliab Eng Syst Saf 2007; 92: 530-534]. Reliability Engineering \& System Safety, v. 93, n. 11, p. 1772-1773, nov. 2008. 
YOU, M.-Y. et al. Statistically planned and individually improved predictive maintenance management for continuously monitored degrading systems. IEEE Transactions on Reliability, v. 59, n. 4, p. 744-753, dez. 2010.

ZHOU, X. Rebuttals to "Comments on 'Reliability-centered predictive maintenance scheduling for a continuously monitored system subject to degradation' by X. Zhou, L. Xi and J. Lee [Reliab Eng Syst Saf 2007; 92: 530-534]."Reliability Engineering \& System Safety, v. 93, n. 11, p. 1774-1775, nov. 2008.

ZHOU, X.; LU, Z.; XI, L. Preventive maintenance optimization for a multi-component system under changing job shop schedule. Reliability Engineering \& System Safety, v. 101, p. 14-20, 2012.

ZHOU, X.; XI, L.; LEE, J. Reliability-centered predictive maintenance scheduling for a continuously monitored system subject to degradation. Reliability Engineering \& System Safety, v. 92, n. 4, p. 530-534, abr. 2007. 


\section{APÊNDICE}




\section{APÊNDICE A- Históricos Operacionais Utilizados nos Estudos de Caso Relacionados à Função Disponibilidade}

Este Apêndice destina-se à apresentação dos dados de histórico operacional gerados pelo módulo "Simulador de Dados de Entrada" do ambiente de desenvolvimento e ensaio para serem utilizados nos estudos de caso abordados nas seções 5.2.3, 5.3.3 e 5.4.3 da Dissertação de Mestrado, que versam sobre a avaliação dos impactos do modelo proposto neste estudo sobre a função disponibilidade dos três sistemas avaliados (sistema simples, sistema com dois componentes em série e sistema com dois componentes em paralelo).

\section{Apêndice A.1 - Históricos Operacionais do Sistema Simples}

Os dados de histórico utilizados nos ensaios normal, otimista e pessimista da função disponibilidade do sistema simples são respectivamente apresentados na Tabela 52, na Tabela 53 e na Tabela 54.

Tabela 52 - Histórico Operacional do Sistema Simples no Ensaio Normal da Função Disponibilidade

\begin{tabular}{|c|c|c|c|c|c|}
\hline Evento & $\begin{array}{c}\text { Instante de } \\
\text { Ocorrência (h) }\end{array}$ & Evento & $\begin{array}{c}\text { Instante de } \\
\text { Ocorrência }(\boldsymbol{h})\end{array}$ & Evento & $\begin{array}{c}\text { Instante de } \\
\text { Ocorrência }(\boldsymbol{h})\end{array}$ \\
\hline F1 & 18221,57276 & F1 & 42350,363 & F1 & 73170,1329 \\
\hline SI1 & 18221,80451 & RI1 & 42350,60227 & RI1 & 73170,20187 \\
\hline SF1 & 18223,37034 & RF1 & 42351,81941 & RF1 & 73171,51265 \\
\hline F1 & 19180,6435 & F1 & 55809,36826 & F1 & 80144,80747 \\
\hline SI1 & 19180,65816 & SI1 & 55809,45132 & RI1 & 80144,82787 \\
\hline SF1 & 19181,55724 & SF1 & 55810,98213 & RF1 & 80146,12194 \\
\hline F1 & 31275,36056 & F1 & 64967,37528 & F1 & 95045,39063 \\
\hline SI1 & 31275,58674 & RI1 & 64967,6633 & RI1 & 95045,84136 \\
\hline SF1 & 31277,02057 & RF1 & 64968,66277 & RF1 & 95047,48286 \\
\hline
\end{tabular}

Fonte: Autor

Tabela 53 - Histórico Operacional do Sistema Simples no Ensaio Otimista da Função Disponibilidade

\begin{tabular}{|c|c|c|c|c|c|}
\hline Evento & $\begin{array}{c}\text { Instante de } \\
\text { Ocorrência (h) }\end{array}$ & Evento & $\begin{array}{c}\text { Instante de } \\
\text { Ocorrência (h) }\end{array}$ & Evento & $\begin{array}{c}\text { Instante de } \\
\text { Ocorrência (h) }\end{array}$ \\
\hline F1 & 8632,426567 & SI1 & 46221,5129 & RF1 & 79305,50055 \\
\hline SI1 & 8632,747474 & SF1 & 46222,51736 & F1 & 92732,67829 \\
\hline SF1 & 8632,773987 & F1 & 62166,47756 & SI1 & 92732,85608 \\
\hline F1 & 28147,52258 & SI1 & 62166,86558 & SF1 & 92734,29169 \\
\hline RI1 & 28147,59729 & SF1 & 62168,04332 & F1 & 92788,0865 \\
\hline
\end{tabular}




\begin{tabular}{|c|c|c|c|c|c|}
\hline Evento & $\begin{array}{c}\text { Instante de } \\
\text { Ocorrência (h) }\end{array}$ & Evento & $\begin{array}{c}\text { Instante de } \\
\text { Ocorrência (h) }\end{array}$ & Evento & $\begin{array}{c}\text { Instante de } \\
\text { Ocorrência (h) }\end{array}$ \\
\hline RF1 & 28147,64569 & F1 & 79305,23001 & RI1 & 92789,26859 \\
\hline F1 & 46221,26525 & RI1 & 79305,29475 & RF1 & 92790,29067 \\
\hline
\end{tabular}

Fonte: Autor

Tabela 54 - Histórico Operacional do Sistema Simples no Ensaio Pessimista da Função Disponibilidade

\begin{tabular}{|c|c|c|c|c|c|}
\hline Evento & $\begin{array}{c}\text { Instante de } \\
\text { Ocorrência (h) }\end{array}$ & Evento & $\begin{array}{c}\text { Instante de } \\
\text { Ocorrência (h) }\end{array}$ & Evento & $\begin{array}{c}\text { Instante de } \\
\text { Ocorrência }(\boldsymbol{h})\end{array}$ \\
\hline F1 & 14522,86027 & SI1 & 37105,42594 & RF1 & 59671,32581 \\
\hline SI1 & 14524,69185 & SF1 & 37106,85708 & F1 & 79646,85967 \\
\hline SF1 & 14525,90573 & F1 & 43579,7376 & RI1 & 79647,20665 \\
\hline F1 & 23531,00778 & RI1 & 43580,02811 & RF1 & 79648,59962 \\
\hline RI1 & 23531,69443 & RF1 & 43581,61506 & F1 & 87361,98752 \\
\hline RF1 & 23533,47752 & F1 & 52099,13595 & RI1 & 87362,71133 \\
\hline F1 & 33189,62173 & RI1 & 52099,16505 & RF1 & 87364,00397 \\
\hline RI1 & 33190,21683 & RF1 & 52100,48956 & F1 & 93263,37941 \\
\hline RF1 & 33191,03465 & F1 & 59668,38038 & RI1 & 93263,43037 \\
\hline F1 & 37104,98679 & RI1 & 59669,36686 & RF1 & 93264,90349 \\
\hline
\end{tabular}

Fonte: Autor

\section{Apêndice A.2 - Históricos Operacionais do Sistema Série de Dois Componentes}

Os dados de histórico utilizados nos ensaios normal, otimista e pessimista da função disponibilidade do sistema com dois componentes em série são respectivamente apresentados na Tabela 55, na Tabela 56 e na Tabela 57. 
Tabela 55 - Histórico Operacional do Sistema Série de Dois Componentes no Ensaio Normal da Função Disponibilidade

\begin{tabular}{|c|c|c|c|c|c|}
\hline Evento & $\begin{array}{c}\text { Instante de } \\
\text { Ocorrência }(\boldsymbol{h})\end{array}$ & Evento & $\begin{array}{c}\text { Instante de } \\
\text { Ocorrência }(\boldsymbol{h})\end{array}$ & Evento & $\begin{array}{c}\text { Instante de } \\
\text { Ocorrência }(\boldsymbol{h})\end{array}$ \\
\hline F1 & 11374,72409 & F2 & 40764,47348 & F1 & 74250,22507 \\
\hline SI1 & 11375,08715 & RI2 & 40766,04509 & SI1 & 74250,58321 \\
\hline SF1 & 11376,05913 & RF2 & 40768,40412 & SF1 & 74251,65001 \\
\hline F1 & 21521,86138 & F1 & 43127,92038 & F2 & 75524,97546 \\
\hline RI1 & 21522,7316 & SI1 & 43128,05772 & RI2 & 75526,01126 \\
\hline RF1 & 21524,03763 & SF1 & 43128,64702 & RF2 & 75527,0782 \\
\hline F2 & 22070,54277 & F1 & 52599,67781 & F1 & 77526,21022 \\
\hline SI2 & 22070,76262 & RI1 & 52599,72678 & RI1 & 77526,25871 \\
\hline SF2 & 22073,79272 & RF1 & 52599,86866 & RF1 & 77527,80469 \\
\hline F1 & 27882,95419 & F2 & 55633,92016 & F1 & 87681,00307 \\
\hline RI1 & 27883,23333 & RI2 & 55633,93772 & RI1 & 87682,99688 \\
\hline RF1 & 27884,48662 & RF2 & 55634,18691 & RF1 & 87684,96272 \\
\hline F1 & 38629,98091 & F1 & 65781,50529 & F2 & 98565,8381 \\
\hline RI1 & 38630,08029 & RI1 & 65782,38276 & SI2 & 98566,94164 \\
\hline RF1 & 38631,51594 & RF1 & 65783,81863 & SF2 & 98567,17316 \\
\hline
\end{tabular}

Fonte: Autor

Tabela 56 - Histórico Operacional do Sistema Série de Dois Componentes no Ensaio Otimista da Função Disponibilidade

\begin{tabular}{|c|c|c|c|c|c|}
\hline Evento & $\begin{array}{c}\text { Instante de } \\
\text { Ocorrência }(\boldsymbol{h})\end{array}$ & Evento & $\begin{array}{c}\text { Instante de } \\
\text { Ocorrência (h) }\end{array}$ & Evento & $\begin{array}{c}\text { Instante de } \\
\text { Ocorrência }(\boldsymbol{h})\end{array}$ \\
\hline F1 & 18972,31691 & SI1 & 50923,49746 & SF1 & 74122,00162 \\
\hline RI1 & 18972,42595 & SF1 & 50924,43073 & F2 & 75358,47151 \\
\hline RF1 & 18973,15633 & F2 & 64820,41118 & SI2 & 75358,83751 \\
\hline F2 & 28071,85923 & RI2 & 64821,57835 & SF2 & 75360,60839 \\
\hline RI2 & 28071,94172 & RF2 & 64823,65232 & F1 & 85310,52909 \\
\hline RF2 & 28071,96068 & F1 & 67025,03463 & RI1 & 85310,88094 \\
\hline F1 & 37000,77604 & SI1 & 67025,32003 & RF1 & 85311,8589 \\
\hline SI1 & 37000,95943 & SF1 & 67026,33123 & F1 & 93392,6639 \\
\hline SF1 & 37002,10393 & F1 & 74120,80432 & RI1 & 93392,69349 \\
\hline F1 & 50923,36783 & SI1 & 74120,97576 & RF1 & 93394,52891 \\
\hline
\end{tabular}

Fonte: Autor

Tabela 57 - Histórico Operacional do Sistema Série de Dois Componentes no Ensaio Pessimista da Função Disponibilidade

\begin{tabular}{|c|c|c|c|c|c|}
\hline Evento & $\begin{array}{c}\text { Instante de } \\
\text { Ocorrência (h) }\end{array}$ & Evento & $\begin{array}{c}\text { Instante de } \\
\text { Ocorrência (h) }\end{array}$ & Evento & $\begin{array}{c}\text { Instante de } \\
\text { Ocorrência (h) }\end{array}$ \\
\hline F1 & 8024,428672 & SI1 & 40330,10755 & SF1 & 71151,2846 \\
\hline SI1 & 8025,567142 & SF1 & 40332,09782 & F1 & 75796,85223 \\
\hline
\end{tabular}




\begin{tabular}{|c|c|c|c|c|c|}
\hline Evento & $\begin{array}{c}\text { Instante de } \\
\text { Ocorrência (h) }\end{array}$ & Evento & $\begin{array}{c}\text { Instante de } \\
\text { Ocorrência (h) }\end{array}$ & Evento & $\begin{array}{c}\text { Instante de } \\
\text { Ocorrência (h) }\end{array}$ \\
\hline SF1 & 8026,934251 & F2 & 47072,16567 & SI1 & 75797,26307 \\
\hline F1 & 17077,18521 & RI2 & 47073,21123 & SF1 & 75799,19438 \\
\hline RI1 & 17077,80819 & RF2 & 47075,53459 & F1 & 83166,10595 \\
\hline RF1 & 17079,05976 & F1 & 48472,25584 & RI1 & 83167,06439 \\
\hline F2 & 19554,1957 & RI1 & 48473,12878 & RF1 & 83168,6431 \\
\hline SI2 & 19555,56532 & RF1 & 48475,1033 & F1 & 83689,06812 \\
\hline SF2 & 19559,17422 & F2 & 51614,04455 & SI1 & 83689,82659 \\
\hline F2 & 21195,62975 & SI2 & 51614,93531 & SF1 & 83691,55076 \\
\hline SI2 & 21195,63135 & SF2 & 51617,39554 & F2 & 84644,22465 \\
\hline SF2 & 21198,79696 & F1 & 57354,64199 & SI2 & 84644,24598 \\
\hline F1 & 24200,88806 & SI1 & 57355,29539 & SF2 & 84648,0112 \\
\hline RI1 & 24201,12684 & SF1 & 57356,58888 & F1 & 89090,26132 \\
\hline RF1 & 24203,03238 & F2 & 65537,59237 & RI1 & 89090,85965 \\
\hline F1 & 28478,61381 & SI2 & 65538,80517 & RF1 & 89091,78543 \\
\hline RI1 & 28480,2206 & SF2 & 65541,14906 & F1 & 94240,7212 \\
\hline RF1 & 28481,26786 & F1 & 65757,78586 & RI1 & 94241,97116 \\
\hline F2 & 30018,09941 & RI1 & 65758,46641 & RF1 & 94243,90406 \\
\hline RI2 & 30018,50826 & RF1 & 65759,75248 & F2 & 97691,43831 \\
\hline RF2 & 30021,17203 & F1 & 71149,98796 & RI2 & 97692,563 \\
\hline F1 & 40329,98191 & SI1 & 71150,4156 & RF2 & 97696,07237 \\
\hline & & & & & \\
\hline
\end{tabular}

Fonte: Autor

\section{Apêndice A.3 - Históricos Operacionais do Sistema Paralelo de Dois Componentes}

Os dados de histórico utilizados nos ensaios normal, otimista e pessimista da função disponibilidade do sistema com dois componentes em paralelo são respectivamente apresentados na Tabela 58, na Tabela 59 e na Tabela 60.

Tabela 58 - Histórico Operacional do Sistema Paralelo de Dois Componentes no Ensaio Normal da Função Disponibilidade

\begin{tabular}{|c|c|c|c|c|c|}
\hline Evento & $\begin{array}{c}\text { Instante de } \\
\text { Ocorrência (h) }\end{array}$ & Evento & $\begin{array}{c}\text { Instante de } \\
\text { Ocorrência (h) }\end{array}$ & Evento & $\begin{array}{c}\text { Instante de } \\
\text { Ocorrência (h) }\end{array}$ \\
\hline F1 & 9806,268683 & RI1 & 37985,25897 & SF1 & 71287,72044 \\
\hline SI1 & 9806,50218 & RF1 & 37986,46976 & F2 & 72227,67236 \\
\hline SF1 & 9807,677838 & F1 & 53695,85505 & RI2 & 72228,23786 \\
\hline F1 & 17879,32449 & SI1 & 53695,98166 & RF2 & 72229,76739 \\
\hline S11 & 17879,44937 & SF1 & 53696,92732 & F1 & 83217,7337 \\
\hline SF1 & 17881,04241 & F2 & 56821,5939 & SI1 & 83217,87333 \\
\hline F2 & 22761,94219 & SI2 & 56822,43281 & SF1 & 83218,87836 \\
\hline RI2 & 22764,0576 & SF2 & 56824,60106 & F1 & 92088,31922 \\
\hline
\end{tabular}




\begin{tabular}{|c|c|c|c|c|c|}
\hline Evento & $\begin{array}{c}\text { Instante de } \\
\text { Ocorrência (h) }\end{array}$ & Evento & $\begin{array}{c}\text { Instante de } \\
\text { Ocorrência (h) }\end{array}$ & Evento & $\begin{array}{c}\text { Instante de } \\
\text { Ocorrência (h) }\end{array}$ \\
\hline RF2 & 22767,82898 & F1 & 66398,23671 & RI1 & 92088,40881 \\
\hline F1 & 29649,09718 & SI1 & 66398,31483 & RF1 & 92089,72649 \\
\hline SI1 & 29649,28445 & SF1 & 66399,10068 & F2 & 93715,36515 \\
\hline SF1 & 29649,71624 & F1 & 71285,77484 & RI2 & 93716,45452 \\
\hline F1 & 37985,06894 & SI1 & 71286,27249 & RF2 & 93719,38696 \\
\hline
\end{tabular}

Fonte: Autor

Tabela 59 - Histórico Operacional do Sistema Paralelo de Dois Componentes no Ensaio Otimista da Função Disponibilidade

\begin{tabular}{|c|c|c|c|c|c|}
\hline Evento & $\begin{array}{c}\text { Instante de } \\
\text { Ocorrência }(\boldsymbol{h})\end{array}$ & Evento & $\begin{array}{c}\text { Instante de } \\
\text { Ocorrência (h) }\end{array}$ & Evento & $\begin{array}{c}\text { Instante de } \\
\text { Ocorrência }(\boldsymbol{h})\end{array}$ \\
\hline F1 & 19882,0414 & SI1 & 39116,91207 & RF1 & 71695,801 \\
\hline SI1 & 19882,21353 & SF1 & 39118,09691 & F2 & 72510,07902 \\
\hline SF1 & 19882,95661 & F1 & 58541,47452 & $\mathbf{R I 2}$ & 72510,29064 \\
\hline F2 & 37999,86994 & RI1 & 58541,66391 & RF2 & 72511,76729 \\
\hline RI2 & 38000,01959 & RF1 & 58541,78306 & F1 & 88867,77532 \\
\hline RF2 & 38000,9931 & F1 & 71694,44465 & SI1 & 88867,89874 \\
\hline F1 & 39116,86518 & RI1 & 71694,57522 & SF1 & 88869,09056 \\
\hline
\end{tabular}

Fonte: Autor

Tabela 60 - Histórico Operacional do Sistema Paralelo de Dois Componentes no Ensaio Pessimista da Função Disponibilidade

\begin{tabular}{|c|c|c|c|c|c|}
\hline Evento & $\begin{array}{c}\text { Instante de } \\
\text { Ocorrência (h) }\end{array}$ & Evento & $\begin{array}{c}\text { Instante de } \\
\text { Ocorrência (h) }\end{array}$ & Evento & $\begin{array}{c}\text { Instante de } \\
\text { Ocorrência (h) }\end{array}$ \\
\hline F1 & 5260,402271 & RF1 & 36426,23403 & SI1 & 71581,08263 \\
\hline RI1 & 5260,611992 & F2 & 39779,20073 & SF1 & 71581,97957 \\
\hline RF1 & 5262,143655 & SI2 & 39779,26837 & F2 & 77541,62555 \\
\hline F1 & 13887,36331 & SF2 & 39782,61 & RI2 & 77543,27923 \\
\hline SI1 & 13887,39247 & F1 & 43493,94337 & RF2 & 77545,1827 \\
\hline SF1 & 13888,75732 & RI1 & 43495,80342 & F1 & 78575,148 \\
\hline F2 & 14595,65433 & RF1 & 43497,32814 & RI1 & 78575,25562 \\
\hline RI2 & 14596,98398 & F2 & 52845,82405 & RF1 & 78576,81141 \\
\hline RF2 & 14597,70626 & RI2 & 52846,08175 & F2 & 81278,59133 \\
\hline F1 & 17422,93218 & RF2 & 52848,78437 & RI2 & 81279,95808 \\
\hline S11 & 17423,78906 & F1 & 55738,49662 & RF2 & 81282,57316 \\
\hline SF1 & 17425,42457 & RI1 & 55738,92821 & F1 & 85508,86792 \\
\hline F1 & 24095,69435 & RF1 & 55740,38633 & RI1 & 85509,68341 \\
\hline RI1 & 24096,38179 & F1 & 61972,18347 & RF1 & 85511,5054 \\
\hline RF1 & 24097,60545 & RI1 & 61972,48653 & F2 & 87246,271 \\
\hline F1 & 28460,33098 & RF1 & 61973,54679 & RI2 & 87247,19988 \\
\hline S11 & 28460,55904 & F1 & 62898,66547 & RF2 & 87250,91098 \\
\hline
\end{tabular}




\begin{tabular}{|c|c|c|c|c|c|}
\hline Evento & $\begin{array}{c}\text { Instante de } \\
\text { Ocorrência (h) }\end{array}$ & Evento & $\begin{array}{c}\text { Instante de } \\
\text { Ocorrência (h) }\end{array}$ & Evento & $\begin{array}{c}\text { Instante de } \\
\text { Ocorrência (h) }\end{array}$ \\
\hline SF1 & 28461,899 & SI1 & 62898,94327 & F1 & 93905,8208 \\
\hline F2 & 33580,07316 & SF1 & 62900,67725 & SI1 & 93906,1741 \\
\hline RI2 & 33580,4044 & F1 & 64555,06898 & SF1 & 93907,97825 \\
\hline RF2 & 33584,06172 & RI1 & 64557,046 & F1 & 99524,68524 \\
\hline F1 & 36424,67483 & RF1 & 64558,64235 & RI1 & 99525,64287 \\
\hline RI1 & 36424,74242 & F1 & 71580,27461 & RF1 & 99527,31456 \\
\hline
\end{tabular}

Fonte: Autor 